Florida International University

FIU Digital Commons

\title{
Target and Non-target Techniques for the Quantitation of Drugs of Abuse, Identification of Transformation Products, and Characterization of Contaminants of Emergent Concern by High Resolution Mass Spectrometry
}

Nubia Vanesa Heuett

Florida International Univeersity, nheue001@fiu.edu

DOI: $10.25148 /$ etd.FIDC000105

Follow this and additional works at: https://digitalcommons.fiu.edu/etd

Part of the Analytical Chemistry Commons, and the Environmental Chemistry Commons

\section{Recommended Citation}

Heuett, Nubia Vanesa, "Target and Non-target Techniques for the Quantitation of Drugs of Abuse, Identification of Transformation Products, and Characterization of Contaminants of Emergent Concern by High Resolution Mass Spectrometry" (2015). FIU

Electronic Theses and Dissertations. 2194.

https://digitalcommons.fiu.edu/etd/2194

This work is brought to you for free and open access by the University Graduate School at FIU Digital Commons. It has been accepted for inclusion in FIU Electronic Theses and Dissertations by an authorized administrator of FIU Digital Commons. For more information, please contact dcc@fiu.edu. 


\title{
FLORIDA INTERNATIONAL UNIVERSITY
}

Miami, Florida

TARGET AND NON-TARGET TECHNIQUES FOR THE QUANTITATION OF DRUGS OF ABUSE, IDENTIFICATION OF TRANSFORMATION PRODUCTS, AND CHARACTERIZATION OF CONTAMINANTS OF EMERGENT CONCERN BY HIGH RESOLUTION MASS SPECTROMETRY

\author{
A dissertation submitted in partial fulfillment \\ of the requirements for the degree of \\ DOCTOR OF PHILOSOPHY \\ in \\ CHEMISTRY \\ by
}

Nubia Vanesa Heuett 
To: Dean Michael R. Heithaus

College of Arts and Sciences

This dissertation, written by Nubia Vanesa Heuett, and entitled Target and Non-target Techniques for the Quantitation of Drugs of Abuse, Identification of Transformation Products, and Characterization of Contaminants of Emergent Concern by High Resolution Mass Spectrometry, having been approved in respect to style and intellectual content, is referred to you for judgment.

We have read this dissertation and recommend that it be approved.

Jose Almirall

Anthony DeCaprio

John Landrum

Berrin Tansel

Piero R. Gardinali, Major Professor

Date of Defense: June 29, 2015

The dissertation of Nubia Vanesa Heuett is approved.

$\begin{array}{r}\hline \begin{array}{r}\text { Dean Michael R. Heithaus } \\ \text { College of Arts and Sciences }\end{array} \\ \hline \begin{array}{r}\text { Dean Lakshmi N. Reddi } \\ \text { University Graduate School }\end{array}\end{array}$

Florida International University, 2015 
(C) Copyright 2015 by Nubia Vanesa Heuett

All rights reserved. 


\section{DEDICATION}

To my son Drakeston Heuett, my dad Dicler Sierra, my sister Cristy Sierra, my brotherin-law Miguel Parra, and Sarita. For their patience and support during this journey. 


\section{ACKNOWLEDGMENTS}

I would like to give thanks to my major professor Dr. Piero R. Gardinali for all his great advise both professionally and personally, his flexibility in hard times, and for his much needed sarcasm. Also, special thanks to my committee members Dr. Jose Amirall, Dr. Anthony DeCaprio, Dr. John Landrum, and Dr. Berrin Tansel for their time, advice, and constructive criticism during our few meetings. I would also like to thank SERC, the chemistry department, and the FIU Graduate School (DYF) for funding my studies.

Special thanks to Ingrid, Adolfo, Cesar, Jian (chino), Luis, and Tati for their friendship, valuable input and advice, and most importantly for the coffee, sweets, and laughter. Additional thanks go to lab coworkers that have come and gone during my time in the lab, Kathia, Anna, Jenny, Carlos, Karina, Margarita, Gabriela, Alina, Sudha, Venkat, Chengtao, Elsa, Ellie, and Mark.

Most important to my family: To my son Drakeston for enduring the $\mathrm{PhD}$. with me, for being such an amazing son, full of life and love for nature. You always have and always will be the light at the end of my tunnel, I love you very much. I also like to thank my dad, my sister (Paola), Sarita, and my brother-in-law (Miguel) for their unconditional love, patience, advice, and support throughout my life. Also, special thanks to Miguel for all the help with computer programming and database development, which made this last project possible. Last but not least to my cousin Kathy and my grandma (Ines) for whom they have been an important part of my life growing up. 


\begin{abstract}
OF THE DISSERTATION
TARGET AND NON-TARGET TECHNIQUES FOR THE QUANTITATION OF

DRUGS OF ABUSE, IDENTIFICATION OF TRANSFORMATION PRODUCTS, AND CHARACTERIZATION OF CONTAMINANTS OF EMERGENT CONCERN

BY HIGH RESOLUTION MASS SPECTROMETRY
\end{abstract}

by

Nubia Vanesa Heuett

Florida International University, 2015

Miami, Florida

Professor Piero R. Gardinali, Major Professor

Development and application of target and non-target techniques for routine analysis, identification of transformation products, and characterization of unknown compounds in water matrices using liquid-chromatography high-resolution mass spectrometry (HRMS) were explored in this dissertation. A novel analytical method based on online-SPE-LCHRMS was developed for the detection of 18 drugs of abuse (DOAs) in raw sewage water from a college campus. Results showed the presence of 14 DOAs for which amphetamine and 11-nor-9-carcoxy-THC (THC metabolite) were the most prevalent and had the highest potential consumption rates.

A second study dedicated to the identification of transformation products (TPs) generated from DOAs was conducted using a combination of HR-MS/MS and metabolic identification and structural elucidation software. Findings confirmed the presence of multiple phase I and II DOA TPs $(n=35)$ in raw sewage influents. Concentrations of all TPs were estimated based on the parent DOAs response factors, and used to calculate the 
percent mole fraction contributions of each $\mathrm{TP}$ to the parent concentrations. High abundance and frequency (compared to the parent drug) was determined for 9 of the TPs coming from drugs like oxycodone, morphine, codeine, methadone, LSD, cocaine, and MDEA.

Non-target analysis using HRMS was explored as a tool to characterize, and compare a series of interconnected water matrices along a river system. Several thousands of formulae were generated using automated heuristic rules from the full-scan acquisition at 140,000 resolution. Samples were part of a trajectory covering upstream, effluent, effluent mixing zone, downstream, drinking water intake, and treated drinking water locations. Graphical representations of the data were used to evaluate commonalities among the system. Using this approach, a total of 64 recalcitrant components were identified throughout the samples downstream of the effluent release point. Using a combination of MS/MS and computer-aid software techniques 4 out of the 64 compounds were tentatively confirmed. In addition, comparison of drinking water intake and finalized treated drinking water sites showed the presence of 1,152 chemical entities that were common to both locations; and 1,857 that were unique to the treated drinking water. Therefore, this non-target technique could be used to identify the potential formation of treatment byproducts. 


\section{TABLE OF CONTENTS}

CHAPTER

PAGE

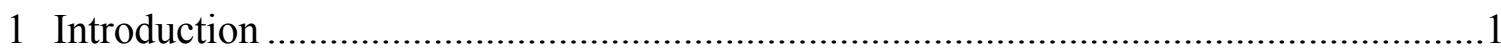

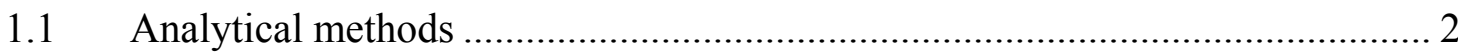

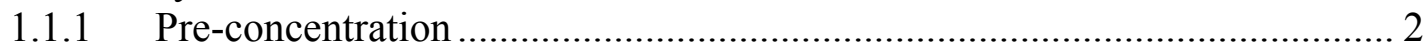

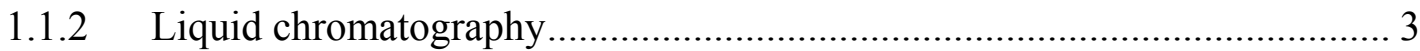

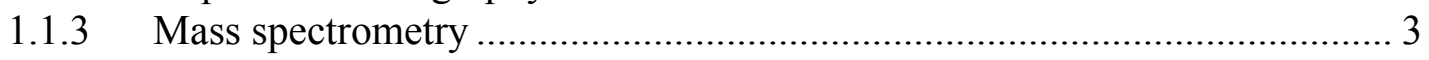

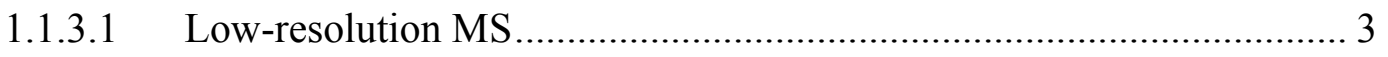

1.1.3.2 High-resolution MS ...................................................................... 4

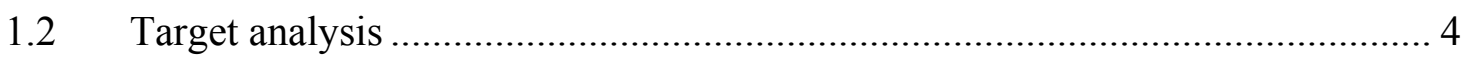

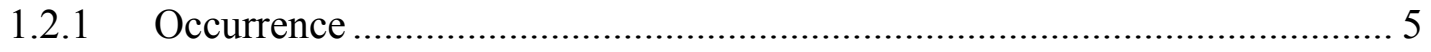

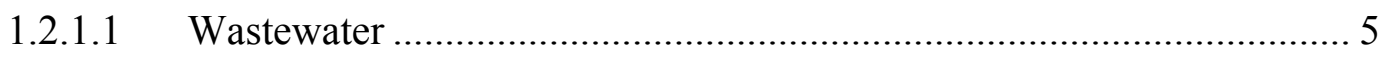

1.2.1.2 Surface and ground water ............................................................... 6

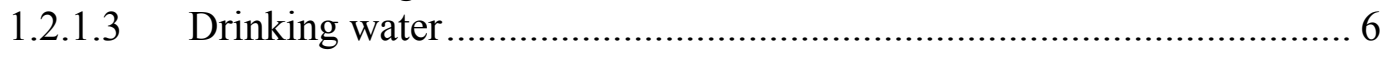

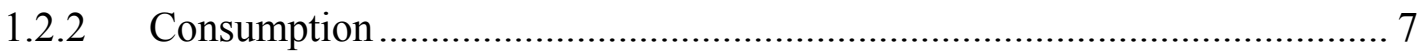

$1.3 \quad$ Identification of transformation products (TPs) ……....................................... 8

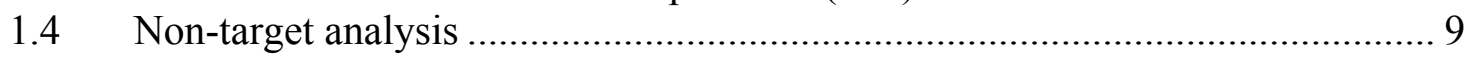

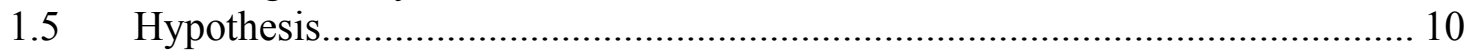

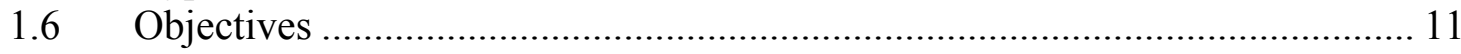

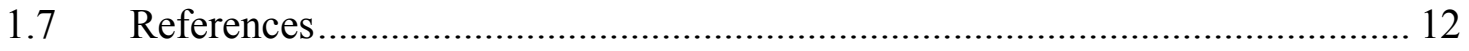

2 Analysis of drugs of abuse by online SPE-LC high-resolution mass spectrometry:

Communal assessment of consumption ............................................................19

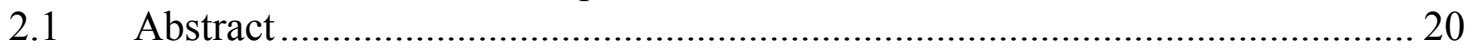

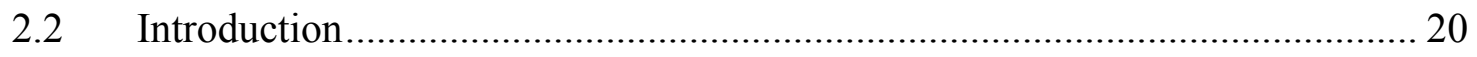

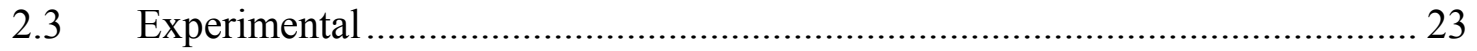

2.3.1 Reagents and chemicals ......................................................................... 23

2.3.2 Sample collection and preparation............................................................ 27

2.3.3 Online SPE pre-concentration and HPLC separation ................................. 28

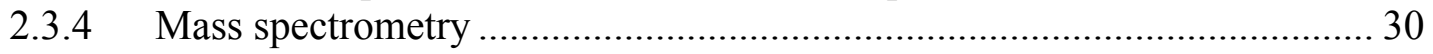

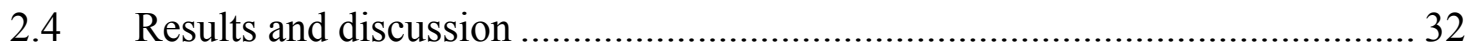

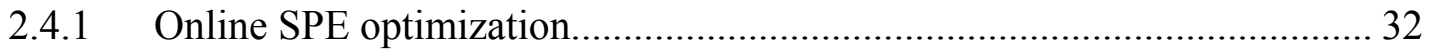

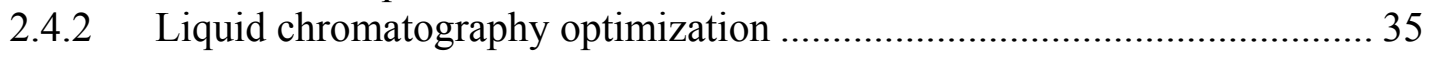

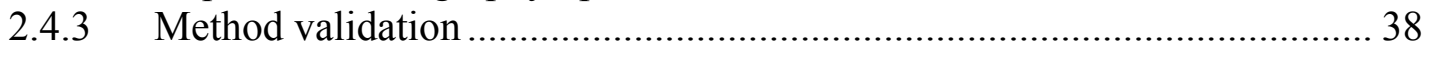

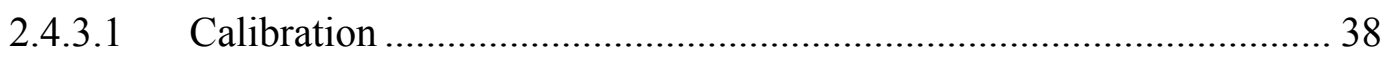

2.4.3.2 Quality control samples.................................................................... 38

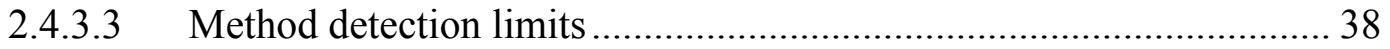

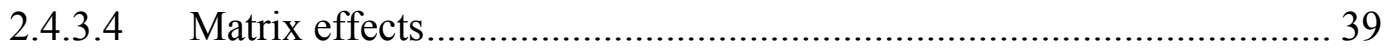

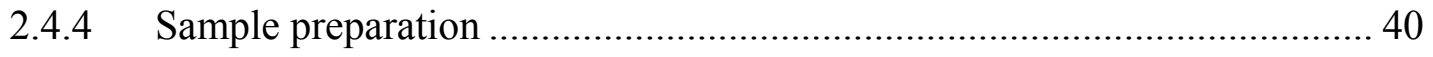

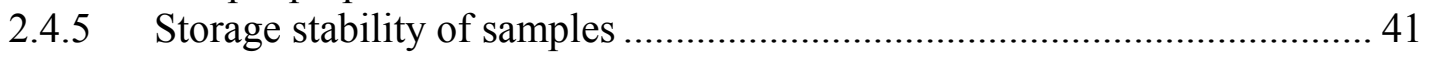


2.4.6 Occurrence of illicit drugs and metabolites in sewage water ...................... 44

2.4.7 Estimation of drug consumption ................................................................ 48

2.4.8 Amphetamine and marijuana consumption variations................................. 51

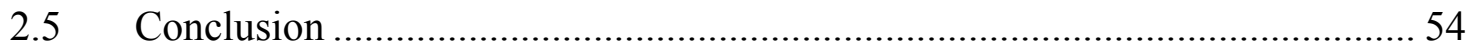

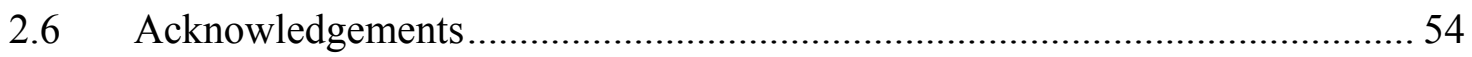

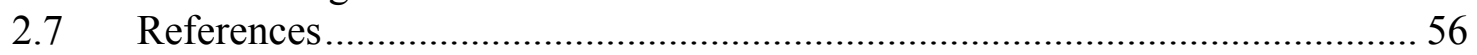

3 Understanding the magnitude of emergent contaminant releases through target screening and metabolite identification using high resolution mass spectrometry:

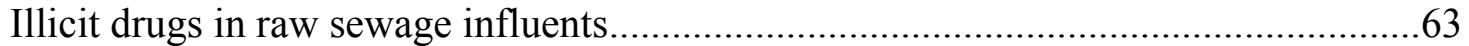

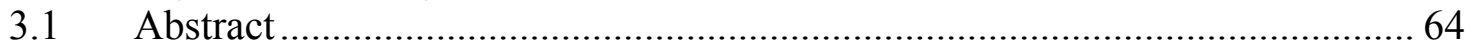

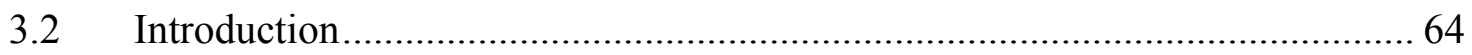

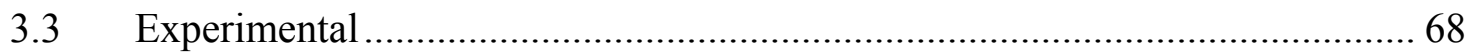

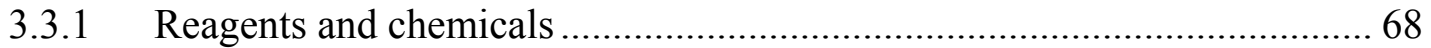

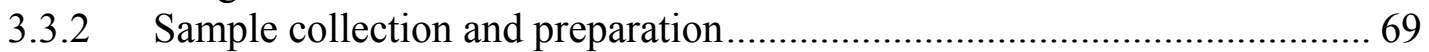

3.3.3 Pre-concentration and chromatographic separation of analytes ................. 69

3.3.4 Mass spectrometric Analysis .................................................................. 72

3.3.5 Concentration and mole fractions of TPs.................................................. 75

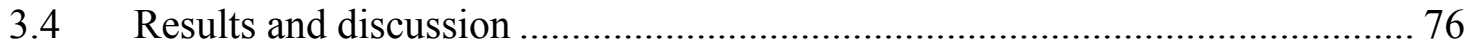

3.4.1 Transformation products of DOAs .......................................................... 76

3.4.2 Structural elucidation of transformation products ...................................... 80

3.4.3 Comparison of data acquisition modes ................................................... 85

3.4.4 Mole fraction of metabolites .................................................................. 88

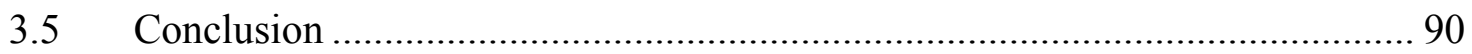

3.6 Acknowledgements............................................................................ 91

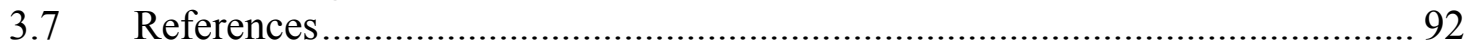

4 Characterization of wastewater effluent, surface, and drinking waters by highresolution mass spectrometry: Understanding the composition of recalcitrant

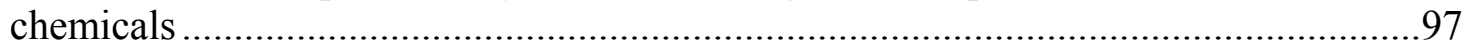

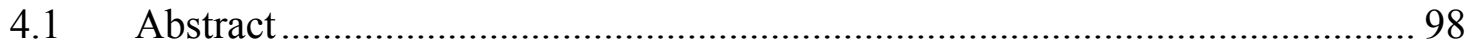

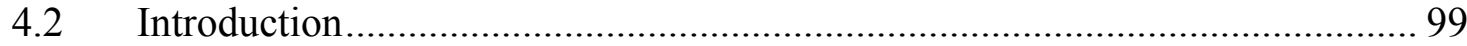

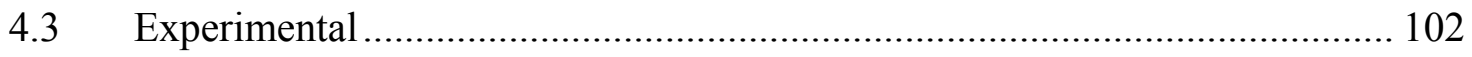

4.3.1 Reagents and chemicals ..................................................................... 102

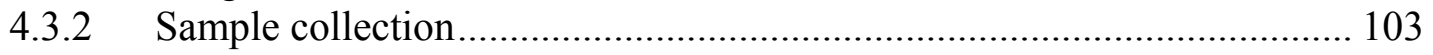

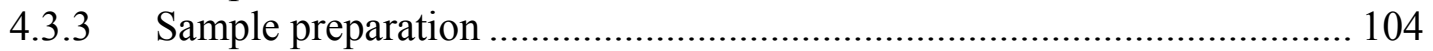

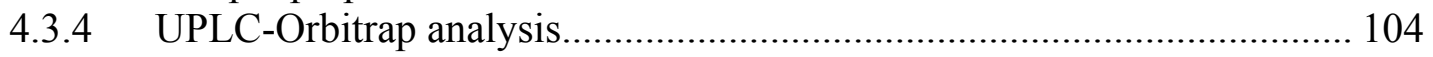

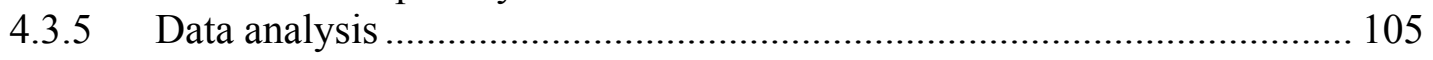

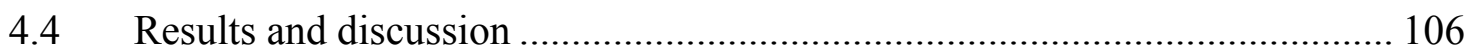

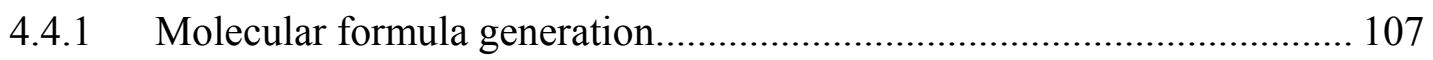

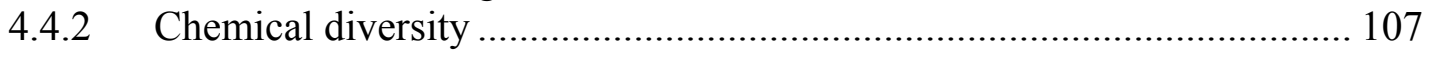

4.4.3 Recalcitrant fraction of chemicals ......................................................... 108

4.4.4 Kendrick mass plots............................................................................ 112

4.4.5 Evaluation of drinking water treatment ................................................... 114 


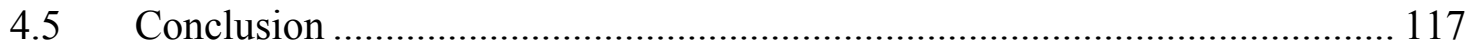

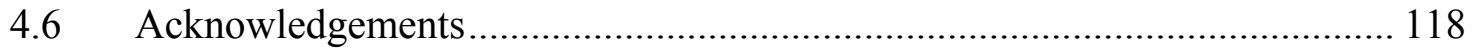

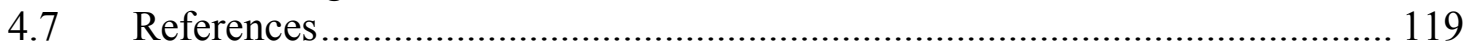

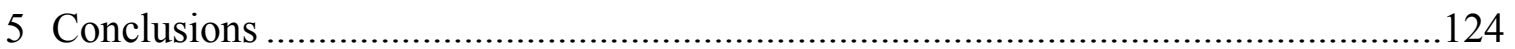

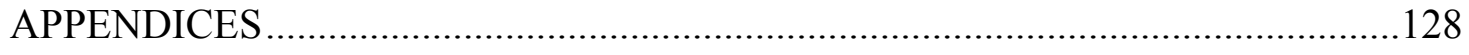

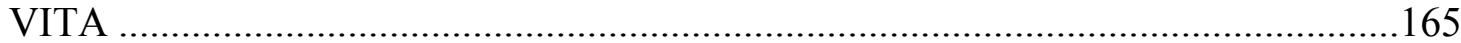




\section{LIST OF TABLES}

TABLE

PAGE

Table 2.1. Structures, elemental formula, exact mass, mass error, pKa, Log Kow, and internal standard used for quantitation of target analytes.

Table 2.2. Analytical pump and SPE pump gradient programs. Mobile phases used: water (A), methanol (B), acetonitrile (C), and 1\% formic acid/100 mM ammonium formate buffer (D).

Table 2.3. Analytical pump gradient for the direct injection method. Mobile phases used: LC-MS grade water (A), methanol (B), and 1\% formic acid/100mM ammonium formate buffer (D).

Table 2.4. Quality control parameter of analytical method: linearity (R2), precision (\%RSD), SPE recoveries, quantitation recoveries, and method detection limits (MDLs) in HPLC water and influent raw sewage water.

Table 2.5. Storage stability test. Results expressed in terms of $\%$ recovery (relative to fortification level, $250 \mathrm{ng} / \mathrm{L}$ ) and \% deviation for all analytes (relative to $\mathrm{T} 0$ ) after 3, 7, 17, 27 and 123 days. Test was performed in four independently stored aliquots of a single sewage sample.

Table 2.6. Concentrations of most frequently ( $>50 \%$ ) detected illicit drugs (ng/L) in influent raw sewage and a comparison with previous studies.

Table 2.7. Concentrations and frequency of detections for parent drugs and metabolites found in sewage waters for both locations (dorms and college campus).

Table 2.8. Analytes, correction factor parameters, and theoretical daily doses used for back-calculation estimates.

Table 3.1. Quality control parameter of analytical method: linearity (R2), precision (\%RSD), relative recoveries (spike recoveries), and method detection limits (MDLs) in HPLC water and influent raw sewage water.

Table 3.2. Phase I and phase II transformations and their exact masses.

Table 3.3. Source, Full scan, and MS/MS operating conditions.

Table 3.4. MS/MS fragmentation for 9 TPs that had a positive spectral match with ephedrine, ethylamphetamine, methylone, and norbenzoylecgonine. 
Table 3.5. Elemental composition, retention time, mass accuracy and the acquisition mode of identified TPs. Names in bold represent the parent molecule.

Table 3.6. Percent frequency of detection and mole fraction of the identified TPs.

Table 4.1. Analytical pump gradient program for direct injection. Mobile phases used: LC-MS grade water (A), methanol (B), acetonitrile (C), and $0.1 \%$ formic acid in water (D).

Table 4.2. Number of compounds detected, number molecular assignments and compound classes, as well as the total intensities for each of the sampling locations. ...108 


\section{LIST OF FIGURES}

FIGURE

PAGE

Fig. 2.1. Positive identification criteria for amphetamine in sewage water sample and its comparison to a calibration standard, and a blank.

Fig. 2.2. Stability of the online SPE procedure based on signal intensity of labelled analogs from $\mathrm{CCV}$ solutions $(100 \mathrm{ng} / \mathrm{L})$ throughout an analytical sequence (68 injections, 17 hour of continuous operation).

Fig. 2.3. Online-SPE-HPLC-HRMS chromatograms of wastewater (top) and fortified (100 ng/L) wastewater (bottom) samples. Including their deuterated analogs.

Fig. 2.4. Matrix effects of the method on analytes in sewage samples compared to HPLC water.

Fig. 2.5. Effects of filtration on illicit drug analytes. Analyte recovery comparison for filtered and unfiltered samples.

Fig. 2.6. Storage stability of drugs of abuse at $-20{ }^{\circ} \mathrm{C}$, during 123 -day period.

Fig. 2.7. Concentrations (ng/L) and frequency of detections (shown in parenthesis) of drugs of abuse in influent sewage samples from college dorms (4A Dorms) and main college campus (4B College Campus). The boundaries of box plot cover 25 th75 th percentile, the center line indicates median of the sample population, error bars (whiskers) above and below the box refer to 90th and 10th percentiles. Dotted line indicates the mean of the sample population.

Fig. 2.8. Daily dose consumption (doses/day/1000 people) estimates for THC, amphetamine, heroin, and cocaine in both dorms (5A) and main campus (5B). Campus estimates were determined using both population sizes.

Fig. 2.9. Drug consumption in the dorms throughout the semester for amphetamine (6A) and THC (6B). The boundaries of box plot cover 25th-75th percentile, the center line indicates median of the sample population, error bars (whiskers) above and below the box ref er to 90th and 10th percentiles. Dotted line indicates the mean of the sample population.

Fig. 2.10. Daily variations of amphetamine (7A) and cannabinoid (7B) consumption during the last three weeks of classes in the main campus. Campus estimates were determined using both population sizes. 
Fig. 3.1. Metabolite identification using two different operational modes in a $\mathrm{Q}$ Exactive Orbitrap.

Fig. 3.2. Diagram distribution of 54 tentatively identified TPs divided in two main categories. TPs formed from parent DOAs (45), and TPs formed from target DOA metabolites (9). Parenthesis indicated number of TPs. X indicates TPs that had the same $\mathrm{m} / \mathrm{z}$ as other compounds, but no spectral match.

Fig. 3.3. LC-Q Exactive Orbitrap extracted ion chromatograms (XICs) of amphetamine $(\mathrm{m} / \mathrm{z} 136.1121)$ and its metabolite $(\mathrm{m} / \mathrm{z} 170.1176)$ in a sewage water sample.

Fig. 3.4. Targeted MS2 spectra of amphetamine metabolite, m/z 170.1176

Fig. 3.5. Targeted MS2 spectra of amphetamine metabolite, $\mathrm{m} / \mathrm{z} 166.1226$.

Fig. 3.6. Methamphetamine's tentative transformation pathway of five identified TPs, including proposed structure, chemical formula, accurate mass $(\mathrm{m} / \mathrm{z})$, and type of transformation.

Fig. 3.7. Comparison of number of scans obtained in full scan, targeted MS2 and data dependent MS2 for one of the most abundant TP of Methamphetamine, MA-3 $(\mathrm{m} / \mathrm{z} 148.1121)$

Fig. 3.8. Percent mole fractions of the most abundant TPs in sewage water (frequency of detection shown in parenthesis). The boundaries of box plot cover 25th-75th percentile, the center line indicates median of the sample population, error bars (whiskers) above and below the box refer to 90th and 10th percentiles. Dotted line indicates the mean of the sample population.

Fig. 4.1. Diagram of sampling locations, upstream (UP), wastewater effluent (EFF), effluent mixing zone (EMZ), downstream (DS), drinking water intake (DWI), and treated drinking water (TDW).

Fig. 4.2. 5-way Venn diagram the effluent (EFF), effluent mixing zone (EMZ), downstream (DS), drinking water intake (DWI), and treated drinking water (TDW) locations.

Fig. 4.3. $\mathrm{m} / \mathrm{z}$ vs. retention time scatter plots of analytes originated at the EFF location and remained constant throughout the trajectory.

Figure 4.4. MS/MS spectral elucidation of four tentatively confirmed compounds. ......112

Fig. 4.5. Kendrick plots for each of the locations. a) UP, b) EFF, c) EMZ, d) DS, e) DWI, and f) TDW. 
Fig. 4.6. 2-way Venn diagram of DWI and TDW samples.........................................115

Fig. 4.7. Percent difference between the DWI and TDW locations using the intensities. Red indicates components found only in DWI. Green indicates components found only in TDW. Purple diamonds indicate the 64 recalcitrant chemicals. Blue dots represent components found in both locations. Dots near the zero line represent chemicals that have similar intensities before and after treatment....116 
ABBREVIATION

6-AMO

ADHD

AGC

ALS

AM

$\mathrm{BE}$

BFRs

$\mathrm{CCV}$

CE

$\mathrm{CO}$

COD

DBE

DBPs

DI

DOAs

DS

DWI

EDDP

EFF

EMZ

ESI
FULL NAME

6-Acetyl Morphine

Attention Deficit Hyperactivity Disorder

Automated Gain Control

Amphetamine-like-stimulants

Amphetamine

Benzoylecgonine

Brominated Flame Retardants

Continuing Calibration Verification

Cocaethylene

Cocaine

Codeine

Double Bond Equivalence

Disinfection Byproducts

Deionized

Drugs of Abuse

Downstream

Drinking Water Intake

2-ethylidene-1,5-dimethyl-3,3-diphenylpyrrolidine

Effluent

Effluent Mixing Zone

Electrospray Ionization 
FISh

Fragment Ion Search

FIU

Florida International University

FTICR

Fourier Transform Ion Cyclotron Resonance

HCD

High Collision Dissociation

HE

Heroin

HESI

Heated Electrospray Ionization

HILIC

Hydrophilic Interaction Liquid Chromatography

HLB

Hydrophilic-Lipophilic Balance

HPLC

High Performance Liquid Chromatography

HRMS

High Resolution Mass Spectrometry

IT

Injection Time

KMD

Kendrick Mass Defect

LC

Liquid Chromatography

LFB

Laboratory Fortified Blank

LFB-DUP

Laboratory Fortified Blank Duplicate

LFM

Laboratory Fortified Matrix

LSD

Lysergic Acid Diethylamide

$\mathrm{m} / \mathrm{z}$

MDA

Mass-to-charge ration

3,4-Methylenedioxyamphetamine

MDEA

MDL

MDMA

3,4-methylenedioxy-methamphetamine

ME

Methadone

xvii 
SPM

SRM

TDW

THC

THC-COOH

TPs

TSQ

UK

UNODC

UP

US-EPA

UV

WWTP
Suspended Particulate Matter

Selected Reaction Monitoring Treated Drinking Water Tetrahydrocannabinol 11-nor-9-carboxy-delta-9-tetrahydrocannabinol Transformation Products Triple Stage Quadrupole United Kingdom United Nations Office on Drugs and Crime Upstream United States Environmental Protection Agency Ultra Violet Wastewater Treatment Plant 
CHAPTER 1

Introduction 
The interdisciplinary nature of the field of high-resolution mass spectrometry has substantially broadened the possibilities in the environmental, forensic, and clinical fields with numerous advances each of the areas or a combination of them. Through multiple studies reported to date, it is now known of the presence of several hundreds of microconstituents ranging from pesticides, drugs of abuse (DOAs), pharmaceuticals and personal care products (PPCPs) in water and soil matrices, food products, and biological samples. While a considerable amount of information regarding the occurrence, fate, transport, toxicity, and consumption of a great variety of analytes is available; there are still many scientific challenges to overcome as human practices continue to expand the list of contaminants of emergent concern.

\subsection{Analytical methods}

\subsubsection{Pre-concentration}

Pre-concentration of aqueous samples has typically been accomplished with the use of solid phase extraction (SPE) (offline and online) because of the large selection of sorbent materials to accommodate compounds with different polarities and physicochemical characteristics (Gilart et al. 2014). Two of the most popular types of cartridges include the polymeric HLB cartridge, which contain functionalized porous polymers capable of extracting a wide range of polar and nonpolar components (Petrović et al. 2010); and mixed-mode cartridges such as cation-exchange and anion-exchange, which have been used to increase selectivity and capacity of extraction through ion-exchange mechanisms (Fontanals et al. 2013). Studies published by Gros et al., and Baker et al., have demonstrated superior recoveries for pharmaceuticals and illicit drugs using 
polymeric HLB and mixed-mode (MCX) cartridges respectively (Gros et al. 2006; Baker and Kasprzyk-hordern 2011).

\subsubsection{Liquid chromatography}

Liquid chromatography-mass spectrometry (LC-MS) has for the past few decades been the gold standard for the investigation of organic compounds in different types of complex matrices. Chromatographic methods have evolved to ultra-fast separation techniques as a result of advances in particle size and types and structures of packing materials (Baker and Kasprzyk-hordern 2011). These advances have provided advantages in terms of sensitivity, resolution of analytes, and sample throughput. For instance, the development of multi-residue methods for the simultaneous detection of multiple classes of compounds have been reported for pharmaceuticals and drugs of abuse (DOAs) with overall good separation and sensitivity (Gros et al. 2006; Kasprzyk-hordern et al. 2008; Loos et al. 2009; Baker and Kasprzyk-hordern 2011; Gago-Ferrero et al. 2015).

\subsubsection{Mass spectrometry}

\subsubsection{Low-resolution MS}

Tandem mass spectrometry (MS/MS) using triple quadrupole (QqQ) instruments has been an ideal detection technique for the target analysis of known compounds. It offers great sensitivity and selectivity in the selected reaction monitoring (SRM) mode, making it an attractive technique for the quantitation and identification of a considerable number of compounds (Petrović et al. 2010). Trace level determinations of numerous classes of emergent contaminants have been published in the literature using triple quadrupole instruments (Postigo et al. 2008; Bijlsma et al. 2009; Castiglioni et al. 2011; Ibáñez et al. 
2012; Batchu et al. 2013; Gorga et al. 2013; Idder et al. 2013; Panditi et al. 2013). However, one of the major pitfalls of this technique is the inability to detect or screen for compounds not compiled in the SRM list, even if their abundance in the sample is high.

\subsubsection{High-resolution MS}

High-resolution instruments are capable of simultaneously analyzing large number of low and high abundant compounds for characterization, screening, identification and even quantitation of known and unknown compounds, with minimal optimization compared to low-resolution quadrupole instruments (Krauss et al. 2010; Díaz et al. 2012; Hopfgartner et al. 2012; Xian et al. 2012; Bijlsma et al. 2013b). These capabilities are attributed to the instruments high resolving power, which allows them to discriminate signals observed in a mass spectrum from ions of similar mass to charge ratio $(\mathrm{m} / \mathrm{z})$ (Hernández et al. 2012; Ojanperä et al. 2012). Fourier transform ion cyclotron (FTICR) and Orbitrap instruments are capable of reaching resolutions of up to $1,000,000$ and 240,000 respectively. High-resolution mass spectrometry (HRMS) has been gaining momentum in the field of environmental science. Several applications for target analysis, suspect screening, metabolite identification, and non-target screening reported in the literature (Bijlsma et al. 2011; Díaz et al. 2012; Chiaia-Hernandez et al. 2013; Moschet et al. 2013; Hug et al. 2014; Li et al. 2014; Vergeynst et al. 2014), have demonstrated the enormous potential of this powerful technique.

\subsection{Target analysis}

Identification and quantitation of compounds has for many decades been with the use of reference standards and their labeled analogs; and with the instrumental power of triple 
quadrupole instruments. While this approach has been implemented for routine analysis of many different types of microconstituents including PPCPs, DOAs, and pesticides, certain limitations have become evident. The requirement to two SRM transitions restricts the number of analytes in a run, as a result of short acquisition times and peak resolution (Krauss et al. 2010). In addition, some low molecular weight ions only provide one transition with low signal intensity, or isobaric interferences may show the same transitions as the analyte of interest (Krauss et al. 2010). High-resolution mass spectrometry resolves these issues with the use of full-scan for detection of thousands of compounds, and data-dependent and target MS/MS acquisition modes for confirmation.

\subsubsection{Occurrence}

Target analytical methods have been used to detect the occurrence of a large number of compounds in water and solid matrices. Excellent reviews have been published throughout the years on the subject of contaminants of emergent concern, providing a great wealth of information on the occurrence of many of these compounds (Petrovic et al. 2008; Barceló et al. 2012; Richardson and Ternes 2014). Some of these compounds include perfluorinated compounds (PFCs), Pharmaceuticals and hormones, disinfection byproducts, pesticides, artificial sweeteners, and drugs of abuse (DOAs).

\subsubsection{Wastewater}

Environmental occurrence of DOAs have been reported in wastewater, surface water, ground water, and air (Zuccato et al. 2005; Postigo et al. 2009, 2010; Jurado et al. 2012; Mastroianni et al. 2013). Drugs of abuse (DOAs) reached wastewater treatment plants (WWTPs) soon after they are excreted or disposed of. In here, a combination of the 
parent DOA and its metabolite(s) can survive treatment and be release surface waters, soil, and sediments. In wastewaters (influents and effluents), prevalence of DOAs range in ppt and ppb levels for cocainics (benzoylecgonine, $7.500 \mathrm{ng} / \mathrm{L}$ ) (Huerta-Fontela et al. 2008a), opioids (codeine, 32,295 ng/L) (Kasprzyk-hordern et al. 2008), cannabinoids (THC-COOH, 402 ng/L) (Boleda et al. 2009), and amphetamines (MDMA, 15,380 ng/L) (Bijlsma et al. 2009).

\subsubsection{Surface and ground water}

While concentration levels of DOAs in surface waters are significantly lower (low ppt) than those in wastewaters, several of these types of drugs are still present in the environment. Drugs like cocaine, morphine, methadone, THC, amphetamine, methamphetamine, MDA, MDMA, and some of their metabolites are found ubiquitously in countries like Spain, Italy, and Switzerland where most research has been reported (Zuccato et al. 2005; Huerta-Fontela et al. 2008b; González-Mariño et al. 2010; Postigo et al. 2010; Bueno et al. 2012; Valcárcel et al. 2012). In addition, Jurado et al., found low ppt levels of MDMA (3.9 ng/L), morphine (1.4 ng/L), methadone (7.4 ng/L), cocaine (3.8 $\mathrm{ng} / \mathrm{L}$ ), and a few of their metabolic products in ground water (Jurado et al. 2012). These findings are very important since drinking water treatment plants rely on surface and ground water as source for drinking water production.

\subsubsection{Drinking water}

Two reports published by Boleda et al., and Valcárcel et al. studied the presence of DOAs in drinking water throughout several countries in Europe, Latin America, and Japan (Boleda et al. 2011; Valcárcel et al. 2012). Their findings demonstrated the 
persistence of cocaine $(0.1 \mathrm{ng} / \mathrm{L}$ to $2.11 \mathrm{ng} / \mathrm{L})$, benzoylecgonine $(0.2 \mathrm{ng} / \mathrm{L}$ to $4.5 \mathrm{ng} / \mathrm{L})$, cocaethylene $(0.2 \mathrm{ng} / \mathrm{L})$, methadone $(0.1 \mathrm{ng} / \mathrm{L}$ to $0.99 \mathrm{ng} / \mathrm{L})$, and $\operatorname{EDDP}(0.1 \mathrm{ng} / \mathrm{L}$ to 0.4 ng/L) after drinking water treatment (Boleda et al. 2011; Valcárcel et al. 2012); which confirms that drinking water facilities require better treatment processes to deal with these types of compounds.

\subsubsection{Consumption}

Drugs of abuse concentration values obtained from wastewater analysis can easily be used to estimate consumption levels in communities. Wastewater flows are utilized to determine daily mass loads of parent drugs and/or metabolites (these values are usually normalized to 1,000 inhabitants) (Zuccato et al. 2005). In addition, excretions rates, metabolite/parent molar ratios, and known doses are then factored into the analysis to ultimately determine the number of daily doses/day/1000 inhabitants for each drug (Zuccato et al. 2005). This approach has been very useful in determining real time prevalence of drug use in a community, as well as rates and patterns of consumption (Nuijs et al. 2011).

Drug consumptions have been estimated in small settings such as a music festival and a prison, in which the major drugs consumed were cannabis (70 daily doses/day/1000 people) and methadone (156 daily doses/day/1000 people) for the festival and the prison, respectively (Postigo et al. 2011; Lai et al. 2013). Regional estimates of drug use have also been determine for cocaine, opiates, cannabis, and amphetamine-like-stimulants (ALS), in order to asses drug prevalence across different areas within a region (Postigo et 
al. 2010), and to identify weekly, monthly, and even yearly patterns of consumption (Zuccato et al. 2008, 2011; Karolak et al. 2010; Kasprzyk-Hordern and Baker 2012).

\subsection{Identification of transformation products (TPs)}

Following drug consumption, drugs can undergo phase I and phase II metabolic processes in the body generating excretion products which may contain portions of the parent drug and some of the metabolic products (Celiz et al. 2009). Following excretion, these microconstituents are exposed to different types of treatments and environmental conditions, and can suffer additional degradation (Pérez and Barceló 2007). As a result, the absence or reduction of drug (illicit and prescription) concentrations in environmental analyses can erroneously provide false negatives on the actual conditions of aquatic ecosystems.

Nowadays, with the use of high-resolution instruments, it is possible to screen and identify transformation products that were not previously known to be present in the environment (Bijlsma et al. 2013a). Methods have been developed to determine transformation products from pharmaceuticals and DOAs. For instance, several transformation products (TPs) from unapproved analogs of the erectile dysfunction drug sildenafil were identified and confirmed in controlled laboratory studies, and two of the TPs were found in environmental samples (Aceña et al. 2014). In addition, our group recently reported the identification and quantitation of two phase II metabolic products of the antibiotic sulfamethoxazole (SMX) in reclaimed water (Wang and Gardinali 2014). The two metabolites represented $54 \%$ of the source of SMX in reclaimed water suggesting the importance of measuring TPs in the environment (Wang and Gardinali 
2014). Other studies have been performed to investigate the degradation products of cocaine and benzoylecgonine in aquatic environments (Bijlsma et al. 2013a); and to identify pharmaceutical TPs from oxidation and disinfection processes in drinking water treatment (Postigo and Richardson 2014).

\subsection{Non-target analysis}

To date, the list of organic pollutants, both regulated and unregulated, comprises chemicals such as pharmaceuticals and personal care products (PPCPs), hormones, pesticides, drugs of abuse (DOAs), artificial sweeteners, nanomaterials, disinfection by products (DBPs), perfluorinated compounds (PFCs), polycyclic aromatic hydrocarbons (PAHs), brominated flame retardants (BFRs), phthalates, suncreens/UV filters, and many more that are being introduced and transformed in the environment (Huerta-Fontela et al. 2008a; Barceló et al. 2012; Zareitalabad et al. 2013; Richardson and Ternes 2014). Since it is not possible to develop a method to monitor such a large number of known and unknown compounds, non-target techniques are used to mine accurate mass data even after being acquired.

Multiple approaches for non-target analysis have been reported in the literature showing commonalities in the workflows used (García-Reyes et al. 2007; Díaz et al. 2012; Chiaia-Hernandez et al. 2014; Hug et al. 2014). The initial step in non-target analysis is the detection of peaks by mass filtering from the chromatographic run (Krauss

et al. 2010). Since high-resolution instruments operating in full scan mode generate massive amounts of data, it is wise (if not necessary) to perform a blank subtraction to remove background ions (Moschet et al. 2013). At this point, stepwise filtering of data is 
applied staring from generation of a peak list, followed by determination and confirmation of formulas (Hug et al. 2014). The latter step follows a series of heuristic rules develop to remove erroneous formula assignments, and reduce the number of possible elemental compositions (Kind and Fiehn 2007).

While a significant number of masses have been filtered throughout these steps, there is still a considerable amount of data. To deal with the dilemma, the following approaches have been used: database search to exclude formulas with no hits (Hug et al. 2014); retention time (rt) filtering, which excludes formulas that do not match the predicted rt (Krauss et al. 2010; Díaz et al. 2012); and data comparisons through graphical interpretations, Venn diagrams, multivariate, and cluster analysis (Müller et al. 2011; Tseng et al. 2013; Vergeynst et al. 2015).

The last step in non-target analysis is confirmation using MS/MS data, and a combination of in-silico fragmentation, structural elucidation, and database search for the predicted structures (Krauss et al. 2010; Hug et al. 2014; Bletsou et al. 2015). It is important to keep in mind that for non-target analysis to be possible, high-resolution and mass accuracy are a must. In addition one of the key elements in this process is automation through different algorithms and databases for it to be efficient.

\subsection{Hypothesis}

Application of target and non-target techniques using the capabilities of high resolution mass spectrometry can be used to understand human activities and habits through assessment of drug consumption, metabolite identification, and characterization of contaminants of emergent concern in water matrices. 


\subsection{Objectives}

To develop an analytical method based on high-resolution mass spectrometry capable of detecting ppt levels of drugs of abuse, and to implement the technique in the communal assessment of consumption.

To develop a workflow using HR-MS/MS for the identification of DOA transformation products in raw sewage influents, to further determine their abundance and assess their prevalence.

To characterize different types of interconnected water matrices using non-target high-resolution mass spectrometry for classification and comparison of compound diversity among the water matrices, to further identify and understand the composition of recalcitrant chemicals. 


\subsection{References}

Aceña J, Pérez S, Gardinali P, Abad JL, Eichhorn P, Heuett N, et al. Structure elucidation of phototransformation products of unapproved analogs of the erectile dysfunction drug sildenafil in artificial freshwater with UPLC-Q Exactive-MS. J Mass Spectrom [Internet]. 2014;49(August):1279-89. Available from:

http://doi.wiley.com/10.1002/jms.3461

Baker DR, Kasprzyk-hordern B. Multi-residue analysis of drugs of abuse in wastewater and surface water by solid-phase extraction and liquid chromatography - positive electrospray ionisation tandem mass spectrometry. J Chromatogr A. 2011;1218:1620-31.

Barceló D, Kostianoy AG, (ed.). The Handbook of Environmental Chemistry: Emerging Organic Contaminants and Human Health. Springer-Verlag. Berlin Heidelberg; 2012.

Batchu SR, Quinete N, Panditi VR, Gardinali PR. Online solid phase extraction liquid chromatography tandem mass spectrometry (SPE-LC-MS/MS) method for the determination of sucralose in reclaimed and drinking waters and its photo degradation in natural waters from South Florida. Chem Cent J. 2013 Jan;7(1):141.

Bijlsma L, Boix C, Niessen WMA, Ibáñez M, Sancho J V, Hernández F. Investigation of degradation products of cocaine and benzoylecgonine in the aquatic environment. Sci Total Environ. Elsevier B.V.; 2013a Jan 15;443:200-8.

Bijlsma L, Emke E, Hernández F, de Voogt P. Performance of the linear ion trap Orbitrap mass analyzer for qualitative and quantitative analysis of drugs of abuse and relevant metabolites in sewage water. Anal Chim Acta. Elsevier B.V.; 2013b Mar 20;768:102-10.

Bijlsma L, Sancho J V, Niessen WMA. Fragmentation pathways of drugs of abuse and their metabolites based on QTOF MS / MS and MS E accurate mass spectra. J Mass Spectrom. 2011;46:865-75.

Bijlsma L, Sancho J V, Pitarch E, Ibáñez M, Hernández F. Simultaneous ultra-highpressure liquid chromatography - tandem mass spectrometry determination of amphetamine and amphetamine-like stimulants , cocaine and its metabolites , and a cannabis metabolite in surface water and urban wastewater $\leftleftarrows$. J Chromatogr A. 2009;1216:3078-89.

Bletsou AA, Jeon J, Hollender J, Archontaki E, Thomaidis NS. Targeted and nontargeted liquid chromatography-mass spectrometric workflows for identification of transformation products of emerging pollutants in the aquatic environment. Trends 
Anal Chem [Internet]. Elsevier B.V.; 2015;66:32-44. Available from: http://dx.doi.org/10.1016/j.trac.2014.11.009

Boleda MR, Galceran MT, Ventura F. Monitoring of opiates, cannabinoids and their metabolites in wastewater, surface water and finished water in Catalonia, Spain. Water Res. 2009;43:1126-36.

Boleda MR, Huerta-Fontela M, Ventura F, Galceran MT. Evaluation of the presence of drugs of abuse in tap waters. Chemosphere [Internet]. Elsevier Ltd; 2011;84:1601-7. Available from: http://dx.doi.org/10.1016/j.chemosphere.2011.05.033

Bueno MJM, Gomez MJ, Herrera S, Hernando MD, Agüera a., Fernández-Alba a. R. Occurrence and persistence of organic emerging contaminants and priority pollutants in five sewage treatment plants of Spain: Two years pilot survey monitoring. Environ Pollut [Internet]. Elsevier Ltd; 2012;164:267-73. Available from: http://dx.doi.org/10.1016/j.envpol.2012.01.038

Castiglioni S, Bagnati R, Melis M, Panawennage D, Chiarelli P, Fanelli R, et al. Identification of cocaine and its metabolites in urban wastewater and comparison with the human excretion profile in urine. Water Res. 2011;45:5141-50.

Celiz MD, Tso J, Aga DS. Pharmaceutical Metabolites in the Environment: Analytical Challenges and Ecological Risks. Environ Toxicol Chem. 2009;28(12):2473-84.

Chiaia-Hernandez AC, Krauss M, Hollender J. Screening of lake sediments for emerging contaminants by liquid chromatography atmospheric pressure photoionization and electrospray ionization coupled to high resolution mass spectrometry. Environ Sci Technol [Internet]. 2013 Jan 15;47(2):976-86. Available from: http://www.ncbi.nlm.nih.gov/pubmed/23215447

Chiaia-Hernandez AC, Schymanski EL, Kumar P, Singer HP, Hollender J. Suspect and nontarget screening approaches to identify organic contaminant records in lake sediments. Anal Bioanal Chem [Internet]. 2014 Sep 26 [cited 2014 Oct 21]; Available from: http://www.ncbi.nlm.nih.gov/pubmed/25258286

Díaz R, Ibáñez M, Sancho J V., Hernández F. Target and non-target screening strategies for organic contaminants, residues and illicit substances in food, environmental and human biological samples by UHPLC-QTOF-MS. Anal Methods. 2012;4:196.

Fontanals N, Borrull F, Marcé RM. On-line weak cationic mixed-mode solid-phase extraction coupled to liquid chromatography-mass spectrometry to determine illicit drugs at low concentration levels from environmental waters. J Chromatogr A. Elsevier B.V.; 2013 Apr 19;1286:16-21. 
Gago-Ferrero P, Borova V, Dasenaki ME, Thomaidis NS. Simultaneous determination of 148 pharmaceuticals and illicit drugs in sewage sludge based on ultrasound-assisted extraction and liquid chromatography-tandem mass spectrometry. Anal Bioanal Chem [Internet]. 2015;4287-97. Available from: http://link.springer.com/10.1007/s00216-015-8540-6

García-Reyes JF, Hernando MD, Molina-Díaz A, Fernández-Alba AR. Comprehensive screening of target, non-target and unknown pesticides in food by LC-TOF-MS. TrAC - Trends Anal Chem. 2007;26(8):828-41.

Gilart N, Borrull F, Fontanals N, Marcé RM. Selective materials for solid-phase extraction in environmental analysis. Trends Environ Anal Chem. 2014;1.

González-Mariño I, Quintana JB, Rodríguez I, Cela R. Determination of drugs of abuse in water by solid-phase extraction, derivatisation and gas chromatography-ion traptandem mass spectrometry. J Chromatogr A. 2010;1217:1748-60.

Gorga M, Petrovic M, Barceló D. Multi-residue analytical method for the determination of endocrine disruptors and related compounds in river and waste water using dual column liquid chromatography switching system coupled to mass spectrometry. J Chromatogr A. Elsevier B.V.; 2013 Jun 21;1295:57-66.

Gros M, Petrović M, Barceló D. Development of a multi-residue analytical methodology based on liquid chromatography-tandem mass spectrometry (LC-MS/MS) for screening and trace level determination of pharmaceuticals in surface and wastewaters. Talanta [Internet]. 2006 Nov 15 [cited 2014 Jul 16];70(4):678-90. Available from: http://www.ncbi.nlm.nih.gov/pubmed/18970827

Hernández F, Sancho J V., Ibáñez M, Abad E, Portolés T, Mattioli L. Current use of high-resolution mass spectrometry in the environmental sciences. Anal Bioanal Chem. 2012;403(5):1251-64.

Hopfgartner G, Tonoli D, Varesio E. High-resolution mass spectrometry for integrated qualitative and quantitative analysis of pharmaceuticals in biological matrices. Anal Bioanal Chem. 2012;402(8):2587-96.

Huerta-Fontela M, Galceran MT, Martin-Alonso J, Ventura F. Occurrence of psychoactive stimulatory drugs in wastewaters in north-eastern Spain. Sci Total Environ. 2008a;397:31-40.

Huerta-Fontela M, Galceran MT, Ventura F. Stimulatory Drugs of Abuse in Surface Waters and Their Removal in a Conventional Drinking Water Treatment Plant. Environ Sci Technol. 2008b;42(18):6809-16. 
Hug C, Ulrich N, Schulze T, Brack W, Krauss M. Identification of novel micropollutants in wastewater by a combination of suspect and nontarget screening. Environ Pollut [Internet]. Elsevier Ltd; 2014 Jan [cited 2014 May 15];184:25-32. Available from: http://www.ncbi.nlm.nih.gov/pubmed/24012788

Ibáñez M, Gracia-Lor E, Sancho J V, Hernández F. Importance of MS selectivity and chromatographic separation in LC-MS/MS-based methods when investigating pharmaceutical metabolites in water. Dipyrone as a case of study. J Mass Spectrom [Internet]. 2012 Aug [cited 2013 Dec 1];47(8):1040-6. Available from: http://www.ncbi.nlm.nih.gov/pubmed/22899513

Idder S, Ley L, Mazellier P, Budzinski H. Quantitative on-line preconcentration-liquid chromatography coupled with tandem mass spectrometry method for the determination of pharmaceutical compounds in water. Anal Chim Acta [Internet]. Elsevier B.V.; 2013 Dec [cited 2013 Dec 1];805:107-15. Available from: http://linkinghub.elsevier.com/retrieve/pii/S0003267013013846

Jurado A, Mastroianni N, Vàzquez-Suñé E, Carrera J, Tubau I, Pujades E, et al. Drugs of abuse in urban groundwater. A case study: Barcelona. Sci Total Environ. Elsevier B.V.; 2012;424:280-8.

Karolak S, Nefau T, Bailly E, Solgadi A, Levi Y. Estimation of illicit drugs consumption by wastewater analysis in Paris area (France). Forensic Sci Int [Internet]. Elsevier Ireland Ltd; 2010;200:153-60. Available from:

http://dx.doi.org/10.1016/j.forsciint.2010.04.007

Kasprzyk-Hordern B, Baker DR. Estimation of community-wide drugs use via stereoselective profiling of sewage. Sci Total Environ. Elsevier B.V.; 2012 Apr $15 ; 423: 142-50$.

Kasprzyk-hordern B, Dinsdale RM, Guwy AJ. Multiresidue methods for the analysis of pharmaceuticals , personal care products and illicit drugs in surface water and wastewater by solid-phase extraction and ultra performance liquid chromatography - electrospray tandem mass spectrometry. Anal Bioanal Chem. 2008;391:1293-308.

Kind T, Fiehn O. Seven Golden Rules for heuristic filtering of molecular formulas obtained by accurate mass spectrometry. BMC Bioinformatics. 2007;8:105.

Krauss M, Singer H, Hollender J. LC-high resolution MS in environmental analysis: from target screening to the identification of unknowns. Anal Bioanal Chem [Internet]. 2010 Jun [cited 2013 Nov 20];397(3):943-51. Available from: http://www.ncbi.nlm.nih.gov/pubmed/20232059

Lai FY, Thai PK, O’Brien J, Gartner C, Bruno R, Kele B, et al. Using quantitative wastewater analysis to measure daily usage of conventional and emerging illicit 
drugs at an annual music festival. Drug Alcohol Rev [Internet]. 2013 Nov [cited 2014 May 29];32(6):594-602. Available from:

http://www.ncbi.nlm.nih.gov/pubmed/23782033

Li Z, Maier MP, Radke M. Screening for pharmaceutical transformation products formed in river sediment by combining ultrahigh performance liquid chromatography/high resolution mass spectrometry with a rapid data-processing method. Anal Chim Acta [Internet]. Elsevier B.V.; 2014;810:61-70. Available from: http://dx.doi.org/10.1016/j.aca.2013.12.012

Loos R, Gawlik BM, Locoro G, Rimaviciute E, Contini S, Bidoglio G. EU-wide survey of polar organic persistent pollutants in European river waters. Environ Pollut [Internet]. Elsevier Ltd; 2009;157(2):561-8. Available from: http://dx.doi.org/10.1016/j.envpol.2008.09.020

Mastroianni N, Postigo C, De Alda ML, Barcelo D. Illicit and abused drugs in sewage sludge: Method optimization and occurrence. J Chromatogr A [Internet]. Elsevier B.V.; 2013;1322:29-37. Available from: http://dx.doi.org/10.1016/j.chroma.2013.10.078

Moschet C, Piazzoli A, Singer H, Hollender J. Alleviating the reference standard dilemma using a systematic exact mass suspect screening approach with liquid chromatography-high resolution mass spectrometry. Anal Chem [Internet]. 2013 Nov 5;85(21):10312-20. Available from: http://www.ncbi.nlm.nih.gov/pubmed/24161211

Müller A, Schulz W, Ruck WKL, Weber WH. A new approach to data evaluation in the non-target screening of organic trace substances in water analysis. Chemosphere. 2011;85:1211-9.

Nuijs ALN Van, Castiglioni S, Tarcomnicu I, Postigo C, Alda ML de, Neels H, et al. Illicit drug consumption estimations derived from wastewater analysis: A critical review 岤. Sci Total Environ [Internet]. Elsevier B.V.; 2011;409:3564-77. Available from: http://dx.doi.org/10.1016/j.scitotenv.2010.05.030

Ojanperä I, Kolmonen M, Pelander A. Current use of high-resolution mass spectrometry in drug screening relevant to clinical and forensic toxicology and doping control. Anal Bioanal Chem. 2012;403(5):1203-20.

Panditi VR, Batchu SR, Gardinali PR. Online solid-phase extraction-liquid chromatography-electrospray-tandem mass spectrometry determination of multiple classes of antibiotics in environmental and treated waters. Anal Bioanal Chem. 2013 Jul;405(18):5953-64. 
Pérez S, Barceló D. Application of advanced MS techniques to analysis and identification of human and microbial metabolites of pharmaceuticals in the aquatic environment. TrAC Trends Anal Chem [Internet]. 2007 Jun [cited 2013 Nov 25];26(6):494-514. Available from: http://linkinghub.elsevier.com/retrieve/pii/S0165993607001124

Petrović M, Farré M, Alda ML de, Perez S, Postigo C, Köck M, et al. Recent trends in the liquid chromatography - mass spectrometry analysis of organic contaminants in environmental samples. J Chromatogr A. 2010;1217:4004-17.

Petrovic M, Radjenovic J, Postigo C, Kuster M, Farré M, Lopez de Alda M, et al. The Handbook of Environmental Chemistry. In: Hutzinger O, Barceló D, Kostianoy A, editors. Springer. Springer-Verlag Berlin Heidelberd; 2008. p. Vol. 5, Part S/1: 135.

Postigo C, Alda MJL De, Barceló D. Fully Automated Determination in the Low Nanogram per Liter Level of Different Classes of Drugs of Abuse in Sewage Water by On-Line Chromatography-Electrospray-Tandem Mass Spectrometry. Anal Chem. 2008;80:3123-34.

Postigo C, Alda MJL De, Barceló D. Drugs of abuse and their metabolites in the Ebro River basin: Occurrence in sewage and surface water, sewage treatment plants removal efficiency, and collective drug usage estimation. Environ Int. Elsevier Ltd; 2010;36(1):75-84.

Postigo C, Alda MJL De, Viana M, Querol X. Determination of Drugs of Abuse in Airborne Particles by Pressurized Liquid Extraction and Liquid ChromatographyElectrospray-Tandem Mass Spectrometry. Anal Chem. 2009;81(11):4382-8.

Postigo C, Alda ML de, Barceló D. Evaluation of drugs of abuse use and trends in a prison through wastewater analysis. Environ Int. Elsevier Ltd; 2011;37(1):49-55.

Postigo C, Richardson SD. Transformation of Pharmaceuticals During Oxidation/Disinfection Processes in Drinking Water Treatment. J Hazard Mater [Internet]. Elsevier B.V.; 2014;279:461-75. Available from: http://linkinghub.elsevier.com/retrieve/pii/S0304389414005949

Richardson SD, Ternes $\mathrm{T}$ a. Water analysis: emerging contaminants and current issues. Anal Chem [Internet]. 2014 Mar 18;86(6):2813-48. Available from: http://www.ncbi.nlm.nih.gov/pubmed/24502364

Tseng LY, Gonsior M, Schmitt-Kopplin P, Cooper WJ, Pitt P, Rosso D. Molecular characteristics and differences of effluent organic matter from parallel activated sludge and integrated fixed-film activated sludge (IFAS) processes. Environ Sci Technol [Internet]. 2013 Sep 17;47(18):10277-84. Available from: http://www.ncbi.nlm.nih.gov/pubmed/23941532 
Valcárcel Y, Martínez F, González-Alonso S, Segura Y, Catalá M, Molina R, et al. Drugs of abuse in surface and tap waters of the Tagus River basin : Heterogeneous photoFenton process is effective in their degradation. Environ Int. Elsevier Ltd; 2012;41:35-43.

Vergeynst L, Van Langenhove H, Demeestere K. Balancing the False Negative and Positive Rates in Suspect Screening with High-Resolution Orbitrap Mass Spectrometry Using Multivariate Statistics. Anal Chem [Internet]. 2015;87:2170-7. Available from: http://pubs.acs.org/doi/abs/10.1021/ac503426k

Vergeynst L, Van Langenhove H, Joos P, Demeestere K. Suspect screening and target quantification of multi-class pharmaceuticals in surface water based on largevolume injection liquid chromatography and time-of-flight mass spectrometry. Anal Bioanal Chem. 2014;406:2533-47.

Wang J, Gardinali PR. Identification of phase II pharmaceutical metabolites in reclaimed water using high resolution benchtop Orbitrap mass spectrometry. Chemosphere [Internet]. Elsevier Ltd; 2014 Jul [cited 2014 Apr 28];107:65-73. Available from: http://linkinghub.elsevier.com/retrieve/pii/S0045653514003701

Xian F, Hendrickson CL, Marshall AG. High resolution mass spectrometry. Anal Chem. 2012;(84):708-19.

Zareitalabad P, Siemens J, Hamer M, Amelung W. Perfluorooctanoic acid (PFOA) and perfluorooctanesulfonic acid (PFOS) in surface waters, sediments, soils and wastewater - A review on concentrations and distribution coefficients. Chemosphere [Internet]. Elsevier Ltd; 2013;91(6):725-32. Available from:

http://dx.doi.org/10.1016/j.chemosphere.2013.02.024

Zuccato E, Castiglioni S, Tettamanti M, Olandese R, Bagnati R, Melis M, et al. Changes in illicit drug consumption patterns in 2009 detected by wastewater analysis. Drug Alcohol Depend [Internet]. 2011 [cited 2014 Jan 28];118(2):464-9. Available from: http://www.sciencedirect.com/science/article/pii/S0376871611002171

Zuccato E, Chiabrando C, Castiglioni S, Bagnati R, Fanelli R. Estimating Community Drug Abuse by Wastewater Analysis. Environ Health Perspect. 2008;116(8):102732.

Zuccato E, Chiabrando C, Castiglioni S, Calamari D, Bagnati R, Schiarea S, et al. Cocaine in surface waters : a new evidence-based tool to monitor community drug abuse. Environ Heal A Glob Access Sci Source. 2005;4(14):1-7. 


\section{CHAPTER 2}

\section{Analysis of drugs of abuse by online SPE-LC high-resolution mass spectrometry: Communal assessment of consumption}

This chapter was published in the journal Science of the Total Environment and adapted with permission from all participating authors.

Nubia V. Heuett, Cesar E. Ramirez, Adolfo Fernandez, and Piero R. Gardinali, Science of the Total Environment 511 (2015) 319-330. 


\subsection{Abstract}

An online SPE-LC-HRMS method was developed to monitor the consumption of 18 drugs of abuse (DOAs) including amphetamines, opioids, cocainics, cannabinoids, lysergics, and their corresponding metabolites in a well characterized college campus setting via wastewater analysis. Filtered and diluted (10X) sewage water samples $(5 \mathrm{~mL}$ inj.) were automatically pre-concentrated and analyzed in 15 min using a Thermo EQuan MAX online SPE system equipped with a HyperSep ${ }^{\mathrm{TM}}$ Retain PEP $(20 \times 2.1 \mathrm{~mm} \times 12$ $\mu \mathrm{m})$ SPE column and a Hypersil Gold ${ }^{\mathrm{TM}} \mathrm{aQ}(150 \times 2.1 \mathrm{~mm} \times 3 \mu \mathrm{m})$ analytical column. A Q Exactive TM $^{\mathrm{TM}}$ Hybid Quadrupole-Orbitrap HRMS was used in full scan mode $(\mathrm{R}=140,000)$ for positive identification, and quantitation of target compounds. Method detection limits for all analytes ranged between 0.6 to $1.7 \mathrm{ng} / \mathrm{L}$ in sewage. A total of 14 DOAs were detected from two different locations (dorms and main college campus) within one-year period. Most frequently detected drugs throughout the entire study were amphetamine (>96\%) and THC's metabolite 11-nor-9-carboxy- $\Delta-9-\mathrm{THC}(>100 \%)$ with maximum concentrations of 5,956 and 2,413 ng/L respectively. Daily doses per 1000 people were determined in order to assess consumption of THC, amphetamine, heroin and cocaine, in both dorms and main campus.

\subsection{Introduction}

Every year, the United Nations Office on Drugs and Crime (UNODC) generates a comprehensive report on the latest developments in drug markets, covering production, trafficking, consumption, and health consequences (UNODC 2014). In the year 2012, the US alone reached its highest levels of illicit drug use in the past 10 years $(16 \%$ of the 
population 12 years and older), with consumption being the greatest among those in their late teens or early twenties, as noted in the World Drug Report 2014 (UNODC 2014). These Fig., however, are not evaluated fast enough to provide real time understanding of the situation for law enforcement officials to take appropriate timely actions.

Multiple studies have reported wastewater-derived Fig. for the consumption of drugs of abuse (illicit and prescription drugs), as they provide a nonintrusive way to quickly assess social trends, usage patterns, and drug prevalence at the community level (Castiglioni et al. 2006; Zuccato et al. 2008; Chiaia and Banta-green 2008; HuertaFontela et al. 2008; Bartelt-hunt et al. 2009; Boleda et al. 2009; Postigo et al. 2010; Baker and Kasprzyk-hordern 2011; Nuijs et al. 2011; Bijlsma et al. 2012; Kasprzyk-Hordern and Baker 2012). This in contrast to the more conservative, time-consuming, and intrusive approaches of social surveys, drug seizures, crime statistics, and medical examiner reports (Nuijs et al. 2009d; Baker and Kasprzyk-hordern 2011; Burgard et al. 2013).

Besides the social, health, and economic implications illicit drugs pose, there is also the impact that these drugs could inflict over aquatic environments. For instance, Parolini et al., reported that exposure to $0.5 \mu \mathrm{g} / \mathrm{L}$ and $1 \mu \mathrm{g} / \mathrm{L}$ of cocaine (benzoylecgonine) caused oxidative stress in freshwater bivalve Dreissena polymorpha, due to imbalances of the enzyme defense chain (Parolini et al. 2013). Similarly to pharmaceuticals, illicit drugs are metabolized in the body and excreted in their unchanged form or as their metabolite(s) reaching water streams (Hummel et al. 2006; Castiglioni et al. 2011; González-Mariño et al. 2012). Moreover, inadequate human disposal of these drugs increases their load and frequency of exposure to the environment, posing possible detrimental effects due to their 
unknown persistence and ecotoxicity (González-Mariño et al. 2012; Jurado et al. 2012; Valcárcel et al. 2012; Pal et al. 2013). This group of emerging contaminants as initially recognized by Petrovic and Richardson are typically assessed via analysis of effluent sewage and surface waters; and include (but are not limited to) parent and metabolites of cocainics, amphetamine like stimulants (ALS), cannabinoids, and opiates (Petrovic et al. 2008; Richardson 2008).

Solid phase extraction (SPE) has been the technique of choice for pre-concentration of illicit drugs in off-line applications. However, offline SPE is time consuming and requires multiple manual sample preparation steps decreasing sample throughput. Despite associated problems such as the need of careful method development for carryover control, online SPE has been gaining popularity for large environmental monitoring efforts as it provides minimal preparation steps, reduced reporting times and lower solvent usage relative to offline techniques (Batchu et al. 2013; Gorga et al. 2013; Panditi et al. 2013; Wang and Gardinali 2013; Ramirez et al. 2014). Although studies using online SPE have been reported in the analysis of illicit drugs in sewage matrices, cannabinoids (one of the most consumed drugs) are only included in two of these methods which still required a separate pre-concentration protocol or suffered from poor sensitivity (Postigo et al. 2008; Fontanals et al. 2013; Ostman et al. 2013; Repice et al. 2013).

From the initial report of analysis of illicit drugs in sewage waters documented by Zuccato et al. in 2005, most analyses of DOAs have been performed using liquid chromatography coupled to MS or MS/MS detection, the latter typically involving triple quadrupole instruments operating in selected reaction monitoring (SRM) mode (Zuccato 
et al. 2005; Boleda et al. 2007; Castiglioni et al. 2008; Postigo et al. 2010; Fontanals et al. 2011, 2013; Hernández et al. 2011; Vazquez-Roig et al. 2013). Nowadays, highresolution instruments such as the quadrupole time of flight (Q-TOF) or the Orbitrap are routinely used in urine analysis as screening tools for doping (Li et al. 2013; Musenga and Cowan 2013; Sundström et al. 2013). However, few methods have been implemented for the analysis of illicit drugs in wastewaters (Bijlsma et al. 2012; González-Mariño et al. 2012; Fedorova et al. 2013) despite clear advantages offered by full-scan HRMS such as enabling the screening of previously-acquired data for drugs of abuse that are identified after initial data processing has occurred.

Considering the fact that drug consumption is the highest among high school/college age students (U.S. Department of Health and Human Services 2013), the objective of the present study is twofold a) to develop and validate a fully automated method using online SPE-HPLC high resolution mass spectrometry for the detection of 18 drugs of abuse including some of their known metabolites in a controlled college campus setting; and b) to assess and quantify potential consumption of prescription and/or illicit drugs within the service population.

\subsection{Experimental}

\subsubsection{Reagents and chemicals}

A total of 18 drugs of abuse and some of their metabolites belonging to five different chemical classes were used in this study: amphetamine-like compounds (ALCs): amphetamine (AM), methamphetamine (MA), MDA, MDEA, MDMA; cannabinoids: $\Delta$ 9-THC (THC), 11-nor-9-carboxy- $\Delta-9-\mathrm{THC}$ (THC-COOH); cocainics: cocaine (CO), 
benzoylecgonine $(\mathrm{BE})$, cocaethylene $(\mathrm{CE})$; opioids: morphine $(\mathrm{MO})$, 6-acetylmorphine (6-AMO), codeine (COD), oxycodone (OXY), heroin (HE), methadone (ME), EDDP; and Lysergic acid diethylamine (LSD). All standards and their deuterated analogs were purchased as certified solutions in methanol or acetonitrile from Cerilliant (Round Rock, TX, USA). Table 2.1 shows a list of analytes used in this study, including their structure, elemental formula, exact mass, mass error (ppm), $\mathrm{pKa}, \log$ Kow, and deuterated analogs used for quantitation.

Individual stock solutions for both target and deuterated compounds were prepared in methanol at concentrations of 5 and $10 \mu \mathrm{g} / \mathrm{mL}$. Working standard and internal standard solutions were prepared in methanol at a concentration of $20 \mathrm{ng} / \mathrm{mL}$, and an additional working standard solution of $5 \mathrm{ng} / \mathrm{mL}$ was made for preparation of low calibration levels (5-50 ng/L). All standards and prepared solutions were stored in the dark at $-20{ }^{\circ} \mathrm{C}$. Optima LC/MS grade methanol, water, and acetonitrile were purchased from Fisher Scientific (Fair Lawn, NJ, USA) and used for standard preparation and HPLC mobile phase. Optima LC/MS grade formic acid and ammonium formate were also purchased from Fisher Scientific and used for modifier mobile phase preparation (1\% formic acid and $100 \mathrm{mM}$ ammonium formate). 
Table 2.1. Structures, elemental formula, exact mass, mass error, pKa, Log Kow, and internal standard used for quantitation of target analytes.

\begin{tabular}{|c|c|c|c|c|c|c|c|c|}
\hline$\frac{\tilde{E}}{U}$ & Analyte & Structure & Formula & $\begin{array}{l}\text { Exact } \\
\text { Mass }\end{array}$ & $\begin{array}{l}\text { Mass } \\
\text { Error } \\
(\mathrm{ppm})\end{array}$ & $\mathbf{p K}_{\mathrm{a}}{ }^{*}$ & $\begin{array}{l}\text { Log } \\
\text { Kow** }\end{array}$ & $\begin{array}{l}\text { Int. } \\
\text { Std. }\end{array}$ \\
\hline & Morphine (MO) & & $\mathrm{C}_{17} \mathrm{H}_{19} \mathrm{NO}_{3}$ & 286.1438 & -2.4 & $\begin{array}{l}10.26 \\
9.12\end{array}$ & 0.89 & MO-D6 \\
\hline & $\begin{array}{l}\text { 6-Acetylmorphine (6- } \\
\text { AMO) }\end{array}$ & & $\mathrm{C}_{19} \mathrm{H}_{21} \mathrm{NO}_{4}$ & 328.1543 & -3.0 & $\begin{array}{l}10.19 \\
9.08\end{array}$ & 0.53 & MO-D6 \\
\hline & Oxycodone (OXY) & & $\mathrm{C}_{18} \mathrm{H}_{21} \mathrm{NO}_{4}$ & 316.1543 & -1.9 & $\begin{array}{l}13.56 \\
8.21\end{array}$ & 0.66 & $\begin{array}{l}\text { OXY- } \\
\text { D6 }\end{array}$ \\
\hline 党 & Codeine (COD) & & $\mathrm{C}_{18} \mathrm{H}_{21} \mathrm{NO}_{3}$ & 300.1594 & -2.7 & $\begin{array}{l}13.78 \\
9.19\end{array}$ & 1.19 & $\begin{array}{l}\text { COD- } \\
\text { D6 }\end{array}$ \\
\hline & Heroin (HE) & & $\mathrm{C}_{21} \mathrm{H}_{23} \mathrm{NO}_{5}$ & 370.16490 & -2.4 & 9.1 & 1.58 & MO-D6 \\
\hline & Methadone (ME) & & $\mathrm{C}_{21} \mathrm{H}_{27} \mathrm{NO}$ & 310.2165 & -2.9 & 9.12 & 3.93 & ME-D9 \\
\hline & $\begin{array}{l}\text { 2-Ethylidene-1,5- } \\
\text { dimethyl-3,3- } \\
\text { diphenylpyrrolidine } \\
\text { (EDDP) }\end{array}$ & & $\mathrm{C}_{20} \mathrm{H}_{23} \mathrm{~N}$ & 278.1903 & -3.2 & 9.64 & 4.94 & ME-D9 \\
\hline 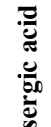 & $\begin{array}{l}\text { Lysergic acid } \\
\text { diethylamide (LSD) }\end{array}$ & & $\mathrm{C}_{20} \mathrm{H}_{25} \mathrm{~N}_{3} \mathrm{O}$ & 324.2070 & -3.1 & 7.98 & 2.95 & LSD-D3 \\
\hline
\end{tabular}




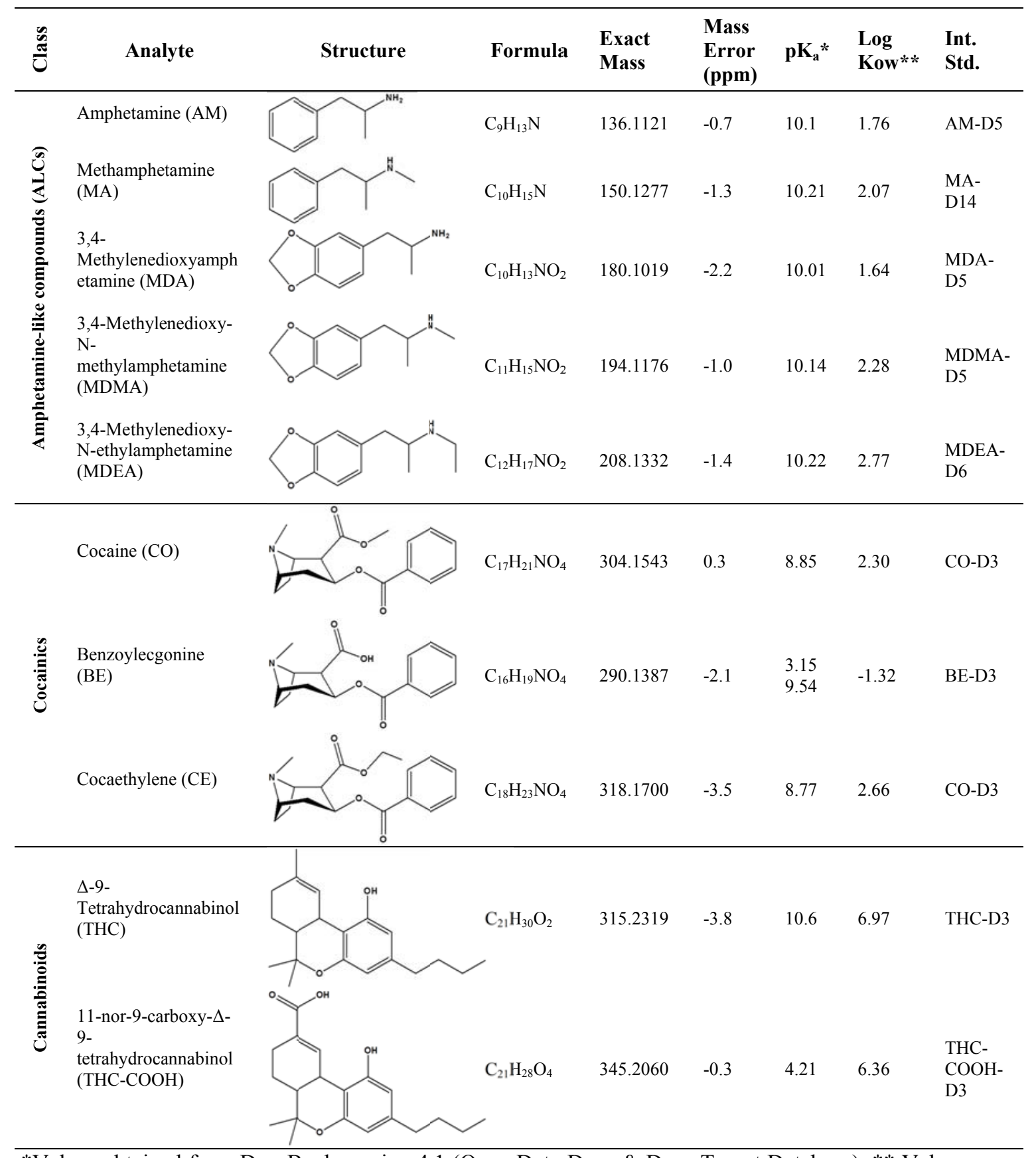

*Values obtained from DrugBank version 4.1 (Open Data Drug \& Drug Target Database). ** Values were obtained from ChemSpider Database. 


\subsubsection{Sample collection and preparation}

Samples were collected in a college campus in the city of Miami, FL USA. An automated ISCO 3700 sampler purchased from Teledyne ISCO (Lincoln, NE) was equipped with twelve $500 \mathrm{~mL}$ wide mouth glass bottles lined with 2 Mil White Block polyethylene reclosable bags purchased from Uline (Pleasant Prairie, WI, USA). The sampler was deployed in a pump station servicing 560 people from a campus dormitory. Monitoring was carried out during the 2012 - 2013 academic year collecting samples for twelve days at the beginning of September, 2012; nine days during the second and third week of December, 2012; and seventeen days between February and March. These times represent the beginning, end, and middle of a semester. A second set of samples was also collected from the main pump station servicing 9,456 people at the main university campus at the end the semester (April $1^{\text {st }}$ to $21^{\text {st }}, 2013$ ) every day for a period of 3 weeks. The automated sampler was programmed to collect samples $(200 \mathrm{~mL})$ every four hours. Wastewater influent samples were vacuum filtered using a coarse $1 \mu \mathrm{m}$ GFC filter followed by a $0.5 \mu \mathrm{m}$ PreSep Prefilter glass fiber filter purchased from Fisher Scientific (Fair Lawn, NJ, USA). Filtered samples were then stored in clear polyethylene terephthalate (PET) bottles (SKS Science, Watervliet, NY, USA) in the dark at $-20{ }^{\circ} \mathrm{C}$ until analysis time (1 day to 3 months).

On the day of analysis, samples were allowed to reach room temperature and shaken for about 10 seconds. A 1-milliliter subsample of pre-filtered sewage influent sample was diluted to $10 \mathrm{~mL}$ with LC/MS grade water, and fortified with the appropriate internal standards (200 ng/L). QA/QC included the preparation of blanks, laboratory fortified blanks (LFBs), laboratory fortified blank duplicate (LFB-DUP), laboratory fortified 
matrix (LFM) samples, duplicate samples, and a seven-point calibration curve $(5 \mathrm{ng} / \mathrm{L}-$ $500 \mathrm{ng} / \mathrm{L})$.

\subsubsection{Online SPE pre-concentration and HPLC separation}

A Thermo EQuan MAX online SPE system (Thermo Scientific, Waltham, MA, USA) was employed in this study. The EQuan system consisted of two six-port rotatory valves (valve $\mathrm{A}$ and valve B), an Accela ${ }^{\mathrm{TM}} 600$ loading pump, an Accela ${ }^{\mathrm{TM}} 1250$ analytical pump, and a HTC-PAL ${ }^{\mathrm{TM}}$ autosampler. Filtered and diluted samples, quality controls, and calibration solutions were loaded at $1 \mathrm{~mL} / \mathrm{min}$ onto a $5 \mathrm{~mL}$ stainless steel loop connected to valve A. The loading pump, also connected to valve A, transferred the sample from the sample loop to a pre-conditioned HyperSep ${ }^{\mathrm{TM}}$ Retain PEP SPE $(20 \times 2.1$ $\mathrm{mm}, 12 \mu \mathrm{m}$ ) column, which was connected to valve B. A three-minute washing step with LC/MS water was used to remove inorganics. Simultaneous to this process, the analytical pump connected to valve B was used to precondition the analytical column. After the washing step, valve B was then switched to connect the loading column to a Hypersil Gold $^{\mathrm{TM}}$ aQ $(150 \times 2.1 \mathrm{~mm}, 3 \mu \mathrm{m})$ analytical column protected by a Hypersil Gold ${ }^{\mathrm{TM}} \mathrm{aQ}$ guard column $(10 \times 2.1 \mathrm{~mm}, 3 \mu \mathrm{m})$. The analytical pump provided the gradient flow and composition for chromatographic separation of analytes using water, methanol, and $1 \%$ formic acid/100 mM ammonium formate buffer as mobile phases. While elution and separation of analytes took place in valve B, valve A switched to rinse and fill the sample loop with methanol and then turned again to allow for the next sample in queue to be injected. Finally, valve B switched one last time to connect the loading pump to the SPE column, for cleaning (acetonitrile/methanol) and conditioning (water). The total run time 
was achieved in $15 \mathrm{~min}$, and at this point, the system was ready to start the process with the preloaded sample. The detailed gradient programs for the loading and analytical pumps are shown in table 2.2 .

Table 2.2. Analytical pump and SPE pump gradient programs. Mobile phases used: water (A), methanol (B), acetonitrile (C), and 1\% formic acid/100 mM ammonium formate buffer (D).

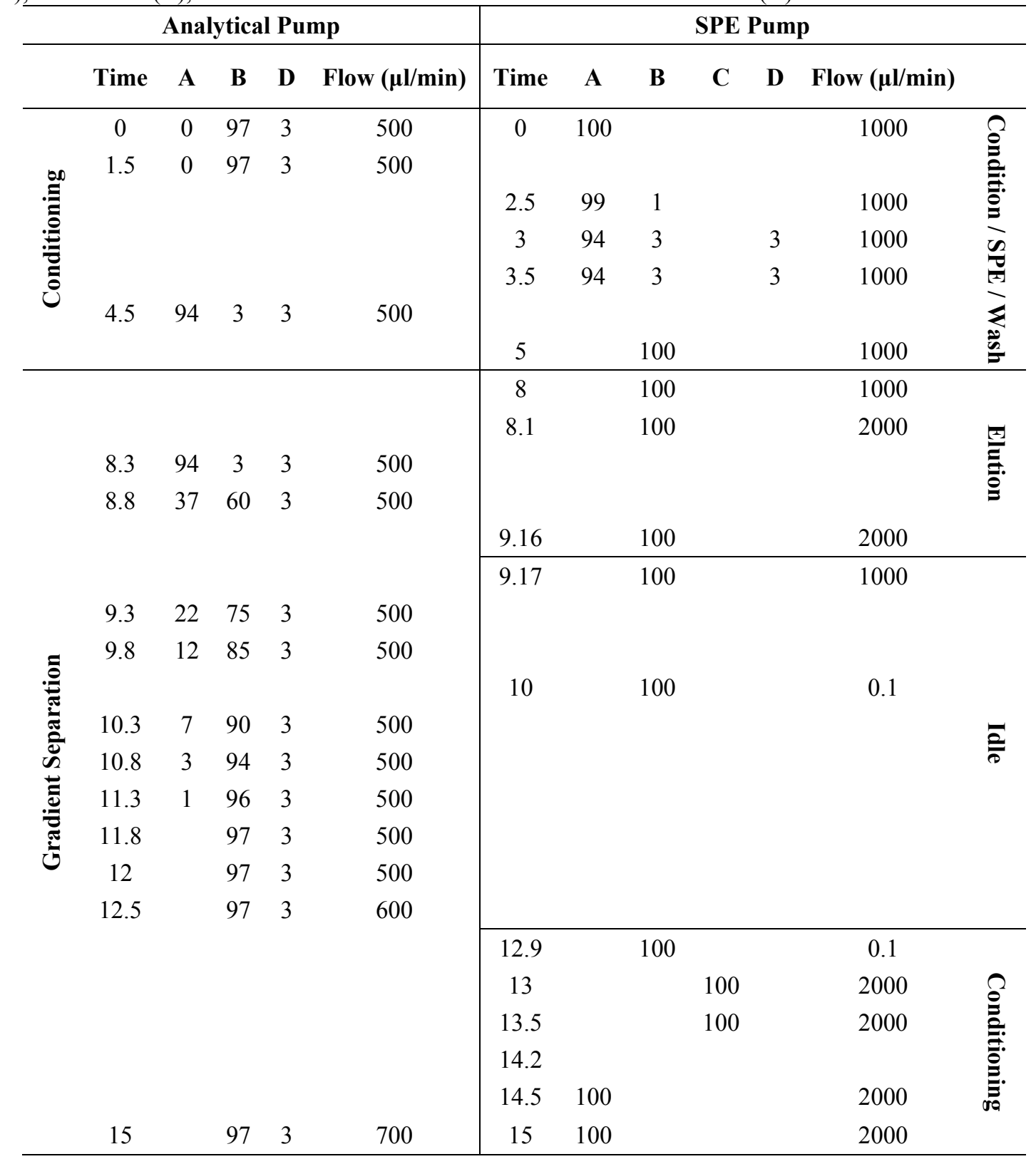




\subsubsection{Mass spectrometry}

Detection of analytes was performed using a Q Exactive ${ }^{\mathrm{TM}}$ hybrid QuadrupoleOrbitrap high-resolution mass spectrometer (Thermo Fisher Scientific, San Jose, CA, USA) equipped with a heated electrospray ionization source (HESI-II) operated in the positive ion mode. Source parameters were the following: capillary temperature $300{ }^{\circ} \mathrm{C}$, S-lens voltage $50 \mathrm{~V}$, and source voltage $3 \mathrm{kV}$. Ultrapure nitrogen was used as ion source gas and collision gas, set at the following arbitrary units: sheath gas 35 , aux gas 30 , and sweep gas 5. The Orbitrap analyzer was operated in full scan mode at a resolving power of 140,000 , with a scan range from $100-500 \mathrm{~m} / \mathrm{z}$. Automated gain control (AGC) was set to $3 \mathrm{X}^{1} 10^{6}$, with a maximum injection time (IT) of $400 \mathrm{~ms}$. Xcalibur 2.1 software was used for instrument control and data acquisition (Thermo Fisher Scientific, San Jose, CA, USA). External mass calibration was performed once a week using Pierce LTQ Velos ESI Positive Calibration Solutions (Thermo Scientific, Rockford, IL) for which mass accuracy was always achieved with $\pm 0.3 \mathrm{ppm}$. Positive identification of analytes was based on the accurate mass of the analyte with less than \pm 5 ppm error, retention time comparison to that of its labelled analog within $\pm 0.03 \mathrm{~min}$, and isotopic distribution match between the measured and expected patterns of the calculated elemental composition ( $\geq 90 \%$ fit threshold, $< \pm 5$ ppm) (Bijlsma et al. 2013b; Moschet et al. 2013). An example of positive identification for amphetamine is shown in Fig. 2.1 of the electronic supplementary material. 


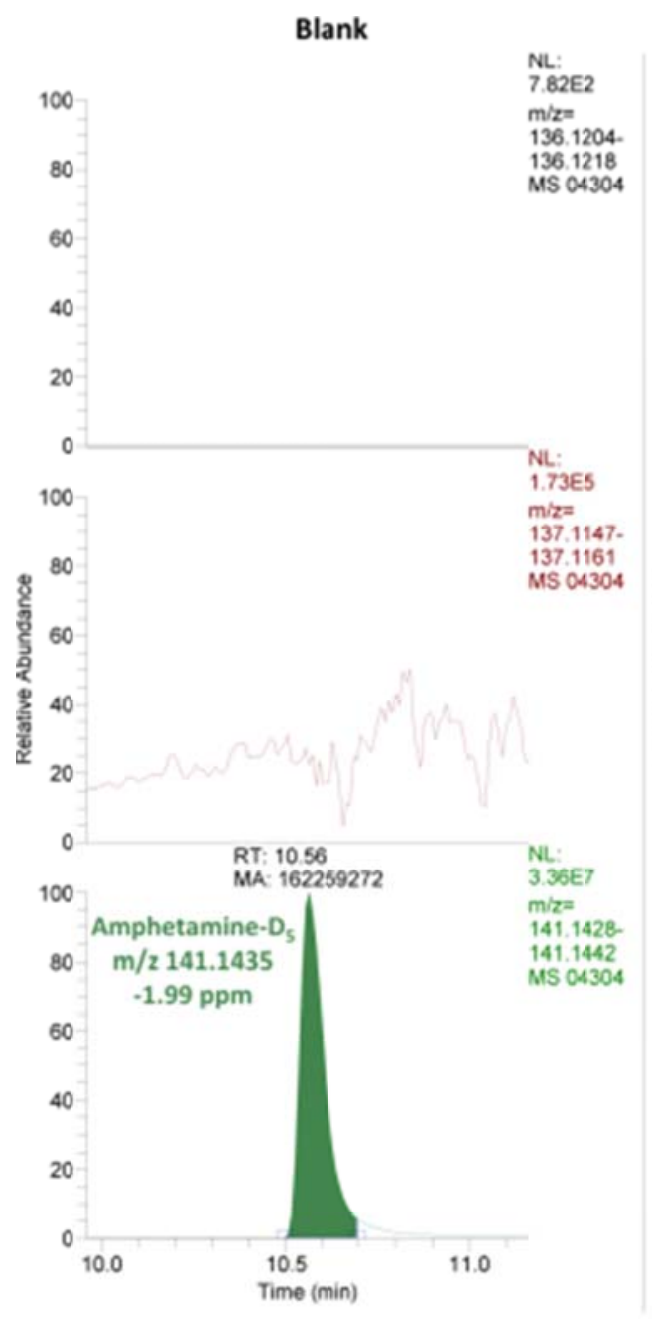

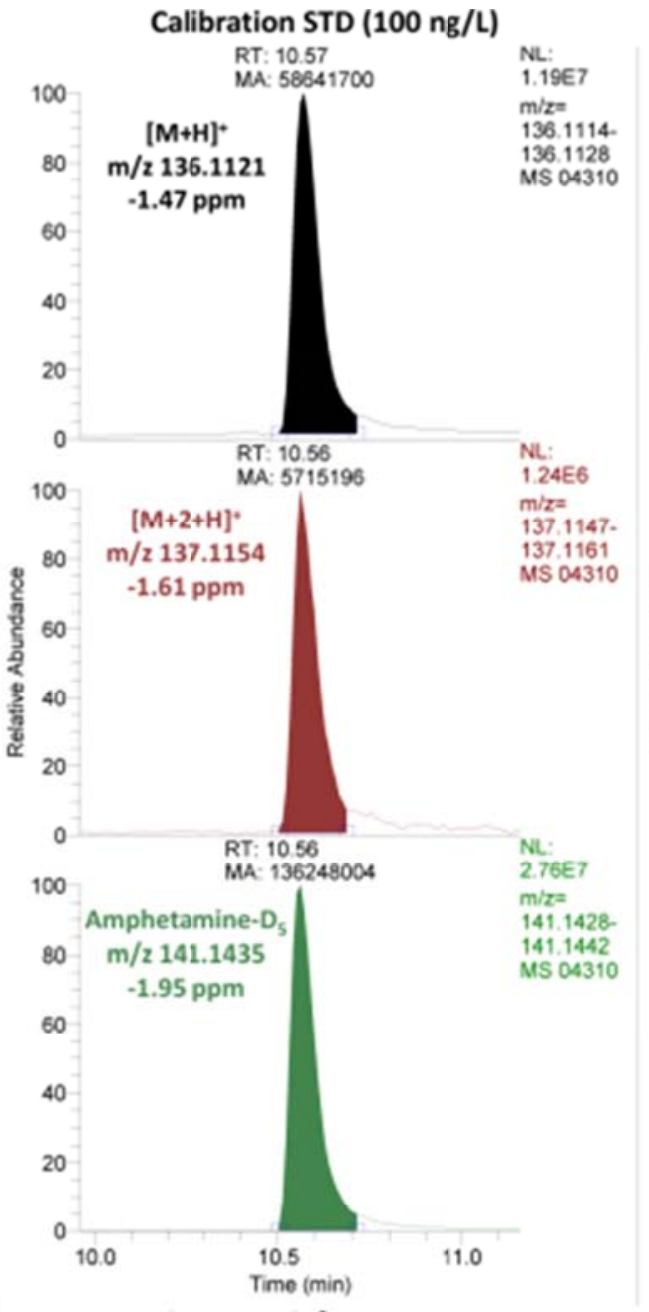

Theoretical $\rightarrow$ 100:10

Observed $\rightarrow$ 100:10

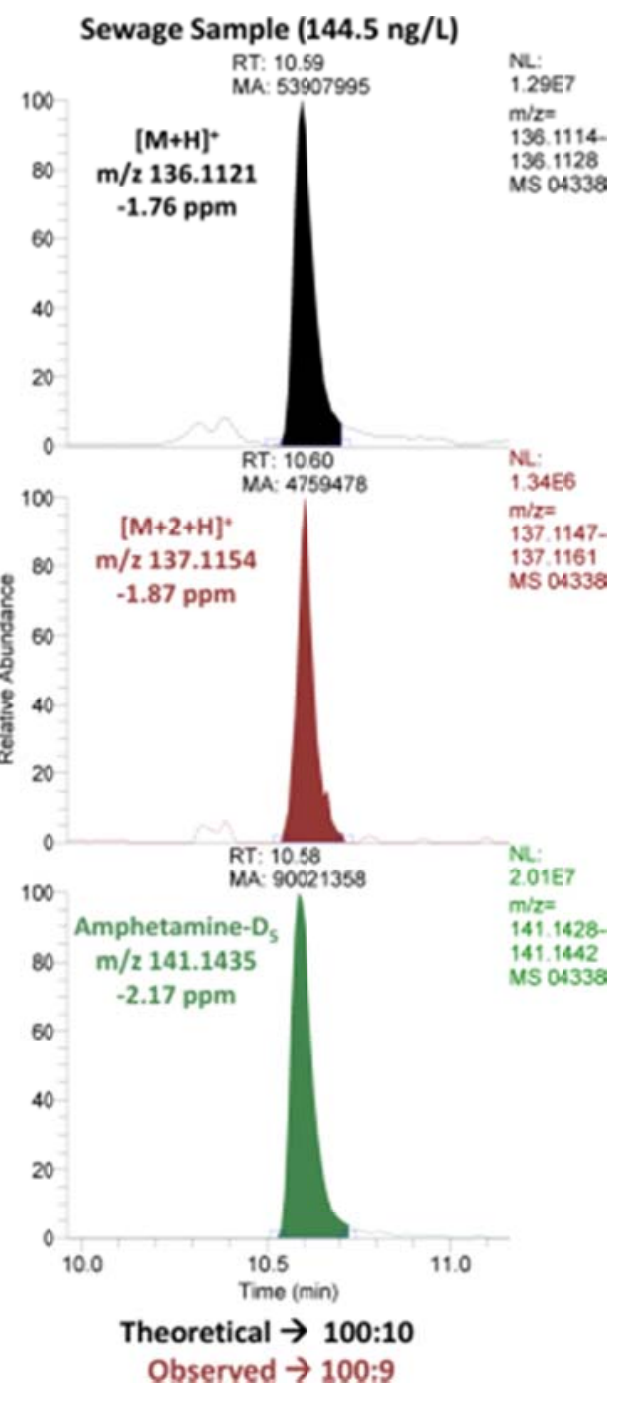

Fig. 2.1. Positive identification criteria for amphetamine in sewage water sample and its comparison to a calibration standard, and a blank. 


\subsection{Results and discussion}

\subsubsection{Online SPE optimization}

Sorbent selection for multi-residue analysis of wastewaters has been previously reviewed in the literature (Petrović et al. 2010). Hydrophilic-lipophilic balance stationary phases have shown good performance for the simultaneous pre-concentration of target analytes with a broad spectrum of polarities, as it is the case of illicit drugs (Zuccato and Castiglioni 2009; Petrović et al. 2010); for this reason the above mentioned sorbent was selected for online SPE.

Online SPE recoveries of analytes were determined in DI water and sewage influent in order to test the extraction efficiency of the online SPE method. A direct injection method was developed using the same analytical gradient as the online SPE method, but taking into account the 8-minute period in which extraction/cleanup takes place (see table 2.3).

Table 2.3. Analytical pump gradient for the direct injection method. Mobile phases used: LC-MS grade water (A), methanol (B), and 1\% formic acid/100mM ammonium formate buffer (D).

\begin{tabular}{ccccc}
\hline Time & A & B & D & Flow $(\boldsymbol{\mu l} / \mathbf{m i n})$ \\
\hline 0 & 94 & 3 & 3 & 500 \\
0.3 & 94 & 3 & 3 & 500 \\
0.8 & 37 & 60 & 3 & 500 \\
1.3 & 22 & 75 & 3 & 500 \\
1.8 & 12 & 85 & 3 & 500 \\
2.3 & 7 & 90 & 3 & 500 \\
2.8 & 3 & 94 & 3 & 500 \\
3.3 & 1 & 96 & 3 & 500 \\
3.8 & 0 & 97 & 3 & 500 \\
4 & 0 & 97 & 3 & 500 \\
4.5 & 0 & 97 & 3 & 600 \\
7 & 0 & 97 & 3 & 700 \\
8.5 & 0 & 97 & 3 & 500 \\
13 & 94 & 3 & 3 & 500 \\
\hline
\end{tabular}


For direct injection, standard solutions of composition similar to that of the starting gradient conditions (94\%: water, $4 \%$ : Methanol, $2 \%$ : water $/ 1 \%$ formic acid/100 $\mathrm{mM}$ ammonium formate) were prepared at the target concentration of 10,000 $\mathrm{ng} / \mathrm{L} .50 \mu \mathrm{L}$ of this mixture were injected (in triplicates) yielding a $0.5 \mathrm{ng}$ on column equivalent for each compound. In addition, triplicate spiked solutions (100 ng/L) in DI water and diluted (1:10) sewage water, were prepared and $5 \mathrm{~mL}$ injections were made, also accounting for $0.5 \mathrm{ng}$ on column for each compound. SPE recoveries are shown in table 2.4. High online SPE recoveries were obtained for most analytes (on average $90 \%$ $\pm 20 \%$ in DI water and $67 \% \pm 6 \%$ in influent sewage water). Those averages exclude $\Delta$-9-THC and morphine which presented relatively low SPE recoveries $(41 \pm 3 \%$ and 39 $\pm 3 \%$ in deionized water, respectively). As can be seen in table 2.4 , excellent relative recoveries are obtained despite of the observed SPE recovery decrease with the presence of the matrix, highlighting the importance of the use of isotopic analogs to enable correct quantitation. The stability of the online SPE procedure was constantly evaluated in terms of signal intensity. As can be seen in Fig. 2.2 (supplementary information) the peak areas of most isotopically labelled analogs remained stable (within one order of magnitude) throughout an analytical sequence (68 injection, 17 hours of continuous operation). This observation indicates that the online SPE is able to remove most of inorganic species that could cause a signal decrease in the ESI source and also that the column is able to hold its extraction capabilities during long sequences. 
Table 2.4. Quality control parameter of analytical method: linearity (R2), precision (\%RSD), SPE recoveries, quantitation recoveries, and method detection limits (MDLs) in HPLC water and influent raw sewage water.

\begin{tabular}{|c|c|c|c|c|c|c|c|c|c|c|c|c|c|c|c|c|c|c|c|c|c|}
\hline \multirow{3}{*}{ Class } & \multirow{3}{*}{$\begin{array}{c}\text { Analyte } \\
\text { AM }\end{array}$} & \multirow{3}{*}{$\begin{array}{c}\mathbf{R}^{2} \\
0.9999\end{array}$} & \multicolumn{7}{|c|}{ DI Water } & \multicolumn{12}{|c|}{ Influent Sewage Water 1:10 Dilution } \\
\hline & & & \multirow{2}{*}{$\begin{array}{c}\begin{array}{c}\text { Interday } \\
\text { \% RSD } \\
\text { (n=5) }\end{array} \\
4\end{array}$} & \multicolumn{3}{|c|}{$\begin{array}{l}\text { SPE Rec. } \\
(\%)(n=3)\end{array}$} & \multicolumn{3}{|c|}{$\begin{array}{l}\text { Relative. Rec. } \\
\text { (\%) }(\mathrm{n}=5)^{*}\end{array}$} & \multirow{2}{*}{$\begin{array}{c}\begin{array}{c}\text { Intraday } \\
\text { \% RSD } \\
\text { (n=7) }\end{array} \\
0.7\end{array}$} & \multirow{2}{*}{$\begin{array}{c}\begin{array}{c}\text { Interday } \\
\text { \% RSD } \\
(\mathbf{n}=\mathbf{5})\end{array} \\
3\end{array}$} & \multicolumn{3}{|c|}{$\begin{array}{l}\text { SPE Rec. } \\
(\%)(n=3)\end{array}$} & \multicolumn{3}{|c|}{$\begin{array}{l}\text { Relative. Rec. } \\
(\%)(\mathrm{n}=5)^{*}\end{array}$} & \multicolumn{3}{|c|}{$\begin{array}{l}\text { Relative. } \\
\text { Rec. }(\%) \\
(\mathbf{n}=7)^{* * *}\end{array}$} & \multirow{2}{*}{$\begin{array}{c}\begin{array}{c}\text { MDLs } \\
(\mathbf{n g} / \mathbf{L}) \\
(\mathbf{n}=7)\end{array} \\
1.3\end{array}$} \\
\hline & & & & 78 & \pm & 6 & 99 & \pm & 4 & & & 60 & \pm & 1 & 104 & \pm & 3 & 119 & \pm & 1 & \\
\hline \multirow{4}{*}{$\begin{array}{l}\text { Amphetamine- } \\
\text { like } \\
\text { compounds } \\
\text { (ALCs) }\end{array}$} & MA & 0.9996 & 2 & 84 & \pm & 5 & 99 & \pm & 3 & 0.8 & 5 & 59 & \pm & 1 & 101 & \pm & 5 & 139 & \pm & 1 & 1.7 \\
\hline & MDA & 0.9999 & 2 & 105 & \pm & 8 & 98 & \pm & 2 & 0.4 & 11 & 65 & \pm & 1 & 117 & \pm & 12 & 101 & \pm & 0 & 0.6 \\
\hline & MDMA & 0.9997 & 5 & 92 & \pm & 2 & 100 & \pm & 5 & 0.7 & 5 & 62 & \pm & 1 & 101 & \pm & 5 & 95 & \pm & 1 & 1.0 \\
\hline & MDEA & 0.9999 & 2 & 91 & \pm & 6 & 100 & \pm & 2 & 0.4 & 5 & 58 & \pm & 1 & 104 & \pm & 5 & 105 & \pm & 0 & 0.7 \\
\hline \multirow{3}{*}{ Cocainics } & $\mathrm{CO}$ & 0.9998 & 10 & 88 & \pm & 5 & 96 & \pm & 9 & 0.4 & 11 & 65 & \pm & 1 & 100 & \pm & 11 & 141 & \pm & 1 & 1.0 \\
\hline & $\mathrm{BE}$ & 0.9999 & 2 & 101 & \pm & 4 & 101 & \pm & 2 & 0.3 & 4 & 68 & \pm & 1 & 99 & \pm & 4 & 127 & \pm & 0 & 0.7 \\
\hline & $\mathrm{CE}$ & 0.9996 & 4 & 87 & \pm & 3 & 95 & \pm & 3 & 0.4 & 5 & 66 & \pm & 2 & 114 & \pm & 5 & 143 & \pm & 1 & 0.8 \\
\hline \multirow{2}{*}{ Cannabinoids } & THC & 0.9998 & 4 & 41 & \pm & 3 & 96 & \pm & 4 & 0.3 & 3 & 36 & \pm & 2 & 97 & \pm & 3 & 131 & \pm & 0 & 0.6 \\
\hline & THC-COOH & 0.9997 & 3 & 102 & \pm & 6 & 98 & \pm & 5 & 0.7 & 6 & 81 & \pm & 1 & 122 & \pm & 4 & 119 & \pm & 1 & 1.3 \\
\hline \multirow{7}{*}{ Opioids } & MO & 0.9997 & 3 & 39 & \pm & 3 & 97 & \pm & 3 & 0.5 & 6 & 70 & \pm & 2 & 98 & \pm & 5 & 147 & \pm & 1 & 1.1 \\
\hline & 6-AMO & 0.9998 & 1 & 87 & \pm & 4 & 99 & \pm & 1 & 0.5 & 5 & 66 & \pm & 2 & 93 & \pm & 4 & 90 & \pm & 0 & 0.7 \\
\hline & OXY & 0.9998 & 3 & 85 & \pm & 4 & 98 & \pm & 3 & 0.4 & 6 & 70 & \pm & 2 & 104 & \pm & 7 & 111 & \pm & 0 & 0.7 \\
\hline & COD & 0.9999 & 3 & 84 & \pm & 6 & 98 & \pm & 4 & 0.5 & 5 & 70 & \pm & 2 & 103 & \pm & 5 & 163 & \pm & 1 & 1.2 \\
\hline & $\mathrm{HE}$ & 0.9964 & 5 & 93 & \pm & 5 & 107 & \pm & 5 & 0.7 & 5 & 66 & \pm & 2 & 95 & \pm & 4 & 83 & \pm & 1 & 0.9 \\
\hline & $\mathrm{ME}$ & 0.9999 & 2 & 91 & \pm & 5 & 101 & \pm & 2 & 0.4 & 4 & 79 & \pm & 2 & 103 & \pm & 4 & 101 & \pm & 0 & 0.7 \\
\hline & EDDP & 0.9997 & 2 & 87 & \pm & 4 & 101 & \pm & 3 & 0.4 & 4 & 76 & \pm & 1 & 108 & \pm & 5 & 129 & \pm & 0 & 0.8 \\
\hline Lysergic acid & LSD & 0.9954 & 4 & 78 & \pm & 2 & 91 & \pm & 3 & 0.5 & 7 & 51 & \pm & 2 & 89 & \pm & 6 & 133 & \pm & 1 & 1.1 \\
\hline
\end{tabular}

* Quantitation recoveries at $100 \mathrm{ng} / \mathrm{L} * *$ Quantitation recoveries at $5 \mathrm{ng} / \mathrm{L}$ 


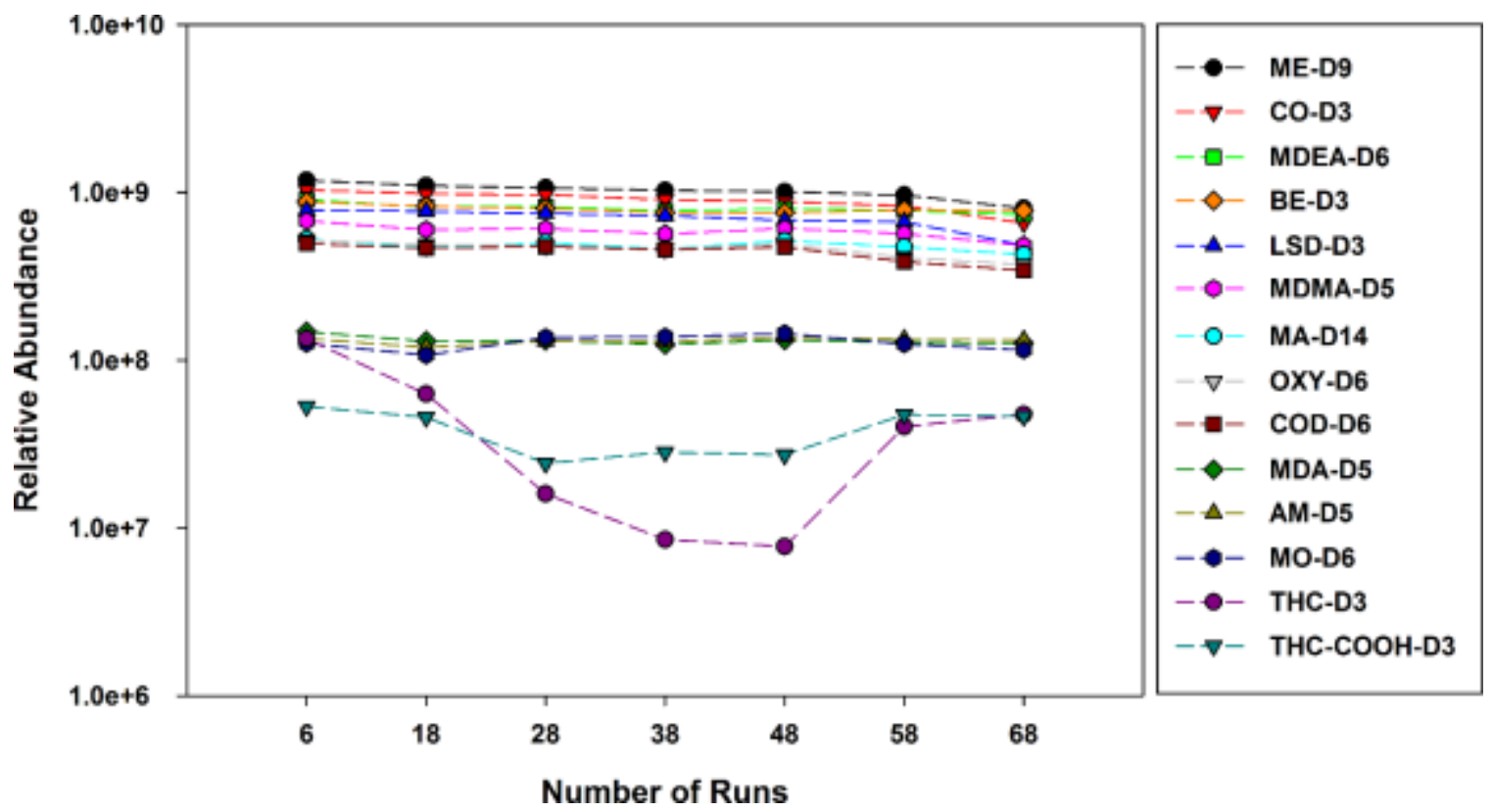

Fig. 2.2. Stability of the online SPE procedure based on signal intensity of labelled analogs from CCV solutions (100 ng/L) throughout an analytical sequence (68 injections, 17 hour of continuous operation).

\subsubsection{Liquid chromatography optimization}

Four different chromatographic columns and three different mobile phase compositions were tested in order to obtain good peak shape for all analytes.

Initially, a Hypersil Gold PFP (50 x $2.1 \mathrm{~mm})$ particle size $(1.9 \mu \mathrm{m})$ was used; this column provided adequate separation for most compounds but poor peak shape for cannabinoids, which was not fixed by mobile phase or flow rate optimizations. In addition, an interfering signal was observed co-eluting with THC-COOH but absent from the $\mathrm{THC}-\mathrm{COOH}-\mathrm{D}_{3}$ chromatogram, which suggested the presence of a possible isobaric interference that required further optimization of the chromatographic separation. A Kinetex $2.6 \mu \mathrm{m}$ HILIC 100A (150 x $2.10 \mathrm{~mm})$ was also tested to inverse elution order and improve cannabinoids peak shape. However, a total retention loss of these compounds was observed, and therefore this approach was abandoned. Next, a highly 
end-capped $\mathrm{C}_{18}$ stationary phase (Hypersil Gold aQ, 50 × $2.1 \mathrm{~mm}$, particle size $1.9 \mu \mathrm{m}$ ) was tested resulting in better peak shape for all the analytes but without resolution of the THC-COOH isobaric interference regardless of gradient optimization. Finally, using a longer column (Hypersil Gold aQ, $150 \times 2.1 \mathrm{~mm}$ particle size $3.0 \mu \mathrm{m}$ ) provided adequate chromatographic separation of $\mathrm{THC}-\mathrm{COOH}$ and its isobaric interference with excellent peak shape for every analyte, and therefore this column was selected for this study (see Fig. 2.3).

Mobile phase composition is another important factor affecting peak shape and signal intensity. An initial gradient using methanol and $0.1 \%$ formic acid in water was tested. This mobile phase composition showed increasingly higher peak tailing at higher retention times. Two actions were taken in order to resolve this issue: the modifier phase (1\% formic acid/ $100 \mathrm{mM}$ ammonium formate in water) was kept constant throughout the program and flow rate was ramped from 500 to $700 \mu \mathrm{L} / \mathrm{min}$ (table 2.2 provides details on the gradient compositions and flow rates). 

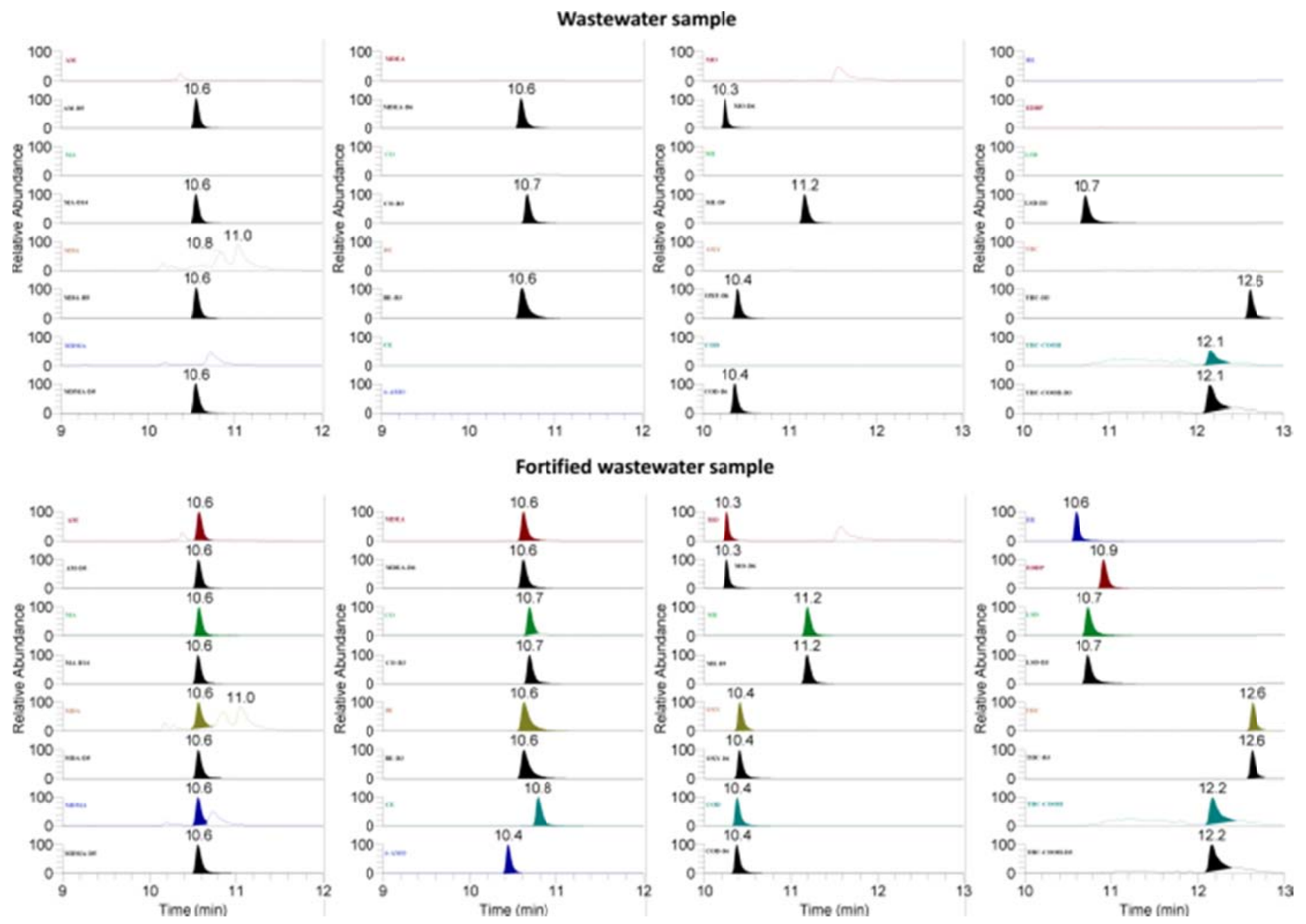

Fig. 2.3. Online-SPE-HPLC-HRMS chromatograms of wastewater (top) and fortified (100 ng/L) wastewater (bottom) samples. Including their deuterated analogs. 


\subsubsection{Method validation}

\subsubsection{Calibration}

DI water calibration curves were obtained from the area ratio of each analyte to its deuterated analog as a function of the analyte concentration. For analytes without an analog, an internal standard of similar chemical structure or retention time was used. Linearity was observed for all analytes $\left(\mathrm{R}^{2}>0.995 ; 5\right.$ to $\left.500 \mathrm{ng} / \mathrm{L}\right)$ (see table 2.2). Every ten runs a continuing calibration verification $(\mathrm{CCV})$ was run to assess its accuracy $( \pm 20$ \%) by injecting a fortified DI water solution (100 ng/L). Sewage samples free of target analytes where not a viable option in this study, therefore, calibration curves in this study were prepared in DI water.

\subsubsection{Quality control samples}

Blanks were run with each set of samples to assess possible contamination and background levels. Two laboratory fortified blanks (LFB and LFB-DUP) (100 ng/L) and a laboratory fortified matrix (LFM) sample $(1: 10,100 \mathrm{ng} / \mathrm{L})$ were also included with each batch as a measure of accuracy and precision of the analytical procedure, and to determine accuracy of the method in the presence of the matrix. High relative recoveries based on deuterated analogs were observed for all compounds in both LFB (99 $\pm 7 \%$ ) and LFM (103 $\pm 25 \%)$ (See table 2.2).

\subsubsection{Method detection limits}

MDLs were calculated by multiplying the standard deviation of seven replicate $1 \mathrm{~mL}$ 
spiked influent sewage samples ( $5 \mathrm{ng} / \mathrm{L} ; 1: 10$ dilution) multiplied by the Student $t$ value $(t=3.143$, six degrees of freedom) according to the procedures outlined by the US-EPA (US EPA 2010). Since sewage samples may contain the target analytes, the same nonspiked sample was also run and the concentration of any analyte present was subtracted from the spiked sample. MDLs were similar or in some cases lower than other available methods which require larger sample volumes (Boleda et al. 2007; Baker and Kasprzykhordern 2011). In addition, reproducibility of the method was assessed from the seven replicate samples with RSDs ranging from 0.3 to $0.8 \%$. Analyte recoveries throughout the seven replicates ranged from $83 \%$ (HE) to $163 \%$ (COD) (see table 2.2).

\subsubsection{Matrix effects}

Matrix effects of the method were evaluated by comparing the area of a spiked sewage sample to the area of spiked DI water, both fortified at the same level $(250 \mathrm{ng} / \mathrm{L})$. Areas from any analytes present in the non-spiked sewage sample were subtracted from the areas in the spiked sample before comparison to spiked DI water areas. Fig. 2.4 shows a decrease in signal ranging from $12 \%(\Delta-9-\mathrm{THC})$ to $38 \%$ (MDA). These results are in agreement to those reported in the literature. However, morphine presented a signal increase of $80 \pm 7 \%(n=3)$ in the presence of the matrix (see Fig. 2.4), which was also observed on the signal of the deuterated analog morphine-D6 $(88 \pm 6 \%, n=3)$. These results are contrasting with previous studies that reported $10-80 \%$ suppression on this compound (Postigo et al. 2008; Nuijs et al. 2009d; González-Mariño et al. 2012; Bijlsma et al. 2013b; Ostman et al. 2013). 


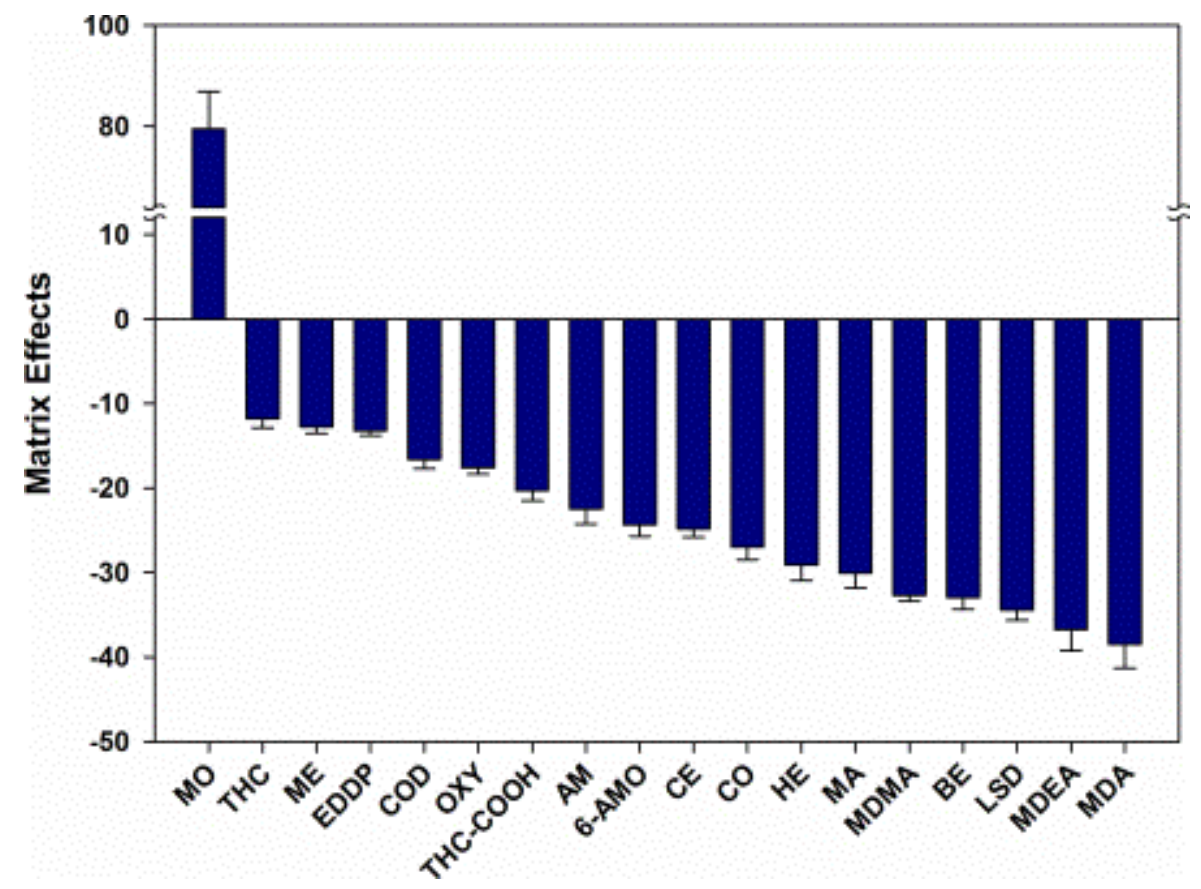

Fig. 2.4. Matrix effects of the method on analytes in sewage samples compared to HPLC water.

\subsubsection{Sample preparation}

Sample preparation steps are limited to filtration, addition of internal standards, and dilution. A recovery test was performed to determine the effect of filtration on the analytes. $100-\mathrm{mL}$ triplicate DI water samples were spiked at $250 \mathrm{ng} / \mathrm{L}$. A total of $10 \mathrm{~mL}$ of each sample were fortified with internal standards and injected. The remaining $90 \mathrm{~mL}$ were passed through the 1.0 and $0.5 \mu \mathrm{m}$ glass fiber filters and $10 \mathrm{~mL}$ filtered aliquots were fortified with internal standards and analyzed. Recoveries were on average $89 \pm 21$ $\%$ for all compounds with the exception of $\Delta-9$-THC, which presented a $42 \pm 6 \%$ recovery (see Fig. 2.5). However, this observation did not significantly affect the calculation of consumption trends for that illicit drug since the concentration of its main metabolite (THC-COOH) is often the predominant parameter used for that purpose. 


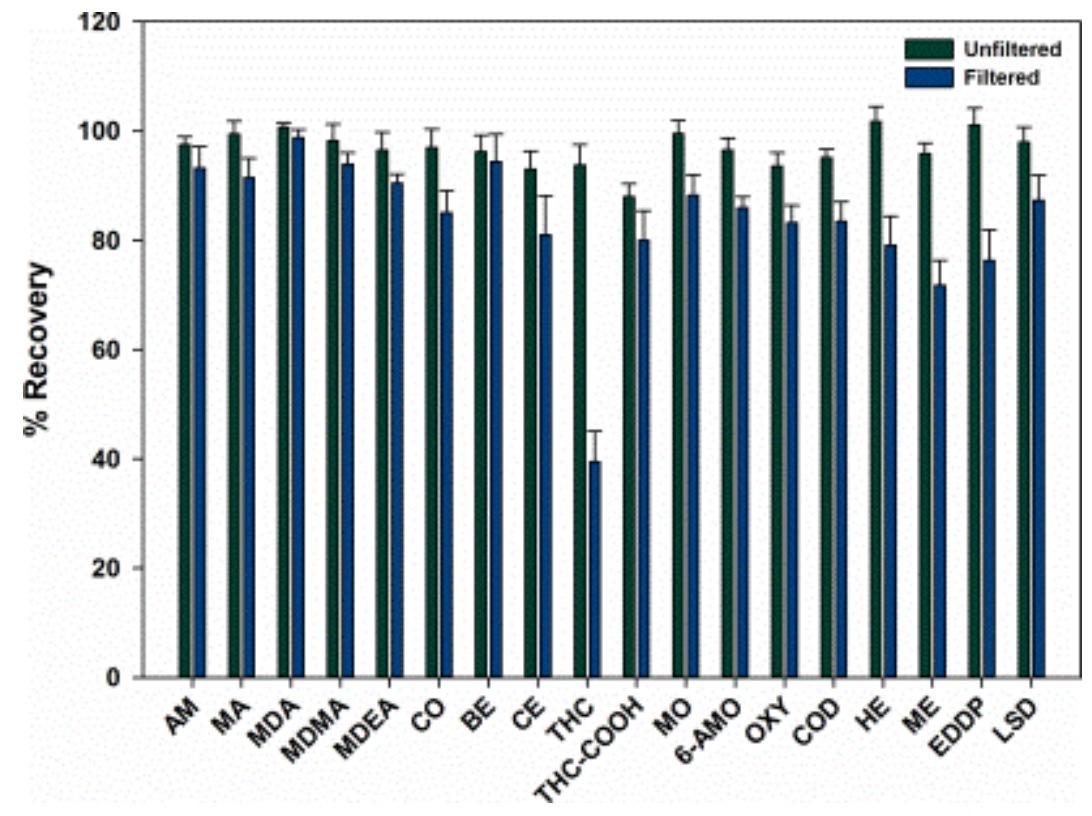

Fig. 2.5. Effects of filtration on illicit drug analytes. Analyte recovery comparison for filtered and unfiltered samples.

\subsubsection{Storage stability of samples}

One common difficulty in DOA analysis is that analytes in sewage samples could be subjected to bacterial degradation and can potentially undergo transformations; therefore, a stability test was performed to determine the effect of the storage conditions. A set of six raw sewage samples was collected for this experiment. Four of the samples were fortified with illicit standards at a 250-ng/L level. A field blank and a fortified field blank $(250 \mathrm{ng} / \mathrm{L})$ were also used in this test. All samples were filtered and a $1 \mathrm{~mL}$ aliquot, of each, was used in sample preparation and analyzed, corresponding to initial point (T0). The remaining volume of the samples was stored in the dark at $-20{ }^{\circ} \mathrm{C}$. Samples were further analyzed after 3, 7, 17, 27, and 123 days (see Fig. 2.6). Labelled standards were added to each sample prior to analysis. All amphetamine-like compounds remained stable throughout the 123 -day period, with overall recovery losses or gains of less than $17 \%$ in relation to T0. Cocaine, however, showed a $29 \%$ loss at seven days, and a $97 \%$ loss 
from $\mathrm{T} 0$ was calculated at the end of the 123 days. In similar manner, cocaethylene also showed losses $(65 \%)$ in relation to $\mathrm{T} 0$. It is known for cocaine and cocaethylene to undergo transformation to benzoylecgonine, and as it is seen from Fig. 2.6, there is an increase in \% recovery of benzoylecgonine from T0 to T123 (Brzezinski et al. 1997; Castiglioni et al. 2008; Bijlsma et al. 2013a).

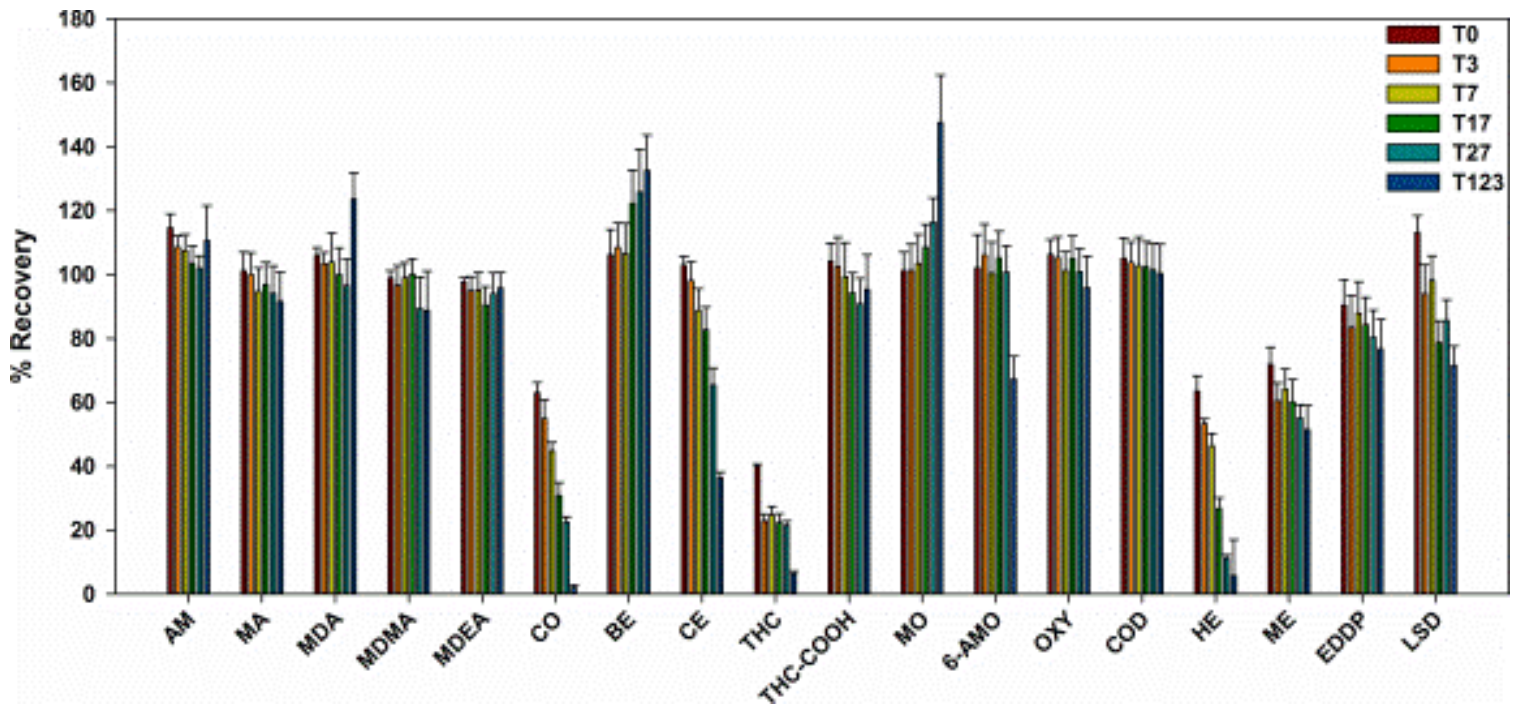

Fig. 2.6. Storage stability of drugs of abuse at $-20{ }^{\circ} \mathrm{C}$, during 123-day period.

In the case of opioids, $\%$ recoveries decrease/increase up to $23 \%$ in the first month (T27) in relation to T0, with the exception of heroin. At the end of the 4-month study (T123) 6-acetylmorphine and methadone concentrations decreased by more than $25 \%$ (34\% and $28 \%$ recovery from T0 respectively). Similarly to cocaine, heroin showed 27 $\%$ recovery losses on the first week (T0 - T7), and $91 \%$ decrease in recovery from $\mathrm{T} 0$ to T123. Analysis of wastewater is typically focused on morphine, a common residue to some opioids including heroin, which concords with the observed loss of heroin and increase of morphine (Castiglioni et al. 2008). 
Table 2.5. Storage stability test. Results expressed in terms of \% recovery (relative to fortification level, $250 \mathrm{ng} / \mathrm{L}$ ) and \% deviation for all analytes (relative to T0) after 3, 7, 17, 27 and 123 days. Test was performed in four independently stored aliquots of a single sewage sample.

\begin{tabular}{|c|c|c|c|c|c|c|c|c|c|c|c|c|c|c|c|c|}
\hline \multirow{2}{*}{ Analyte } & \multicolumn{6}{|c|}{ \% Recovery } & \multicolumn{5}{|c|}{$\%$ Deviation } & \multicolumn{5}{|c|}{ \% Deviation } \\
\hline & T0 & T3 & $\mathbf{T} 7$ & T17 & T27 & T123 & T0- T3 & T0 - T7 & T0 - T17 & T0 - T27 & T0 - T123 & T0 - T3 & T3 - T7 & T7 - T17 & T17 - T27 & T27 - T123 \\
\hline $\mathbf{A M}$ & 115 & 109 & 108 & 103 & 102 & 111 & -5 & -6 & -10 & -11 & -4 & -5 & -1 & -4 & -1 & 8 \\
\hline MDA & 106 & 103 & 104 & 100 & 97 & 124 & -3 & -2 & -6 & -9 & 17 & -3 & 1 & -4 & -3 & 28 \\
\hline MDEA & 98 & 95 & 95 & 90 & 94 & 96 & -3 & -2 & -7 & -4 & -2 & -3 & 0 & -5 & 4 & 2 \\
\hline MDMA & 99 & 97 & 99 & 100 & 89 & 89 & -2 & 0 & 1 & -10 & -10 & -2 & 3 & 1 & -11 & -1 \\
\hline MA & 101 & 100 & 95 & 97 & 94 & 92 & -1 & -6 & -4 & -7 & -10 & -1 & -5 & 2 & -3 & -3 \\
\hline $\mathbf{B E}$ & 106 & 108 & 107 & 122 & 126 & 133 & 2 & 0 & 15 & 18 & 25 & 2 & -2 & 15 & 3 & 5 \\
\hline $\mathbf{C E}$ & 103 & 98 & 89 & 83 & 65 & 36 & -5 & -14 & -20 & -37 & -65 & -5 & -10 & -7 & -21 & -44 \\
\hline $\mathrm{CO}$ & 63 & 55 & 45 & 31 & 22 & 2 & -13 & -29 & -51 & -64 & -97 & -13 & -18 & -31 & -27 & -91 \\
\hline 6-AMO & 102 & 106 & 100 & 105 & 101 & 67 & 4 & -2 & 3 & -1 & -34 & 4 & -5 & 5 & -4 & -33 \\
\hline COD & 105 & 104 & 103 & 102 & 101 & 100 & -1 & -2 & -3 & -3 & -4 & -1 & -1 & 0 & -1 & -1 \\
\hline ME & 72 & 60 & 64 & 60 & 55 & 51 & -16 & -11 & -16 & -23 & -28 & -16 & 6 & -6 & -8 & -7 \\
\hline EDDP & 90 & 83 & 88 & 84 & 80 & 77 & -8 & -3 & -7 & -11 & -15 & -8 & 5 & -4 & -5 & -5 \\
\hline HE & 63 & 53 & 46 & 27 & 11 & 6 & -16 & -27 & -58 & -82 & -91 & -16 & -13 & -42 & -58 & -49 \\
\hline MO & 101 & 101 & 104 & 109 & 116 & 148 & 0 & 2 & 7 & 15 & 46 & 0 & 2 & 5 & 7 & 27 \\
\hline OXY & 106 & 105 & 101 & 105 & 101 & 96 & -1 & -5 & -1 & -5 & -10 & -1 & -4 & 4 & -4 & -5 \\
\hline THC-COOH & 104 & 102 & 99 & 94 & 91 & 95 & -2 & -5 & -10 & -13 & -9 & -2 & -3 & -5 & -4 & 5 \\
\hline THC & 40 & 23 & 25 & 22 & 22 & 6 & -43 & -38 & -44 & -46 & -84 & -43 & 8 & -10 & -3 & -71 \\
\hline LSD & 113 & 94 & 98 & 79 & 86 & 72 & -17 & -13 & -31 & -24 & -37 & -17 & 4 & -20 & 9 & -16 \\
\hline
\end{tabular}


Almost half (46\%) of $\Delta-9-\mathrm{THC}$ was lost during the first month (T0 - T27), and by the end of the study only $6 \%$ from the initial concentration $(250 \mathrm{ng} / \mathrm{L})$ was recovered. In contrast, THC-COOH remained stable throughout the four-month study (up to $9 \%$ loss from $\mathrm{T} 0-\mathrm{T} 123)$. This may suggest the potential presence of other type of transformation products (Heuett et al. 2014). The reported results in this study are in agreement with previous studies on storage stability of illicit drugs and their metabolites (Chiaia and Banta-green 2008; González-Mariño et al. 2010). Details on \% recovery and \% deviation values are shown in table 2.5 .

\subsubsection{Occurrence of illicit drugs and metabolites in sewage water}

A total of 14 drugs of abuse were detected during the period of this study. Concentrations of the parent drugs and metabolites found in sewage waters for both locations (dorms and college campus) were plotted as box plots and shown in Fig. 2.7A and $\mathrm{B}$. The frequency of detection is shown in parenthesis above the box plot. The boundaries of box plot cover 25th-75th percentile, the centerline indicates median of the sample population, error bars (whiskers) above and below the box refer to 90th and 10th percentiles. THC-COOH (99\%), AM (95\%), and $\Delta-9$-THC (44\%) were the most frequently detected compounds in the campus dorms, with median concentration of 420 $\mathrm{ng} / \mathrm{L}, 320 \mathrm{ng} / \mathrm{L}$, and $46 \mathrm{ng} / \mathrm{L}$ respectively (See Fig. 2.7A). This makes amphetamine and THC the two most potentially consumed drugs in the campus dorms. The remaining eleven parent drugs and metabolites were found in less than $15 \%$ of the samples, with concentrations ranging from $4.4 \mathrm{ng} / \mathrm{L}$ (BE) to $980.7 \mathrm{ng} / \mathrm{L}$ (COD). Heroin, LSD, MDEA, and 6-acetylmorphine metabolite were not detected in any of the dorm samples. In 
similar manner, THC-COOH (100 \%) and AM (99 \%) were also detected in high frequency in the main college campus pump station, with median concentrations of 464 ng/L and $1098 \mathrm{ng} / \mathrm{L}$ respectively (See Fig. 2.7B). In addition, compounds like benzoylecgonine, morphine, and codeine were also found in more than $50 \%$ of the samples. Cocaine, EDDP, heroin, LSD, MDA, MDEA, Methadone, and $\Delta-9-\mathrm{THC}$ were not detected in any of this group of samples. Concentrations found throughout the course of this study were for the most part highly variable. Levels (ng/L) for all compounds were in the same range as those published in other countries with the exception of THC-COOH $(30-2413 \mathrm{ng} / \mathrm{L})$, which displayed higher levels than those commonly reported in the literature (see table 2.6) (Castiglioni et al. 2006; Huerta-Fontela et al. 2008; Boleda et al. 2009; Kasprzyk-hordern et al. 2009b; Postigo et al. 2010; Terzic et al. 2010; Baker and Kasprzyk-hordern 2011; Bijlsma et al. 2012). Concentration ranges and frequency of detection for all analytes are found in table 2.7.

Table 2.6. Concentrations of most frequently (>50\%) detected illicit drugs $(\mathrm{ng} / \mathrm{L})$ in influent raw sewage and a comparison with previous studies.

\begin{tabular}{llllllll}
\hline Analyte & Netherlands $^{\mathbf{a}}$ & Italy $^{\mathbf{b}}$ & Switzerland $^{\mathbf{b}}$ & Spain $^{\text {c,d,e }}$ & Croatia $^{\mathbf{f}}$ & UK $^{\mathbf{g}, \mathbf{h}}$ & This study $^{-}$ \\
\hline Amphetamine & $<4-682$ & 14.7 & $<$ LOQ & $3-688$ & $2.6-31$ & $292-12020$ & $30-5956$ \\
Benzoylecgonine & $<2-2306$ & 1132 & $100-547$ & $545-3790$ & $89-325$ & $126-2114$ & $4-1214$ \\
THC-COOH & $<7-375$ & 62.7 & $7.2-91.2$ & $23.5-402$ & $21-128$ & - & $30-2413$ \\
Morphine & - & 83.3 & $55.4-204.4$ & $25.5-278$ & $160-476$ & 819.2 & $21-491$ \\
Codeine & $73-894$ & - & - & $5.7-120$ & $159-364$ & $1732-32295$ & $14-981$
\end{tabular}

a. Bijlsma et al. 2012, b. Castiglioni et al. 2006, c. Huerta-Fontela et al. 2008, d. Postigo et al. 2010, e. Boleda et al. 2009, f. Terzic et al. 2010, g. Kasprzyk-hordern et al. 2009, h. Baker and Kasprzyk-hordern 2011. 

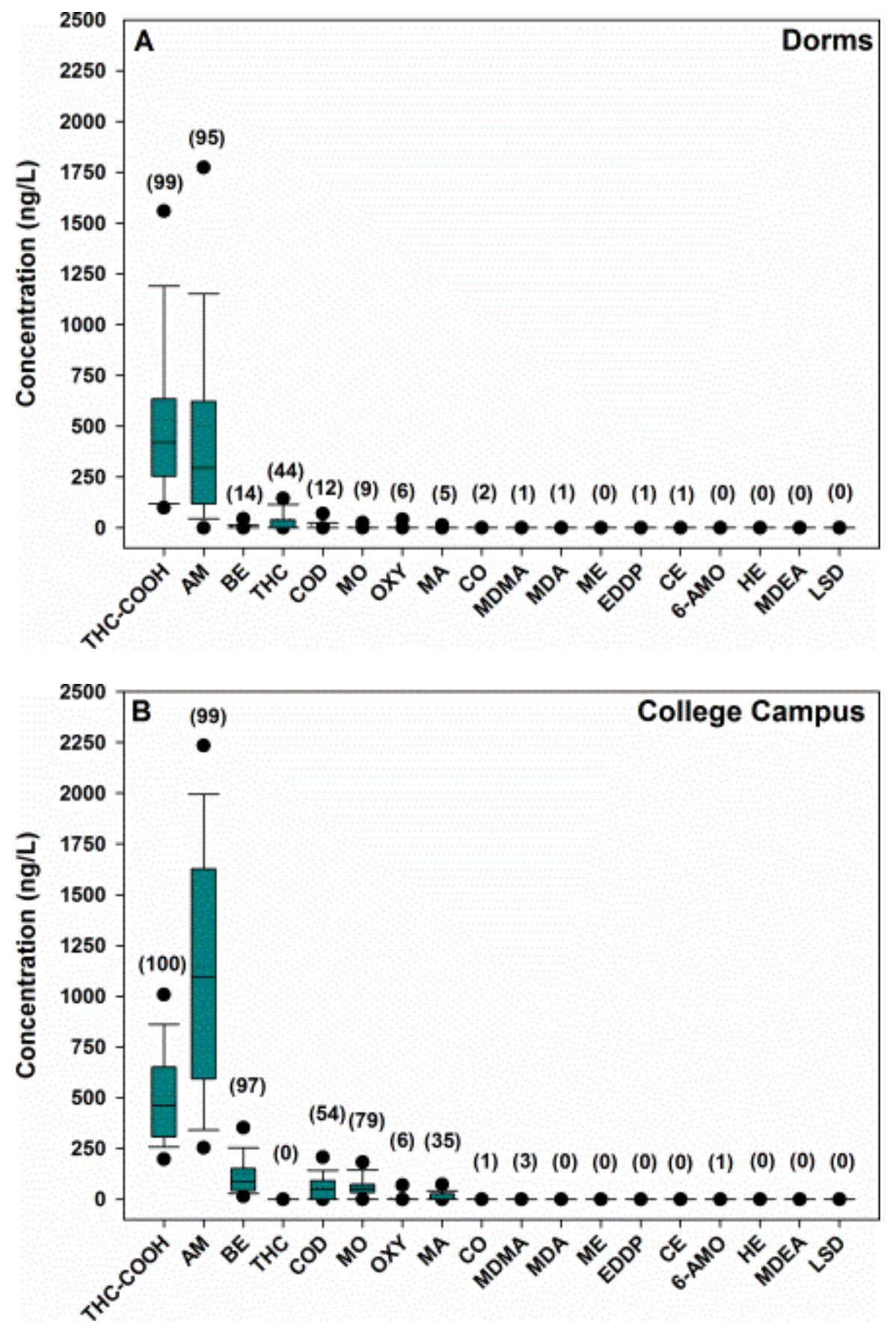

Fig. 2.7. Concentrations (ng/L) and frequency of detections (shown in parenthesis) of drugs of abuse in influent sewage samples from college dorms (4A Dorms) and main college campus (4B College Campus).

The boundaries of box plot cover 25th-75th percentile, the center line indicates median of the sample population, error bars (whiskers) above and below the box refer to 90th and 10th percentiles. Dotted line indicates the mean of the sample population. 
Table 2.7. Concentrations and frequency of detections for parent drugs and metabolites found in sewage waters for both locations (dorms and college campus).

\begin{tabular}{|c|c|c|c|c|c|c|c|c|}
\hline \multirow[b]{2}{*}{ Analyte } & \multicolumn{4}{|c|}{ Dorms Sewage Water $(n=149)$} & \multicolumn{4}{|c|}{ College Campus Sewage Water $(n=96)$} \\
\hline & Freq. (\%) & $\begin{array}{c}\text { Median } \\
\text { (ng/L) }\end{array}$ & Min. (ng/L) & Max. (ng/L) & Freq. (\%) & $\begin{array}{c}\text { Median } \\
\text { (ng/L) }\end{array}$ & $\operatorname{Min} .(n g / L)$ & $\operatorname{Max} .(n g / L)$ \\
\hline THC-COOH & 99 & 420 & 30 & 2413 & 100 & 464 & 152 & 1373 \\
\hline 6-AMO & - & - & - & - & 1 & 44 & 44 & 44 \\
\hline $\mathbf{A M}$ & 95 & 320 & 30 & 5956 & 99 & 1098 & 195 & 3017 \\
\hline BE & 14 & 25 & 4 & 350 & 97 & 87 & 13 & 1214 \\
\hline $\mathbf{C E}$ & 1 & 77 & 77 & 77 & - & - & - & - \\
\hline $\mathrm{CO}$ & 2 & 93 & 24 & 184 & 1 & 40 & 40 & 40 \\
\hline COD & 12 & 46 & 14 & 981 & 54 & 91 & 43 & 575 \\
\hline EDDP & 1 & 30 & 30 & 30 & - & - & - & - \\
\hline HE & - & - & - & - & - & - & - & - \\
\hline LSD & - & - & - & - & - & - & - & - \\
\hline MDA & 1 & 348 & 348 & 348 & - & - & - & - \\
\hline MDEA & - & - & - & - & - & - & - & - \\
\hline MDMA & 1 & 30 & 30 & 30 & 3 & 81 & 79 & 108 \\
\hline ME & - & - & - & - & - & - & - & - \\
\hline MA & 5 & 44 & 26 & 56 & 35 & 32 & 20 & 783 \\
\hline MO & 9 & 25 & 21 & 217 & 79 & 59 & 23 & 491 \\
\hline OXY & 6 & 43 & 40 & 66 & 6 & 79 & 60 & 169 \\
\hline ТHC & 44 & 45 & 22 & 2070 & - & - & - & - \\
\hline
\end{tabular}




\subsubsection{Estimation of drug consumption}

Doses were back-calculated for $\mathrm{THC}$, amphetamine, cocaine, and heroin in both dorms and main campus (see Fig. 2.8A and B). For THC, cocaine, and heroin, doses were produced using their major metabolites $\mathrm{THC}-\mathrm{COOH}$, benzoylecgonine, and morphine respectively using previously reported calculations (Zuccato et al. 2008; Postigo et al. 2011). Even though 6-acetylmorphine is an exclusive metabolic product of heroin, its excretion rate is low which may explain why it was only detected once in this study. Amphetamine is excreted mostly intact and therefore it was used for the calculations. Measured concentrations (ng/L) for THC-COOH, BE, MO, and AM where multiplied by daily flow rates (L/day) to obtain mass loads (mg/day) for the student population. Mass loads where normalized on a 1000 people, and a correction factor accounting for parent/drug residue molar ratio and excretion rate of the metabolite or parent compound was applied (Zuccato et al. 2008). Two recent publications by Baker et al. and Jones et al. proposed and implemented a more formal statistical framework to better account for sources of uncertainty. In addition to the back-calculation parameters listed above, analyte stability in wastewater and sorption to suspended particulate matter (SPM) was also accounted for (Baker et al. 2014; Jones et al. 2014). For this study, these additional variables (Analyte stability in wastewater and sorption to SPM) where not accounted for in our sampling process, therefore, the approach first described by Zuccato et al. was implemented here. Correction factor parameters, and theoretical daily doses used in this study are found in table 2.8 . 
Table 2.8. Analytes, correction factor parameters, and theoretical daily doses used for back-calculation estimates.

\begin{tabular}{ccccc}
\hline Analyte & $\begin{array}{c}\text { Metabolite } \\
\text { used for } \\
\text { calculation }\end{array}$ & $\begin{array}{c}\text { Molar mass ratio } \\
\text { (Metabolite/Parent) }\end{array}$ & $\begin{array}{c}\text { Excretion } \\
\text { rate (\%) }\end{array}$ & $\begin{array}{c}\text { Daily } \\
\text { Dose (mg) }\end{array}$ \\
\hline AM & - & 1 & 30 & 30 \\
THC & THC-COOH & 0.91 & 0.6 & 125 \\
CO & $\mathrm{BE}$ & 1.05 & 45 & 100 \\
HE & $\mathrm{MO}$ & 1.29 & 42.5 & 100 \\
\hline
\end{tabular}

Zuccato et al. 2008

Even though campus population could reach as many as 34,187 people, due to the largely commute dependent and transient nature of the student population, it is difficult to estimate a typical population size. Therefore, for this study we have calculated possible minimum and maximum consumption levels using both the total campus population $(35,187$ people) and the maximum number of daily occupied parking spaces $(9,456)$. The rationale behind the parking spaces is based on a 2009 FIU's climate action plan report, in which it was estimated that more than $97 \%$ of the student, faculty and staff population commuted by personal vehicle distances of approximately 15 miles per trip (FIU President's Climate Commitment Task Force 2009).

Fig. 2.8 shows box plots of consumption levels for THC, amphetamine, cocaine, and heroin in the dorms $(2.8 \mathrm{~A})$ and the main campus (2.8B). THC average dose levels in the dorms were higher $(233 \pm 199$ doses/day/1000 people) than those in the main campus and those reported in the literature ( $4-61$ doses/day/1000 people) (Zuccato et al. 2008; Boleda et al. 2009; Postigo et al. 2010). THC intake within the main campus ranged between 12.7 and 46 daily doses/1000 people. These values were based on a $125 \mathrm{mg}$ daily dose of marijuana (Zuccato et al. 2008). Moreover, Average levels of amphetamine among the student population in the dorms (22 \pm 31 daily doses/1000 people) were within 
the range of those reported by Huerta-Fontela et al. ( 2.5 doses/day/1000 people), Zuccato et al. (2.6 doses/day/1000 people), Postigo et al. (9.2 daily doses/1000 people), and Kasprzyk et al. (83.3 daily doses/1000 people) (Huerta-Fontela et al. 2008; Zuccato et al. 2008; Kasprzyk-hordern et al. 2009a; Postigo et al. 2010). In addition, consumption of amphetamine within the main campus was in the range of 2.7 and 9.8 doses/day/1000 people, which is much lower than those from the dorms, yet still within the range of those reported in the literature as mentioned previously. Dose levels were based on a $30 \mathrm{mg}$ daily intake of amphetamine (Zuccato et al. 2008).

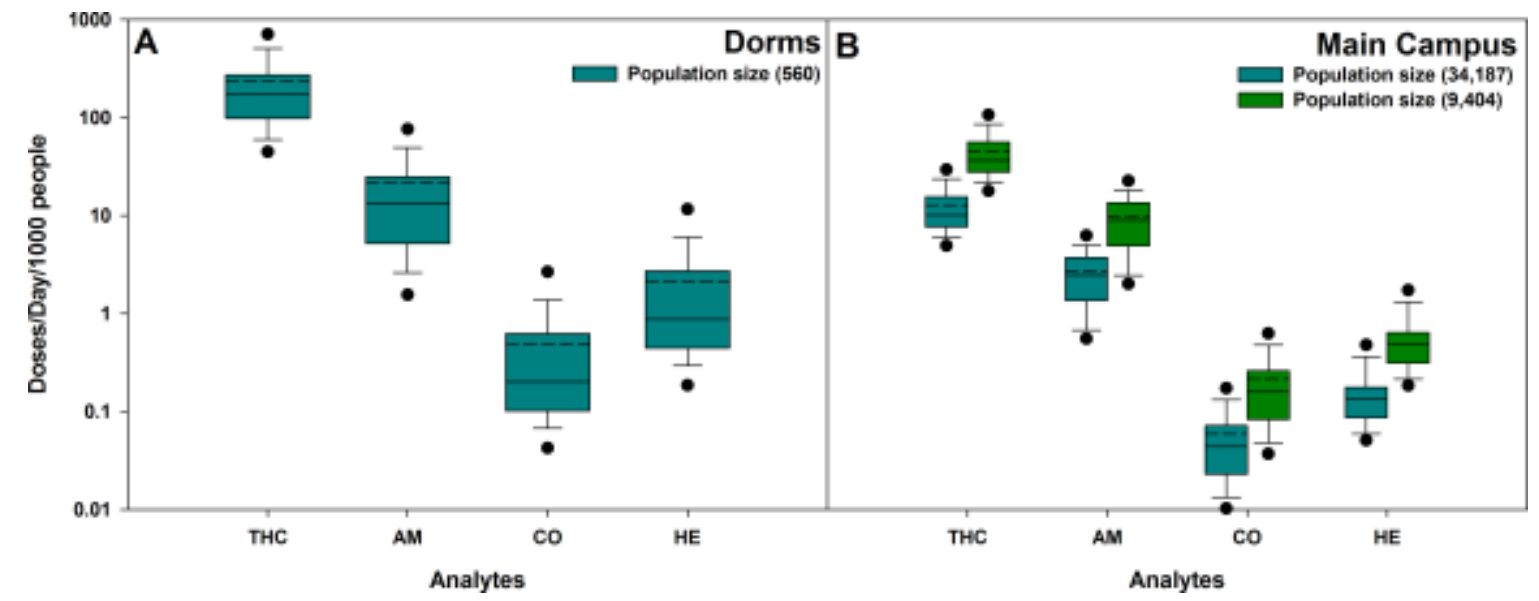

Fig. 2.8. Daily dose consumption (doses/day/1000 people) estimates for THC, amphetamine, heroin, and cocaine in both dorms $(5 \mathrm{~A})$ and main campus $(5 \mathrm{~B})$. Campus estimates were determined using both population sizes.

Average heroin intake in the dorms was similar to reported values by Zuccato ( 2.3 doses/day/1000 people) (Zuccato et al. 2008). Main campus heroin intake, on the other hand, was very minor with average levels ranging from 0.18 and 0.64 daily doses/1000 people depending on the population size used to calculate these values. As mention before morphine (target residue used for back-calculation purposes) could be a transformation product for other opiates including morphine itself. This introduces even 
greater uncertainty of encountering any heroin consumption in the dorms and/or campus. With regards to cocaine, even though benzoylecgonine (metabolite used for cocaine consumption determination) was found in $97 \%$ of the samples in the main college campus, the magnitude of its levels is rather low $(0.1-0.2$ doses/day/1000 people $)$ suggesting consumption by only a minor fraction of the student population, or possible degradation in the samples. Low consumption levels of cocaine were also observed in the

dorms with maximum observed levels of 2.8 doses/day/1000 people (dorms). All observed cocaine consumption levels were lower than mean values reported in Belgium, Ireland, Italy, Spain, Switzerland, and UK (Bones et al. 2007; Zuccato et al. 2008; Kasprzyk-hordern et al. 2009a; Nuijs et al. 2009a, 2009b, 2009c; Postigo et al. 2010). Dose determination for heroin and cocaine was based on single daily doses equivalent to $30 \mathrm{mg}$ and $100 \mathrm{mg}$ respectively (Zuccato et al. 2008).

\subsubsection{Amphetamine and marijuana consumption variations}

Consumption levels of samples collected at the beginning, middle, and end of a semester (2012-2013 academic year) in one of the college dorms were compared to determine potential variations throughout the semester. Adderall, an Attention Deficit Hyperactivity Disorder (ADHD) drug composed of a mixture of amphetamine salts, is known to be frequently used by students without prescription for performance and cognitive enhancement purposes (Burgard et al. 2013). In recent years, a study done at a college campus in Oregon demonstrated an increase in amphetamine levels during periods of high stress levels such as midterms and finals week, with a $760 \%$ consumption increase (compared to base-line levels) during finals week (end of the 
semester) (Burgard et al. 2013). In contrast to the previously mentioned study, Fig. 2.9A shows that the average amphetamine dose consumption remained relatively constant at the beginning, middle and end of the semester, yet larger variability was seen at the end of the semester. On the contrary, higher average doses of cannabinoids were observed at the end of the semester, suggesting larger consumption of marijuana during this period (see Fig. 2.9B). In general, consumption of marijuana was always greater than amphetamine throughout the semester.
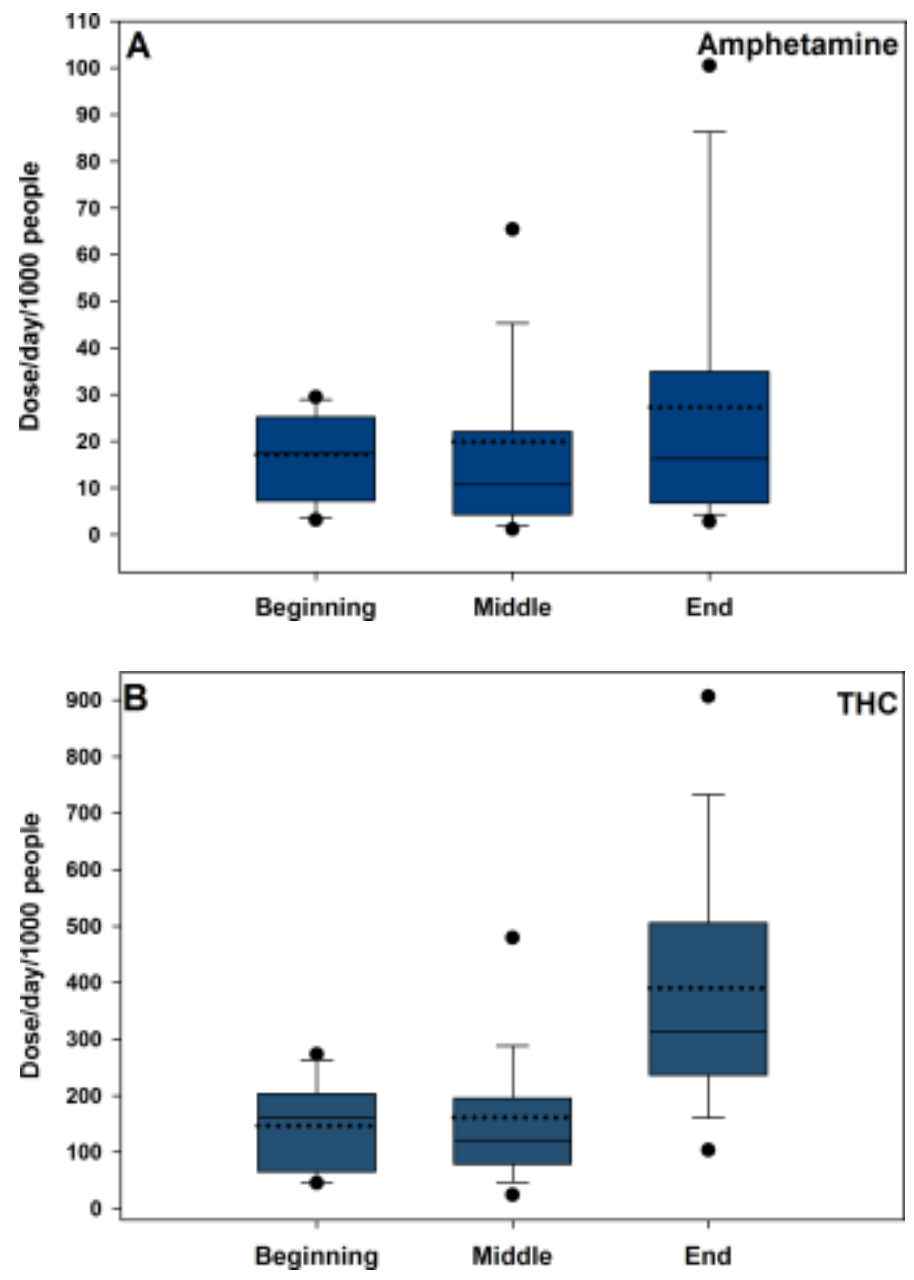

Fig. 2.9. Drug consumption in the dorms throughout the semester for amphetamine (6A) and THC (6B). The boundaries of box plot cover 25th-75th percentile, the center line indicates median of the sample population, error bars (whiskers) above and below the box ref er to 90th and 10th percentiles. Dotted line indicates the mean of the sample population. 
Daily variations of amphetamine and cannabinoids were assessed in the main campus during the last three weeks of classes. Fig. 2.10A and B show the average daily doses of amphetamine and marijuana (respectively) consumed during this period. A statistically significant change in consumption levels between the weekdays and the weekends for both amphetamine $(p<0.001)$ and marijuana $(p<0.001)$ was observed, with higher doses taken during the week. These findings are consistent with the number of students attending classes during the weekdays versus the weekends.
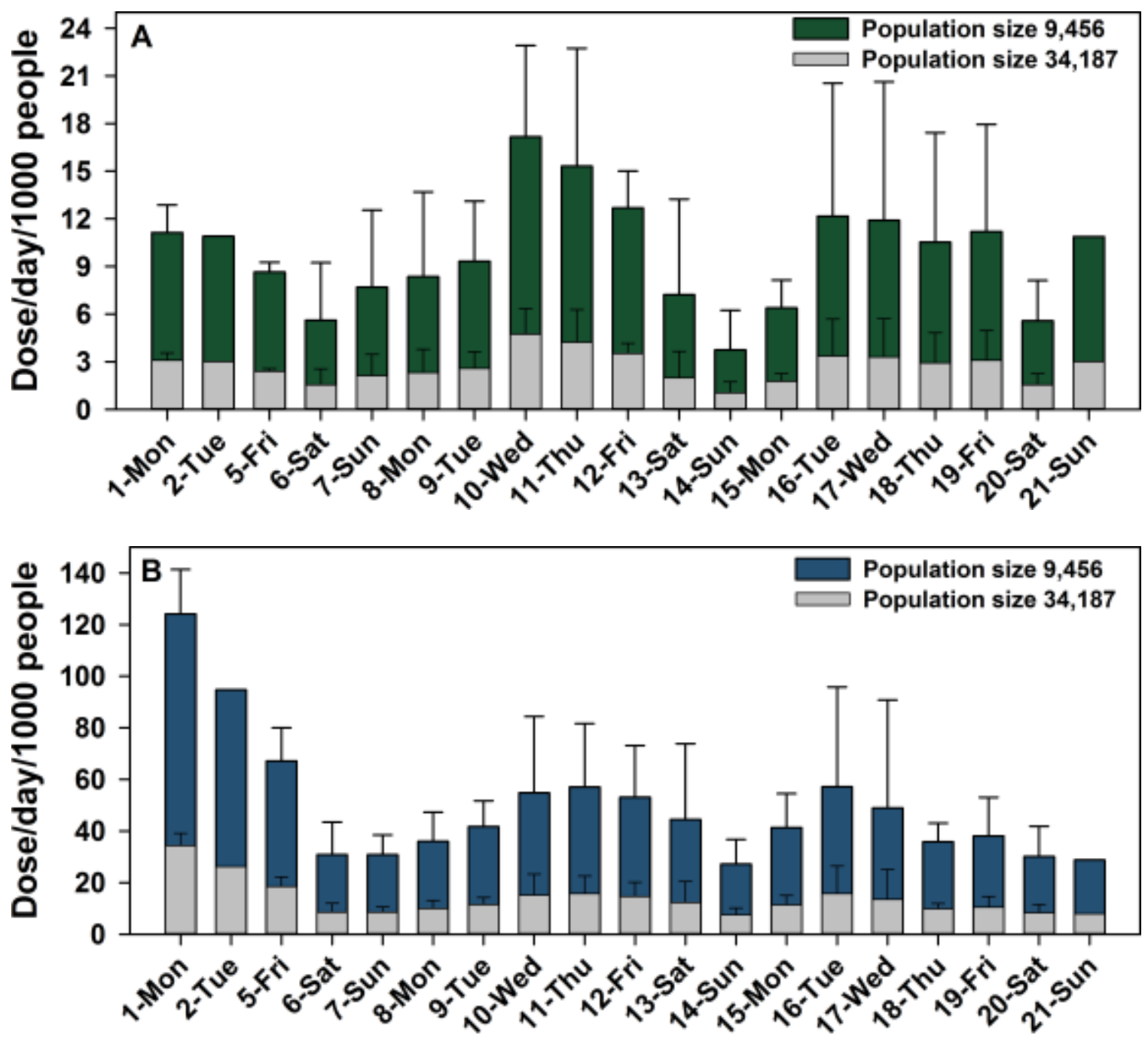

Fig. 2.10. Daily variations of amphetamine (7A) and cannabinoid (7B) consumption during the last three weeks of classes in the main campus. Campus estimates were determined using both population sizes. 


\subsection{Conclusion}

This manuscript reports a novel online-SPE-LC-HRMS method, developed for the analysis of 18 drugs of abuse and their metabolites in sewage water matrixes. The method consisted of three very simple steps (filtration, $10 \mathrm{X}$ dilution, and fortification) prior to automated injection $(5 \mathrm{~mL})$, pre-concentration, and clean-up of samples. Method validation parameters such as SPE recoveries, matrix effects, linearity, reproducibility, and method detection limits were successfully assessed and optimized. The validated method was applied to real samples collected from two different locations at a college campus (college dormitory and campus-wide). Average concentrations for college students residing in the dorms ranged from $30 \mathrm{ng} / \mathrm{L}$ to $537 \mathrm{ng} / \mathrm{L}$ for EDDP/MDMA and THC-COOH respectively. Detections in the main campus ranged from $40 \mathrm{ng} / \mathrm{L}$ to 1,159 ng/L for cocaine and amphetamine. Measured concentration values for amphetamine, THC-COOH, benzoylecgonine, and morphine were used for mass loads and daily dose consumption determination of amphetamine, THC, cocaine, and heroin respectively. Results suggest greater consumption of these drugs in the dorms than the main campus, with a peak in THC intake at the end of the semester in the dorm population. In addition, similar daily trends are seen for both amphetamine and THC in the main campus (higher consumption during the weekdays and the weekends).

\subsection{Acknowledgements}

The environmental Analysis Laboratory acknowledges the support from the Thermo Scientific Corporation in the development of this work. The authors would also like to acknowledge Florida International University Facilities Management for their 
collaboration for sample collection. This is contribution number 707 from the Southeast Environmental Research Center at Florida International University. 


\subsection{References}

Baker DR, Barron L, Kasprzyk-Hordern B. Illicit and pharmaceutical drug consumption estimated via wastewater analysis. Part A: chemical analysis and drug use estimates. Sci Total Environ [Internet]. Elsevier B.V.; 2014 Jul 15 [cited 2014 Sep 25];487:629-41. Available from: http://www.ncbi.nlm.nih.gov/pubmed/24377678

Baker DR, Kasprzyk-hordern B. Multi-residue analysis of drugs of abuse in wastewater and surface water by solid-phase extraction and liquid chromatography - positive electrospray ionisation tandem mass spectrometry. J Chromatogr A. 2011;1218:1620-31.

Bartelt-hunt SL, Snow DD, Damon T, Shockley J, Hoagland K. The occurrence of illicit and therapeutic pharmaceuticals in wastewater effluent and surface waters in Nebraska. Environ Pollut. 2009;157:786-91.

Batchu SR, Quinete N, Panditi VR, Gardinali PR. Online solid phase extraction liquid chromatography tandem mass spectrometry (SPE-LC-MS/MS) method for the determination of sucralose in reclaimed and drinking waters and its photo degradation in natural waters from South Florida. Chem Cent J. 2013 Jan;7(1):141.

Bijlsma L, Boix C, Niessen WMA, Ibáñez M, Sancho J V, Hernández F. Investigation of degradation products of cocaine and benzoylecgonine in the aquatic environment. Sci Total Environ. Elsevier B.V.; 2013a Jan 15;443:200-8.

Bijlsma L, Emke E, Hernández F, Voogt $\mathrm{P}$ de. Investigation of drugs of abuse and relevant metabolites in Dutch sewage water by liquid chromatography coupled to high resolution mass spectrometry. Chemosphere. Elsevier Ltd; 2012 Nov;89(11):1399-406.

Bijlsma L, Emke E, Hernández F, de Voogt P. Performance of the linear ion trap Orbitrap mass analyzer for qualitative and quantitative analysis of drugs of abuse and relevant metabolites in sewage water. Anal Chim Acta. Elsevier B.V.; 2013b Mar 20;768:102-10.

Boleda MR, Galceran MT, Ventura F. Trace determination of cannabinoids and opiates in wastewater and surface waters by ultra-performance liquid chromatography tandem mass spectrometry. J Chromatogr A. 2007;1175:38-48.

Boleda MR, Galceran MT, Ventura F. Monitoring of opiates, cannabinoids and their metabolites in wastewater, surface water and finished water in Catalonia, Spain. Water Res. 2009;43:1126-36. 
Bones J, Thomas K V, Paull B. Using environmental analytical data to estimate levels of community consumption of illicit drugs and abused pharmaceuticals. J Environ Monit. 2007;9:701-7.

Brzezinski MR, Spink BJ, Dean RA, Berkman CE, Cashman JR, Bosron WF, et al. Human liver carboxylesterase hCE-1: binding specificity for cocaine, heroin, and their metabolites and analogs. Drug Metab Dispos. 1997;25(9):1089-96.

Burgard DA, Fuller R, Becker B, Ferrell R, Dinglasan-Panlilio MJ. Potential trends in Attention Deficit Hyperactivity Disorder (ADHD) drug use on a college campus: wastewater analysis of amphetamine and ritalinic acid. Sci Total Environ. Elsevier B.V.; 2013 Apr 15;450-451:242-9.

Castiglioni S, Bagnati R, Melis M, Panawennage D, Chiarelli P, Fanelli R, et al. Identification of cocaine and its metabolites in urban wastewater and comparison with the human excretion profile in urine. Water Res. 2011;45:5141-50.

Castiglioni S, Zuccato E, Chiabrando C, Fanelli R, Bagnati R. Mass spectrometric analysis of illicit drugs in wastewater and surface water. Mass Spectrom Rev. 2008;27:378-94.

Castiglioni S, Zuccato E, Crisci E, Chiabrando C, Fanelli R. Identification and Measurement of Illicit Drugs and Their Metabolites in Urban Wastewater by Liquid Chromatography-Tandem Mass Spectrometry. Anal Chem. 2006;78:8421-9.

Chiaia AC, Banta-green C. Eliminating Solid Phase Extraction with Large-Volume Injection LC/MS/MS: Analysis of Illicit and Legal Drugs and Human Urine Indicators in US Wastewaters. Environ Sci Technol. 2008;42:8841-8.

Fedorova G, Randak T, Lindberg RH, Grabic R. Comparison of the quantitative performance of a Q-Exactive high-resolution mass spectrometer with that of a triple quadrupole tandem mass spectrometer for the analysis of illicit drugs in wastewater. Rapid Commun Mass Spectrom. 2013 Aug 15;27(15):1751-62.

FIU President's Climate Commitment Task Force. FIU's Climate Action Plan [Internet]. 2009 p. 1-74. Available from: http://gogreen.fiu.edu/_assets/documents/FIUClimate-Action-Plan.pdf

Fontanals N, Borrull F, Marcé RM. On-line weak cationic mixed-mode solid-phase extraction coupled to liquid chromatography-mass spectrometry to determine illicit drugs at low concentration levels from environmental waters. J Chromatogr A. Elsevier B.V.; 2013 Apr 19;1286:16-21. 
Fontanals N, Marcé RM, Borrull F. On-line solid-phase extraction coupled to hydrophilic interaction chromatography-mass spectrometry for the determination of polar drugs. J Chromatogr A. 2011 Sep 2;1218(35):5975-80.

González-Mariño I, Quintana JB, Rodríguez I, Cela R. Determination of drugs of abuse in water by solid-phase extraction, derivatisation and gas chromatography-ion traptandem mass spectrometry. J Chromatogr A. 2010;1217:1748-60.

González-Mariño I, Quintana JB, Rodríguez I, González-Díez M, Cela R. Screening and Selective Quantification of Illicit Drugs in Wastewater by Mixed-Mode Solid-Phase Extraction and Quadrupole-Time-of- Flight Liquid Chromatography-Mass Spectrometry. Anal Chem. 2012;84:1708-17.

Gorga M, Petrovic M, Barceló D. Multi-residue analytical method for the determination of endocrine disruptors and related compounds in river and waste water using dual column liquid chromatography switching system coupled to mass spectrometry. J Chromatogr A. Elsevier B.V.; 2013 Jun 21;1295:57-66.

Hernández F, Bijlsma L, Sancho J V, Díaz R, Ibáñez M. Rapid wide-scope screening of drugs of abuse , prescription drugs with potential for abuse and their metabolites in influent and effluent urban wastewater by ultrahigh pressure liquid chromatography - quadrupole-time-of-flight-mass. Anal Chim Acta. 2011;684:96-106.

Heuett N V, Batchu SR, Gardinali PR. Understanding the magnitude of emergent contaminant releases through target screening and metabolite identification using high resolution mass spectrometry: Illicit drugs in raw sewage influents. J Hazard Mater. Elsevier B.V.; 2014 Aug 17;

Huerta-Fontela M, Galceran MT, Martin-Alonso J, Ventura F. Occurrence of psychoactive stimulatory drugs in wastewaters in north-eastern Spain. Sci Total Environ. 2008;397:31-40.

Hummel D, Loffler D, Fink G, Ternes TA. Simultaneous Determination of Psychoactive Drugs and Their Metabolites in Aqueous Matrices by Liquid Chromatography Mass. Environ Sci Technol. 2006;40:7321-8.

Jones HE, Hickman M, Kasprzyk-Hordern B, Welton NJ, Baker DR, Ades a E. Illicit and pharmaceutical drug consumption estimated via wastewater analysis. Part B: placing back-calculations in a formal statistical framework. Sci Total Environ [Internet]. Elsevier B.V.; 2014 Jul 15 [cited 2014 Nov 2];487:642-50. Available from: http://www.pubmedcentral.nih.gov/articlerender.fcgi?artid=4039139\&tool=pmcentre $\mathrm{z} \&$ rendertype $=$ abstract 
Jurado A, Mastroianni N, Vàzquez-Suñé E, Carrera J, Tubau I, Pujades E, et al. Drugs of abuse in urban groundwater. A case study: Barcelona. Sci Total Environ. Elsevier B.V.; 2012;424:280-8.

Kasprzyk-Hordern B, Baker DR. Estimation of community-wide drugs use via stereoselective profiling of sewage. Sci Total Environ. Elsevier B.V.; 2012 Apr 15;423:142-50.

Kasprzyk-hordern B, Dinsdale RM, Guwy AJ. Illicit drugs and pharmaceuticals in the environment - Forensic applications of environmental data . Part 1: Estimation of the usage of drugs in local communities. Environ Pollut [Internet]. Elsevier Ltd; 2009a;157:1773-7. Available from: http://dx.doi.org/10.1016/j.envpol.2009.03.017

Kasprzyk-hordern B, Dinsdale RM, Guwy AJ. The removal of pharmaceuticals, personal care products, endocrine disruptors and illicit drugs during wastewater treatment and its impact on the quality of receiving waters. Water Res. Elsevier Ltd; 2009b;43:363-80.

Li X, Shen B, Jiang Z, Huang Y, Zhuo X. Rapid screening of drugs of abuse in human urine by high-performance liquid chromatography coupled with high resolution and high mass accuracy hybrid linear ion trap-Orbitrap mass spectrometry. J Chromatogr A. Elsevier B.V.; 2013 Aug 9;1302:95-104.

Moschet C, Piazzoli A, Singer H, Hollender J. Alleviating the reference standard dilemma using a systematic exact mass suspect screening approach with liquid chromatography-high resolution mass spectrometry. Anal Chem [Internet]. 2013 Nov 5;85(21):10312-20. Available from: http://www.ncbi.nlm.nih.gov/pubmed/24161211

Musenga A, Cowan DA. Use of ultra-high pressure liquid chromatography coupled to high resolution mass spectrometry for fast screening in high throughput doping control. J Chromatogr A. Elsevier B.V.; 2013 May 3;1288:82-95.

Nuijs ALN Van, Mougel J, Tarcomnicu I, Bervoets L, Blust R, Jorens PG, et al. Sewage epidemiology - A real-time approach to estimate the consumption of illicit drugs in Brussels , Belgium. Environ Int. Elsevier Ltd; 2011;37:612-21.

Nuijs ALN Van, Pecceu B, Theunis L, Dubois N, Charlier C, Jorens PG, et al. Can cocaine use be evaluated through analysis of wastewater? A nation-wide approach conducted in Belgium. Addiction. 2009a;104:734-41.

Nuijs ALN Van, Pecceu B, Theunis L, Dubois N, Charlier C, Jorens PG, et al. Cocaine and metabolites in waste and surface water across Belgium. Environ Pollut. Elsevier Ltd; 2009b;157:123-9. 
Nuijs ALN Van, Pecceu B, Theunis L, Dubois N, Charlier C, Jorens PG, et al. Spatial and temporal variations in the occurrence of cocaine and benzoylecgonine in wasteand surface water from Belgium and removal during wastewater treatment. Water Res. Elsevier Ltd; 2009c;43:1341-9.

Nuijs ALN Van, Tarcomnicu I, Bervoets L, Blust R, Jorens PG, Neels H, et al. Analysis of drugs of abuse in wastewater by hydrophilic interaction liquid chromatography tandem mass spectrometry. Anal Bioanal Chem. 2009d;395:819-28.

Ostman M, Fick J, Näsström E, Lindberg RH. A snapshot of illicit drug use in Sweden acquired through sewage water analysis. Sci Total Environ. Elsevier B.V.; 2013 Dec $13 ; 472 \mathrm{C}: 862-71$.

Pal R, Megharaj M, Kirkbride KP, Naidu R. Illicit drugs and the environment - A review. Sci Total Environ [Internet]. Elsevier B.V.; 2013 Oct 1 [cited 2013 Oct 17];463464:1079-92. Available from: http://www.ncbi.nlm.nih.gov/pubmed/22726813

Panditi VR, Batchu SR, Gardinali PR. Online solid-phase extraction-liquid chromatography-electrospray-tandem mass spectrometry determination of multiple classes of antibiotics in environmental and treated waters. Anal Bioanal Chem. 2013 Jul;405(18):5953-64.

Parolini M, Pedriali A, Riva C, Binelli A. Sub-lethal effects caused by the cocaine metabolite benzoylecgonine to the freshwater mussel Dreissena polymorpha. Sci Total Environ. Elsevier B.V.; 2013 Feb 1;444:43-50.

Petrović M, Farré M, Alda ML de, Perez S, Postigo C, Köck M, et al. Recent trends in the liquid chromatography - mass spectrometry analysis of organic contaminants in environmental samples. J Chromatogr A. 2010;1217:4004-17.

Petrovic M, Radjenovic J, Postigo C, Kuster M, Farré M, Lopez de Alda M, et al. The Handbook of Environmental Chemistry. In: Hutzinger O, Barceló D, Kostianoy A, editors. Springer. Springer-Verlag Berlin Heidelberd; 2008. p. Vol. 5, Part S/1: 1-35.

Postigo C, Alda MJL De, Barceló D. Fully Automated Determination in the Low Nanogram per Liter Level of Different Classes of Drugs of Abuse in Sewage Water by On-Line Chromatography-Electrospray-Tandem Mass Spectrometry. Anal Chem. 2008;80:3123-34.

Postigo C, Alda MJL De, Barceló D. Drugs of abuse and their metabolites in the Ebro River basin: Occurrence in sewage and surface water, sewage treatment plants removal efficiency, and collective drug usage estimation. Environ Int. Elsevier Ltd; 2010;36(1):75-84. 
Postigo C, Alda ML de, Barceló D. Evaluation of drugs of abuse use and trends in a prison through wastewater analysis. Environ Int. Elsevier Ltd; 2011;37(1):49-55.

Ramirez CE, Wang C, Gardinali PR. Fully automated trace level determination of parent and alkylated PAHs in environmental waters by online SPE-LC-APPI-MS/MS. Anal Bioanal Chem. 2014 Jan 12;406(1):329-44.

Repice C, Dal Grande M, Maggi R, Pedrazzani R. Licit and illicit drugs in a wastewater treatment plant in Verona, Italy. Sci Total Environ. Elsevier B.V.; 2013 Oct 1;463464:27-34.

Richardson SD. Environmental Mass Spectrometry: Emerging Contaminants and Current Issues. Anal Chem. 2008;80(12):4373-402.

Sundström M, Pelander A, Angerer V, Hutter M, Kneisel S, Ojanperä I. A highsensitivity ultra-high performance liquid chromatography/high-resolution time-offlight mass spectrometry (UHPLC-HR-TOFMS) method for screening synthetic cannabinoids and other drugs of abuse in urine. Anal Bioanal Chem. 2013 Oct;405(26):8463-74.

Terzic S, Senta I, Ahel M. Illicit drugs in wastewater of the city of Zagreb ( Croatia ) Estimation of drug abuse in a transition country. Environ Pollut. Elsevier Ltd; 2010;158(8):2686-93.

U.S. Department of Health and Human Services. Results from the 2012 National Survey on Drug Use and Health: Summary of National Findings. Rockville, MD; 2013 p. NSDUH Series H - 46, HHS Publication No. (SMA) 13-47.

UNODC. World drug report 2014. New York; 2014 Dec.

US EPA. Guidelines establishing test procedures for the analysis of pollutants. Appendix B, part 136. Definition and procedures for the determination of the method detection limit. U.S. Code of Federal Regulations, Title 40. Revision 1.11 43. 2010 p. Appendix B, part 136.

Valcárcel Y, Martínez F, González-Alonso S, Segura Y, Catalá M, Molina R, et al. Drugs of abuse in surface and tap waters of the Tagus River basin: Heterogeneous photoFenton process is effective in their degradation. Environ Int. Elsevier Ltd; 2012;41:35-43.

Vazquez-Roig P, Blasco C, Picó Y. Advances in the analysis of legal and illegal drugs in the aquatic environment. TrAC Trends Anal Chem. Elsevier Ltd; 2013 Oct;50:6577. 
Wang C, Gardinali PR. Detection and occurrence of microconstituents in reclaimed water used for irrigation--a potentially overlooked source. Anal Bioanal Chem. 2013 Jul;405(18):5925-35.

Zuccato E, Castiglioni S. Illicit drugs in the environment. R Soc Chem. 2009;367:396578.

Zuccato E, Chiabrando C, Castiglioni S, Bagnati R, Fanelli R. Estimating Community Drug Abuse by Wastewater Analysis. Environ Health Perspect. 2008;116(8):102732.

Zuccato E, Chiabrando C, Castiglioni S, Calamari D, Bagnati R, Schiarea S, et al. Cocaine in surface waters : a new evidence-based tool to monitor community drug abuse. Environ Heal A Glob Access Sci Source. 2005;4(14):1-7. 


\section{CHAPTER 3}

Understanding the magnitude of emergent contaminant releases through target screening and metabolite identification using high resolution mass spectrometry:

\section{Illicit drugs in raw sewage influents}

This chapter was published in the Journal of Hazardous Materials and adapted with permission from all participating authors.

Nubia V. Heuett, Sudha Rani Batchu, and Piero R. Gardinali, Journal of Hazardous Materials $282(2015)$ 41-50 


\subsection{Abstract}

A QExactive Orbitrap was used for the identification of phase I and II transformation products (TPs) of illicit drugs in raw sewage influents. Two operating modes, (targeted $\mathrm{MS}^{2}$ and Data-dependent screening) were used for data acquisition. Even though, datadependent scan is a faster route towards the potential identification of metabolites, it suffered from its limitation to provide enough data points across the chromatographic peak during the $\mathrm{MS}^{2}$ cycle in contrast to targeted $\mathrm{MS}^{2}$. Therefore, the later technique was implemented as the method of choice in this study for the positive confirmation and quantitation of TPs $(n=54)$. The vast majority of the identified TPs were products of phase I transformation reactions, with the latter being more prevalent in the nature. Estimated mole fractions showed that for a large number of the analytes, TPs must also be monitored in order to fully understand their environmental fate and calculate potential consumption.

\subsection{Introduction}

The prevalence of illicit drug consumption continues to be a growing problem worldwide. In US alone, it was estimated that 23.9 million Americans aged 12 or older used illicit drug in 2012 [1]. These figures do not even consider the abuse of common prescription drugs such as Adderall (amphetamine) and Oxycontin (oxycodone) [2-4]. Upon consumption, drugs of abuse (DOA; illicits and prescription) are subjected to phase I and II metabolic transformations in the body. Phase I reactions involve hydrolysis, reduction, and oxidation, making their products slightly more hydrophilic than the parent by exposing or introducing functional groups such as $-\mathrm{OH},-\mathrm{NH}_{2},-\mathrm{SH}$, or $-\mathrm{COOH}$. In 
addition, Phase II reactions include glucuronidation, sulfation, acetylation, methylation, glutathione conjugation, and conjugation with amino acids such as glycine, taurine, and glutamic acid [5,6], also increasing the polarity of their transformation products (TPs)[7]. A combination of phase I and phase II TPs plus their unchanged parents are excreted via urine and/or faeces. Multiple studies have demonstrated that once these excretion products reach wastewater treatment plants, not all of the compounds can be efficiently removed prior to the release of effluent waters into aquatic environments[8-11]. Even treatment plants equipped with what could be classified as advanced treatment are not designed to eliminate these compounds from their effluents. Emission of these compounds will likely continue until new materials and or technologies are developed for their removal. Occurrence of DOAs in sewage influents, effluents, as well as surface waters, have previously been reported with concentrations reaching up to $27,500 \mathrm{ng} / \mathrm{L}$ [12]. Moreover, analysis of raw sewage water from small settings such as a college campus can provide further information on metabolic transformation products since the residence time of these compounds in the actual sewage is minimal compared to that of influent waters arriving at WWTPs where additional TPs can be produced by microbial activity during transit. For instance, amphetamine concentrations of 2,100 ng/L were reported in a college campus in Oregon, when comparing this value to those reported by Chiaia from influent sewage waters throughout the US $(550 \mathrm{ng} / \mathrm{L})$, a loss of the parent compound is noted confirming the possibility of external transformations [2]. External transformations include photodegradation, hydrolysis, chemical oxidation and biodegradation, and could also be observed in aquatic environments, increasing the possibility of finding new metabolites that were not previously taken into account. 
Assessment on the occurrence of illicit drugs have been for the most part monitored using the unchanged form of the drug (parent), and in some cases by the evaluation of very few well known metabolites $[10,13-17]$. Furthermore, it is sometimes critical to monitor metabolites since many compounds are excreted as glucuronide or sulfate conjugates and are likely to be transformed back into the parent molecule from adducts during treatment process $[15,18]$. As an example, deconjugation of one of the phase II metabolites of morphine and heroin (morphine-3 $\beta$-D-glucuronide) is converted back into the parent molecule (morphine) once it reaches aquatic environments $[19,20]$. As in the case with antibiotics, lack of availability of metabolite standards in the market, diminishes the ability for identification of metabolites and other transformation products [21]. In any way, absence of the parent drug does not necessarily indicate lack of consumption, efficiency of treatment plants, or analytical issues with the method of detection; it could very well mean that there is simply not enough information on metabolic transformations to confirm their presence.

Robust and sensitive analytical tools are required to identify and confirm the low abundant metabolites (parts per trillion level) in the complex matrices. To date, high resolution mass spectrometric instruments such as the quadrupole-time-of-flight (qTOF), Fourier transform-ion cyclotron resonance (FT-ICR), and the Orbitrap have become the ideal tools for the identification of metabolites and transformation products, thanks to their high resolving power $(30,000-1,000,000)$, high mass accuracy $(<5 \mathrm{ppm})$, linear dynamic range, and sensitivity [5,22-24]. The Orbitrap is, however, gaining popularity for the identification of metabolites due to its sensitivity, large dynamic range and its 
ability to use an external calibration as opposed to an internal calibration to maintain high accuracy (as in the qTOF) $[23,25,26]$.

In the recent years there have been some reports in the identification of new TPs for cocaine and codeine utilizing high resolution instruments as the ones mention above [27,28] (Bijlsma 2013, Wick 2011). Bijlsma's group focused on the degradation products of cocaine and its major metabolite (benzoylecgonine) resulting from in lab controlled degradation experiments (e.g. chlorination, hydrolysis, and photo-degradation. Four newly identified TPs were reported in this study, three of them were isomers. However, target screening of these TPs in influent, effluent, and surface waters was carried out using a TSQ (QqQ) mass spectrometer in SRM. The downside of this approach is that it increases the possibility for neglecting potential TPs that can arise from matrix interactions. In addition, a similar screening method to the one reported in this manuscript have been perform in the area of pesticides, validating the importance of combined target analysis and target screening for the efficient identification and monitoring of TPs [29].

Data acquisition is an important aspect in the process of TP identification when using an Orbitrap, since intensity threshold parameters and limited data points across the chromatographic peak can potentially omit useful data or, on the contrary, acquire unreliable data. Therefore, the objective of the present study is a threefold: (1) to develop and compare two workflows based on two different types of acquisition modes (targeted$\mathrm{MS}^{2}$ and data-dependent) to identify the most complete and reliable manner of data collection; (2) to implement these workflows in the identification of illicit drug metabolic contaminants of emerging concern; and (3) to further determine their abundances relative 
to their parent compounds from $\%$ mole fraction determinations, and their prevalence as a way to demonstrate the importance of their assessment.

\subsection{Experimental}

\subsubsection{Reagents and chemicals}

Illicit drug and metabolite standards as well as some of their deuterated analogs used in the analytical method cocaine (CO, cocaine-d3), benzoylecgonine (BE, benzoylecgonine-d3), cocaethylene (CE, cocaine-d3), codeine (COD, codeine-d6), morphine (MO, morphine-d6), 6-acetylmorphine (6-AMO, morphine-d6), oxycodone (OXY, oxycodone-d6), methadone (ME, methadone-d9), EDDP (methadone-d9), heroin (HE, morphine-d6), LSD (LSD-d3), $\Delta$-9-THC (THC, $\Delta$-9-THC-d3), 11-nor-9-carboxy- $\Delta$ -

9-THC (THC-COOH, 11-nor-9-carboxy- $\Delta-9-\mathrm{THC}-\mathrm{d} 3$ ), amphetamine (AM, amphetamine-d5), MDA (MDA-D5), MDEA (MDEA-D6), MDMA (MDMA-D5), and, methamphetamine (MA, Methamphetamine-d14). However, 6-AMO and HE were never detected, nor any possible TPs, therefore they were left out of the rest of the study. Standards and deuterated analogues were purchased from Cerilliant (Round Rock, TX, USA). Standard stock solutions containing target analytes or deuterated compounds were prepared at a concentration of $20 \mu \mathrm{g} / \mathrm{L}$ in methanol and stored in the dark at $-20^{\circ} \mathrm{C}$. Optima LC/MS grade methanol, water, and acetonitrile were purchased from Fisher Scientific (Fair Lawn, NJ, USA) and used for standard preparation and HPLC mobile phases. Optima LC/MS grade formic acid was purchased from Fisher Scientific (Fair Lawn, NJ, USA) and used to prepare $0.1 \%$ solutions for modifier mobile phase. 1.0 and 0.45 micrometer PreSep Prefilter, glass filters were also purchased from Fisher Scientific. 


\subsubsection{Sample collection and preparation}

A total of $12200 \mathrm{~mL}$ grab influent raw sewage water samples were collected during the month of April 2013 from the main lift station at a college campus using an automated ISCO sampler. Samples were transported to the laboratory and were filtered using a 1.0 micron PreSep Prefilter glass filter followed by $0.45 \mu \mathrm{m}$ PreSep Prefilter glass filter. Samples were stored in clear polyethylene terephthalate (PET) bottles in the dark at $-20^{\circ} \mathrm{C}$ until the time of analysis. Filtration of the sample is essential to remove most of the matrix components including bacteria. Therefore, very minimal or no biological activity, or photodegradation should be observed in the dark and at $-20^{\circ} \mathrm{C}[30,31]$. On the day of analysis raw sewage water samples were allowed to thaw at room temperature and shaken for about 10 seconds. Samples were diluted ten times (10x) in deionized water (DI) water, and fortified with the appropriate internal standards (200 ng/L). A seven-point calibration curve $(5 \mathrm{ng} / \mathrm{L}-500 \mathrm{ng} / \mathrm{L})$ containing illicit standards and their deuterated analogues was prepared using DI water.

\subsubsection{Pre-concentration and chromatographic separation of analytes}

Pre-concentration of samples was achieved using an EQuan online solid phase extraction (SPE) system from Thermo Scientific (Waltham, MA, USA). The on-line EQuan SPE procedure has been explained in detail elsewhere [32,33]. In short, the preconcentration and analytical separation of analytes were performed using a Thermo EQuan Max online-SPE system equipped with a Hypersep Retain PEP column (20 x 2.1 $\mathrm{mm} \times 12 \mu \mathrm{m})$ and Hypersil Gold PFP $(50 \times 2.1 \mathrm{~mm} \times 1.9 \mu \mathrm{m})$, respectively, both purchased from the same manufacturer (Thermo Scientific, USA). Methanol and 0.1\% 
formic acid were used in gradient elution mode for separation of analytes at $1000 \mu \mathrm{L} / \mathrm{min}$ and $200 \mu \mathrm{L} / \mathrm{min}$ for pre-concentration and analytical separation, respectively [34]. Sample volume selected was $5 \mathrm{~mL}$, and a three minute washing step was performed to remove most of the matrix components. This small volume is a compromise between method sensitivity and matrix effects. Larger sample volumes can increase ion suppression due to matrix effects, affecting the overall sensitivity of the method. Moreover, to account for possible ion suppression due to interactions with matrix components, isotopically label internal standards were used. Future studies should, however, be conducted to fully understand the magnitude of the effect the sample matrix imposes on the TPs. Figures of merit for the method including linearity, precision (\%RSD), relative recoveries, and method detection limits (MDLs) are shown in table 3.1. 
Table 3.1. Quality control parameter of analytical method: linearity (R2), precision (\%RSD), relative recoveries (spike recoveries), and method detection limits (MDLs) in HPLC water and influent raw sewage water.

\begin{tabular}{|c|c|c|c|c|c|c|c|}
\hline \multirow[b]{2}{*}{ ANALYTE } & \multirow[b]{2}{*}{$\begin{array}{c}\text { LINEARITY } \\
\quad \mathbf{R}^{2}(\mathbf{n}=\mathbf{8})\end{array}$} & \multicolumn{3}{|c|}{ HPLC WATER } & \multicolumn{3}{|c|}{ SEWAGE WATER } \\
\hline & & $\begin{array}{c}\% \text { RSD } \\
(n=3)\end{array}$ & $\begin{array}{c}\text { RELATIVE } \\
\text { RECOVERIE } \\
\text { S (\%) }(\mathbf{n}=\mathbf{3})\end{array}$ & $\begin{array}{c}\text { MDLs } \\
(\mathrm{ng} / \mathrm{L}) \\
(\mathrm{n}=7)\end{array}$ & $\begin{array}{c}\% \text { RSD } \\
(n=3)\end{array}$ & $\begin{array}{c}\text { RELATIVE } \\
\text { RECOVERIE } \\
\text { S (\%) }(\mathrm{n}=\mathbf{3})\end{array}$ & $\begin{array}{c}\text { MDLs } \\
(n g / L) \\
(n=7)\end{array}$ \\
\hline AMPHETAMINE & 0.9995 & 1.92 & 102 & 0.87 & 3.03 & 98 & 9.83 \\
\hline (-)-11-NOR-CARBOXY-THC & 0.9965 & 1.33 & 102 & 1.81 & 3.08 & 89 & $--^{d}$ \\
\hline 6-ACETYLMORPHINE & 0.9993 & 5.93 & 103 & 1.59 & 1.76 & 76 & 70.9 \\
\hline BENZOYLECGONINE & 0.9999 & 0.50 & 100 & 0.48 & 5.01 & 100 & 4.74 \\
\hline COCAETHYLENE $^{\mathrm{a}}$ & 0.9985 & 1.04 & 98 & 1.18 & 0.62 & 121 & 24.71 \\
\hline COCAINE & 0.9995 & 1.50 & 101 & 0.62 & 0.90 & 115 & 12.77 \\
\hline CODEINE & 0.9986 & 2.03 & 98 & 0.60 & 1.44 & 103 & 23.44 \\
\hline DELTA-9-THC & 0.9986 & 2.45 & 86 & 0.79 & 11.59 & 108 & $--^{\mathrm{d}}$ \\
\hline DL-METHADONE & 0.9996 & 1.07 & 102 & 0.76 & 1.54 & 102 & 35.74 \\
\hline $\mathrm{EDDP}^{\mathrm{c}}$ & 0.9996 & 1.33 & 101 & 0.64 & 1.20 & 107 & 18.19 \\
\hline HEROIN $^{\mathrm{b}}$ & 0.9987 & 4.66 & 110 & 1.92 & 4.48 & 60 & 18.57 \\
\hline LSD & 0.9989 & 3.23 & 96 & 0.71 & 0.75 & 95 & 61.8 \\
\hline MDA & 0.9998 & 2.16 & 100 & 0.79 & 3.52 & 118 & 19.45 \\
\hline MDEA & 0.9998 & 0.69 & 102 & 0.43 & 3.50 & 114 & 4.00 \\
\hline MDMA & 0.9989 & 1.63 & 101 & 0.68 & 3.34 & 111 & 10.50 \\
\hline METHAMPHETAMINE & 0.9998 & 2.65 & 100 & 0.76 & 1.07 & 112 & 3.39 \\
\hline MORPHINE & 0.9999 & 1.50 & 100 & 0.83 & 0.97 & 102 & 61.52 \\
\hline OXYCODONE & 0.9998 & 1.77 & 98 & 1.28 & 3.93 & 113 & 4.53 \\
\hline
\end{tabular}




\subsubsection{Mass spectrometric Analysis}

Detection of analytes was performed in positive ionization mode on a QExactive Orbitrap high resolution mass spectrometer equipped with heated electrospray ionization source (HESI-II) (Thermo Scientific, NJ, USA). Data was acquired using two different pathways explained in the schematic presented in Fig. 3.1. In the first pathway, samples were initially run in full scan mode $(\mathrm{m} / \mathrm{z} 100-\mathrm{m} / \mathrm{z} 500)$ at a resolving power of 70,000 and quantitation of known target analytes was performed using TraceFinder 3.0 processing software (Thermo Scientific, NJ, USA). In addition, raw data was also processes using a metabolite finding software (MetWorks 1.3 from Thermo Scientific, NJ, USA). The software created a list of possible phase I and II reactions and their corresponding exact mass difference expected in the products (Table 3.2). Given the target analyte molecular formula, polarity, a minimal signal to noise ratio $(>3)$ threshold and the desired mass accuracy $(<5 \mathrm{ppm})$, the software identified potential phase I and II TPs by comparing raw files from a sample and a standard (control). Full scan raw data files were searched (in Xcalibur software) for these exact masses and an elemental composition was obtained based on the observed mass. In the case where multiple elemental compositions were possible for an observed mass, mass error (in ppm) and knowledge obtained on the type of transformation in MetWorks software was used for the final structure selection. Targeted MS/MS was then performed on the identified TPs at 35,000 resolution and at varying levels of collision energies $(10,25$ and 35$)$ to obtain the best fragmentation patterns. At this point, the potentially identified molecule was fragmented in-silico using spectral interpretation software (Mass Frontier from Thermo 
Scientific, NJ, USA) to confirm the identity of the TPs using the accurate mass MS/MS data.

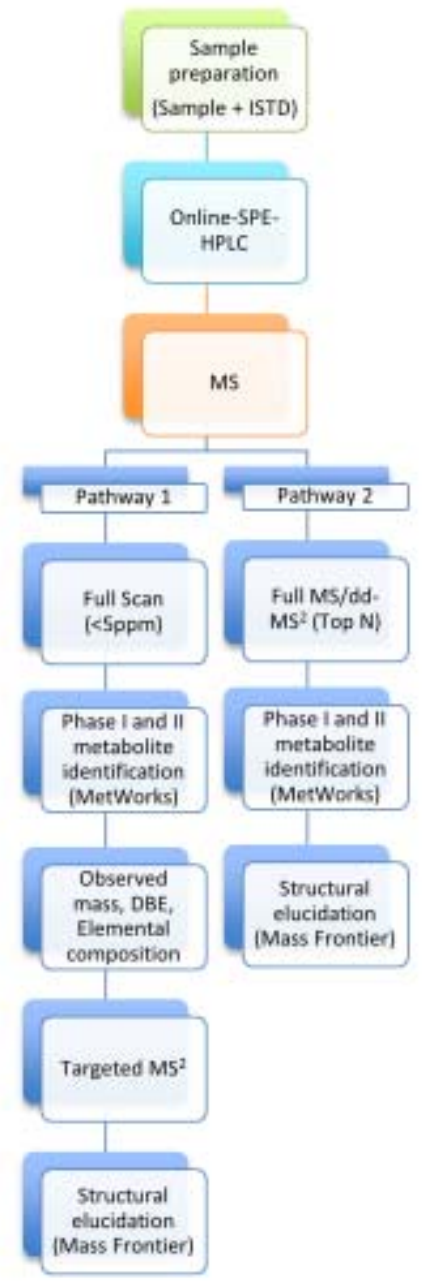

Fig. 3.1. Metabolite identification using two different operational modes in a Q Exactive Orbitrap.

In the second pathway, data was acquired in data dependent mode which includes a full scan $(\mathrm{m} / \mathrm{z} 100-\mathrm{m} / \mathrm{z} 500)$ at a resolving power of 70,000 followed by a MS/MS data dependent scan event (at 35,000 resolution) triggered by the set intensity threshold (AGC target $1 \times 10^{5}$ ) for the 3 most abundant precursor ions. Normalized collision energy (NCE) was set constant to 35 for MS/MS all selected ions. The full scan data was processed in MetWorks in the same way as explained before. For the identified TPs, 
acquired MS/MS data was compared with the theoretical spectra generated from the assigned chemical structure by the fragment ion search (FISh) feature in Mass Frontier software, similar to above. Similarities between the spectra, DBE along with isotope patterns were considered to help in the structural assignment of TPs. Detailed operating conditions of both the acquisition modes (targeted MS/MS and data dependent scan) are listed in Table 3.3.

Table 3.2. Phase I and phase II transformations and their exact masses.

\begin{tabular}{lcr}
\hline Modification $^{\text {a }}$ & Phase type & Exact mass \\
\hline Debenzylation & I & -90.047 \\
Decarboxylation & I & -43.9898 \\
Hydroxymethylene Loss & I & -30.0106 \\
Nitro Reduction & I & -29.9742 \\
Deethylation & I & -28.0313 \\
Alcohol Dehydration & I & -18.0106 \\
Sulfoxide to Thioether & I & -15.9949 \\
Isopropyl to Acid & I & -14.052 \\
Demethylation & I & -14.0157 \\
Desaturation & I & -2.0157 \\
Oxidation and Demethylation & I & -1.9793 \\
Saturation & I & 2.0157 \\
Hydroxylation and Desaturation & I & 13.9793 \\
Aromatic Hydroxylation & I & 15.9585 \\
Hydrolysis & I & 18.0106 \\
Demethylation to Carboxylic Acid & I & 29.9742 \\
Alkenes to Dihydrodiols & I & 34.0055 \\
\hline Methylation & II & 14.0157 \\
Hydroxylation and Methylation & II & 30.0106 \\
Acetylation & II & 42.0106 \\
Glycine Conjugation & II & 57.0215 \\
Taurine Conjugation & II & 107.0041 \\
Glutathion Conjugation & II & 305.0682 \\
Sulfation & II & 79.9568 \\
\hline${ }^{a}$ Suggested modification by MetWorks metabolic profiling software
\end{tabular}

${ }^{a}$ Suggested modification by MetWorks metabolic profiling software 
Table 3.3. Source, Full scan, and MS/MS operating conditions.

\begin{tabular}{|c|c|c|}
\hline PARAMETER & \multicolumn{2}{|r|}{ SETTING } \\
\hline Source & \multicolumn{2}{|r|}{${ }^{\mathrm{a}}$ HESI II } \\
\hline Capillary temperature $\left({ }^{\circ} \mathrm{C}\right)$ & \multicolumn{2}{|r|}{300} \\
\hline S-lens voltage & \multicolumn{2}{|r|}{50} \\
\hline Source voltage $(\mathrm{kV})$ & \multicolumn{2}{|r|}{3} \\
\hline \multicolumn{3}{|l|}{ FULL-MS PARAMETERS } \\
\hline Mass range $(\mathrm{m} / \mathrm{z})$ & \multicolumn{2}{|r|}{$100-500$} \\
\hline Resolution settings & \multicolumn{2}{|r|}{70,000} \\
\hline AGC Target & \multicolumn{2}{|r|}{$3 \times 10^{6}$} \\
\hline Max injection time (ms) & \multicolumn{2}{|r|}{200} \\
\hline $\begin{array}{l}\text { MS/MS PARAMETERS } \\
\text { HCD }\end{array}$ & $\begin{array}{l}\text { Targeted- } \\
\text { MS/MS }\end{array}$ & dd-MS/MS \\
\hline Resolution settings & 35,000 & 35,000 \\
\hline AGC Target & $2 \times 10^{4}$ & $1 \times 10^{5}$ \\
\hline Max injection time (ms) & 40 & 100 \\
\hline Isolation window (m/z) & 2 & 2 \\
\hline Collision energy NCE & $10,25,35$ & 35 \\
\hline Intensity threshold & -- & $1 \times 10^{5}(10.0 \%$ underfill $)$ \\
\hline Loop count & -- & 3 \\
\hline
\end{tabular}

\subsubsection{Concentration and mole fractions of TPs}

Trace Finder 3.0 (Thermo Scientific, NJ, USA) was used to calculate the concentration of all target analytes. Because of lack of available authentic standards for TPs and because of their structural similarity with the parent molecule, a relative response factor obtained for the parent DOAs was used to determine metabolite concentrations. Mole fractions of the parent DOAs and their TPs were calculated by taking the ratio of measured concentration to the molar masses. The mole fraction of each TP was computed for every sample and these values were used to compute standard deviation and average mole fraction. 


\subsection{Results and discussion}

\subsubsection{Transformation products of DOAs}

Initially 16 target analytes (DOAs) including 12 parent compounds and 4 of their metabolites were used to further identify 54 TPs in raw sewage influents. From the 12 parents, 45 TPs were identified. 7 of them were target analytes (parents and metabolites) leaving 38 remaining TPs. Out of the 38, 19 of them had an initial positive match (based on $\mathrm{m} / \mathrm{z}$ ) with other compounds. After further MS/MS analysis, it was determined that only 9 of them had a positive spectral match with other compounds (ephedrine, ethylamphetamine, methylone, and norbenzoylecgonine) from TraceFinder database and/or had been previously been reported $[27,35,36]$ (see table 3.4 ). Up to this point 29 TPs remained. 2 of the 29 TPs were formed from different parents; therefore, from 12 initial parents positive identification was obtained for 27 TPs. From the group of the 4 target metabolites, 9 TPs were originally identified. However, one of them resulted being benzoylecgonine $(\mathrm{BE})$ which had formed from cocaethylene $(\mathrm{CE}) .3$ of the remaining 8 had an initial positive match with other compounds. Nevertheless, none of them had a positive MS/MS spectral match. Hence, 8 TPs were identified from the 4 target metabolites. In the end and to our knowledge, a total of 35 TPs (never monitored in the environment) formed from 16 target analytes (12 parents and 4 metabolites) have been potentially identified. The overall description of the process is shown in Fig. 3.2. 


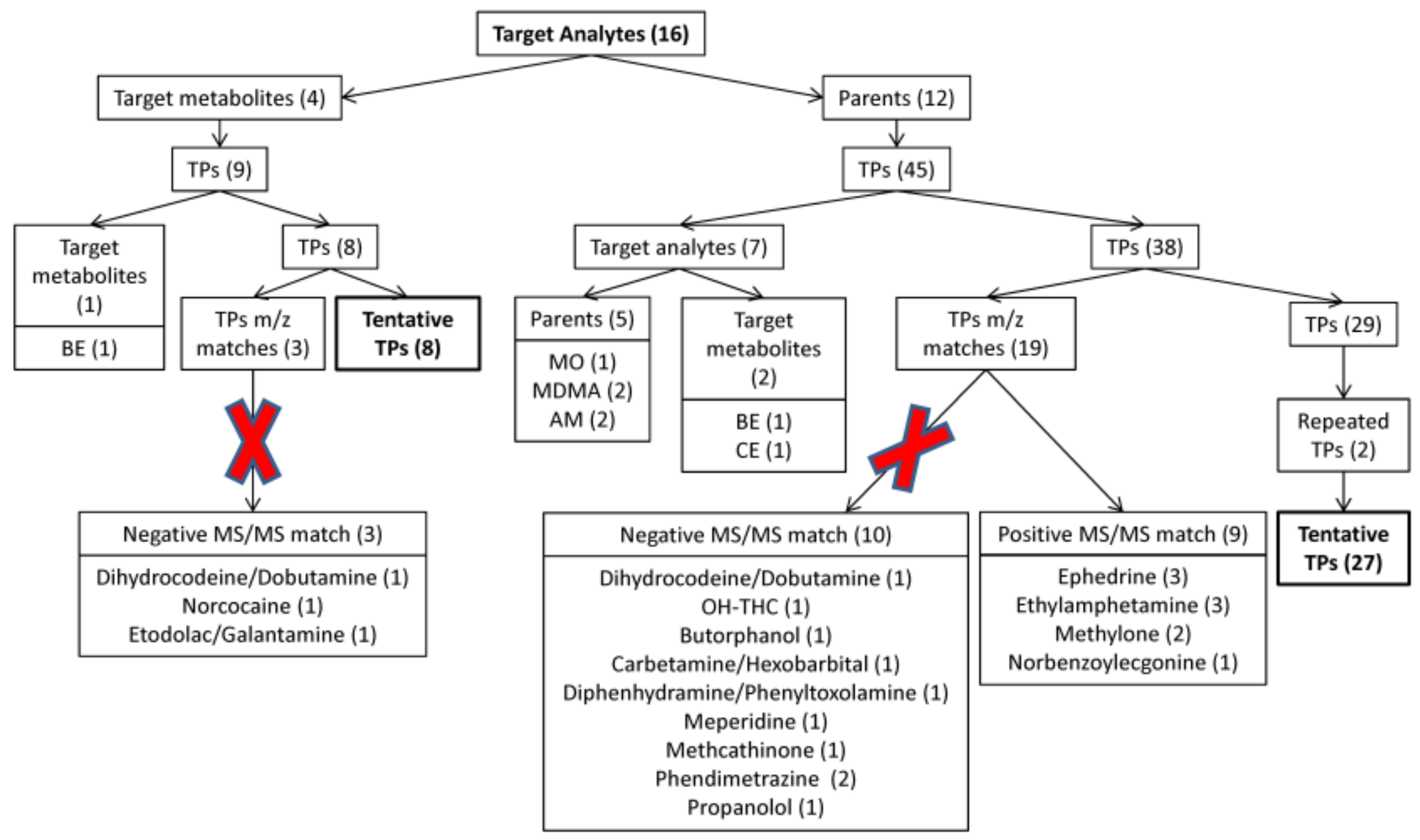

Fig. 3.2. Diagram distribution of 54 tentatively identified TPs divided in two main categories. TPs formed from parent DOAs (45), and TPs formed from target DOA metabolites (9). Parenthesis indicated number of TPs. X indicates TPs that had the same m/z as other compounds, but no spectral match. 
Table 3.4. MS/MS fragmentation for 9 TPs that had a positive spectral match with ephedrine, ethylamphetamine, methylone, and norbenzoylecgonine.

\begin{tabular}{|c|c|c|c|c|c|c|c|c|}
\hline NAME & $\begin{array}{l}\text { ELEMENTAL } \\
\text { FORMULA }\end{array}$ & $\begin{array}{c}\text { EXACT } \\
\text { MASS } \\
(\mathbf{m} / \mathbf{z})\end{array}$ & $\begin{array}{l}\text { OBSERVED } \\
\text { MASS (m/z) }\end{array}$ & $\begin{array}{l}\text { RETENTION } \\
\text { TIME }\end{array}$ & DBE & $\begin{array}{c}\text { MASS } \\
\text { ACCURACY } \\
(\text { ppm })\end{array}$ & COMPOUND MATCH & $\begin{array}{l}\text { REPORTED } \\
\operatorname{MASS}(\mathbf{m} / \mathbf{z})\end{array}$ \\
\hline \multirow[t]{6}{*}{ AM-4, MA-1, MDMA-3 } & $\mathrm{C}_{10} \mathrm{H}_{16} \mathrm{NO}$ & 166.1226 & 166.1223 & 11.55 & 3.5 & -1.8 & Ephedrine & 166.1232 \\
\hline & $\mathrm{C}_{7} \mathrm{H}_{7}$ & 91.0542 & 91.0548 & & 4.5 & 6.8 & & 91.0550 \\
\hline & $\mathrm{C}_{9} \mathrm{H}_{7}$ & 115.0542 & 115.0549 & & 6.5 & 5.8 & & 115.0547 \\
\hline & $\mathrm{C}_{9} \mathrm{H}_{11} \mathrm{~N}$ & 133.0886 & 133.0888 & & 5.0 & 1.3 & & 133.0891 \\
\hline & $\mathrm{C}_{10} \mathrm{H}_{14} \mathrm{~N}$ & 148.1120 & 148.1123 & & 4.5 & 0.8 & & 148.1126 \\
\hline & $\mathrm{C}_{9} \mathrm{H}_{9}$ & 117.0699 & 117.0703 & & 5.5 & 3.4 & & - \\
\hline \multirow[t]{6}{*}{ MA-4, MDEA-4, MDMA-5 } & $\mathrm{C}_{11} \mathrm{H}_{18} \mathrm{~N}$ & 164.1434 & 164.1431 & 12.03 & 3.5 & -1.8 & Ethylamphetamine & 164.1434 \\
\hline & $\mathrm{C}_{7} \mathrm{H}_{7}$ & 91.0542 & 91.0547 & & 4.5 & 5.5 & & 91.0542 \\
\hline & $\mathrm{C}_{9} \mathrm{H}_{11}$ & 119.0855 & 119.0858 & & 4.5 & 2.0 & & 119.0856 \\
\hline & $\mathrm{C}_{8} \mathrm{H}_{9}$ & 105.0699 & 105.0703 & & 4.5 & 4.0 & & - \\
\hline & $\mathrm{C}_{8} \mathrm{H}_{11} \mathrm{O}$ & 123.0804 & 123.0807 & & 3.5 & 2.1 & & - \\
\hline & $\mathrm{C}_{10} \mathrm{H}_{11} \mathrm{O}$ & 147.0804 & 147.0805 & & 5.5 & 0.4 & & - \\
\hline \multirow[t]{3}{*}{ MDEA-6, MDMA-4 } & $\mathrm{C}_{11} \mathrm{H}_{14} \mathrm{NO}_{3}$ & 208.0968 & 208.0969 & 11.72 & 5.5 & -0.2 & Methylone & 208.0968 \\
\hline & $\mathrm{C}_{10} \mathrm{H}_{10} \mathrm{NO}$ & 160.0757 & 160.0758 & & 6.5 & 0.7 & & 160.0756 \\
\hline & $\mathrm{C}_{11} \mathrm{H}_{12} \mathrm{NO}_{2}$ & 190.0862 & 190.0863 & & 6.5 & 0.2 & & 190.0861 \\
\hline \multirow[t]{5}{*}{$\mathrm{CO}-2$} & $\mathrm{C}_{15} \mathrm{H}_{18} \mathrm{NO}_{4}$ & 276.1230 & 276.1226 & 11.90 & 7.5 & -1.4 & Norbenzoylecgonine & 276.1229 \\
\hline & $\mathrm{C}_{8} \mathrm{H}_{12} \mathrm{NO}_{2}$ & 154.0862 & 154.0864 & & 3.5 & 0.6 & & 154.0853 \\
\hline & $\mathrm{C}_{8} \mathrm{H}_{10} \mathrm{NO}$ & 136.0757 & 136.0758 & & 4.5 & 1.8 & & 136.0744 \\
\hline & $\mathrm{C}_{7} \mathrm{H}_{5} \mathrm{O}$ & 105.0335 & 105.0338 & & 5.5 & 2.9 & & 105.0332 \\
\hline & $\mathrm{C}_{4} \mathrm{H}_{12} \mathrm{NO}_{2}$ & 106.0863 & 106.0867 & & -0.5 & 3.9 & & - \\
\hline
\end{tabular}


Table 3.5. Elemental composition, retention time, mass accuracy and the acquisition mode of identified TPs. Names in bold represent the parent molecule.

\begin{tabular}{|c|c|c|c|c|c|c|c|c|}
\hline Name & $\begin{array}{c}\text { Metabolite } \\
\text { type }\end{array}$ & $\begin{array}{l}\text { Elemental } \\
\text { formula }\end{array}$ & $\begin{array}{l}\text { Exact } \\
\text { mass } \\
(\mathbf{m} / \mathbf{z})\end{array}$ & $\begin{array}{c}\text { Observed } \\
\text { mass } \\
(\mathbf{m} / \mathbf{z})\end{array}$ & RT & DBE & $\begin{array}{c}\text { Mass } \\
\text { accuracy } \\
(\text { ppm) }\end{array}$ & MS/MS \\
\hline $\mathbf{A M}$ & & $\mathrm{C}_{9} \mathrm{H}_{14} \mathrm{~N}$ & 136.1121 & 136.1120 & 11.43 & 3.5 & -0.7 & $\mathrm{t}-\mathrm{MS}^{2}$ \\
\hline $\mathrm{AM}-1^{\mathrm{b}}$ & I & $\mathrm{C}_{8} \mathrm{H}_{12} \mathrm{~N}$ & 122.0964 & 122.0965 & 11.51 & 3.5 & 0.8 & $\mathrm{t}-\mathrm{MS}^{2}$ \\
\hline $\mathrm{AM}-2^{\mathrm{b}}$ & $\mathbf{I}$ & $\mathrm{C}_{9} \mathrm{H}_{16} \mathrm{NO}_{2}$ & 170.1176 & 170.1173 & 11.87 & 2.5 & -1.8 & $\mathrm{t}-\mathrm{MS}^{2}$ \\
\hline $\mathrm{AM}-3^{\mathrm{b}}$ & I & $\mathrm{C}_{9} \mathrm{H}_{16} \mathrm{NO}$ & 154.1226 & 154.1223 & 12.12 & 2.5 & -1.9 & $\mathrm{t}-\mathrm{MS}^{2}$ \\
\hline AM-4 (MA-1, MDMA-3) ${ }^{\mathrm{a}}$ & II & $\mathrm{C}_{10} \mathrm{H}_{16} \mathrm{NO}$ & 166.1226 & 166.1223 & 11.55 & 3.5 & -1.8 & $\mathrm{t}-\mathrm{MS}^{2}$ \\
\hline $\mathrm{AM}-5^{\mathrm{b}}$ & II & $\mathrm{C}_{19} \mathrm{H}_{29} \mathrm{~N}_{4} \mathrm{O}_{6} \mathrm{~S}$ & 441.1802 & 441.1810 & 12.05 & 7.5 & 1.8 & $\mathrm{t}-\mathrm{MS}^{2}$ \\
\hline AM- $6^{\mathrm{b}}$ & I & $\mathrm{C}_{8} \mathrm{H}_{12} \mathrm{NO}$ & 138.0913 & 138.0911 & 12.08 & 3.5 & -1.4 & $\mathrm{t}-\mathrm{MS}^{2}$ \\
\hline $\mathrm{AM}-7^{\mathrm{b}}$ & $\mathbf{I}$ & $\mathrm{C}_{7} \mathrm{H}_{10} \mathrm{NO}$ & 124.0757 & 124.0758 & 11.38 & 3.5 & 0.8 & $\mathrm{t}-\mathrm{MS}^{2}$ \\
\hline MDA & & $\mathrm{C}_{10} \mathrm{H}_{14} \mathrm{NO}_{2}$ & 180.1019 & 180.1015 & 11.82 & 4.5 & -2.2 & $\mathrm{t}-\mathrm{MS}^{2}$ \\
\hline MDA-1 (AM, MA-2) ${ }^{\mathrm{a}}$ & $\mathbf{I}$ & $\mathrm{C}_{9} \mathrm{H}_{14} \mathrm{~N}$ & 136.1121 & 136.1120 & 11.43 & 3.5 & -0.7 & $\mathrm{t}-\mathrm{MS}^{2} / \mathrm{DD}$ \\
\hline MDA- $2^{\mathrm{b}}$ & $\mathbf{I}$ & $\mathrm{C}_{10} \mathrm{H}_{14} \mathrm{NO}$ & 164.1070 & 164.1065 & 12.15 & 4.5 & -3.0 & $\mathrm{t}-\mathrm{MS}^{2}$ \\
\hline MDA- $3^{\mathrm{b}}$ & I & $\mathrm{C}_{10} \mathrm{H}_{14} \mathrm{NO}_{4}$ & 212.0917 & 212.0926 & 13.06 & 4.5 & 4.2 & $\mathrm{t}-\mathrm{MS}^{2}$ \\
\hline MDA-4 (MDMA, MDEA-2) ${ }^{\mathrm{a}}$ & II & $\mathrm{C}_{11} \mathrm{H}_{16} \mathrm{NO}_{2}$ & 194.1176 & 194.1174 & 11.92 & 4.5 & -1.0 & $\mathrm{t}-\mathrm{MS}^{2} / \mathrm{DD}$ \\
\hline MDA- $5^{\mathrm{b}}$ & II & $\mathrm{C}_{12} \mathrm{H}_{17} \mathrm{~N}_{2} \mathrm{O}_{3}$ & 237.1234 & 237.1230 & 11.51 & 5.5 & -1.7 & $\mathrm{t}-\mathrm{MS}^{2}$ \\
\hline MDA- $6^{\mathrm{b}}\left(\right.$ MDMA-1, COD-3) ${ }^{\mathrm{a}}$ & II & $\mathrm{C}_{11} \mathrm{H}_{16} \mathrm{NO}_{3}$ & 210.1125 & 210.1122 & 11.45 & 4.5 & -1.4 & $\mathrm{t}-\mathrm{MS}^{2}$ \\
\hline MDA- $7^{\mathrm{b}}$ & I & $\mathrm{C}_{10} \mathrm{H}_{10} \mathrm{NO}_{2}$ & 176.0706 & 176.0704 & 11.44 & 6.5 & -1.1 & $\mathrm{t}-\mathrm{MS}^{2}$ \\
\hline MDA- $8^{b}$ & $\mathbf{I}$ & $\mathrm{C}_{9} \mathrm{H}_{12} \mathrm{NO}_{3}$ & 182.0812 & 182.0808 & 11.68 & 4.5 & -2.2 & $\mathrm{t}-\mathrm{MS}^{2}$ \\
\hline MA & & $\mathrm{C}_{10} \mathrm{H}_{16} \mathrm{~N}$ & 150.1277 & 150.1275 & 11.80 & 3.5 & -1.3 & $\mathrm{t}-\mathrm{MS}^{2}$ \\
\hline MA-1 (AM-4, MDMA-3) ${ }^{\mathrm{a}}$ & I & $\mathrm{C}_{10} \mathrm{H}_{16} \mathrm{NO}$ & 166.1226 & 166.1223 & 11.56 & 3.5 & -1.8 & $\mathrm{t}-\mathrm{MS}^{2} / \mathrm{DD}$ \\
\hline MA-2 (AM, MDA-1) & $\mathbf{I}$ & $\mathrm{C}_{9} \mathrm{H}_{14} \mathrm{~N}$ & 136.1121 & 136.1120 & 11.40 & 3.5 & -0.7 & $\mathrm{t}-\mathrm{MS}^{2} / \mathrm{DD}$ \\
\hline $\mathrm{MA}-3^{\mathrm{b}}$ & I & $\mathrm{C}_{10} \mathrm{H}_{14} \mathrm{~N}$ & 148.1121 & 148.1118 & 11.50 & 4.5 & -2.0 & $\mathrm{t}-\mathrm{MS}^{2} / \mathrm{DD}$ \\
\hline MA-4 (MDEA-4, MDMA-5) & II & $\mathrm{C}_{11} \mathrm{H}_{18} \mathrm{~N}$ & 164.1434 & 164.1431 & 12.03 & 3.5 & -1.8 & $\mathrm{t}-\mathrm{MS}^{2}$ \\
\hline MA- $5^{\mathrm{b}}(\mathrm{MDEA}-5)^{\mathrm{a}}$ & II & $\mathrm{C}_{12} \mathrm{H}_{18} \mathrm{NO}$ & 192.1383 & 192.1378 & 12.30 & 4.5 & -2.6 & $\mathrm{t}-\mathrm{MS}^{2}$ \\
\hline MDEA & & $\mathrm{C}_{12} \mathrm{H}_{18} \mathrm{NO}_{2}$ & 208.1332 & 208.1329 & 11.97 & 4.5 & -1.4 & $\mathrm{t}-\mathrm{MS}^{2}$ \\
\hline MDEA-1 $1^{\mathrm{b}}$ & $\mathbf{I}$ & $\mathrm{C}_{12} \mathrm{H}_{18} \mathrm{NO}_{3}$ & 224.1281 & 224.1278 & 11.50 & 4.5 & -1.3 & $\mathrm{t}-\mathrm{MS}^{2}$ \\
\hline MDEA-2 (MDMA, MDA-4) ${ }^{\mathrm{a}}$ & $\mathbf{I}$ & $\mathrm{C}_{11} \mathrm{H}_{16} \mathrm{NO}_{2}$ & 194.1176 & 194.1174 & 11.92 & 4.5 & -1.0 & $\mathrm{t}-\mathrm{MS}^{2} / \mathrm{DD}$ \\
\hline MDEA-3 $3^{b}$ & $\mathbf{I}$ & $\mathrm{C}_{12} \mathrm{H}_{20} \mathrm{~N}$ & 178.1590 & 178.1587 & 12.10 & 3.5 & -1.7 & $\mathrm{t}-\mathrm{MS}^{2}$ \\
\hline MDEA-4 (MA-4, MDMA-5) ${ }^{\mathrm{a}}$ & $\mathbf{I}$ & $\mathrm{C}_{11} \mathrm{H}_{18} \mathrm{~N}$ & 164.1434 & 164.1431 & 12.01 & 3.5 & -1.8 & $\mathrm{t}-\mathrm{MS}^{2} / \mathrm{DD}$ \\
\hline MDEA-5 ${ }^{\mathrm{b}}(\mathrm{MA}-5)^{\mathrm{a}}$ & $\mathbf{I}$ & $\mathrm{C}_{12} \mathrm{H}_{18} \mathrm{NO}$ & 192.1383 & 192.1378 & 12.30 & 4.5 & -2.6 & $\mathrm{t}-\mathrm{MS}^{2}$ \\
\hline MDEA-6 (MDMA-4) ${ }^{\mathrm{a}}$ & I & $\mathrm{C}_{11} \mathrm{H}_{14} \mathrm{NO}_{3}$ & 208.0968 & 208.0968 & 11.72 & 5.5 & 0.0 & $\mathrm{t}-\mathrm{MS}^{2} / \mathrm{DD}$ \\
\hline MDEA- $7^{\mathrm{b}}$ & II & $\mathrm{C}_{14} \mathrm{H}_{21} \mathrm{~N}_{2} \mathrm{O}_{3}$ & 265.1547 & 265.1545 & 11.68 & 5.5 & -0.8 & DD \\
\hline MDMA & & $\mathrm{C}_{11} \mathrm{H}_{16} \mathrm{NO}_{2}$ & 194.1176 & 194.1174 & 11.90 & 4.5 & -1.0 & $\mathrm{t}-\mathrm{MS}^{2}$ \\
\hline MDMA- $1^{\mathrm{b}}(\mathrm{MDA}-6, \mathrm{COD}-3)^{\mathrm{a}}$ & $\mathbf{I}$ & $\mathrm{C}_{11} \mathrm{H}_{16} \mathrm{NO}_{3}$ & 210.1125 & 210.1122 & 11.40 & 4.5 & -1.4 & $\mathrm{t}-\mathrm{MS}^{2} / \mathrm{DD}$ \\
\hline MDMA- $2^{\mathrm{b}}$ & $\mathbf{I}$ & $\mathrm{C}_{11} \mathrm{H}_{14} \mathrm{NO}_{2}$ & 192.1019 & 192.1015 & 11.60 & 5.5 & -2.1 & $\mathrm{t}-\mathrm{MS}^{2} / \mathrm{DD}$ \\
\hline MDMA-3 (AM-4, MA-1) ${ }^{\mathrm{a}}$ & $\mathbf{I}$ & $\mathrm{C}_{10} \mathrm{H}_{16} \mathrm{NO}$ & 166.1226 & 166.1223 & 11.56 & 3.5 & -1.8 & $\mathrm{t}-\mathrm{MS}^{2} / \mathrm{DD}$ \\
\hline MDMA-4 (MDEA-6) & $\mathbf{I}$ & $\mathrm{C}_{11} \mathrm{H}_{14} \mathrm{NO}_{3}$ & 208.0968 & 208.0964 & 11.69 & 5.5 & -1.9 & $\mathrm{t}-\mathrm{MS}^{2} / \mathrm{DD}$ \\
\hline MDMA-5 (MA-4, MDEA-4) ${ }^{\mathrm{a}}$ & $\mathbf{I}$ & $\mathrm{C}_{11} \mathrm{H}_{18} \mathrm{~N}$ & 164.1434 & 164.1433 & 12.05 & 3.5 & -0.6 & $\mathrm{t}-\mathrm{MS}^{2} / \mathrm{DD}$ \\
\hline $\mathrm{CO}$ & & $\mathrm{C}_{17} \mathrm{H}_{22} \mathrm{NO}_{4}$ & 304.1543 & 304.1544 & 12.16 & 7.5 & 0.3 & $\mathrm{t}-\mathrm{MS}^{2}$ \\
\hline $\mathrm{CO}-1^{\mathrm{b}}$ & $\mathbf{I}$ & $\mathrm{C}_{16} \mathrm{H}_{22} \mathrm{NO}_{2}$ & 260.1645 & 260.1640 & 12.70 & 6.5 & -1.9 & $\mathrm{t}-\mathrm{MS}^{2} / \mathrm{DD}$ \\
\hline $\mathrm{CO}-2$ & I & $\mathrm{C}_{15} \mathrm{H}_{18} \mathrm{NO}_{4}$ & 276.1230 & 276.1226 & 11.90 & 7.5 & -1.4 & $\mathrm{t}-\mathrm{MS}^{2}$ \\
\hline BE & & $\mathrm{C}_{16} \mathrm{H}_{20} \mathrm{NO}_{4}$ & 290.1387 & 290.1381 & 11.96 & 7.5 & -2.1 & $\mathrm{t}-\mathrm{MS}^{2} / \mathrm{DD}$ \\
\hline $\mathrm{BE}-1^{\mathrm{b}}$ & $\mathbf{I}$ & $\mathrm{C}_{15} \mathrm{H}_{20} \mathrm{NO}_{2}$ & 246.1489 & 246.1483 & 12.60 & 6.5 & -2.4 & $\mathrm{t}-\mathrm{MS}^{2} / \mathrm{DD}$ \\
\hline $\mathrm{BE}-2^{\mathrm{b}}$ & $\mathbf{I}$ & $\mathrm{C}_{16} \mathrm{H}_{22} \mathrm{NO}_{5}$ & 308.1492 & 308.1481 & 11.80 & 6.5 & -3.6 & $\mathrm{t}-\mathrm{MS}^{2}$ \\
\hline $\mathrm{BE}-3^{\mathrm{b}}$ & I & $\mathrm{C}_{16} \mathrm{H}_{18} \mathrm{NO}_{4}$ & 288.1230 & 288.1226 & 11.40 & 8.5 & -1.4 & $\mathrm{t}-\mathrm{MS}^{2}$ \\
\hline $\mathbf{C E}$ & & $\mathrm{C}_{18} \mathrm{H}_{24} \mathrm{NO}_{4}$ & 318.1700 & 318.1689 & 12.38 & 7.5 & -3.5 & $\mathrm{t}-\mathrm{MS}^{2}$ \\
\hline CE-1 $(\mathrm{BE})^{\mathrm{a}}$ & I & $\mathrm{C}_{16} \mathrm{H}_{20} \mathrm{NO}_{4}$ & 290.1387 & 290.1381 & 11.96 & 7.5 & -2.1 & $\mathrm{t}-\mathrm{MS}^{2}$ \\
\hline $\mathrm{CE}-2^{\mathrm{b}}$ & I & $\mathrm{C}_{18} \mathrm{H}_{26} \mathrm{NO}_{6}$ & 352.1755 & 352.1743 & 11.80 & 6.5 & -3.4 & $\mathrm{t}-\mathrm{MS}^{2}$ \\
\hline CE-3 & I & $\mathrm{C}_{17} \mathrm{H}_{22} \mathrm{NO}_{3}$ & 288.1594 & 288.1588 & 12.50 & 7.5 & -2.1 & $\mathrm{t}-\mathrm{MS}^{2}$ \\
\hline $\mathrm{CE}-4^{\mathrm{b}}(\mathrm{COD}-2)^{\mathrm{a}}$ & I & $\mathrm{C}_{18} \mathrm{H}_{24} \mathrm{NO}_{3}$ & 302.1751 & 302.1743 & 12.40 & 7.5 & -2.6 & $\mathrm{t}-\mathrm{MS}^{2}$ \\
\hline OXY & & $\mathrm{C}_{18} \mathrm{H}_{22} \mathrm{NO}_{4}$ & 316.1543 & 316.1537 & 11.67 & 8.5 & -1.9 & $\mathrm{t}-\mathrm{MS}^{2}$ \\
\hline$O X Y-1^{b}$ & I & $\mathrm{C}_{15} \mathrm{H}_{22} \mathrm{NO}_{2}$ & 248.1670 & 248.1674 & 12.70 & 5.5 & 1.6 & $\mathrm{t}-\mathrm{MS}^{2}$ \\
\hline COD & & $\mathrm{C}_{18} \mathrm{H}_{22} \mathrm{NO}_{3}$ & 300.1594 & 300.1586 & 11.50 & 8.5 & -2.7 & $\mathrm{t}-\mathrm{MS}^{2}$ \\
\hline
\end{tabular}




\begin{tabular}{|c|c|c|c|c|c|c|c|c|}
\hline Name & $\begin{array}{c}\text { Metabolite } \\
\text { type }\end{array}$ & $\begin{array}{l}\text { Elemental } \\
\text { formula }\end{array}$ & $\begin{array}{l}\text { Exact } \\
\text { mass } \\
(\mathbf{m} / \mathbf{z}) \\
\end{array}$ & $\begin{array}{c}\text { Observed } \\
\text { mass } \\
(\mathbf{m} / \mathbf{z}) \\
\end{array}$ & RT & DBE & $\begin{array}{c}\text { Mass } \\
\text { accuracy } \\
\text { (ppm) }\end{array}$ & MS/MS \\
\hline COD-1 (MO) ${ }^{\mathrm{a}}$ & $\mathbf{I}$ & $\mathrm{C}_{17} \mathrm{H}_{20} \mathrm{NO}_{3}$ & 286.1438 & 286.1431 & 11.24 & 8.5 & -2.4 & $\mathrm{t}-\mathrm{MS}^{2}$ \\
\hline $\mathrm{COD}-2^{\mathrm{b}}(\mathrm{CE}-4)^{\mathrm{a}}$ & $\mathbf{I}$ & $\mathrm{C}_{18} \mathrm{H}_{24} \mathrm{NO}_{3}$ & 302.1751 & 302.1744 & 12.40 & 7.5 & -2.3 & $\mathrm{t}-\mathrm{MS}^{2} / \mathrm{DD}$ \\
\hline COD-3 ${ }^{\mathrm{b}}$ (MDA-6, MDMA-1) ${ }^{\mathrm{a}}$ & $\mathbf{I}$ & $\mathrm{C}_{11} \mathrm{H}_{16} \mathrm{NO}_{3}$ & 210.1125 & 210.1122 & 11.45 & 4.5 & -1.4 & $\mathrm{t}-\mathrm{MS}^{2} / \mathrm{DD}$ \\
\hline MO & & $\mathrm{C}_{17} \mathrm{H}_{20} \mathrm{NO}_{3}$ & 286.1438 & 286.1431 & 11.26 & 8.5 & -2.4 & $\mathrm{t}-\mathrm{MS}^{2}$ \\
\hline $\mathrm{MO}-1^{\mathrm{b}}$ & $\mathbf{I}$ & $\mathrm{C}_{17} \mathrm{H}_{22} \mathrm{NO}$ & 256.1696 & 256.1690 & 12.50 & 7.5 & -2.3 & $\mathrm{t}-\mathrm{MS}^{2}$ \\
\hline ME & & $\mathrm{C}_{21} \mathrm{H}_{28} \mathrm{NO}$ & 310.2165 & 310.2156 & 13.21 & 8.5 & -2.9 & $\mathrm{t}-\mathrm{MS}^{2}$ \\
\hline ME- $1^{b}$ & $\mathbf{I}$ & $\mathrm{C}_{21} \mathrm{H}_{30} \mathrm{NO}_{2}$ & 328.2271 & 328.2283 & 12.20 & 7.5 & 3.7 & $\mathrm{t}-\mathrm{MS}^{2}$ \\
\hline $\mathrm{ME}-2^{\mathrm{b}}$ & II & $\mathrm{C}_{23} \mathrm{H}_{33} \mathrm{~N}_{2} \mathrm{O}_{3} \mathrm{~S}$ & 417.2206 & 417.2206 & 11.90 & 8.5 & 0.0 & $\mathrm{t}-\mathrm{MS}^{2}$ \\
\hline EDDP & & $\mathrm{C}_{20} \mathrm{H}_{24} \mathrm{~N}$ & 278.1903 & 278.1894 & 12.80 & 9.5 & -3.2 & $\mathrm{t}-\mathrm{MS}^{2}$ \\
\hline EDDP- $1^{\mathrm{b}}$ & $\mathbf{I}$ & $\mathrm{C}_{20} \mathrm{H}_{22} \mathrm{NO}_{2}$ & 308.1645 & 308.1643 & 12.40 & 10.5 & -0.6 & $\mathrm{t}-\mathrm{MS}^{2}$ \\
\hline LSD & & $\mathrm{C}_{20} \mathrm{H}_{26} \mathrm{~N}_{3} \mathrm{O}$ & 324.2070 & 324.2060 & 12.20 & 9.5 & -3.1 & $\mathrm{t}-\mathrm{MS}^{2}$ \\
\hline LSD $-1^{\mathrm{b}}$ & $\mathbf{I}$ & $\mathrm{C}_{20} \mathrm{H}_{24} \mathrm{~N}_{3} \mathrm{O}$ & 322.1914 & 322.1913 & 11.60 & 10.5 & -0.3 & $\mathrm{t}-\mathrm{MS}^{2} / \mathrm{DD}$ \\
\hline $\operatorname{LSD}^{\mathrm{b}}{ }^{\mathrm{b}}$ & $\mathbf{I}$ & $\mathrm{C}_{20} \mathrm{H}_{24} \mathrm{~N}_{3}$ & 306.1965 & 306.1962 & 11.50 & 10.5 & -1.0 & $\mathrm{t}-\mathrm{MS}^{2} / \mathrm{DD}$ \\
\hline$\Delta-9-T H C$ & & $\mathrm{C}_{21} \mathrm{H}_{31} \mathrm{O}_{2}$ & 315.2319 & 315.2307 & 13.50 & 6.5 & -3.8 & $\mathrm{t}-\mathrm{MS}^{2}$ \\
\hline THC- $1^{\mathrm{b}}$ & $\mathbf{I}$ & $\mathrm{C}_{19} \mathrm{H}_{25} \mathrm{O}_{3}$ & 301.1798 & 301.1790 & 12.20 & 7.5 & -2.7 & $\mathrm{t}-\mathrm{MS}^{2} / \mathrm{DD}$ \\
\hline THC- $2^{\mathrm{b}}$ & $\mathbf{I}$ & $\mathrm{C}_{21} \mathrm{H}_{31} \mathrm{O}_{3}$ & 331.2268 & 331.2259 & 12.40 & 6.5 & -2.7 & DD \\
\hline ТНС-СООН & & $\mathrm{C}_{21} \mathrm{H}_{29} \mathrm{O}_{4}$ & 345.2060 & 345.2059 & 13.18 & 7.5 & -0.3 & DD \\
\hline THC-COOH-1 ${ }^{\mathrm{b}}$ & $\mathbf{I}$ & $\mathrm{C}_{17} \mathrm{H}_{21} \mathrm{O}_{5}$ & 305.1384 & 305.1379 & 11.49 & 7.5 & -1.6 & DD \\
\hline
\end{tabular}

Table 3.5 shows the elemental composition, retention time, mass accuracy and the acquisition mode for all of the identified DOAs and their TPs. The majority of the identified metabolites (45 out of 54) were phase I transformations, which could happen both inside human body and also in the environment. For all the TPs, the mass error between the observed mass and exact mass was less than $4.2 \mathrm{ppm}$. Observed phase II transformations included acetyl, glycine, glutathione and taurine conjugations. Acetyl conjugates of sulfomethoxazole have also been reported for reclaimed waters from South Florida WWTP [37].

\subsubsection{Structural elucidation of transformation products}

Amphetamine was chosen as the target analyte to show the steps in structure elucidation using pathway 1 shown in Fig. 3.1. In short, raw sewage water samples were run in full scan mode at high resolution and processed in the MetWorks software, which identified 7 (5-phase I and 2-phase II) possible TPs of amphetamine. A sample 
chromatogram of amphetamine and one of its phase II metabolite (AM-2, m/z 170.1176) is shown in Fig. 3.3. Then it's observed mass, corresponding elemental composition, DBE and mass error was recorded in Xcalibur software. Using this information and the type of transformation, a preliminary structure was proposed. Next, targeted MS/MS was performed for m/z 170.1176 with varying collision energies. The MS/MS spectra showed $\mathrm{m} / \mathrm{z} 138.0915,110.0604,95.0860$ and 85.0653 as abundant fragments (Fig. 3.4). The Fragment ion search (FISh) algorithm in Mass Frontier software was run in-silico with the proposed structure. As a result, all the fragments observed in the MS/MS spectra were explained and a mechanism of formation of the TP from the parent molecule could be elaborated. As shown in the Fig. 3.4, the mass error for all the fragments was less than $0.8 \mathrm{ppm}$ validating the structural assignment for the transformation product $\mathrm{m} / \mathrm{z}$ 170.1176 .

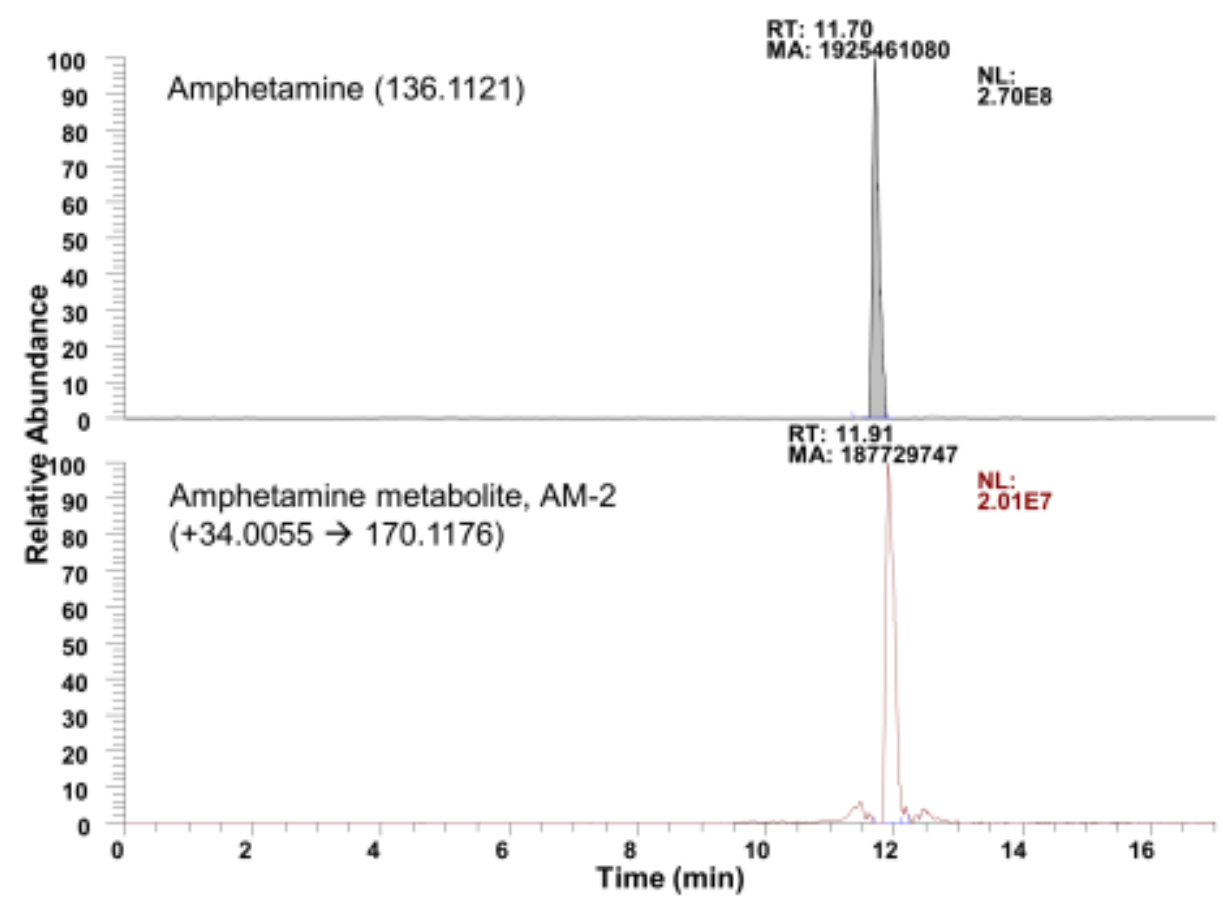

Fig. 3.3. LC-Q Exactive Orbitrap extracted ion chromatograms (XICs) of amphetamine ( $\mathrm{m} / \mathrm{z}$ 136.1121) and its metabolite $(\mathrm{m} / \mathrm{z} 170.1176)$ in a sewage water sample. 


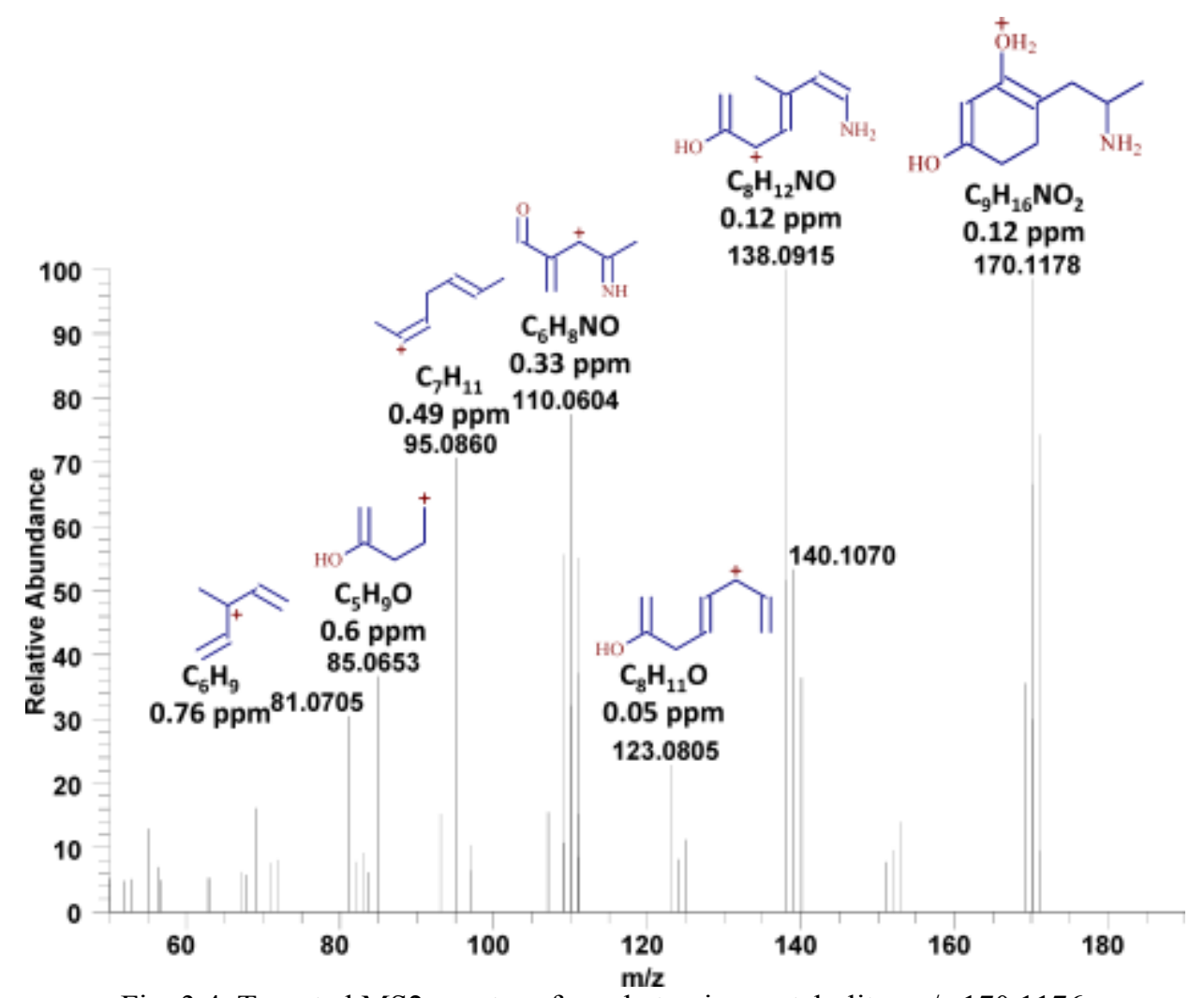

Fig. 3.4. Targeted MS2 spectra of amphetamine metabolite, m/z 170.1176.

The structure proposed for another metabolite, $\mathrm{m} / \mathrm{z} 166.1226$ identified as a TP from amphetamine (AM-4), methamphetamine (MA-1), and, MDMA (MDMA-3), matches with a known compound; ephedrine. Moreover, the abundant fragments observed in MS/MS spectra, m/z 148.1121, m/z 133.0887 and 117.0701 also match with those generated by the FISh search for ephedrine, with mass errors less than $0.2 \mathrm{ppm}$ and with those reported by Bijlsma group [22]. In addition, ephedrine reference standard was obtained, and MS/MS fragmentation was performed for validation purposes (Fig. 3.5). It is important to keep in mind that since ephedrine and MA-4 share the spectral information, it is not possible to identify the exact source of the signal. MS/MS spectral confirmation against reference standards was also done for n-ethylamphetamine and norcocaine (See appendices 1 and 2). 

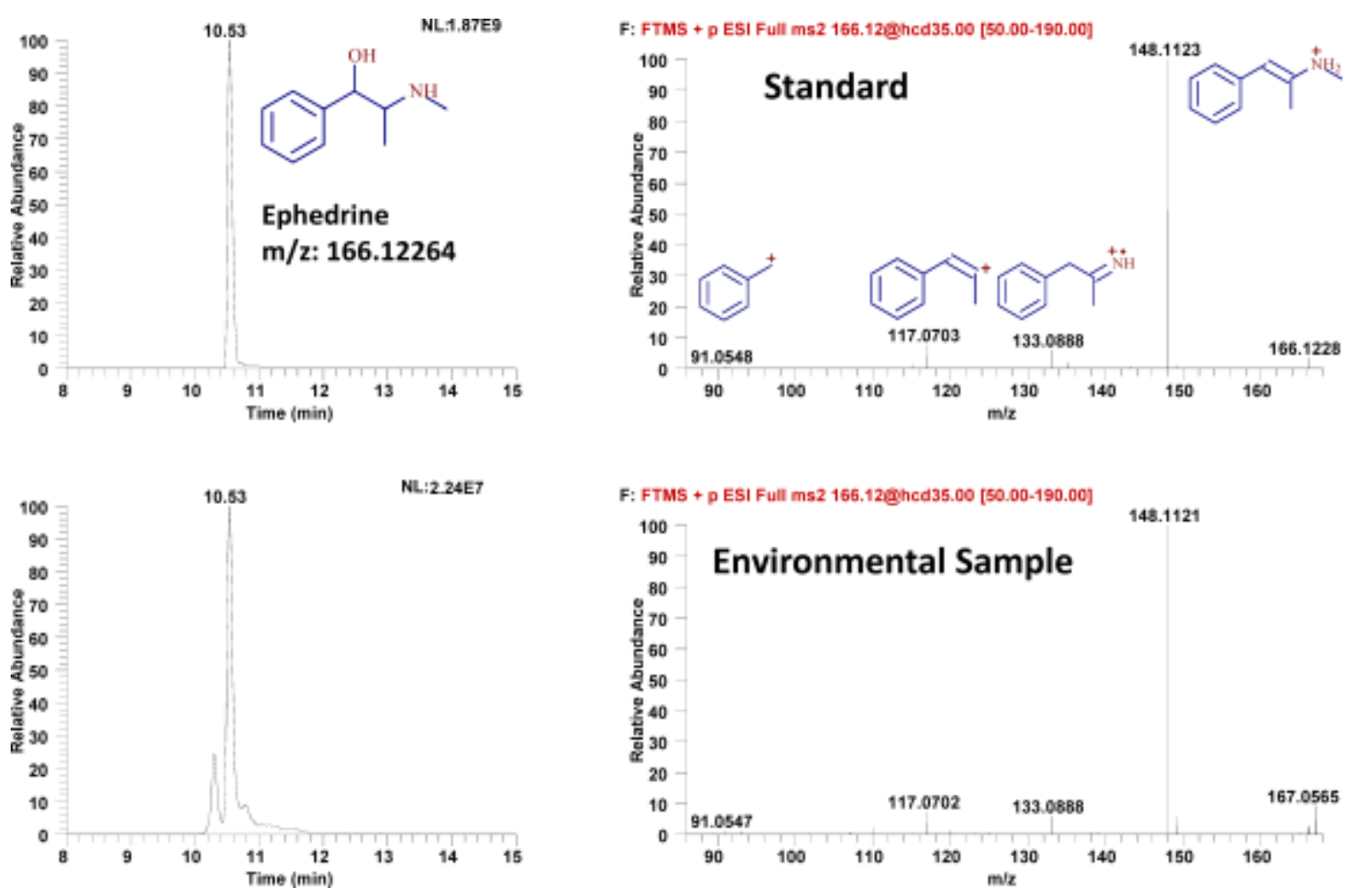

Fig. 3.5. Targeted MS2 spectra of amphetamine metabolite, m/z 166.1226.

MetWorks also identified an acetylation conjugate of amphetamine at m/z 178.1226. However, a sympathomimetic drug, phenmetrazine has the same exact mass but these two molecules are structurally very different. The MS/MS of m/z 178.1226 yielded two major fragments at m/z 146.0601 and m/z 119.0494, which could only be explained with confidence (mass error $<0.3 \mathrm{ppm}$ ) using phenmetrazine and therefore the acetyl conjugate was not included in the list of metabolites for amphetamine.

Methamphetamine (MA) produced a total of 5 TPs (MA-1 - MA-5), 3 phase-I and 2 phase-II. Fig. 3.6 demonstrates tentative chemical structures, formulas, and possible pathways of TP formation. Briefly, MA-1 (ephedrine) is shown a hydroxylation product of methamphetamine. MA-1 undergoes further dehydroxylation forming MA-3. MA-2 
(amphetamine), as it has previously been demonstrated, is a demethylation product methamphetamine [13]. The remaining phase II metabolites shown, come from methylation and acetylation processes. All these examples prove that tandem mass spectrometry data in combination with high resolution accurate mass measurements is valuable in producing accurate structural assignment of unknown metabolites. MS/MS spectral elucidation for all target analytes (parents and metabolites) and some of the identified TPs, showing tentative structure, chemical formulas, and mass error (ppm); and MS/MS spectra for all 54 TPs is provided in appendix 3.

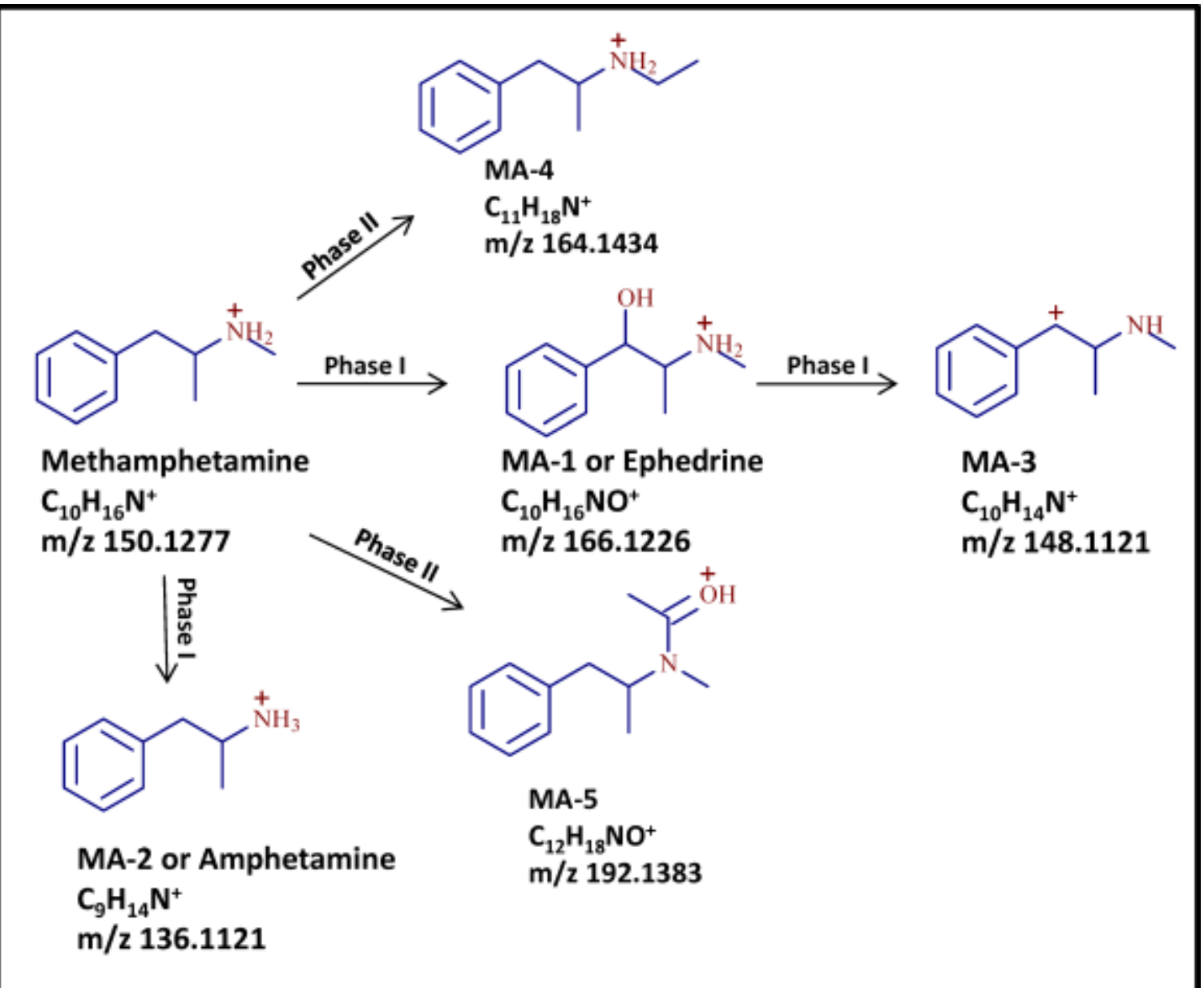

Fig. 3.6. Methamphetamine's tentative transformation pathway of five identified TPs, including proposed structure, chemical formula, accurate mass $(\mathrm{m} / \mathrm{z})$, and type of transformation. 
Other researchers from our group used pathway 2 (Fig. 3.1) for the identification of metabolites of antibiotics in reclaimed waters. Acetyl-sulfamethoxazole and desmethyl anhydroerythromycin was found as the major metabolite and theoretical fragments generated by FISh (from Mass Frontier) provided a good correlation with the observed MS/MS spectra from data dependent scan [38]. Because the success of pathway 2 may be related to analyte concentration and chromatographic separation a comparison was conducted using the same samples.

\subsubsection{Comparison of data acquisition modes}

The two acquisition modes used for generating the data in the present study are targeted MS/MS (pathway 1) and data dependent scan (pathway 2). Identical samples were run in both the modes for comparison. The pathway 1 is longer and needs two injections per sample, one for full scan and the other for MS/MS whereas the pathway 2 is completely automated and requires only one run. An initial full scan performed in both pathways under same settings yielded $\sim 50$ transformation products (in MetWorks), most

of them being similar. However, it was only possible to "shortlist" half of the TPs identified from the data dependent acquisition due to the small number of successful MS/MS scans across the chromatographic peaks (Fig. 3.7). Since MS/MS event is intensity threshold driven in data dependent scan, one must be very careful in choosing the detection thresholds and isolation-time events. One approach is to set a low threshold value $\left(2 \times 10^{4}\right)$ to allow the detection of low abundant TPs; however, this approach leads to the collection of unnecessary background ions. The other approach is to set a high 
threshold value $\left(5 \times 10^{6}\right)$ to remove the majority of the background noise by acquiring less MS/MS spectra at the expense of losing a large array of meaningful TPs [39].

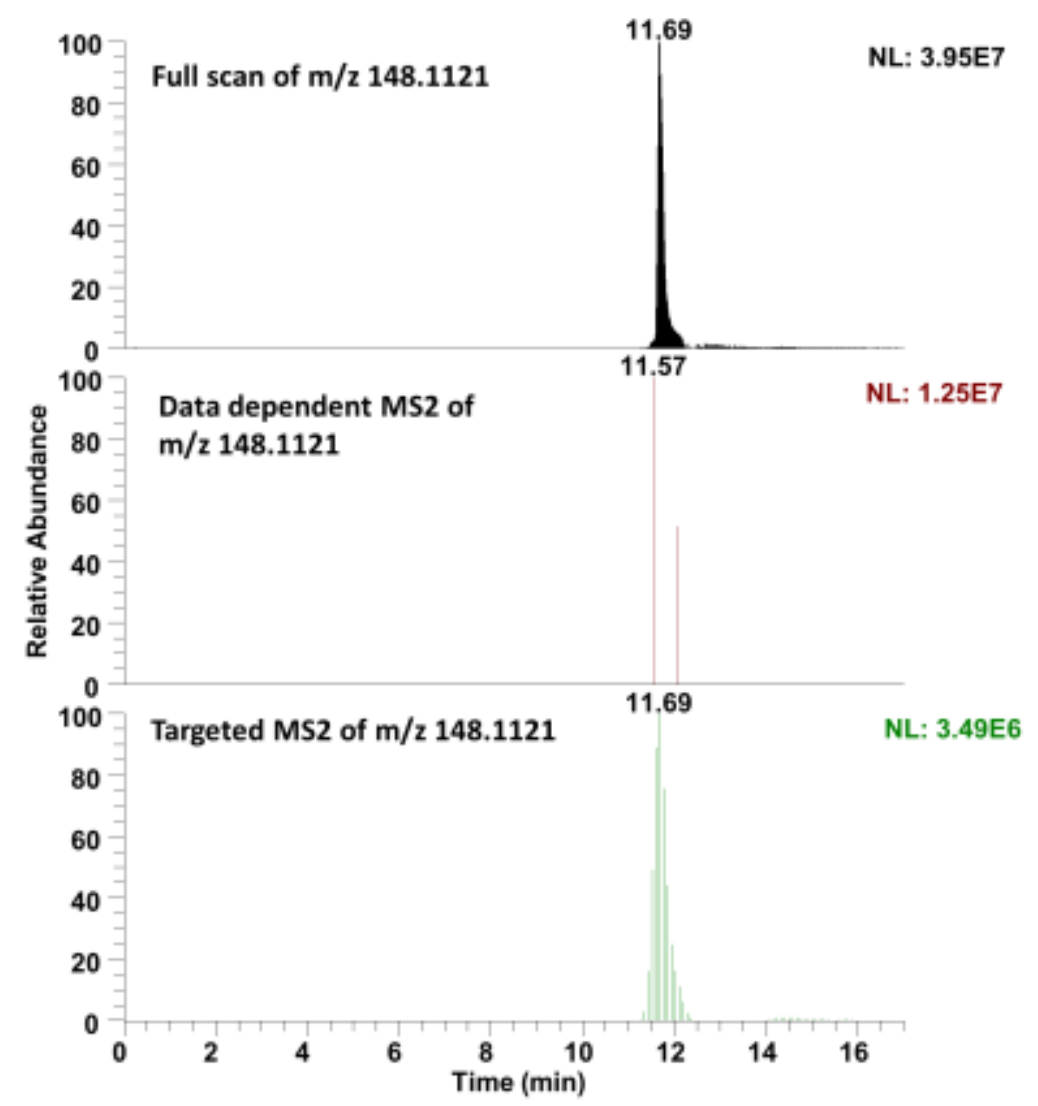

Fig. 3.7. Comparison of number of scans obtained in full scan, targeted MS2 and data dependent MS2 for one of the most abundant TP of Methamphetamine, MA-3 (m/z 148.1121).

One drawback of FTMS instruments such as the Orbitrap is that quality of MS/MS data gets compromised as the acquisition time decreases, which is likely the limitation for data dependent scans at low concentrations. However, this scan mode is still a powerful tool to acquire the data provided the intensity of the TPs is high enough and the chromatographic resolution is good. Moreover, one of the main advantages of datadependent acquisition mode is the ability to obtain MS/MS fragmentation for all precursors above the specified threshold, facilitating the search for any other possible 
analytes and transformation products of interest (full scan) plus their fragment ions without the need to run again. Some examples of this advantage include caffeine $(\mathrm{m} / \mathrm{z}$ : 195.0877, $0.01 \mathrm{ppm})$, the aromatic hydroxylation product of sulfadimidine $(\mathrm{m} / \mathrm{z}$ : $295.0860,0.28 \mathrm{ppm})$, and the aromatic hydroxylation product of propyphenazone $(\mathrm{m} / \mathrm{z}$ : $247.1438,1.19 \mathrm{ppm})$, which were identified at a later time but were not part of this study. For low-abundance TPs, data acquisition using pathway 1 is the preferred method of choice and was used in the present study to report mole fractions of TPs shown in Table 3.6 .

Table 3.6. Percent frequency of detection and mole fraction of the identified TPs.

\begin{tabular}{|c|c|c|c|}
\hline NAME & $\begin{array}{c}\text { FREQUENCY OF } \\
\text { DETECTION }(n=12)\end{array}$ & $\begin{array}{l}\% \text { MOLE } \\
\text { FRACTION }\end{array}$ & SD \\
\hline EDDP $^{\mathbf{a}}$ & 0 & 0.0 & 0.0 \\
\hline EDDP-1 & 58 & 58 & 51 \\
\hline LSD & 0 & 0.0 & 0.0 \\
\hline LSD-1 & 100 & 42 & 0.5 \\
\hline LSD-2 & 100 & 58 & 0.5 \\
\hline ME & 0 & 0.0 & 0.0 \\
\hline ME-1 & 100 & 81 & 20 \\
\hline ME-2 & 58 & 19 & 20 \\
\hline $\mathrm{EDDP}^{\mathrm{a}}$ & 0 & 0.0 & 0.0 \\
\hline OXY & 0 & 0.0 & 0.0 \\
\hline OXY-1 & 100 & 100 & 0.0 \\
\hline$\Delta-9-$ ТHC & 0 & 0.0 & 0.0 \\
\hline THC-1 & 25 & 25 & 45 \\
\hline $\mathbf{C E} \mathbf{E}^{\mathbf{a}}$ & 8 & 0.4 & 1.5 \\
\hline $\mathrm{CE}-1(\mathrm{BE})^{\mathrm{b}}$ & 92 & 6.0 & 4.7 \\
\hline CE-2 & 58 & 3.3 & 3.0 \\
\hline CE-3 & 100 & 28 & 15 \\
\hline CE-4 & 100 & 62 & 16 \\
\hline MA & 25 & 0.5 & 0.9 \\
\hline MA-1 (AM-4, MDMA-3) $)^{\mathrm{b}}$ & 42 & 3.1 & 4.1 \\
\hline MA-2 (AM, MDA-1) ${ }^{\mathrm{b}}$ & 100 & 27 & 10 \\
\hline MA-3 & 100 & 21 & 15 \\
\hline MA-4 (MDEA-4, MDMA-5) & 92 & 4.9 & 3.7 \\
\hline MA-5 (MDEA-5) ${ }^{\mathrm{b}}$ & 100 & 43 & 18 \\
\hline MDEA & 42 & 1.1 & 1.6 \\
\hline MDEA-1 & 58 & 1.3 & 1.5 \\
\hline MDEA-2 (MDMA, MDA-4) ${ }^{\mathrm{b}}$ & 100 & 15 & 6.8 \\
\hline MDEA-3 & 25 & 0.5 & 0.9 \\
\hline MDEA-4 (MA-4, MDMA-5) & 92 & 9.2 & 7.8 \\
\hline MDEA-5 (MA-5) ${ }^{\mathrm{b}}$ & 100 & 67 & 13 \\
\hline MDEA-6 (MDMA-4) ${ }^{\mathrm{b}}$ & 25 & 5.4 & 11 \\
\hline MO & 17 & 1.7 & 4.0 \\
\hline
\end{tabular}




\begin{tabular}{|c|c|c|c|}
\hline NAME & $\begin{array}{c}\text { FREQUENCY OF } \\
\text { DETECTION }(n=12)\end{array}$ & $\begin{array}{l}\text { \% MOLE } \\
\text { FRACTION }\end{array}$ & SD \\
\hline MO-1 & 100 & 98 & 4.0 \\
\hline COD & 17 & 2.4 & 6.4 \\
\hline COD-1 (MO) $)^{\mathrm{b}}$ & 17 & 2.2 & 5.7 \\
\hline COD-2 (CE-4) $)^{b}$ & 100 & 89 & 17 \\
\hline COD-3 (MDA-6, MDMA-1) & 17 & 6.5 & 15 \\
\hline MDA & 42 & 4.8 & 6.0 \\
\hline MDA-1 (AM, MA-2) ${ }^{\mathrm{b}}$ & 100 & 25 & 13 \\
\hline MDA-2 & 50 & 4.9 & 5.3 \\
\hline MDA-3 & 100 & 6.7 & 3.4 \\
\hline MDA-4 (MDMA, MDEA-2) ${ }^{\mathrm{b}}$ & 100 & 7.2 & 2.6 \\
\hline MDA-5 & 92 & 7.5 & 3.0 \\
\hline MDA-6 (MDMA-1, COD-3) & 17 & 3.5 & 8.7 \\
\hline MDA-7 & 67 & 14 & 12 \\
\hline MDA-8 & 92 & 26 & 16 \\
\hline $\mathrm{CO}$ & 67 & 15 & 14 \\
\hline $\mathrm{CO}-1$ & 75 & 44 & 31 \\
\hline $\mathrm{CO}-2$ & 8 & 0.6 & 2.1 \\
\hline $\mathrm{BE}^{\mathrm{a}}$ & 92 & 31 & 27 \\
\hline $\mathrm{CE}^{\mathrm{a}}$ & 8 & 1.0 & 3.5 \\
\hline AM & 100 & 22 & 10 \\
\hline AM-1 & 92 & 21 & 11 \\
\hline AM-2 & 100 & 22 & 8.0 \\
\hline AM-3 & 8 & 1.0 & 3.4 \\
\hline AM-4 (MA-1, MDMA-3) ${ }^{\mathrm{b}}$ & 42 & 7.4 & 10 \\
\hline AM-5 & 42 & 0.5 & 0.7 \\
\hline AM-6 & 83 & 11 & 7.1 \\
\hline AM-7 & 100 & 16 & 9.0 \\
\hline $\mathbf{B E}^{\mathbf{a}}$ & 92 & 30 & 17 \\
\hline BE-1 & 83 & 47 & 31 \\
\hline BE-2 & 92 & 19 & 27 \\
\hline BE-3 & 25 & 3.8 & 6.8 \\
\hline MDMA & 100 & 40 & 24 \\
\hline MDMA-1 (MDA-6, COD-3) & 17 & 2.4 & 5.6 \\
\hline MDMA-2 & 50 & 5.3 & 6.0 \\
\hline MDMA-3 (AM-4, MA-1) ${ }^{\mathrm{b}}$ & 42 & 13 & 16 \\
\hline MDMA-4 (MDEA-6) ${ }^{\mathrm{b}}$ & 25 & 12 & 24 \\
\hline MDMA-5 (MA-4, MDEA-4) & 92 & 28 & 23 \\
\hline
\end{tabular}

\subsubsection{Mole fraction of metabolites}

The estimated \% mole fractions (Mf) and frequency of detection of all TPs are shown in Table 3.6. Target analytes benzoylecognine and cocaethylene are well-known metabolites of cocaine and were included as metabolites for the Mf calculation for cocaine. However, each of them has their own TPs and therefore was also treated as 
parent DOA. Same was true with EDDP, a known metabolite of methadone. Based on the mf, all DOAs were classified into three categories: low (0-20\%),medium (20-70\%) and high-abundance (70-100\%). Results in Table 3.6 are sorted according to the parent DOAs Mf category. The Low-abundance category included 12 parent DOAs (out of 15 total) meaning that majority of the parent DOAs are converted to TPs before they enter WWTPs and therefore TPs should always be monitored instead of parent DOAs in this category. Many drugs (i.e. AM and MDA) produce a large number of metabolites so it will be difficult to assess their occurrence and consumption patterns unless extensive monitoring is conducted. $\mathrm{AM}, \mathrm{BE}$ and MDMA are the DOAs that fall under medium abundance category with respective mole fractions of $22 \%, 30 \%$ and $61 \%$, the category in which it is important to monitor both the parent and its TPs. No DOAs were found to contain Mfs $>70 \%$ and therefore none was included in high abundance category. When parent drug is found with relatively high $\mathrm{Mf}(>70 \%)$ it is safe to assume that metabolites can be ignored. One such example would be the artificial sweetener, sucralose, which is very persistent in the environment and hence used as tracer to track anthropogenic wastewater intrusions in to the environmental waters [40]. Results presented here clearly highlight the importance of monitoring metabolites rather than the parent molecules for drugs of abuse. The mole fraction distribution of the 10 most abundant TPs from this study were plotted as box plots and shown in Fig. 3.8. The frequency of detection is shown in parenthesis above the box plot. The boundaries of box plot cover 25th-75th percentile, the centerline indicates median of the sample population, error bars (whiskers) above and below the box refer to 90th and 10th percentiles. 


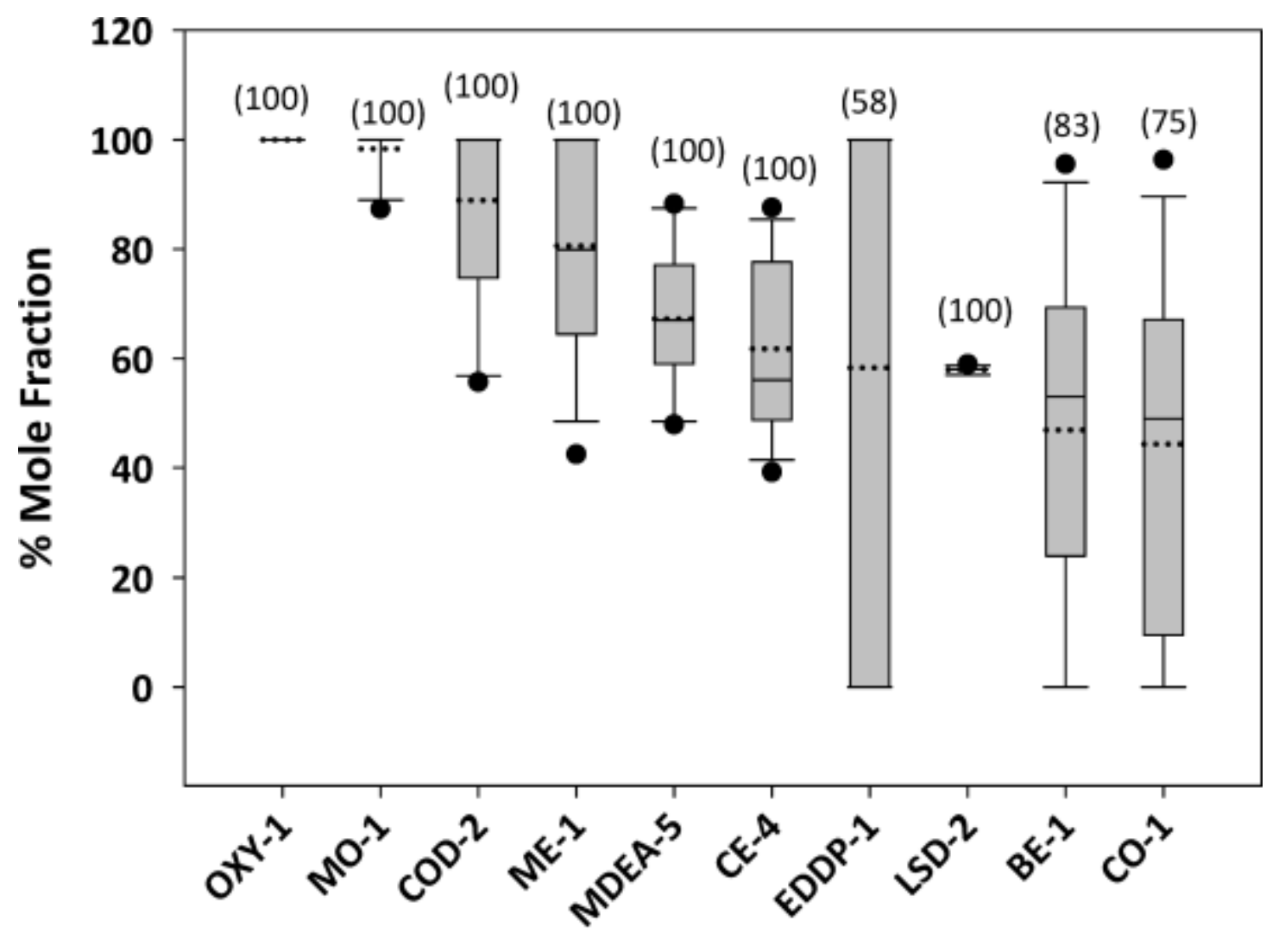

\section{DOAs}

Fig. 3.8. Percent mole fractions of the most abundant TPs in sewage water (frequency of detection shown in parenthesis). The boundaries of box plot cover 25th-75th percentile, the center line indicates median of the sample population, error bars (whiskers) above and below the box refer to 90th and 10th percentiles.

Dotted line indicates the mean of the sample population.

\subsection{Conclusion}

A total of 54 phase I and phase II metabolites of drugs of abuse were successfully detected and identified in raw sewage from a small population setting using high resolution mass spectrometry. Targeted $\mathrm{MS}^{2}$ and data-dependent acquisition modes were compared and used in combination with metabolic profiling software to achieve identification of transformation products with a mass accuracy of $4.2 \mathrm{ppm}$ or better. Concentrations of all TPs were estimated based on the parent DOAs response factor and 
used to calculate the percent mole fractions (Mf). A group of 9 metabolites, all detected at high frequency, were observed to be more abundant (higher $\%$ mole fraction) than the parent compounds, and thus should be used as the main analytes for routine monitoring. Based on this simplistic example, until new technologies and materials for the treatment of emerging contaminants in domestic wastewater streams developed are tested a comprehensive monitoring of degradation products needs to be conducted in order to fully assess their fate, transport, and toxicological impact to the natural environment.

\subsection{Acknowledgements}

The Environmental Analysis Research Laboratory acknowledges the support from the Thermo Scientific Corporation in the development of this work. This is SERC contribution 686. 


\subsection{References}

[1] U.S. Department of Health and Human Services, Results from the 2012 National Survey on Drug Use and Health: Summary of National Findings, Rockville, MD, 2013.

[2] D.A. Burgard, R. Fuller, B. Becker, R. Ferrell, M.J. Dinglasan-Panlilio, Potential trends in Attention Deficit Hyperactivity Disorder (ADHD) drug use on a college campus: wastewater analysis of amphetamine and ritalinic acid., Sci. Total Environ. 450-451 (2013) 242-9. doi:10.1016/j.scitotenv.2013.02.020.

[3] UNODC, World drug report 2013, New York, 2013.

[4] S.C. Harris, P.J. Perrino, I. Smith, M.J. Shram, S. V Colucci, C. Bartlett, et al., Abuse potential, pharmacokinetics, pharmacodynamics, and safety of intranasally administered crushed oxycodone $\mathrm{HCl}$ abuse-deterrent controlled-release tablets in recreational opioid users., J. Clin. Pharmacol. 54 (2014) 468-77. doi:10.1002/jcph.235.

[5] S. Pérez, D. Barceló, Application of advanced MS techniques to analysis and identification of human and microbial metabolites of pharmaceuticals in the aquatic environment, TrAC Trends Anal. Chem. 26 (2007) 494-514. doi:10.1016/j.trac.2007.05.004.

[6] M.D. Celiz, J. Tso, D.S. Aga, Pharmaceutical Metabolites in the Environment: Analytical Challenges and Ecological Risks, Environ. Toxicol. Chem. 28 (2009) 2473-2484.

[7] D.J. Liska, The detoxification enzyme systems., Altern. Med. Rev. 3 (1998) 187-98.

[8] B. Kasprzyk-hordern, R.M. Dinsdale, A.J. Guwy, The removal of pharmaceuticals , personal care products, endocrine disruptors and illicit drugs during wastewater treatment and its impact on the quality of receiving waters, Water Res. 43 (2009) 363-380. doi:10.1016/j.watres.2008.10.047.

[9] M. Petrović, C. Postigo, M.L. de Alda, A. Ginebreda, Occurrence and Fate of Pharmaceuticals and Illicit Drugs Under Water Scarcity, 2010. doi:10.1007/698.

[10] C. Postigo, M.J.L. De Alda, D. Barceló, Drugs of abuse and their metabolites in the Ebro River basin: Occurrence in sewage and surface water, sewage treatment plants removal efficiency, and collective drug usage estimation, Environ. Int. 36 (2010) 75-84. doi:10.1016/j.envint.2009.10.004.

[11] E. Zuccato, S. Castiglioni, M. Tettamanti, R. Olandese, R. Bagnati, M. Melis, et al., Changes in illicit drug consumption patterns in 2009 detected by wastewater 
analysis., Drug Alcohol Depend. $118 \quad$ (2011) 464-9. doi:10.1016/j.drugalcdep.2011.05.007.

[12] R. Pal, M. Megharaj, K.P. Kirkbride, R. Naidu, Illicit drugs and the environment - A review., Sci. Total Environ. 463-464 (2013) 1079-92. doi:10.1016/j.scitotenv.2012.05.086.

[13] S. Castiglioni, E. Zuccato, C. Chiabrando, R. Fanelli, R. Bagnati, Mass spectrometric analysis of illicit drugs in wastewater and surface water, Mass Spectrom. Rev. 27 (2008) 378-394. doi:10.1002/mas.

[14] E. Zuccato, S. Castiglioni, Illicit drugs in the environment, R. Soc. Chem. 367 (2009) 3965-3978. doi:10.1098/rsta.2009.0107.

[15] L. Bijlsma, E. Emke, F. Hernández, P. de Voogt, Investigation of drugs of abuse and relevant metabolites in Dutch sewage water by liquid chromatography coupled to high resolution mass spectrometry., Chemosphere. 89 (2012) 1399-406. doi:10.1016/j.chemosphere.2012.05.110.

[16] J. Berset, R. Brenneisen, C. Mathieu, Analysis of llicit and illicit drugs in waste, surface and lake water samples using large volume direct injection high performance liquid chromatography--electrospray tandem mass spectrometry (HPLC-MS/MS)., Chemosphere. 81 (2010) 859-866. doi:10.1016/j.chemosphere.2010.08.011.

[17] M. Huerta-Fontela, M.T. Galceran, J. Martin-Alonso, F. Ventura, Occurrence of psychoactive stimulatory drugs in wastewaters in north-eastern Spain, Sci. Total Environ. 397 (2008) 31-40. doi:10.1016/j.scitotenv.2008.02.057.

[18] A. Musenga, D.A. Cowan, Use of ultra-high pressure liquid chromatography coupled to high resolution mass spectrometry for fast screening in high throughput doping control., J. Chromatogr. A. $1288 \quad$ (2013) 82-95. doi:10.1016/j.chroma.2013.03.006.

[19] C. Postigo, M.J.L. De Alda, D. Barceló, Ananlysis of drugs of abuse and their human metabolites in water by LC-MS: A non-intrusive tool for drug abuse estimation at the community level, Trends Anal. Chem. 27 (2008) 1053-1069. doi:10.1016/j.trac.2008.10.002.

[20] I. Senta, I. Krizman, M. Ahel, S. Terzic, Assessment of stability of drug biomarkers in municipal wastewater as a factor influencing the estimation of drug consumption using sewage epidemiology., Sci. Total Environ. (2014). doi:10.1016/j.scitotenv.2013.12.054. 
[21] F. Hernández, M. Ibáñez, E. Gracia-Lor, J. V Sancho, Retrospective LC-QTOF-MS analysis searching for pharmaceutical metabolites in urban wastewater., J. Sep. Sci. 34 (2011) 3517-26. doi:10.1002/jssc.201100540.

[22] L. Bijlsma, J. V Sancho, W.M.A. Niessen, Fragmentation pathways of drugs of abuse and their metabolites based on QTOF MS / MS and MS E accurate mass spectra, J. Mass Spectrom. 46 (2011) 865-875. doi:10.1002/jms.1963.

[23] M. Krauss, H. Singer, J. Hollender, LC-high resolution MS in environmental analysis: from target screening to the identification of unknowns., Anal. Bioanal. Chem. 397 (2010) 943-51. doi:10.1007/s00216-010-3608-9.

[24] J. Nurmi, J. Pellinen, A.-L. Rantalainen, Critical evaluation of screening techniques for emerging environmental contaminants based on accurate mass measurements with time-of-flight mass spectrometry., J. Mass Spectrom. 47 (2012) 303-12. doi: $10.1002 /$ jms.2964.

[25] P. Calza, C. Medana, E. Padovano, V. Giancotti, C. Baiocchi, Identification of the unknown transformation products derived from clarithromycin and carbamazepine using liquid chromatography/high-resolution mass spectrometry., Rapid Commun. Mass Spectrom. 26 (2012) 1687-704. doi:10.1002/rcm.6279.

[26] A.C. Hogenboom, J.A. van Leerdam, P. de Voogt, Accurate mass screening and identification of emerging contaminants in environmental samples by liquid chromatography-hybrid linear ion trap Orbitrap mass spectrometry., J. Chromatogr. A. 1216 (2009) 510-9. doi:10.1016/j.chroma.2008.08.053.

[27] L. Bijlsma, C. Boix, W.M.A. Niessen, M. Ibáñez, J. V Sancho, F. Hernández, Investigation of degradation products of cocaine and benzoylecgonine in the aquatic environment., Sci. Total Environ. 443 (2013) 200-8. doi:10.1016/j.scitotenv.2012.11.006.

[28] A. Wick, M. Wagner, T.A. Ternes, Elucidation of the transformation pathway of the opium alkaloid codeine in biological wastewater treatment., Environ. Sci. Technol. 45 (2011) 3374-85. doi:10.1021/es103489x.

[29] C. Moschet, A. Piazzoli, H. Singer, J. Hollender, Alleviating the reference standard dilemma using a systematic exact mass suspect screening approach with liquid chromatography-high resolution mass spectrometry., Anal. Chem. 85 (2013) 1031220. doi:10.1021/ac4021598.

[30] I. González-Mariño, J.B. Quintana, I. Rodríguez, R. Cela, Determination of drugs of abuse in water by solid-phase extraction, derivatisation and gas chromatography-ion trap-tandem mass spectrometry, J. Chromatogr. A. 1217 (2010) 1748-1760. doi:10.1016/j.chroma.2010.01.046. 
[31] A.C. Chiaia, C. Banta-green, Eliminating Solid Phase Extraction with Large-Volume Injection LC/MS/MS: Analysis of Illicit and Legal Drugs and Human Urine Indicators in US Wastewaters, Environ. Sci. Technol. 42 (2008) 8841-8848.

[32] M. Gorga, M. Petrovic, D. Barceló, Multi-residue analytical method for the determination of endocrine disruptors and related compounds in river and waste water using dual column liquid chromatography switching system coupled to mass spectrometry., J. Chromatogr. A. 1295 (2013) 57-66. doi:10.1016/j.chroma.2013.04.028.

[33] S. Idder, L. Ley, P. Mazellier, H. Budzinski, Quantitative on-line preconcentrationliquid chromatography coupled with tandem mass spectrometry method for the determination of pharmaceutical compounds in water, Anal. Chim. Acta. 805 (2013) 107-115. doi:10.1016/j.aca.2013.10.041.

[34] N. V. Heuett, Detection and Analysis of Drugs of Abuse and their Metabolites in Waters and Airborne Particles, Florida International University (Unpublished Ph. D. dissertation), 2015.

[35] B. Kasprzyk-hordern, V.V.R. Kondakal, D.R. Baker, Enantiomeric analysis of drugs of abuse in wastewater by chiral liquid chromatography coupled with tandem mass spectrometry, J. Chromatogr. A. $1217 \quad$ (2010) 4575-4586. doi:10.1016/j.chroma.2010.04.073.

[36] F.Y. Lai, P.K. Thai, J. O’Brien, C. Gartner, R. Bruno, B. Kele, et al., Using quantitative wastewater analysis to measure daily usage of conventional and emerging illicit drugs at an annual music festival., Drug Alcohol Rev. 32 (2013) 594-602. doi:10.1111/dar.12061.

[37] J. Wang, P.R. Gardinali, Identification of phase II pharmaceutical metabolites in reclaimed water using high resolution benchtop Orbitrap mass spectrometry, Chemosphere. 107 (2014) 65-73. doi:10.1016/j.chemosphere.2014.03.021.

[38] V.R. Panditi, Assessment of the Occurence and Potential Risks of Antibiotics and their Metabolites in South Florida Waters using Liquid Chromatography Tandem Mass Spectrometry, Florida International University, 2013.

[39] C.C.L. Wong, D. Cociorva, J.D. Venable, T. Xu, J.R. Yates III, Comparison of Different Signal Thresholds on Data Dependent Sampling in Orbitrap and LTQ Mass Spectrometry for the Identification of Peptides and Proteins in Complex Mixtures, Am. Soc. Mass Spectrom. 20 (2009) 1405-1414. doi:10.1016/j.jasms.2009.04.007.Comparison.

[40] S.R. Batchu, N. Quinete, V.R. Panditi, P.R. Gardinali, Online solid phase extraction liquid chromatography tandem mass spectrometry (SPE-LC-MS/MS) method for the 
determination of sucralose in reclaimed and drinking waters and its photo degradation in natural waters from South Florida., Chem. Cent. J. 7 (2013) 141. doi:10.1186/1752-153X-7-141. 


\section{CHAPTER 4}

Characterization of wastewater effluent, surface, and drinking waters by highresolution mass spectrometry: Understanding the composition of recalcitrant chemicals 


\subsection{Abstract}

Contaminants of emergent concern are continuously reaching waterways through wastewater effluents, storm water and agricultural runoff, and many other sources produced by human activity. The current study investigates the chemical diversity in a typical river basin transect affected by domestic treated water discharges that also serves as source for downstream drinking water production. The trajectory along the model river includes an upstream site (not influenced), the effluent release site (point source), an effluent mixing zone (heavily influenced), a downstream location, the point for drinking water production intake, and finalized treated drinking water. Compound diversity, defined as the number of chemical formulas identifiable from the high-resolution mass spectrometry analysis (HRMS) proved to be greatest in the effluent (97 unique compound classes) and the treated drinking water (95 compound classes) locations. However, the summed response for all the detected formulas was much higher in the effluent than in any other sample in the system. Combination of $\mathrm{m} / \mathrm{z}$ (accurate mass) vs. retention time scatter plots and Venn diagrams were used to recognize recalcitrant compounds that remained in all the water samples from the effluent release, and also to identify analytes analytes introduced during the drinking water treatment process. A total of 64 compounds originated at the effluent location persisted throughout the entire process. A combination of MS/MS spectral analysis and in-silico fragmentation prediction were used to identify and tentatively confirm 4 compounds. From the 3,227 chemical features (individual accurate masses that met selection criteria) present in the drinking water source; 1,152 were retained after the drinking water treatment while 1857 features were introduced to the final drinking water product. This fact clearly shows the potential importance of 
treatment byproducts introduced by either water polishing (polymers) or formed during the disinfection processes. The use of high resolution mass spectrometry instruments capable of performing both MS and MS/MS experiments at resolutions above 100K such as the Q-Exactive Orbitrap played a crucial role in this study as it provided both the sensitivity and mass accuracy needed for screening target and non-target components for the complete characterization of the different water matrices.

\subsection{Introduction}

In order to fulfill human "needs" in our rapidly changing society, a great variety of products ranging from pharmaceuticals and personal care products (PPCPs), drugs (illicit and prescription), artificial sweeteners, nanomaterials, perfluorinated compounds (PFCs), sunscreens, and pesticides to name a few, are being manufactured, consumed, used, and disposed of, on a daily basis in households and industrial settings (Chiaia-Hernandez et al. 2013; Hernández et al. 2014; Richardson and Ternes 2014). A large portion of these compounds (in their unchanged form or as transformation products) reaches wastewater treatment facilities where in many cases they can persist throughout the treatment process. (Huerta-Fontela et al. 2008; Bartelt-hunt et al. 2009; Gros et al. 2010; Barceló et al. 2012). The result of this persistence is a chronic source of contamination to sensitive aquatic ecosystems, which can potentially be affected (Ben-Jonathan and Steinmetz 1998; Rabiet et al. 2006; Kasprzyk-hordern et al. 2008; Barceló et al. 2012; Lacey et al. 2012; Parolini et al. 2013). To further aggravate the increasing pollution, stormwater and agricultural runoff introduces additional inputs of organic pollutants, as these waters 
receive inadequate treatment or no treatment before entering waterways (Xiao et al. 2012; Jernberg et al. 2013; Moschet et al. 2013, 2014).

Surface water is in many cases the main source of water to be used for drinking water production. Upon entering treatment facilities, physical treatment (e.g., flocculation, sedimentation, filtration) followed by chemical disinfection (e.g., chlorination, ozone, and/or ultraviolet radiation) is performed to remove suspended matter and pathogens (Barceló et al. 2012; Postigo and Richardson 2014). However, these types of treatments may not be sufficient enough to remove the more persistent compounds. For instance, Segura et al. (2011) reported low levels (parts per trillion, ng/L) of atrazine and carbamazepine in drinking water from cities in Canada. Similarly, the presence of sucralose has previously been reported by our group, in which concentrations for the artificial sweetener reached as high as $465 \mathrm{ng} / \mathrm{L}$ in drinking water (Batchu et al. 2013). A recently published review on the transformation pathways of pharmaceuticals during disinfection processes, clearly showed the formation of disinfection byproducts (DBPs) upon treatment with chlorine, chloramine, ozone, chlorine dioxide, $\mathrm{UV}$, or $\mathrm{UV} / \mathrm{H}_{2} \mathrm{O}_{2}$ (Postigo and Richardson 2014).

To better understand chemical diversity of different water matrices, it is essential to take advantage of high-resolution instruments such as the Orbitrap, which offer great sensitivity and optimal resolution capable of resolving thousands of species in a single spectrum with the high mass accuracy needed for molecular assignment (Gonsior et al. 2011; Chiaia-Hernandez et al. 2014). Such features make high-resolution instruments ideal for the characterization of unknowns identification and confirmation of low and high abundant contaminants and their potential transformation products (Moschet et al. 
2013; Tseng et al. 2013; Schymanski et al. 2014). Target analysis of known compounds is usually done using a suite of reference standards plus their labeled analogs for quantitation purposes. Multiple methods using this approach have been reported in the literature, for a wide variety of compounds (Postigo et al. 2010; Baker and Kasprzykhordern 2011; Panditi et al. 2013; Wang and Gardinali 2013; Castiglioni et al. 2014).

Non-target techniques encompass the analysis of known and unknown compounds using a combination of full scan and MS/MS experiments. One such technique is the so called suspect screening, for which databases (instead of reference standards) are used to tentatively identify and confirm the presence of known analytes on the basis of mass accuracy, retention time, isotopic pattern determination, and structure confirmation using MS/MS experiments (Krauss et al. 2010; González-Mariño et al. 2012; Moschet et al. 2013; Chiaia-Hernandez et al. 2014). In addition, non-target techniques have been implemented for the identification of potential transformation products from known target analytes using metabolite identification tools in conjunction with in-silico structural elucidation models followed by confirmation using accurate mass MS/MS data (Moschet et al. 2013; Bletsou et al. 2015; Heuett et al. 2015).

One last, yet more challenging approach is the use of non-target screening techniques for the characterization and tentative identification of unknown compounds in complex matrices such as wastewater. In non-target screening techniques, no prior information is known about the compounds to be detected and thus, it is of upmost importance to acquire the data using high-resolution instruments. Accurate mass data censored to a confidence level ( $5 \mathrm{ppm})$ is used to generate a peak list, for which molecular composition is determined using formula generator tools, to then determine possible structures from 
databases (Krauss et al. 2010; Bletsou et al. 2015). Studies have been implemented using the above protocols in the evaluation of molecular composition changes from degradation or treatment processes (Gonsior et al. 2011; Tseng et al. 2013; Schymanski et al. 2014); and in the tentative identification of analytes from environmental samples (Müller et al. 2011; Hug et al. 2014; Leerdam et al. 2014).

Understanding the composition of different types of samples of the same matrix that are interconnected to one another could help to potentially pin point sources of pollution, measure treatment efficiency in wastewater and drinking water facilities, and identify the presence of persistent microconstituents. Therefore the goal of this study is twofold: a) to characterize effluent, surface, and drinking water samples linked by a common trajectory using non-target high-resolution mass spectrometry, and b) to classify and compare the chemical diversity in each matrix, to further identify and understand the composition of newly formed or recalcitrant chemicals.

\subsection{Experimental}

\subsubsection{Reagents and chemicals}

High performance liquid chromatography (HPLC) grade water, methanol, acetonitrile, formic acid, ammonium formate, and optimal grade methylene chloride were purchased from Fisher Scientific (Fair Lawn, NJ, USA) and used as received. Clear polyethylene terephthalate (PET) bottles for sample collection were purchased from SKS Science (Watervliet, NY, USA). Glass fiber filter were purchased from Fisher Scientific (Fair Lawn, NJ, USA). 


\subsubsection{Sample collection}

Grab surface water samples $(500 \mathrm{~mL})$ were collected on multiple locations along a river system on October $7^{\text {th }}$ and $8^{\text {th }}, 2014$. Sampling locations included upstream $(\sim 800$ meters above the wastewater effluent), the outfall itself, an effluent mixing zone $(\sim 200$ meters downstream from the outfall), and a downstream site ( $\sim 9$ kilometers from the outfall). In addition, samples were also collected at the drinking water treatment plant intake $(\sim 13.5$ kilometers downstream from the outfall) and at the end of the treated drinking water process (see diagram in Fig. 4.1). Samples were vacuum filtered using a 0.5 um PreSep Prefilter glass fiber filter and stored in the dark at $-20{ }^{\circ} \mathrm{C}$ until analysis time.

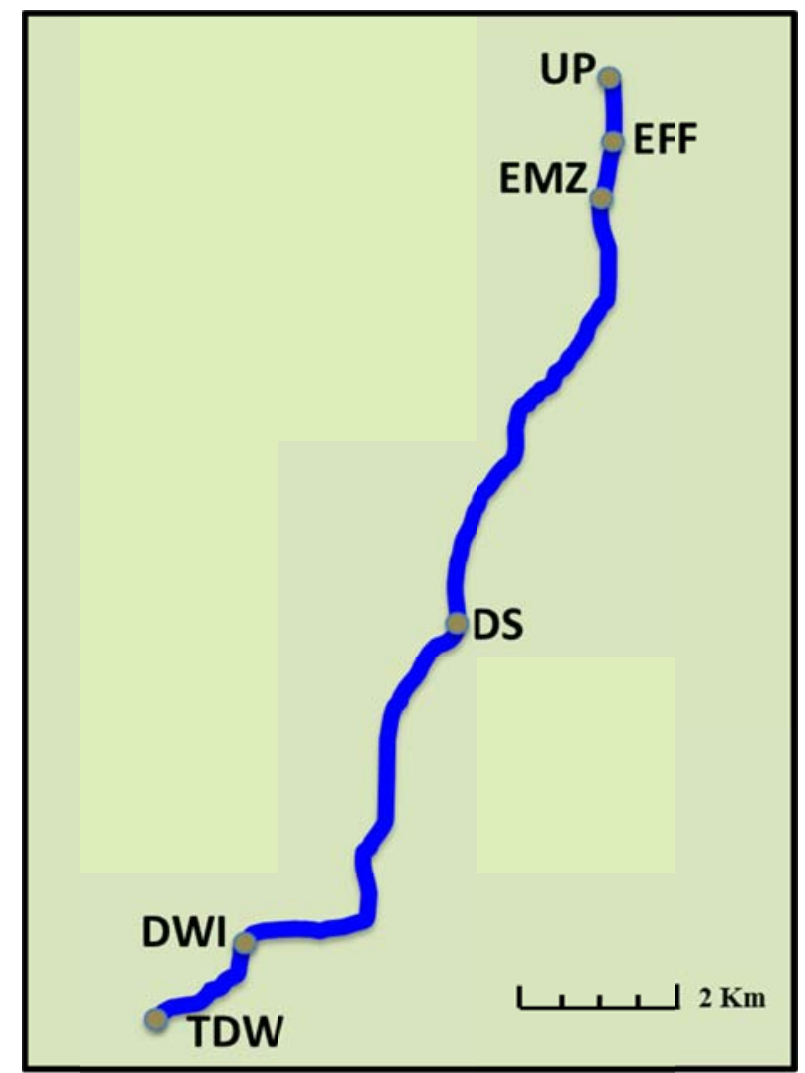

Fig. 4.1. Diagram of sampling locations, upstream (UP), wastewater effluent (EFF), effluent mixing zone (EMZ), downstream (DS), drinking water intake (DWI), and treated drinking water (TDW). 


\subsubsection{Sample preparation}

As a result of the unknown nature of the analytes present in the water samples, exhaustive extraction was performed by liquid-liquid extraction against methylene chloride. Prior to extraction, filtered samples were basified to $\mathrm{pH} 10$ using ammonium hydroxide and placed in individual $1 \mathrm{~L}$ separatory funnels. Analytes were extracted using a total of $250 \mathrm{~mL}$ of methylene chloride. After collecting the organic phase, the remaining aqueous phase was acidified using formic acid to reach $\mathrm{pH} 4$. The acidified sample was then extracted using $250 \mathrm{~mL}$ of methylene chloride. The organic phases from the basic and acid extractions were combined to obtain a total sample extract. Organic extracts were dried over anhydrous sodium sulfate and were concentrated using a water bath; dried under a stream of purified nitrogen gas; and reconstituted to $1 \mathrm{~mL}$ using methanol before analysis.

\subsubsection{UPLC-Orbitrap analysis}

Extracts were analyzed on a UPLC high-resolution Q-Exactive Orbitrap mass spectrometer (Thermo Fisher Scientific, San Jose, CA, USA) equipped with HESI II electrospray source operated in the positive ion mode. The mass spectrometer was operated in full scan mode $(100-1000 \mathrm{~m} / \mathrm{z})$ at a 140,000 resolution, and MS/MS mode at 35,000 resolution (HCD collision energy 35). Chromatographic separation of analytes was performed using a Hypersil Gold ${ }^{\mathrm{TM}}$ aQ analytical column (50 x $2.1 \mathrm{~mm}, 1.9$ um) protected by a Hypersil Gold ${ }^{\mathrm{TM}}$ aQ guard column $(10 \times 2.1 \mathrm{~mm}, 1.9 \mathrm{um})$. The above mentioned method was adapted from an existing online SPE method (Wang and Gardinali 2013), and modified to a direct injection method. Mobile phase composition 
consisted of water modified with $0.1 \%$ formic acid, and a binary mixture of acetonitrile:methanol (50:50). Details on the modified gradient program and flow rate are shown in table 4.1.

Table 4.1. Analytical pump gradient program for direct injection. Mobile phases used: LC-MS grade water (A), methanol (B), acetonitrile (C), and $0.1 \%$ formic acid in water (D).

\begin{tabular}{cccccc} 
Time & A & B & C & D & $\begin{array}{c}\text { Flow } \\
(\boldsymbol{\mu l} / \mathbf{m i n})\end{array}$ \\
\hline 0 & 0 & 1 & 1 & 98 & 500 \\
0.2 & 0 & 1 & 1 & 98 & 500 \\
0.5 & 0 & 1 & 1 & 98 & 500 \\
5 & 0 & 47 & 50 & 3 & 500 \\
9 & 0 & 47 & 50 & 3 & 500 \\
11 & 0 & 47 & 50 & 3 & 500 \\
11.5 & 0 & 1 & 1 & 98 & 500 \\
13 & 0 & 1 & 1 & 98 & 500 \\
\hline
\end{tabular}

\subsubsection{Data analysis}

Post-acquisition data mining of samples was performed using Compound Discoverer 1.0 software for peak list generation (Thermo Scientific, San Jose, CA, USA). Subsequently, a blank subtraction was done for each of the samples to remove background ions and chemical noise introduced by the lab procedures. Peak lists including exact mass $(\mathrm{m} / \mathrm{z})$, their intensity and the retention time for each of peaks found in each one of the blank-subtracted samples were exported and uploaded into an in-house database. Molecular formulae were assigned for all $\mathrm{m} / \mathrm{z}$ 's that had intensities above 10,000 using the formula generation package from Spidermass. The formula generation software was adapted to apply the seven golden rules (SGR) for heuristic filtering of molecular formulas obtained by high resolution mass spectrometry (Kind and Fiehn 2007). Elements considered in the molecular assignment (and their minimum and 
maximum counts) included: $\mathrm{C}(3-60), \mathrm{H}(2-120), \mathrm{N}(0-20), \mathrm{O}(0-25), \mathrm{P}(0-6), \mathrm{S}(0-8), \mathrm{F}$ (0-10), $\mathrm{Cl}$ (0-10), and $\mathrm{Br}(0-7)$. Data was further censored with ring double bond equivalence values (RDBE) not greater than 40, and elemental composition error less than $0.5 \mathrm{mDa}$ from the accurate mass. Element ratios, element probability check and isotopic pattern check were evaluated as part of the SGR approach. Visual representations (e.g. graphs and diagrams) were used to recognize similarities/differences among the samples, as well as to identify compositional patterns.

\subsection{Results and discussion}

Non-target analysis and post-acquisition strategies were implemented in this study to determine chemical diversity, recognize persistent chemicals, and identify contaminants of emergent concern in surface water samples from a river system that serves both as a point of discharge for treated domestic wastewater upstream and as a source for drinking water production downstream. Liquid-liquid extraction (LLE) was used in this study to screen for as many organic components as possible while avoiding the potential segregation (washout or irreversible retention) of analytes that can result from using a specific packing material as in the case of solid phase extractions. A liquid-liquid extraction was performed at different $\mathrm{pH}$ levels $(\mathrm{pH} 4,7,10)$ using a set of reclaimed water samples $(n=3)$ as a proof of concept test to understand the influence of $\mathrm{pH}$ in the number of components extracted. This test demonstrated that under basic conditions $(\mathrm{pH}$ 10) a larger number of components with a higher diversity (as depicted by the range of Kendrick mass defect (KMD) values) are extracted in comparison to neutral or acidic $\mathrm{pH}$

conditions (data not shown). Therefore, during the extraction procedure for the surface 
water samples, $\mathrm{pH}$ of the sample was sequentially modified with ammonium hydroxide ( $\mathrm{pH} \mathrm{10),} \mathrm{followed} \mathrm{by} \mathrm{formic} \mathrm{acid} \mathrm{(} \mathrm{pH} 4)$ in order to be able to extract a the largest array of acidic and basic compounds. A laboratory blank (LC/MS water) was extracted in the same manner and used as background subtraction during the post-acquisition data mining.

\subsubsection{Molecular formula generation}

Molecular formulae containing $\mathrm{C}, \mathrm{H}, \mathrm{N}, \mathrm{O}, \mathrm{P}, \mathrm{S}, \mathrm{F}, \mathrm{Cl}$, and $\mathrm{Br}$ elements were generated for all samples using the SGR approach. Neutral masses were obtained from protonated ions by subtracting the proton mass $(1.007825 \mathrm{u})$ from the accurate mass and used to generate formulae. It is important to note that, by assuming protonation of all detected ions, all other possible adducts generated during acquisition are excluded. Initially, several hundreds of thousands of formulae were generated; however, by following the application of the SGR the number of formulas was drastically reduced.

\subsubsection{Chemical diversity}

Chemical composition was evaluated and compared between the samples to determine chemical diversity among the different sites. A compound class contains an elemental composition with the same heteroatom content (e.g., CHNO), and the variety of compound classes in a sample makes up its diversity. Water samples generated molecular signatures containing a substantial number of compound classes. Table 4.2 outlines the number of compounds detected, the number of molecular assignments and compound classes, as well as the total intensities for each of the sampling locations. Effluent location presented the highest number of detections and compound classes 
demonstrating a significant input of a large variety of chemicals in comparison to all the other sites. On the other hand, TDW site showed the least number of formulae, with the lowest total intensity, which is in agreement with the type of location (treated drinking water). However, chemical diversity for this location proved to be very similar (in numbers) to that of the EFF site, indicating a wide variety of chemical species found in the treated drinking water.

Table 4.2. Number of compounds detected, number molecular assignments and compound classes, as well as the total intensities for each of the sampling locations.

\begin{tabular}{ccccc}
\hline Location & $\begin{array}{c}\text { Number } \\
\text { of masses } \\
\text { detected }\end{array}$ & $\begin{array}{c}\text { Number of } \\
\text { formulas } \\
\text { generated }\end{array}$ & $\begin{array}{c}\text { Number of } \\
\text { compound } \\
\text { classes }\end{array}$ & $\begin{array}{c}\text { Total } \\
\text { intensity }\end{array}$ \\
\hline UP & 3858 & 2415 & 37 & $5.81 \mathrm{e}+8$ \\
EFF & 6690 & 4817 & 97 & $4.99 \mathrm{e}+9$ \\
EMZ & 4032 & 2268 & 63 & $3.78 \mathrm{e}+8$ \\
DS & 4431 & 2178 & 76 & $3.20 \mathrm{e}+8$ \\
DWI & 4381 & 2438 & 75 & $4.01 \mathrm{e}+8$ \\
TDW & 3009 & 1562 & 95 & $2.86 \mathrm{e}+8$ \\
\hline
\end{tabular}

\subsubsection{Recalcitrant fraction of chemicals}

Effluent inputs were evaluated to identify chemicals that survive the river system trajectory and made it into the treated drinking water. The first step consisted of eliminating the molecular entities found in the upstream sample (UP) from all the other samples. In order to isolate these recalcitrant chemicals, the remaining commonalities among the EFF, EMZ, DS, DWI, and TDW locations were assessed by means of a 5-way Venn diagram (Fig. 4.2), and through mass vs. retention time scatter plots (Fig. 4.3). After excluding all chemical inputs from the upstream, a total of 5,978 components were detected in the effluent location (Fig. 4.3a), and only 530 of these components were 
observed in the effluent mixing zone (Fig. 4.3b). Nine kilometers down from the effluent at the downstream location, 247 components were found to be common between the EFF, EMZ, and DS sites (Fig. 4.3c), and less than 3\% (169 components) of the chemicals detected in the effluent made it to the drinking water intake (Fig. 4.3d). Finally, a total of 64 masses found in the treated drinking water (Fig. 4.3e), were observed to be ubiquitous in all locations (except the upstream) demonstrating their persistence throughout the trajectory.

\section{Venn Diagram}

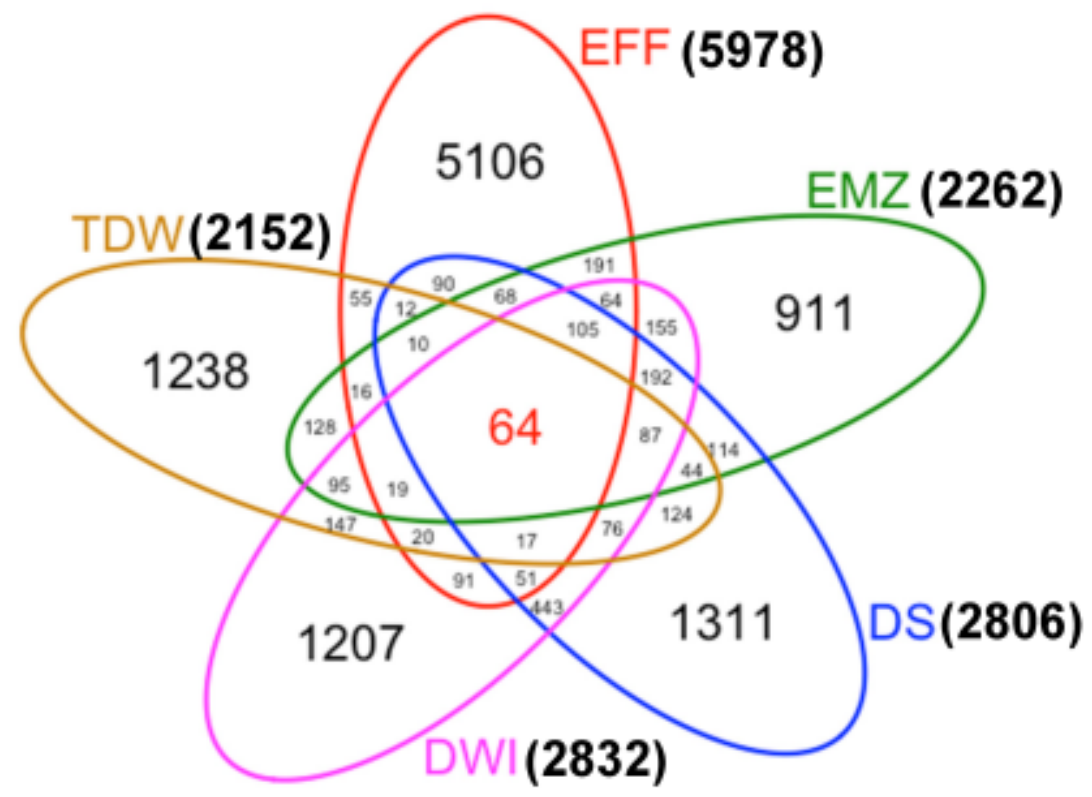

Fig. 4.2. 5-way Venn diagram the effluent (EFF), effluent mixing zone (EMZ), downstream (DS), drinking water intake (DWI), and treated drinking water (TDW) locations.

The Venn diagram in Fig. 4.2 shows the intersection of features among the EFF, EMZ, DS, DWI, and TDW locations indicating the 64 common chemical entities. In addition, $\mathrm{m} / \mathrm{z}$ vs. retention time scatterplots presented in Fig. 4.3 show the distribution of 
masses across a chromatographic run for each of the sampling locations. Early eluting high $\mathrm{m} / \mathrm{z}$ values, as well as late eluting chemical species that are originally detected in the effluent location disappear gradually in each of the subsequent sites (See Fig. 4.3) and are drastically reduced in the finished drinking water.

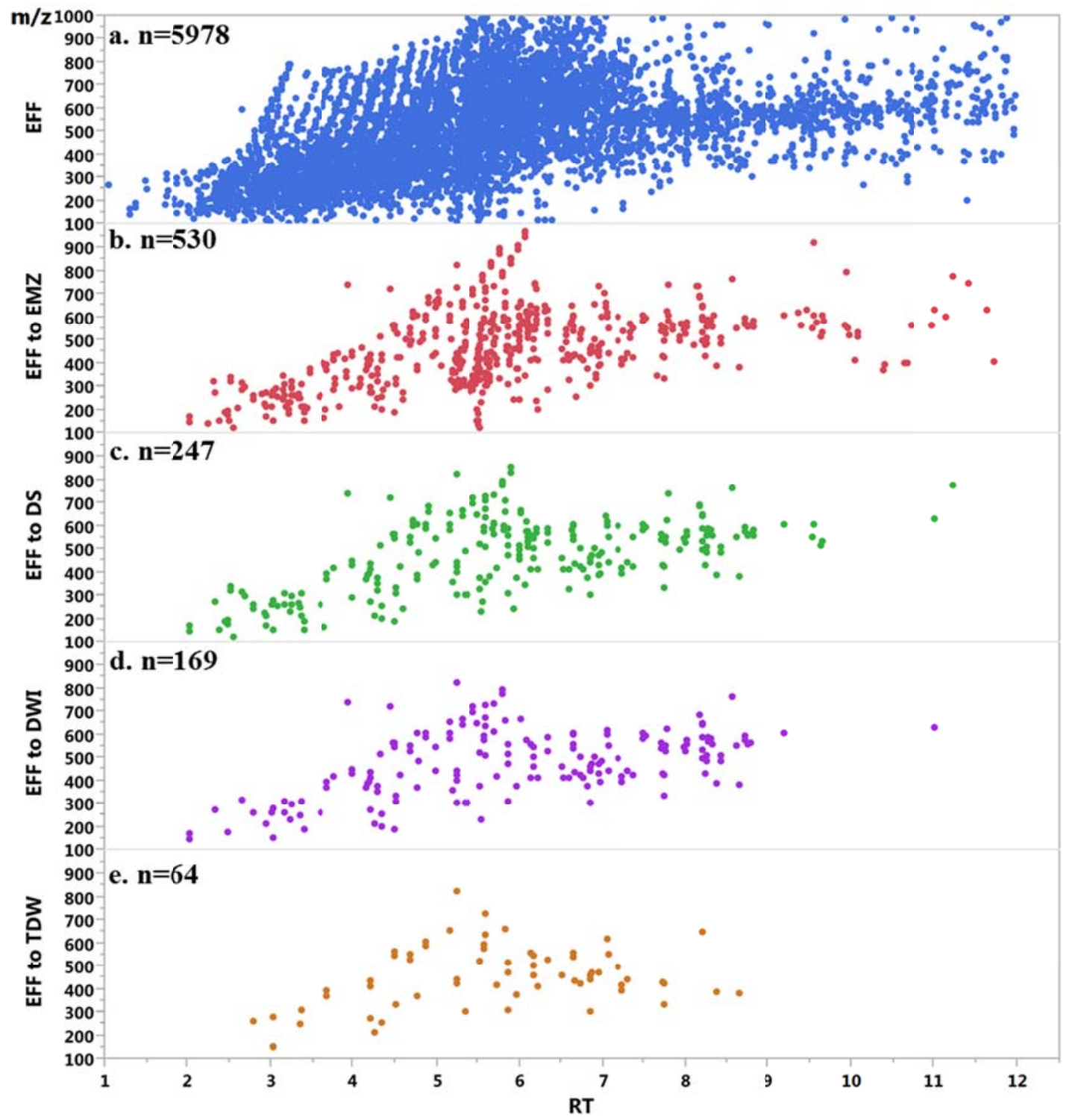

Fig. 4.3. $\mathrm{m} / \mathrm{z}$ vs. retention time scatter plots of analytes originated at the EFF location and remained constant throughout the trajectory. 
Target MS/MS spectra for the 64 recalcitrant chemicals species were generated by rerunning the samples for the specific 64 accurate masses and the fragmentation patterns obtained were evaluated through in-silico fragmentation software packages and spectral libraries (Mass Frontier, MetFrag, MassBank) to recognize and confirm their potential structure. Among the 64 candidates the identity of only four compounds was tentatively confirmed to previously reported chemicals to a mass accuracy threshold of less than 5 ppm (See Fig. 4.4). Compounds were positively identified as: 4-(4ethylphenyl)butoxymethanol $\quad\left(\mathrm{C}_{13} \mathrm{H}_{20} \mathrm{O}_{2}, \quad \mathrm{~m} / \mathrm{z} \quad\right.$ 209.1536), 3-(3-cyclohexyl-4methoxyphenyl)-1-propanol $\left(\mathrm{C}_{16} \mathrm{H}_{24} \mathrm{O}_{2}, \mathrm{~m} / \mathrm{z} 249.1849\right)$, nonoxynol-8 $\left(\mathrm{C}_{31} \mathrm{H}_{56} \mathrm{O}_{9}, \mathrm{~m} / \mathrm{z}\right.$ 573.3997), and nonoxynol-9 $\left(\mathrm{C}_{33} \mathrm{H}_{60} \mathrm{O}_{10}, \mathrm{M} / \mathrm{Z}\right.$ 617.4255). The two latter compounds are well known as components in nonionic surfactants of the nonoxynol family, and are used in cosmetics, detergents, and contraceptives (Musah et al., 2012). Despite the robustness of the HR-MS/MS approach and the in-silico ratification for their unambiguous confirmation to occur authentic standards will have to be used. 


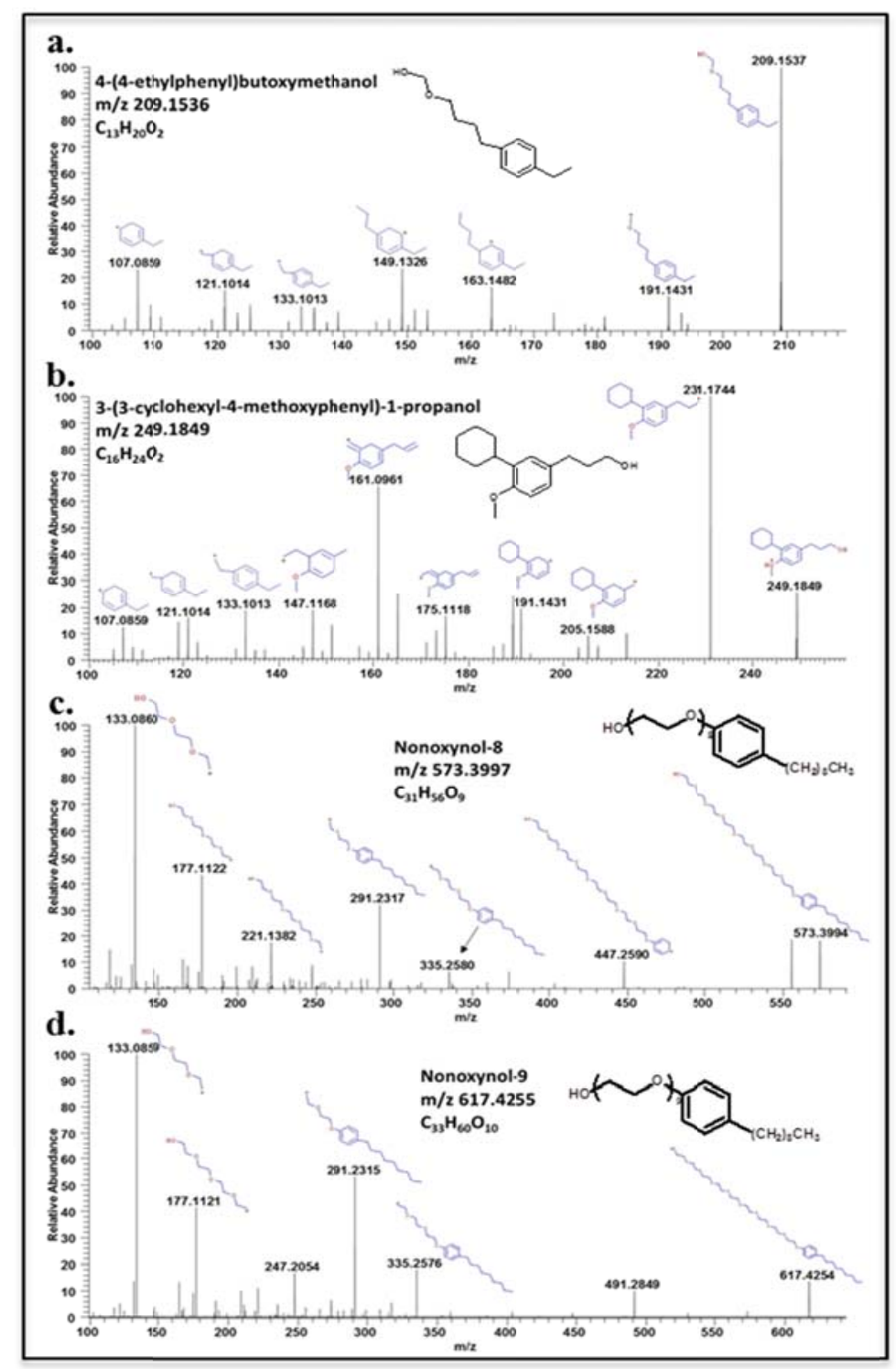

Figure 4.4. MS/MS spectral elucidation of four tentatively confirmed compounds.

\subsubsection{Kendrick mass plots}

Characterizing and comparing complex matrices is a difficult task because of the large amounts of data generated by high-resolution instruments. One way to simplify mass spectra is through mass defect filtering by plotting the nominal mass as a function of Kendrick mass defect. Mass defect is observed in all compounds as a result of differences in the binding energy of elements, and it is defined as the difference between 
a compound's observed mass and its nominal mass. In Kendrick plots, the measured mass is multiplied by $14.0000 / 14.01565$ (nominal mass/exact mass of $\mathrm{CH}_{2}$ ) to simplify the display to rectilinear peak patterns (Sleno 2012). Kendrick mass defect plots were used in this study to visualize shifts in mass spectra for identification of possible distribution patterns among sample locations (Fig. 4.5). Blue areas, showing a positive Kendrick mass defect were ubiquitous in all samples (Fig. 4.5). This positive section of the plots had a chemical composition largely of CHNOS and CHNO compound classes, which is the typical composition of natural organic matter (NOM) (Mesfioui et al. 2012; Tseng et al. 2013). In addition, distribution of the 64 identified recalcitrant compounds (red diamonds in Fig. 4.5) show a positive Kendrick mass defect, falling within the main blue region of the graph. Despite the complexity of the different types of matrices, it is possible to differentiate the chemical diversity inputs coming from the effluent (Fig. 4.5b). Lower purple and green bands, which show to be unique to this location, indicate the presence of compounds abundant in $\mathrm{S}, \mathrm{P}, \mathrm{Cl}$ and $\mathrm{Br}$ heteroatoms, as these elements display uniquely negative mass defects (Sleno 2012). Most common compound classes found in this region were $\mathrm{CHNOSCl}$ and $\mathrm{CHNOCl}$. Absence of these bands from all the other locations following the effluent suggests possible dilution and/or degradation of this group of compounds. Lower orange band predominantly present in the upstream location (Fig. 4.5a) was mainly comprised of CHNOPS, CHNOF and CHNOSCl compound families. This ubiquitous fraction of compounds (orange) appears to originate from the upstream location or to be part of the natural environment. 

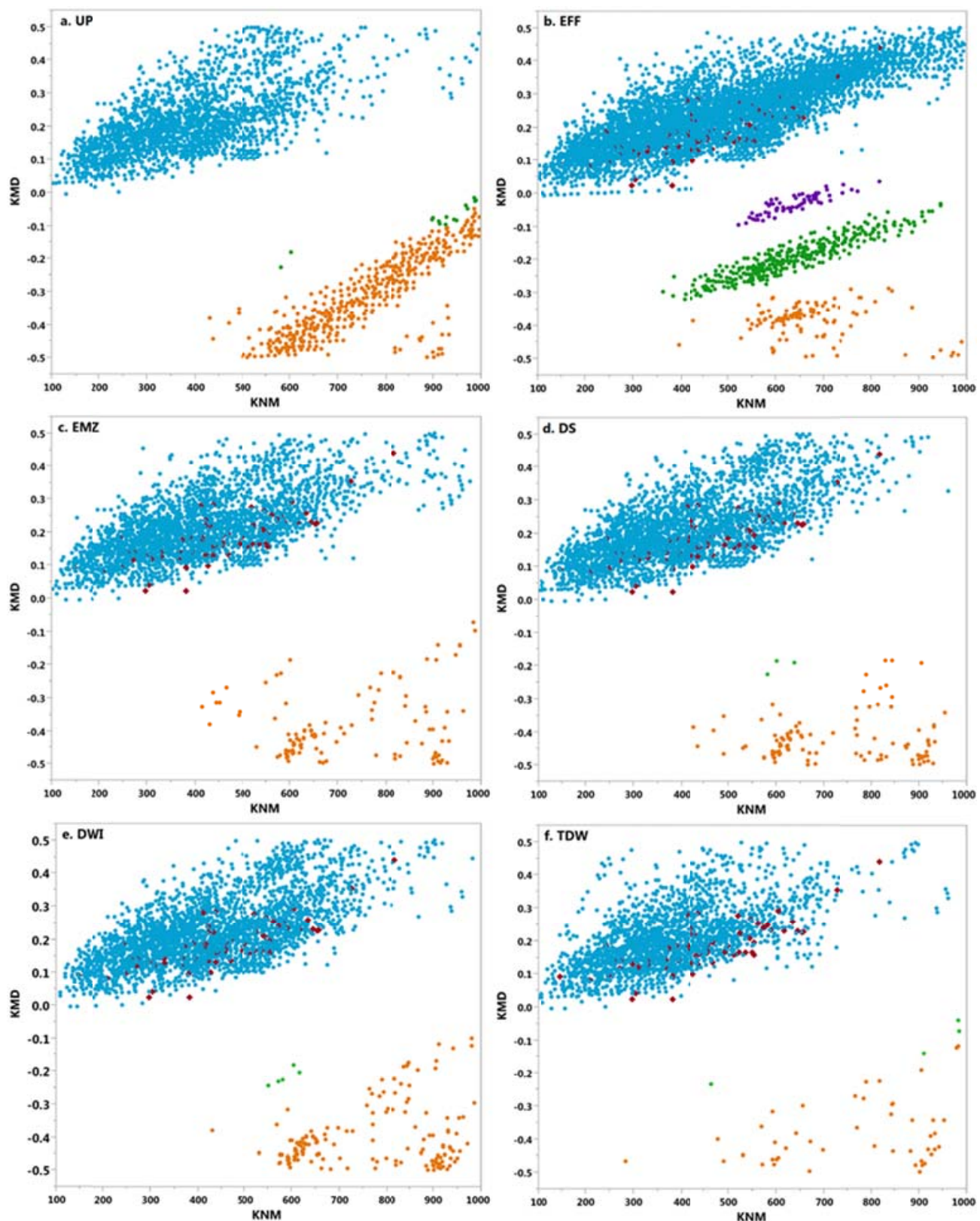

Fig. 4.5. Kendrick plots for each of the locations. a) UP, b) EFF, c) EMZ, d) DS, e) DWI, and f) TDW.

\subsubsection{Evaluation of drinking water treatment}

Qualitative comparison of DWI and TDW samples using a 2-way Venn diagram shown in Fig. 4.6 provided a general overview of relevant features from the intersections of these two sources. As shown in table 4.2, drinking water intake contained a wide 
number of chemicals that are exposed to different types of processes upon entering the treatment facility. Chlorine is typically used as a disinfectant in drinking water and multiple controlled laboratory and real finish drinking water studies have reported the formation of pharmaceutical DBPs upon interaction with chlorine (Deborde and von Gunten 2008; Postigo and Richardson 2014); in addition, other disinfection methods such as the use of Chloramine, Ozone or UV radiation could also introduce additional unintended byproducts to the finished drinking water. Therefore, it is not only important to recognize chemical features that may persist through treatment but also those that appear during treatment. A total of 4,381 features were initially detected in the drinking water intake, and $26 \%$ of these masses were additionally identified in the treated water. This percentage represents the fraction of chemicals that withstand treatment. Moreover, treated water demonstrated the presence of several chemical species that were unique to the TDW location (Fig. 4.6).

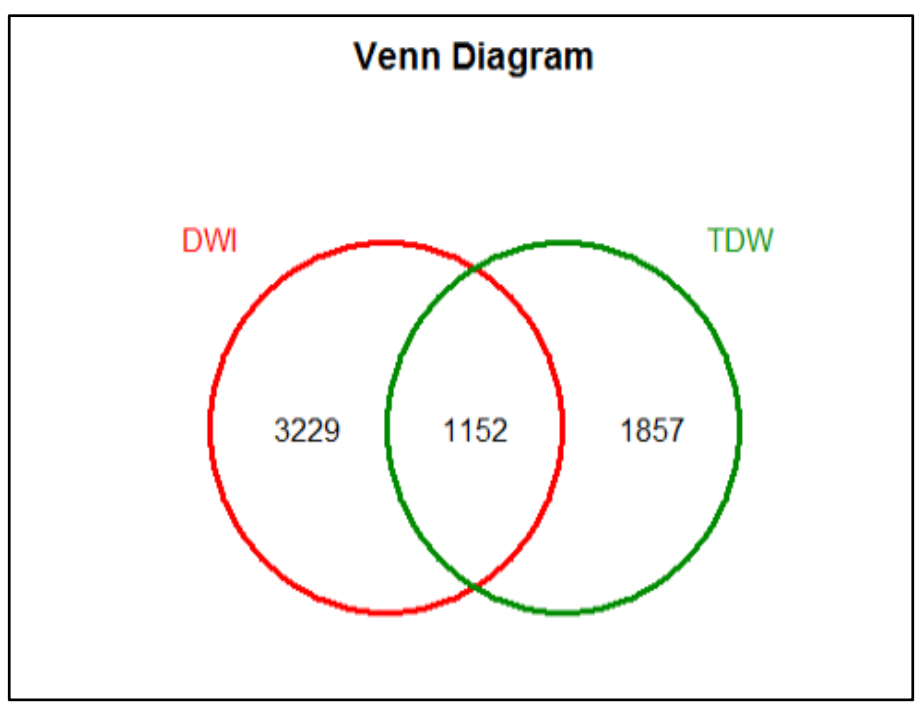

Fig. 4.6. 2-way Venn diagram of DWI and TDW samples. 
Sample intensities were used to determine the percent difference between the two sources. Despite limitations introduced by the ionization efficiencies, possible losses during the extraction process and differences associated with the water retention time in the treatment plant, Fig. 4.7 clearly shows a fraction of chemicals that were unique to the drinking water intake (red) and treated drinking water (green) locations. The blue symbols in the central region of the graph represent the chemical entities that were found in both end members (purple diamonds represent the 64 recalcitrant chemicals). This area can be further divided into three: chemicals that showed higher intensity values in the DWI than the TDW location (above the zero line), components in which an increase in signal was observed in the TDW location (below the zero line), and features near the zero line, for which their abundance remained similar before and after treatment.

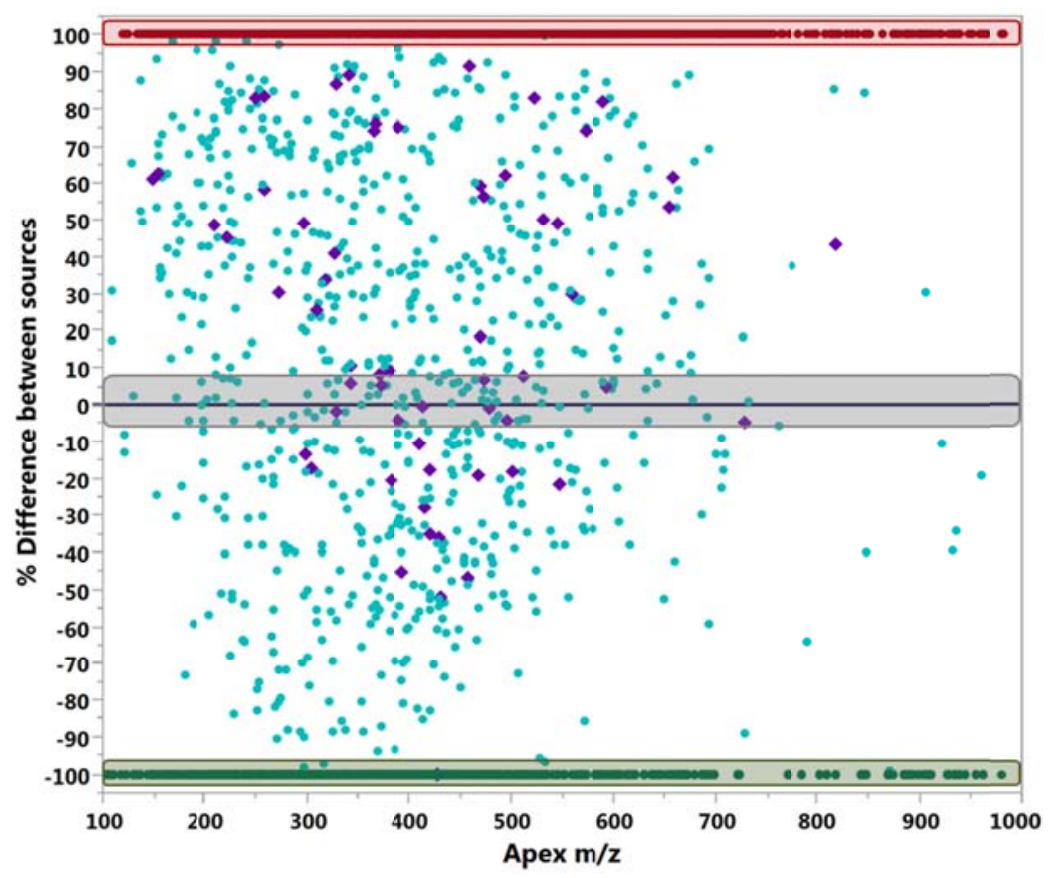

Fig. 4.7. Percent difference between the DWI and TDW locations using the intensities. Red indicates components found only in DWI. Green indicates components found only in TDW. Purple diamonds indicate the 64 recalcitrant chemicals. Blue dots represent components found in both locations. Dots near the zero line represent chemicals that have similar intensities before and after treatment. 


\subsection{Conclusion}

Non-target analysis of treated wastewater effluent, surface water, and treated drinking water using a high-resolution QExactive mass spectrometer revealed the presence of a large array of chemical formulae. Wastewater effluent and treated drinking water proved to be the most chemically diverse samples with 97 and 95 different compound classes respectively. However, total intensities for treated drinking water were more than an order of magnitude lower than those from the effluent. In addition, upon exclusion of any molecular formulae present at the upstream location, it was determined that a total of 64 components introduced from the effluent location persistent through all the samples including the final treated drinking water. Target MS/MS in combination with in-silico fragmentation software packages were used to tentatively confirm the identity of four of these 64 recalcitrant chemicals.

Comparison between the drinking water intake and the treated drinking water demonstrated that $74 \%$ of the chemicals entering the drinking treatment plant were no longer present in the treated water following treatment. A portion of persistent chemical entities $(n=1,152)$ were observed in both end-members showing differences in intensity before and after treatment. These findings suggest that treatment technologies to date are not fully capable to remove chemical residues which may be present in wastewater and/or drinking water sources.

The combination of high-resolution instruments, fragmentation prediction software packages, and post-acquisition data mining provided the means necessary for characterization, identification, and tentative confirmation of chemicals found in surface waters matrices. This approach can be applied to other scenarios to help recognize 
differences and similarities among multiple sites, and to identify potential sources of contamination.

\subsection{Acknowledgements}

We would like to thank Drs. Susan Glassmeyer and Mark Mills from the US Environmental Protection Agency (USEPA) for providing all of the samples for this work as part of the WW2DW project. NH acknowledges the support from FIU's University Graduate School through the award of a Dissertation Year Fellowship (DYF). We would also like to thank Thermo Scientific for providing partial analytical support. Special thanks to Miguel Parra for providing statistical analysis and software support. 


\subsection{References}

Baker DR, Kasprzyk-hordern B. Multi-residue analysis of drugs of abuse in wastewater and surface water by solid-phase extraction and liquid chromatography - positive electrospray ionisation tandem mass spectrometry. J Chromatogr A. 2011;1218:1620-31.

Barceló D, Kostianoy AG, (ed.). The Handbook of Environmental Chemistry: Emerging Organic Contaminants and Human Health. Springer-Verlag. Berlin Heidelberg; 2012.

Bartelt-hunt SL, Snow DD, Damon T, Shockley J, Hoagland K. The occurrence of illicit and therapeutic pharmaceuticals in wastewater effluent and surface waters in Nebraska. Environ Pollut. 2009;157:786-91.

Batchu SR, Quinete N, Panditi VR, Gardinali PR. Online solid phase extraction liquid chromatography tandem mass spectrometry (SPE-LC-MS/MS) method for the determination of sucralose in reclaimed and drinking waters and its photo degradation in natural waters from South Florida. Chem Cent J. 2013 Jan;7(1):141.

Ben-Jonathan N, Steinmetz R. Xenoestrogens: the emerging story of bisphenol a. Trends Endocrinol Metab [Internet]. 1998 Apr;9(3):124-8. Available from: http://www.ncbi.nlm.nih.gov/pubmed/18406253

Bletsou AA, Jeon J, Hollender J, Archontaki E, Thomaidis NS. Targeted and nontargeted liquid chromatography-mass spectrometric workflows for identification of transformation products of emerging pollutants in the aquatic environment. Trends Anal Chem [Internet]. Elsevier B.V.; 2015;66:32-44. Available from: http://dx.doi.org/10.1016/j.trac.2014.11.009

Castiglioni S, Valsecchi S, Polesello S, Rusconi M, Melis M, Palmiotto M, et al. Sources and fate of perfluorinated compounds in the aqueous environment and in drinking water of a highly urbanized and industrialized area in Italy. J Hazard Mater [Internet]. Elsevier B.V.; 2014;282:51-60. Available from: http://dx.doi.org/10.1016/j.jhazmat.2014.06.007

Chiaia-Hernandez AC, Krauss M, Hollender J. Screening of lake sediments for emerging contaminants by liquid chromatography atmospheric pressure photoionization and electrospray ionization coupled to high resolution mass spectrometry. Environ Sci Technol [Internet]. 2013 Jan 15;47(2):976-86. Available from: http://www.ncbi.nlm.nih.gov/pubmed/23215447

Chiaia-Hernandez AC, Schymanski EL, Kumar P, Singer HP, Hollender J. Suspect and nontarget screening approaches to identify organic contaminant records in lake 
sediments. Anal Bioanal Chem [Internet]. 2014 Sep 26 [cited 2014 Oct 21]; Available from: http://www.ncbi.nlm.nih.gov/pubmed/25258286

Deborde M, von Gunten U. Reactions of chlorine with inorganic and organic compounds during water treatment-Kinetics and mechanisms: A critical review. Water Res. 2008;42(1-2):13-51.

Gonsior M, Zwartjes M, Cooper WJ, Song W, Ishida KP, Tseng LY, et al. Molecular characterization of effluent organic matter identified by ultrahigh resolution mass spectrometry. Water Res [Internet]. Elsevier Ltd; 2011 Apr [cited 2014 Sep 7];45(9):2943-53. Available from: http://www.ncbi.nlm.nih.gov/pubmed/21477837

González-Mariño I, Quintana JB, Rodríguez I, González-Díez M, Cela R. Screening and Selective Quantification of Illicit Drugs in Wastewater by Mixed-Mode Solid-Phase Extraction and Quadrupole-Time-of- Flight Liquid Chromatography-Mass Spectrometry. Anal Chem. 2012;84:1708-17.

Gros M, Petrović M, Ginebreda A, Barceló D. Removal of pharmaceuticals during wastewater treatment and environmental risk assessment using hazard indexes. Environ Int [Internet]. Elsevier Ltd; 2010;36:15-26. Available from: http://dx.doi.org/10.1016/j.envint.2009.09.002

Hernández F, Ibáñez M, Portolés T, Cervera MI, Sancho J V., López FJ. Advancing Towards Universal Screening for Organic Pollutants in Waters. J Hazard Mater [Internet]. 2014;282:86-95. Available from: http://linkinghub.elsevier.com/retrieve/pii/S030438941400661X

Heuett N V., Batchu SR, Gardinali PR. Understanding the magnitude of emergent contaminant releases through target screening and metabolite identification using high resolution mass spectrometry: Illicit drugs in raw sewage influents. J Hazard Mater [Internet]. Elsevier B.V.; 2015;282:41-50. Available from: http://linkinghub.elsevier.com/retrieve/pii/S0304389414006645

Huerta-Fontela M, Galceran MT, Martin-Alonso J, Ventura F. Occurrence of psychoactive stimulatory drugs in wastewaters in north-eastern Spain. Sci Total Environ. 2008;397:31-40.

Hug C, Ulrich N, Schulze T, Brack W, Krauss M. Identification of novel micropollutants in wastewater by a combination of suspect and nontarget screening. Environ Pollut [Internet]. Elsevier Ltd; 2014 Jan [cited 2014 May 15];184:25-32. Available from: http://www.ncbi.nlm.nih.gov/pubmed/24012788

Jernberg J, Pellinen J, Rantalainen A-L. Identification of organic xenobiotics in urban aquatic environments using time-of-flight mass spectrometry. Sci Total Environ 
[Internet]. Elsevier B.V.; 2013;450-451:1-6. Available from: http://www.ncbi.nlm.nih.gov/pubmed/23454570

Kasprzyk-hordern B, Dinsdale RM, Guwy AJ. Multiresidue methods for the analysis of pharmaceuticals, personal care products and illicit drugs in surface water and wastewater by solid-phase extraction and ultra performance liquid chromatography - electrospray tandem mass spectrometry. Anal Bioanal Chem. 2008;391:1293-308.

Kind T, Fiehn O. Seven Golden Rules for heuristic filtering of molecular formulas obtained by accurate mass spectrometry. BMC Bioinformatics. 2007;8:105.

Krauss M, Singer H, Hollender J. LC-high resolution MS in environmental analysis: from target screening to the identification of unknowns. Anal Bioanal Chem [Internet]. 2010 Jun [cited 2013 Nov 20];397(3):943-51. Available from: http://www.ncbi.nlm.nih.gov/pubmed/20232059

Lacey C, Basha S, Morrissey A, Tobin JM. Occurrence of pharmaceutical compounds in wastewater process streams in Dublin, Ireland. Environ Monit Assess [Internet]. 2012 Jan [cited 2014 Sep 2];184(2):1049-62. Available from: http://www.ncbi.nlm.nih.gov/pubmed/21479558

Leerdam JA Van, Vervoort J, Stroomberg G, Voogt P De. Identification of Unknown Microcontaminants in Dutch River Water by Liquid Chromatography-High Resolution Mass Spectrometry and Nuclear Magnetic Resonance Spectroscopy. Environ Sci Technol. 2014;

Mesfioui R, Love NG, Bronk D a., Mulholland MR, Hatcher PG. Reactivity and chemical characterization of effluent organic nitrogen from wastewater treatment plants determined by Fourier transform ion cyclotron resonance mass spectrometry. Water Res [Internet]. Elsevier Ltd; 2012;46(3):622-34. Available from: http://dx.doi.org/10.1016/j.watres.2011.11.022

Moschet C, Piazzoli A, Singer H, Hollender J. Alleviating the reference standard dilemma using a systematic exact mass suspect screening approach with liquid chromatography-high resolution mass spectrometry. Anal Chem [Internet]. 2013 Nov 5;85(21):10312-20. Available from: http://www.ncbi.nlm.nih.gov/pubmed/24161211

Moschet C, Wittmer I, Simovic J, Junghans M, Piazzoli A, Singer H, et al. How a complete pesticide screening changes the assessment of surface water quality. Environ Sci Technol [Internet]. 2014 May 20;48(10):5423-32. Available from: http://www.ncbi.nlm.nih.gov/pubmed/24821647 
Müller A, Schulz W, Ruck WKL, Weber WH. A new approach to data evaluation in the non-target screening of organic trace substances in water analysis. Chemosphere. 2011;85:1211-9.

Panditi VR, Batchu SR, Gardinali PR. Online solid-phase extraction-liquid chromatography-electrospray-tandem mass spectrometry determination of multiple classes of antibiotics in environmental and treated waters. Anal Bioanal Chem. 2013 Jul;405(18):5953-64.

Parolini M, Pedriali A, Riva C, Binelli A. Sub-lethal effects caused by the cocaine metabolite benzoylecgonine to the freshwater mussel Dreissena polymorpha. Sci Total Environ. Elsevier B.V.; 2013 Feb 1;444:43-50.

Postigo C, Alda MJL De, Barceló D. Drugs of abuse and their metabolites in the Ebro River basin: Occurrence in sewage and surface water, sewage treatment plants removal efficiency, and collective drug usage estimation. Environ Int. Elsevier Ltd; 2010;36(1):75-84.

Postigo C, Richardson SD. Transformation of Pharmaceuticals During Oxidation/Disinfection Processes in Drinking Water Treatment. J Hazard Mater [Internet]. Elsevier B.V.; 2014;279:461-75. Available from: http://linkinghub.elsevier.com/retrieve/pii/S0304389414005949

Rabiet M, Togola A, Brissaud F, Seidel J-L, Budzinski H, Elbaz-Poulichet F. Consequences of treated water recycling as regards pharmaceuticals and drugs in surface and ground waters of a medium-sized Mediterranean catchment. Environ Sci Technol [Internet]. 2006 Sep 1;40(17):5282-8. Available from: http://www.ncbi.nlm.nih.gov/pubmed/16999100

Richardson SD, Ternes $\mathrm{T}$ a. Water analysis: emerging contaminants and current issues. Anal Chem [Internet]. 2014 Mar 18;86(6):2813-48. Available from: http://www.ncbi.nlm.nih.gov/pubmed/24502364

Schymanski EL, Singer HP, Longrée P, Loos M, Ruff M, Stravs M a, et al. Strategies to characterize polar organic contamination in wastewater: exploring the capability of high resolution mass spectrometry. Environ Sci Technol [Internet]. 2014 Feb 4;48(3):1811-8. Available from: http://www.ncbi.nlm.nih.gov/pubmed/24417318

Segura P a., MacLeod SL, Lemoine P, Sauvé S, Gagnon C. Quantification of carbamazepine and atrazine and screening of suspect organic contaminants in surface and drinking waters. Chemosphere [Internet]. Elsevier Ltd; 2011;84(8):1085-94. Available from: http://dx.doi.org/10.1016/j.chemosphere.2011.04.056 
Sleno L. The use of mass defect in modern mass spectrometry. J Mass Spectrom [Internet]. 2012 Feb [cited 2014 Oct 19];47(2):226-36. Available from: http://www.ncbi.nlm.nih.gov/pubmed/22359333

Tseng LY, Gonsior M, Schmitt-Kopplin P, Cooper WJ, Pitt P, Rosso D. Molecular characteristics and differences of effluent organic matter from parallel activated sludge and integrated fixed-film activated sludge (IFAS) processes. Environ Sci Technol [Internet]. 2013 Sep 17;47(18):10277-84. Available from: http://www.ncbi.nlm.nih.gov/pubmed/23941532

Wang C, Gardinali PR. Detection and occurrence of microconstituents in reclaimed water used for irrigation--a potentially overlooked source. Anal Bioanal Chem. 2013 Jul;405(18):5925-35.

Wolf S, Schmidt S, Müller-Hannemann M, Neumann S. In silico fragmentation for computer assisted identification of metabolite mass spectra. BMC Bioinformatics. 2010;11:148.

Xiao F, Simcik MF, Gulliver JS. Perfluoroalkyl acids in urban stormwater runoff: Influence of land use. Water Res [Internet]. Elsevier Ltd; 2012;46(20):6601-8. Available from: http://dx.doi.org/10.1016/j.watres.2011.11.029 
CHAPTER 5

\section{Conclusions}


The overall objectives of this study were to develop target and non-target analytical methodologies on the basis of high-resolution mass spectrometry for the analysis and assessment of drugs of abuse (DOA) from raw sewage waters in a college campus, the identification of phase I and phase II DOA transformation products, and the identification and characterization of unknown recalcitrant compounds in different types of interconnected water matrices.

During the first part of this research, the successful development of a fully automated online-SPE-LC-HRMS method accomplished, and implemented to the comprehensive analysis of 18 drugs of abuse including some of their well-known metabolites. Two different locations (dorms and main campus) within a college campus yield detections for 14 DOAs. The two most abundant and prevalent drugs found among the two locations were amphetamine and THCs main metabolite (THC-COOH). Maximum concentrations observed throughout the one-year study were $5,956 \mathrm{ng} / \mathrm{L}$ and $2,413 \mathrm{ng} / \mathrm{L}$ for amphetamine and THC-COOH respectively.

Drug consumption estimates were determined for amphetamine, THC, heroin, and cocaine in the dorms and main campus. Low Levels of consumption $(<3$ doses/day/1000 people on average) were found for heroin and cocaine in both locations. Amphetamine intake range between 10 and 20 doses/day/1000 people (with higher levels being in the dorms), and remain constant throughout the beginning, middle and end of the semester in the dorms. THC consumption estimates were significantly higher in the dorms $(233 \pm 199$ doses/day/ 1000 people) than those in the main campus ( $46 \pm 26$ doses/day/1000 people). In addition, an increase in consumption for THC was noticeable and at the end of the semester in the dorms location. 
In the second portion of this study, two different acquisition modes (target MS/MS and data-dependent MS/MS) were compared and used in combination to metabolic identification and structural elucidation software to identify and confirmed a total of 35 phase I and phase II DOA metabolic transformation products. Even though, datadependent scan is a faster approach towards the potential identification of metabolites and acquires MS/MS data for all precursor ions above a specific intensity, target MS/MS was selected because it offered an acceptable and consistent number of data points across the chromatographic peak needed for the reliable confirmation of TPs.

Raw sewage samples collected in the main campus were used in this portion of the study, and concentrations for all detected TPs $(\mathrm{n}=54)$ were estimated based on the parent DOAs response factor and used to calculate the percent mole fractions (Mf). High frequency and abundance (compared to the parent compound) for nine of the TPs identified, solidifies the importance of evaluating the presence of TPs in water matrices to assess treatment efficiency in wastewater and drinking water treatment facilities; and to determine their fate, transport and potential toxicity in aquatic ecosystems.

Lastly, non-target analysis was carried out on six samples, from locations covering about nine miles of upstream (UP), effluent wastewater (EFF), effluent mixing zone, downstream (EMZ), drinking water intake (DWI), and treated drinking water (TDW). Full-scan post-acquisition data was mined following a series of heuristic steps for determining molecular compositions to establish their abundance (in number of formulas), and identify compound diversity among the locations.

Graphical interpretations of data (plots and diagrams) were used to identify relationship among locations following the effluent, and between the drinking water 
intake and the treated drinking water. Results show that a total of 64 compounds between the EFF-TDW trajectory remain persistent throughout this process. In addition, when comparing DWI and TDW, it was observed that 1,152 compounds survive drinking water treatment, and 1,857 analytes are formed during treatment. This demonstrates that treatment technologies to date are not designed to remove a substantial quantity of compounds. 
APPENDICES 
Appendix 1. MS/MS spectral comparison for TP identified as N-ethylamphetamine from TraceFinder database, and formed from methamphetamine (MA-4), MDEA (MDEA-4), and MDMA (MDMA-5) against an N-methylamphetamine reference standard.
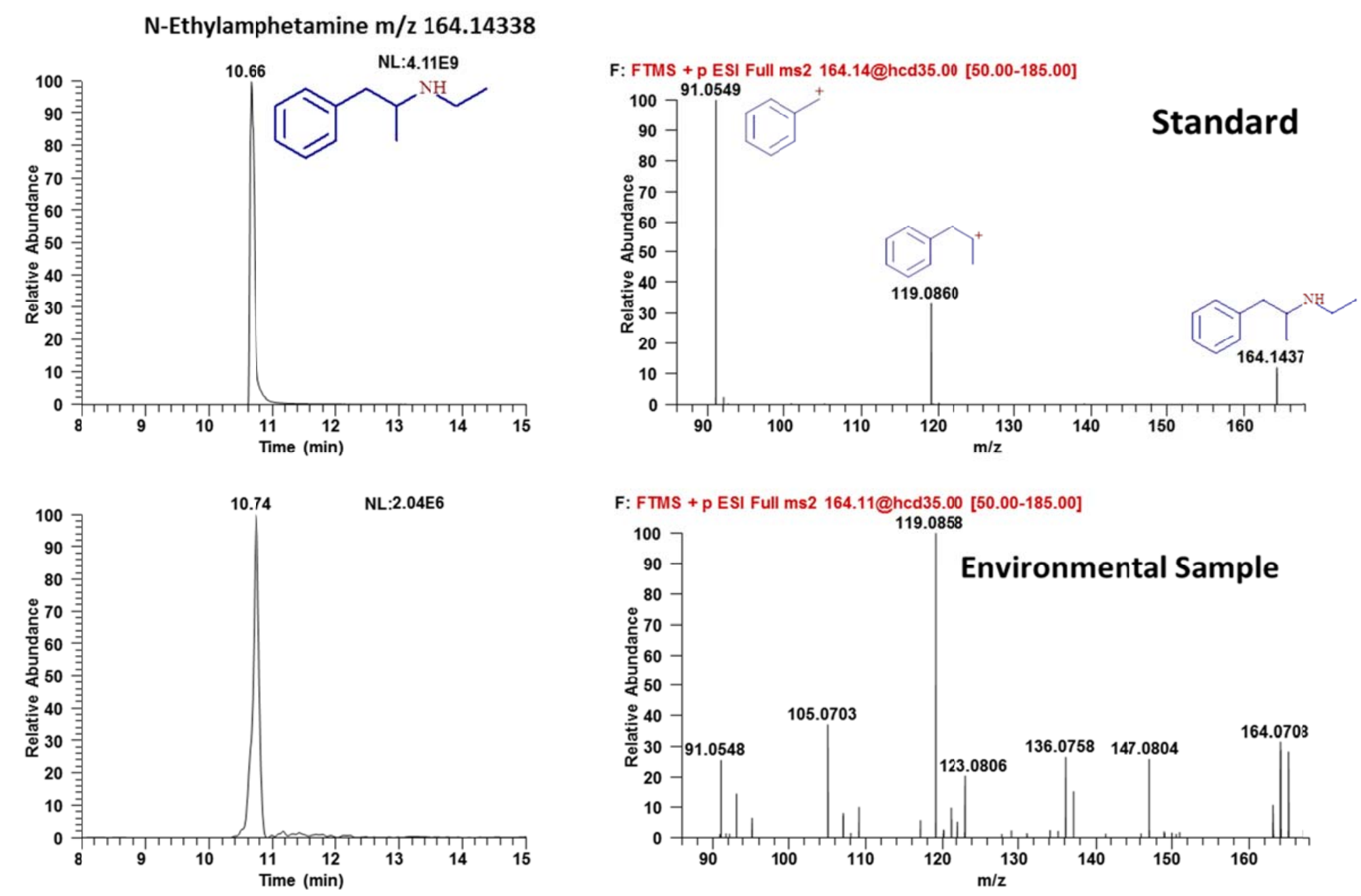
Appendix 2. MS/MS spectral comparison for TP identified as CE-1 formed from cocaethylene, had the same $\mathrm{m} / \mathrm{z} 290.1387$ as norcocaine and as the target metabolite benzoylecgonine. MS/MS fragmentation of sample was compared to both reference standards.
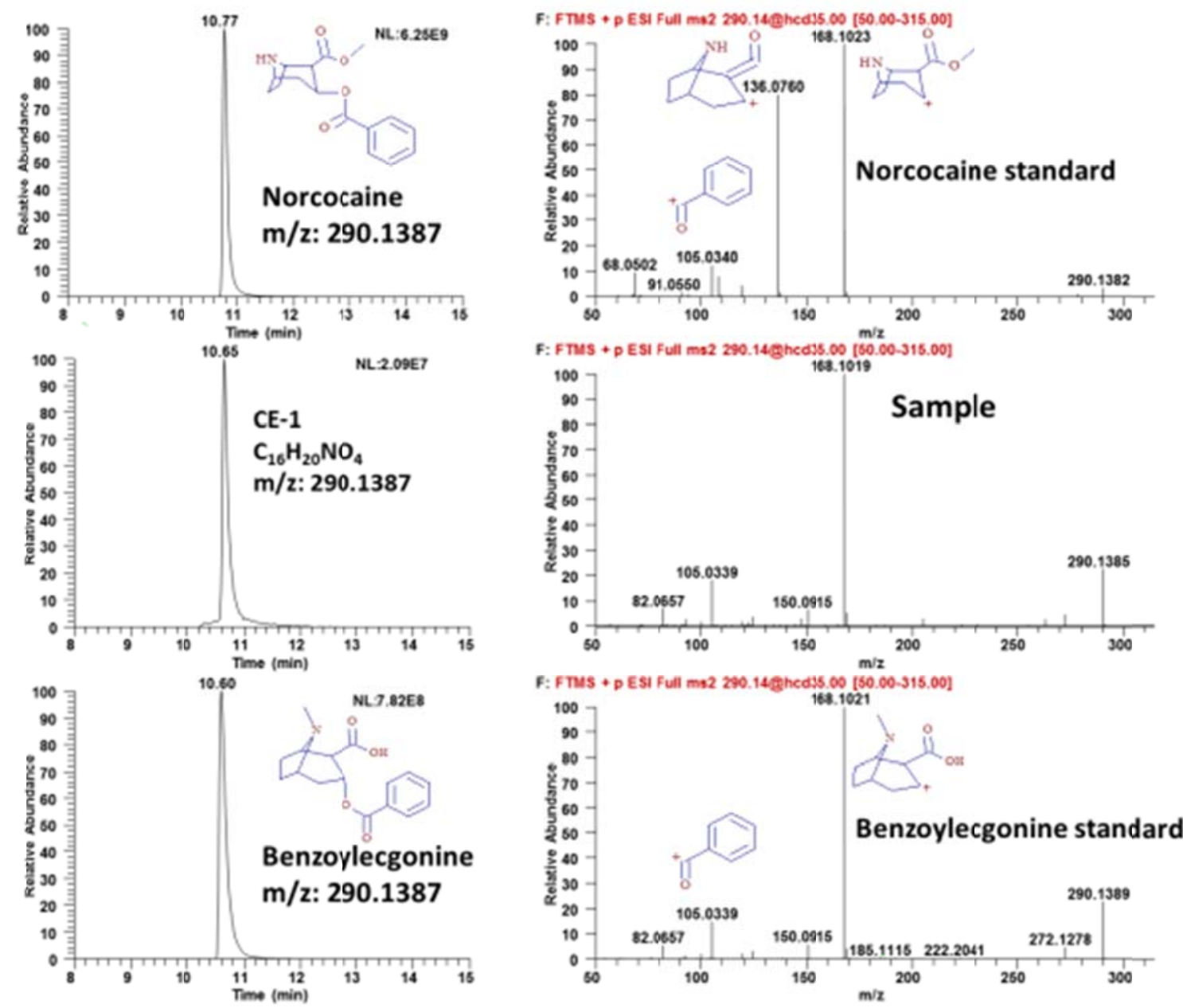
Appendix 1. MS/MS spectral elucidation for all target analytes (parents and their metabolites) and spectral elucidation for some of the identified TPs, showing tentative structure, chemical formulas, and mass error ( $\mathrm{ppm})$ is demonstrated. MS/MS spectra for all 54 TPs is presented.

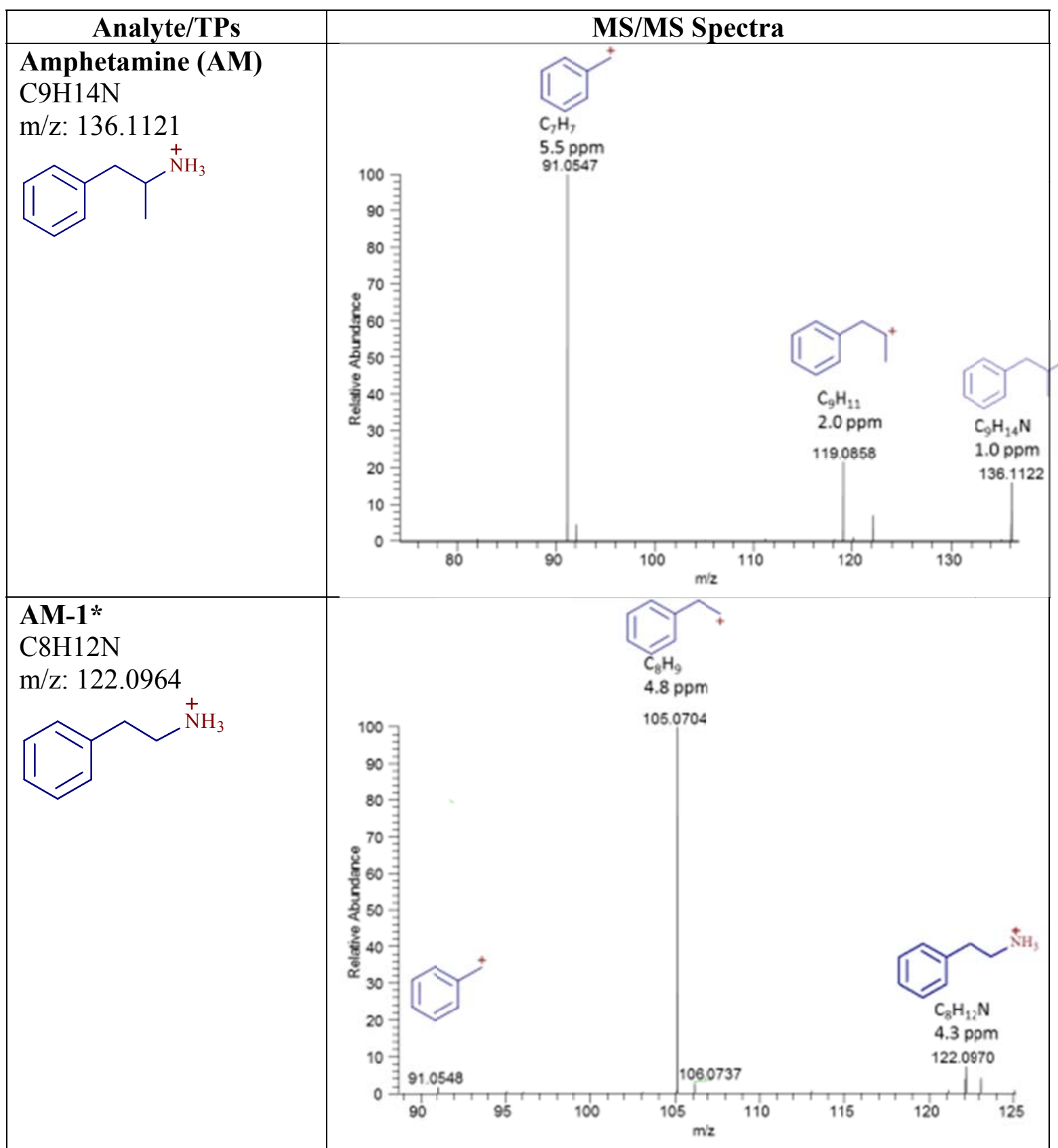




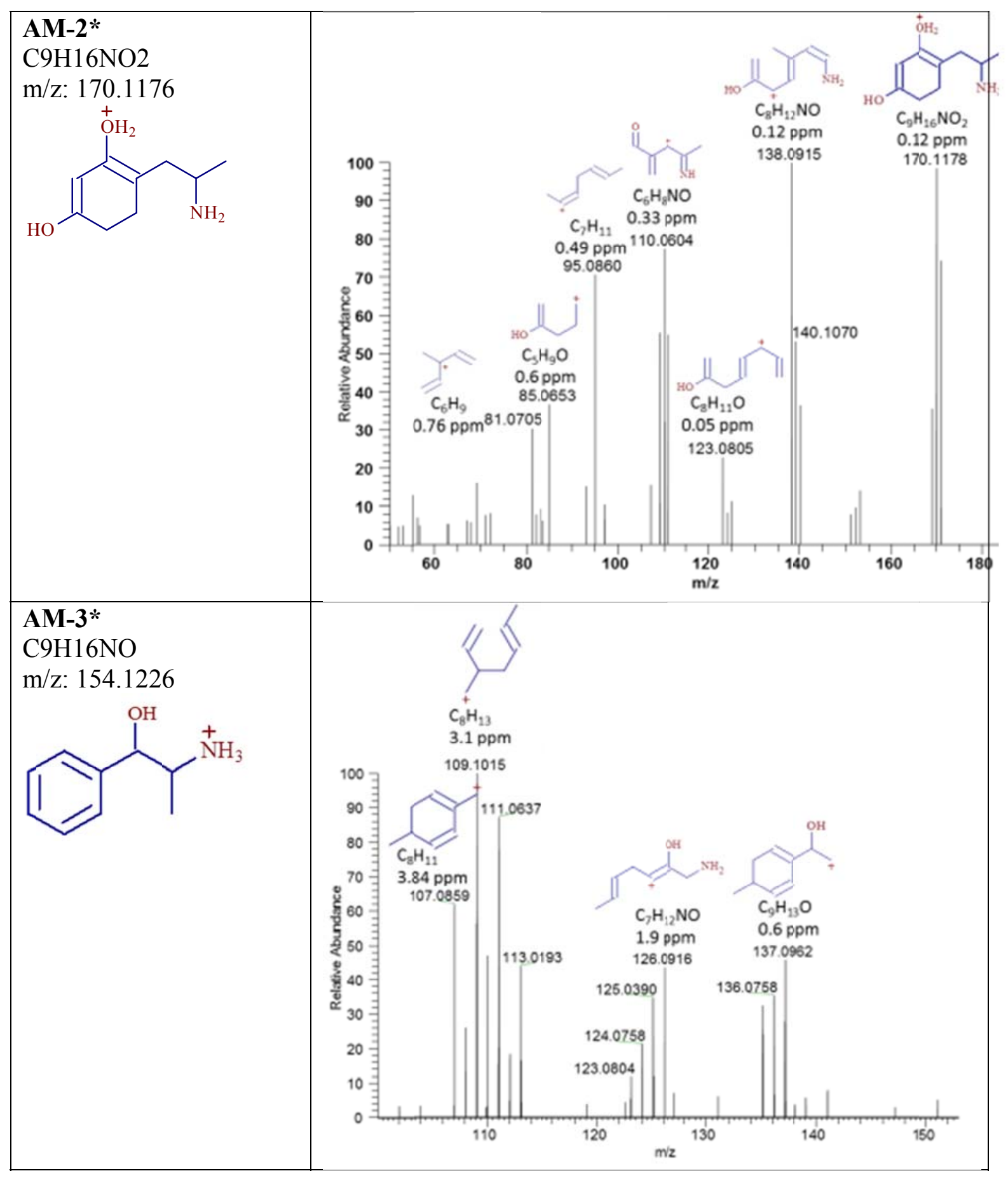




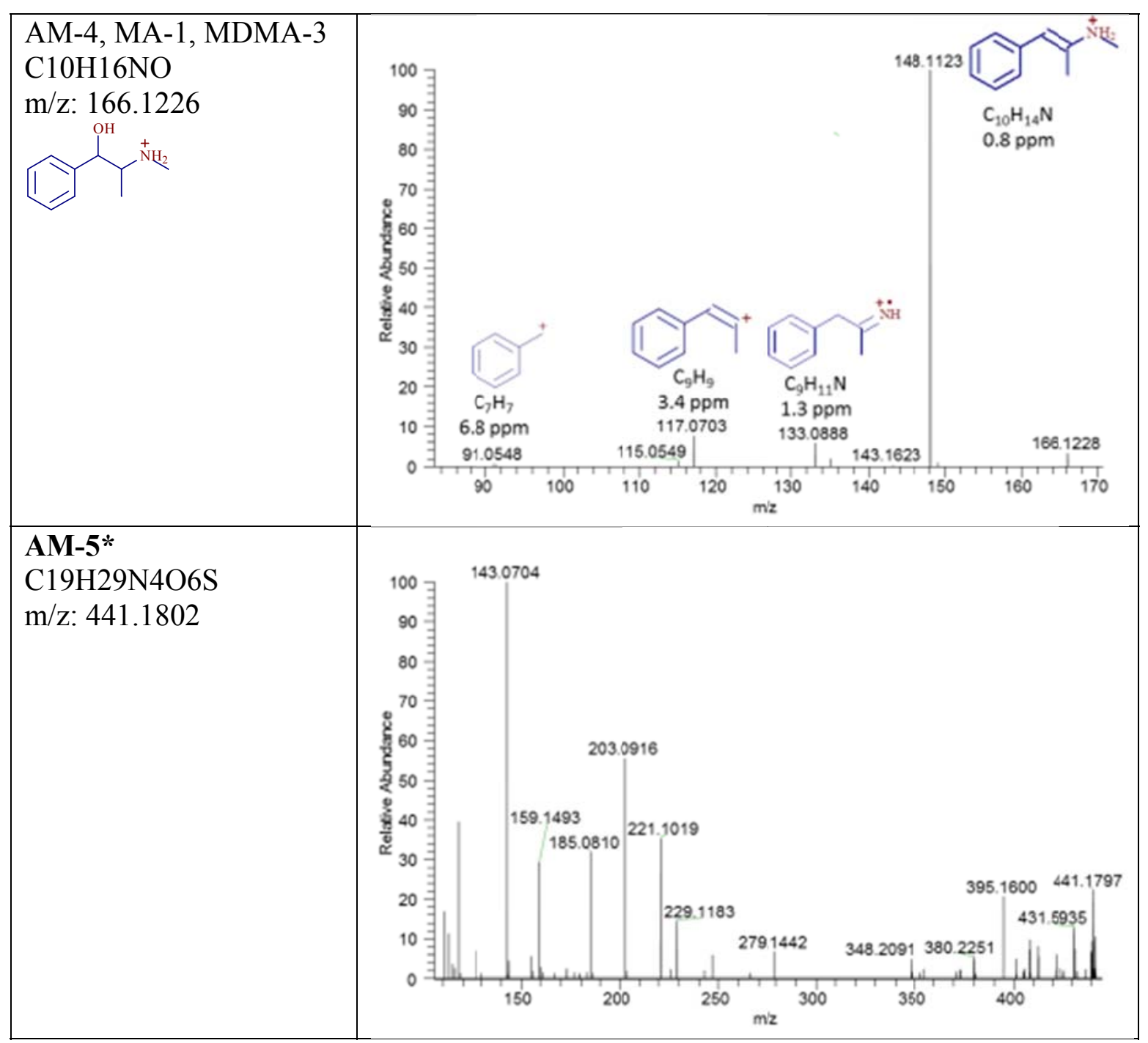




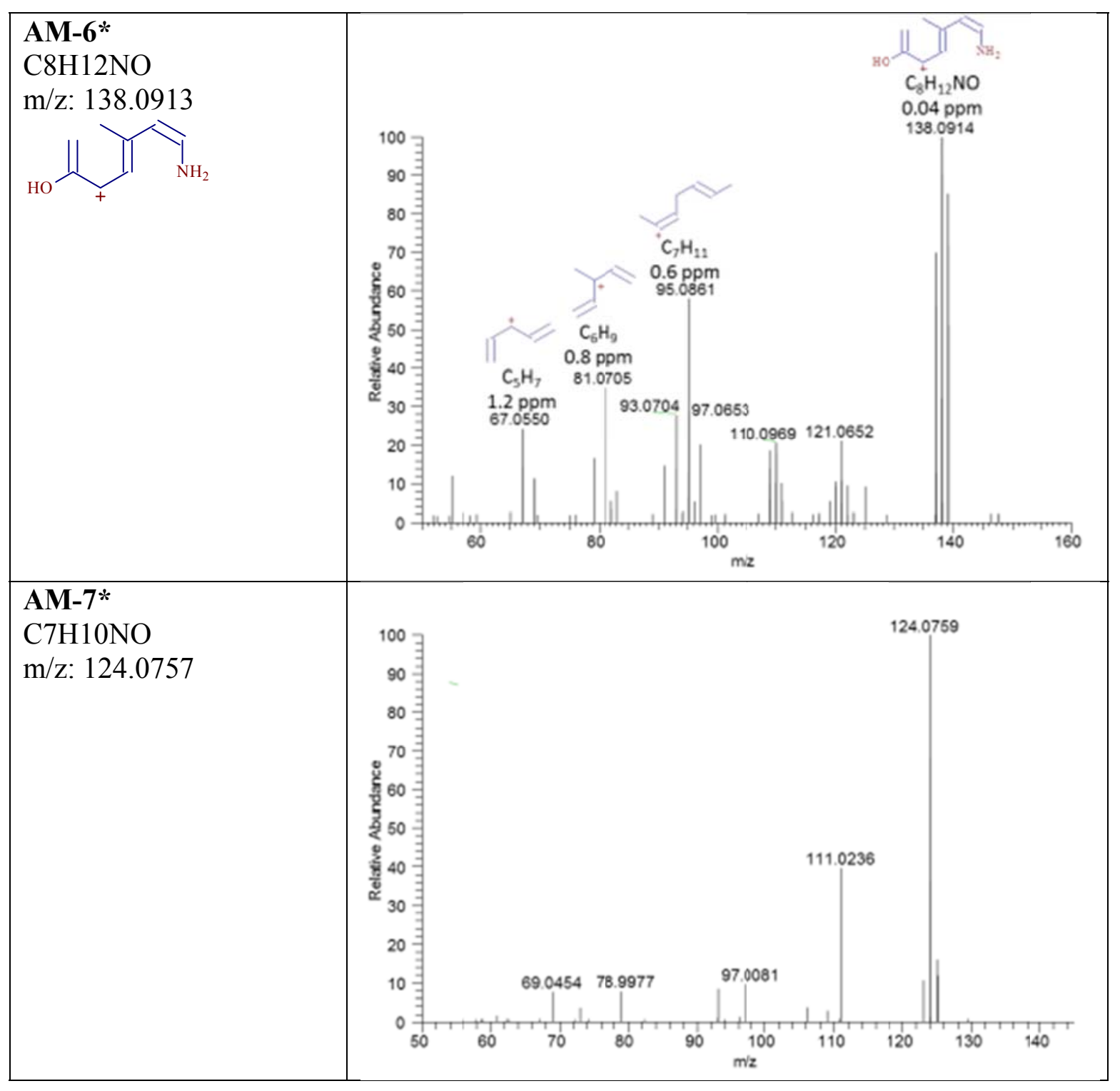




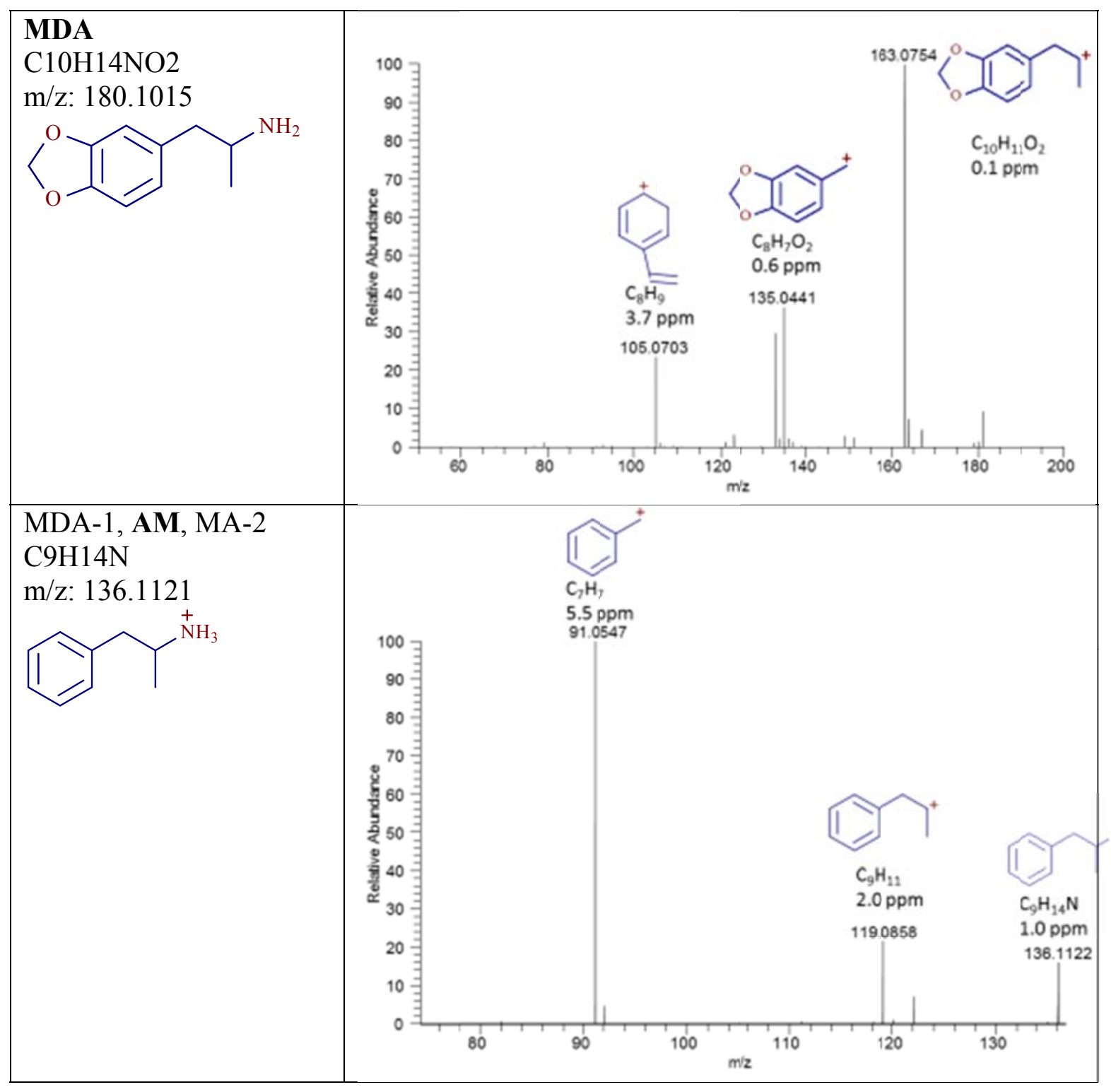




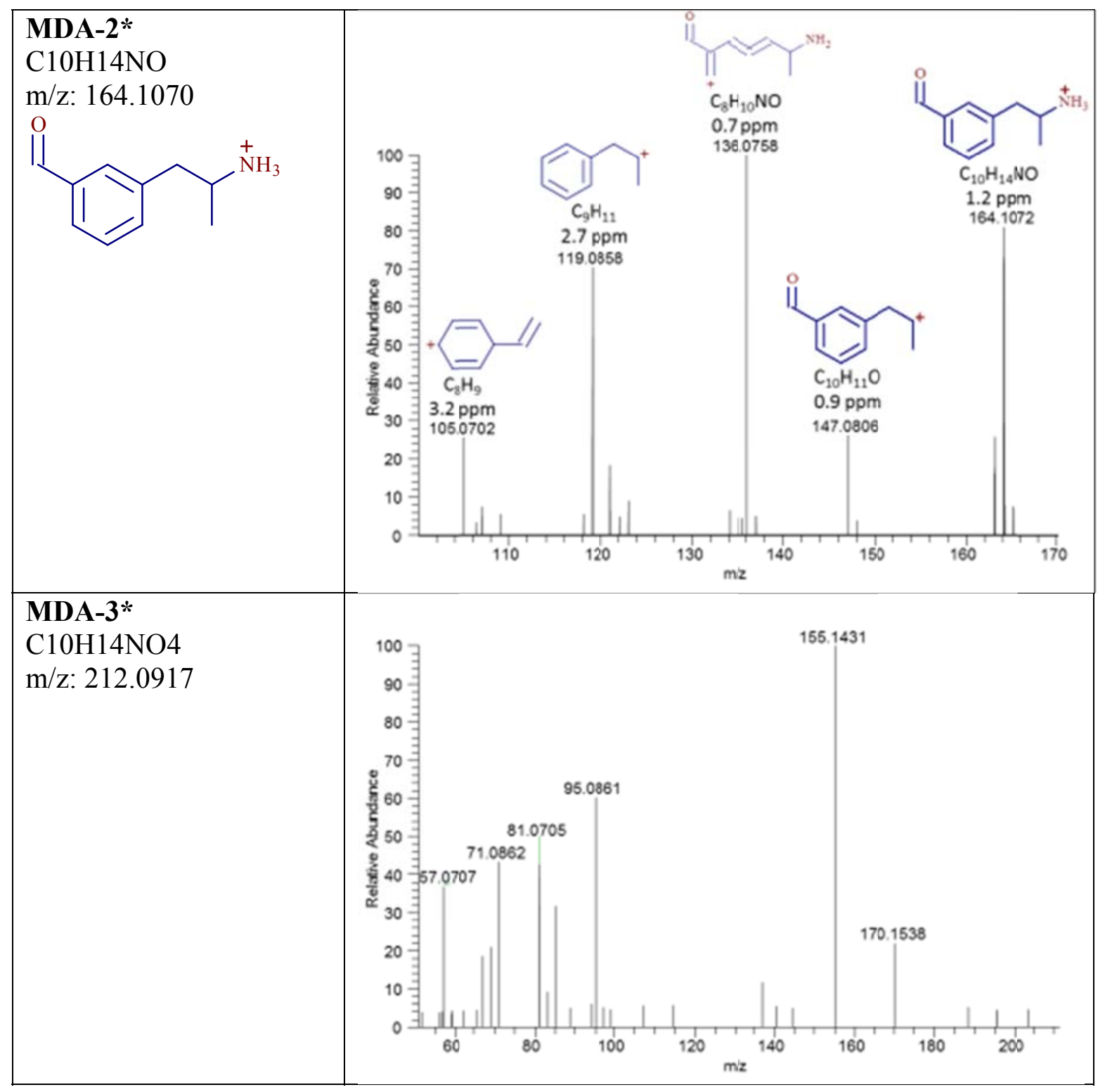




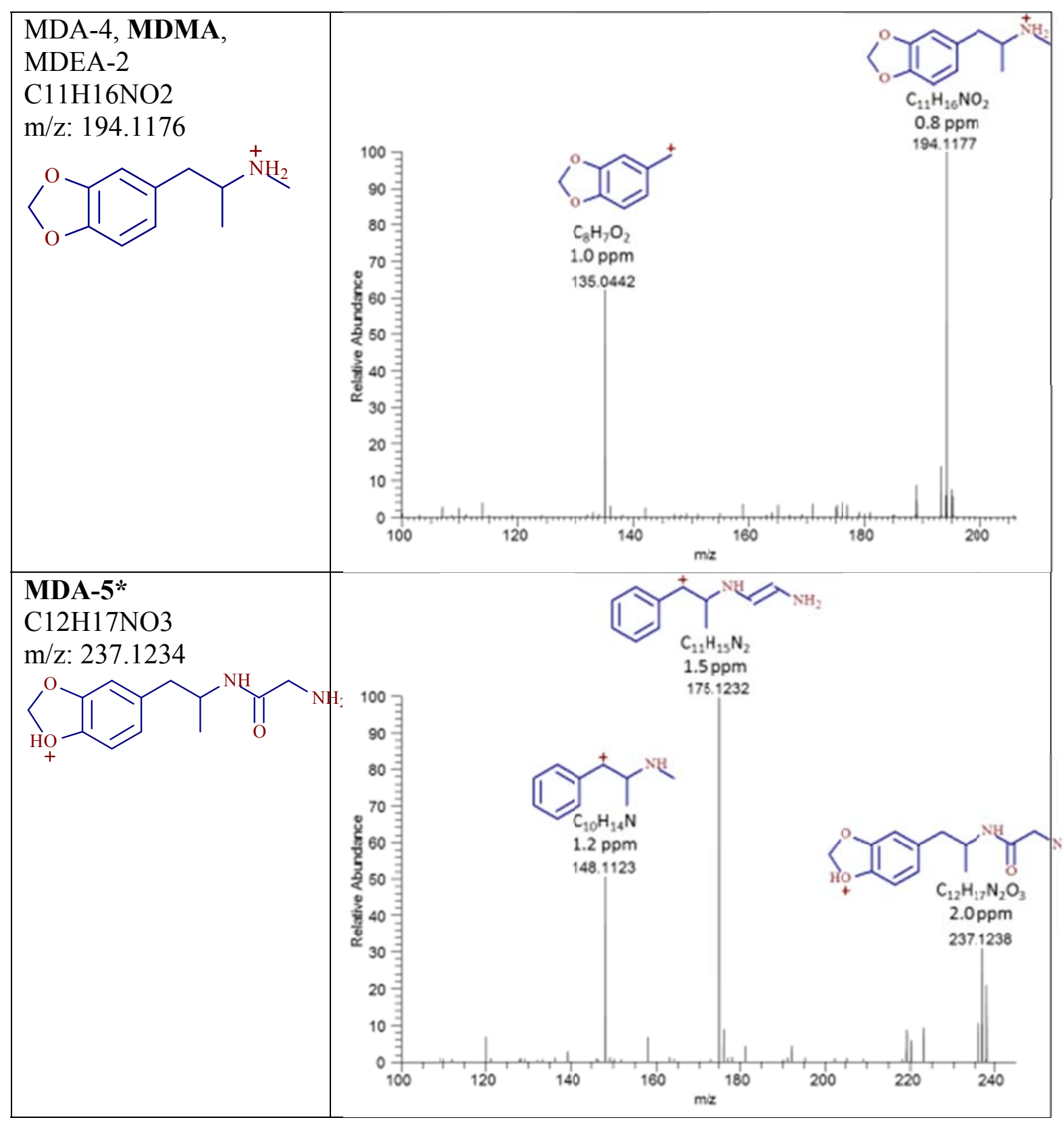




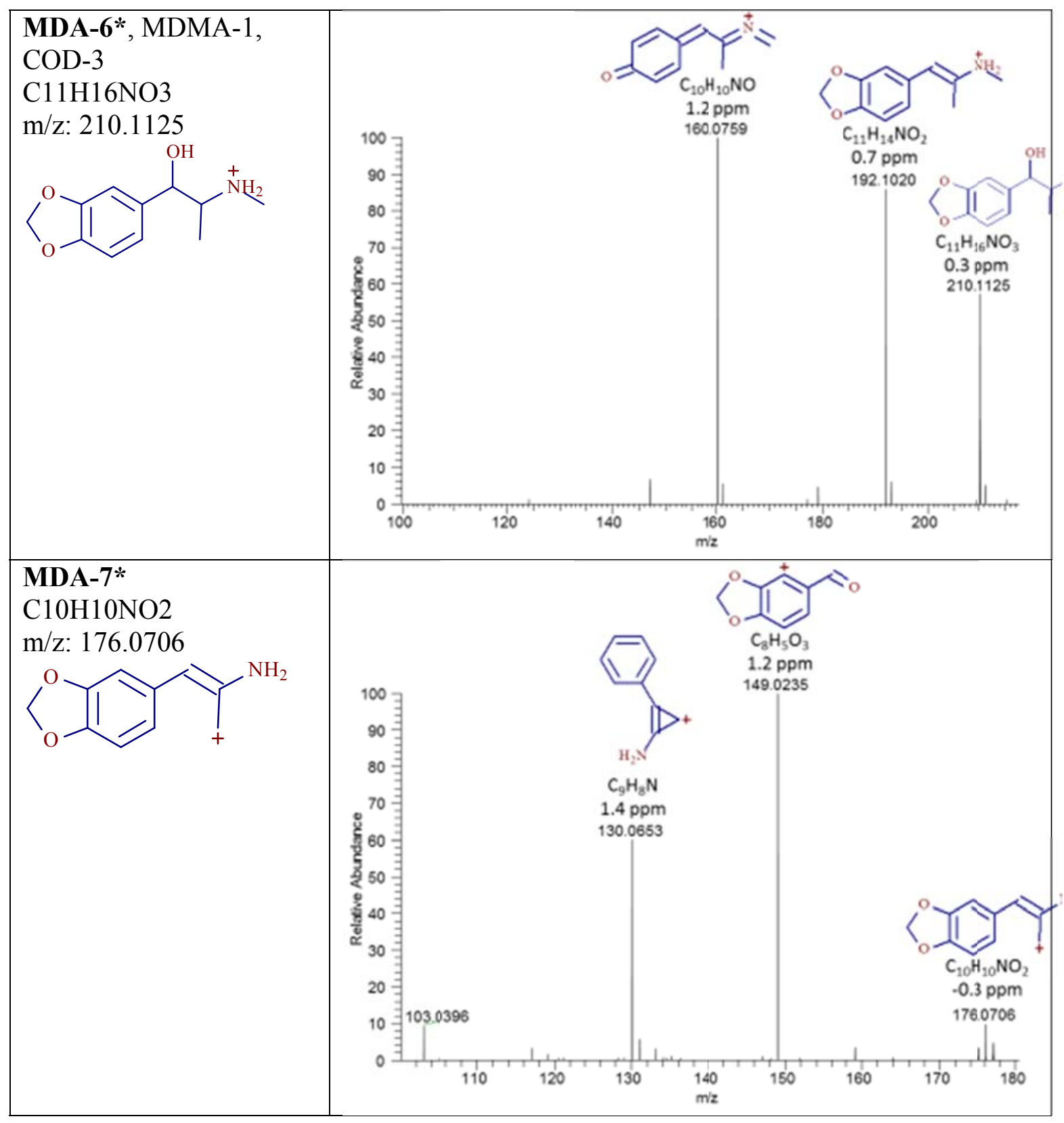




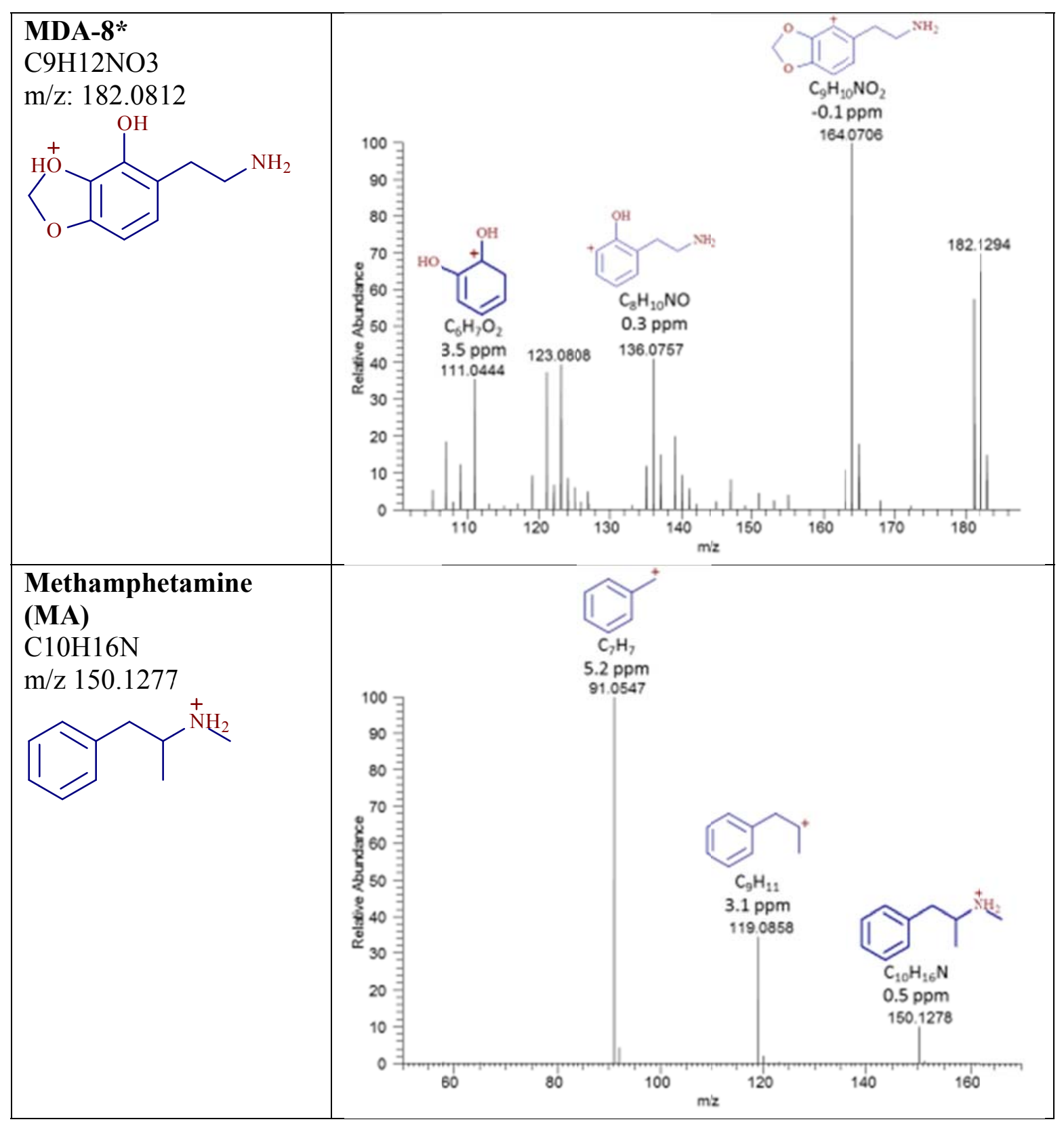




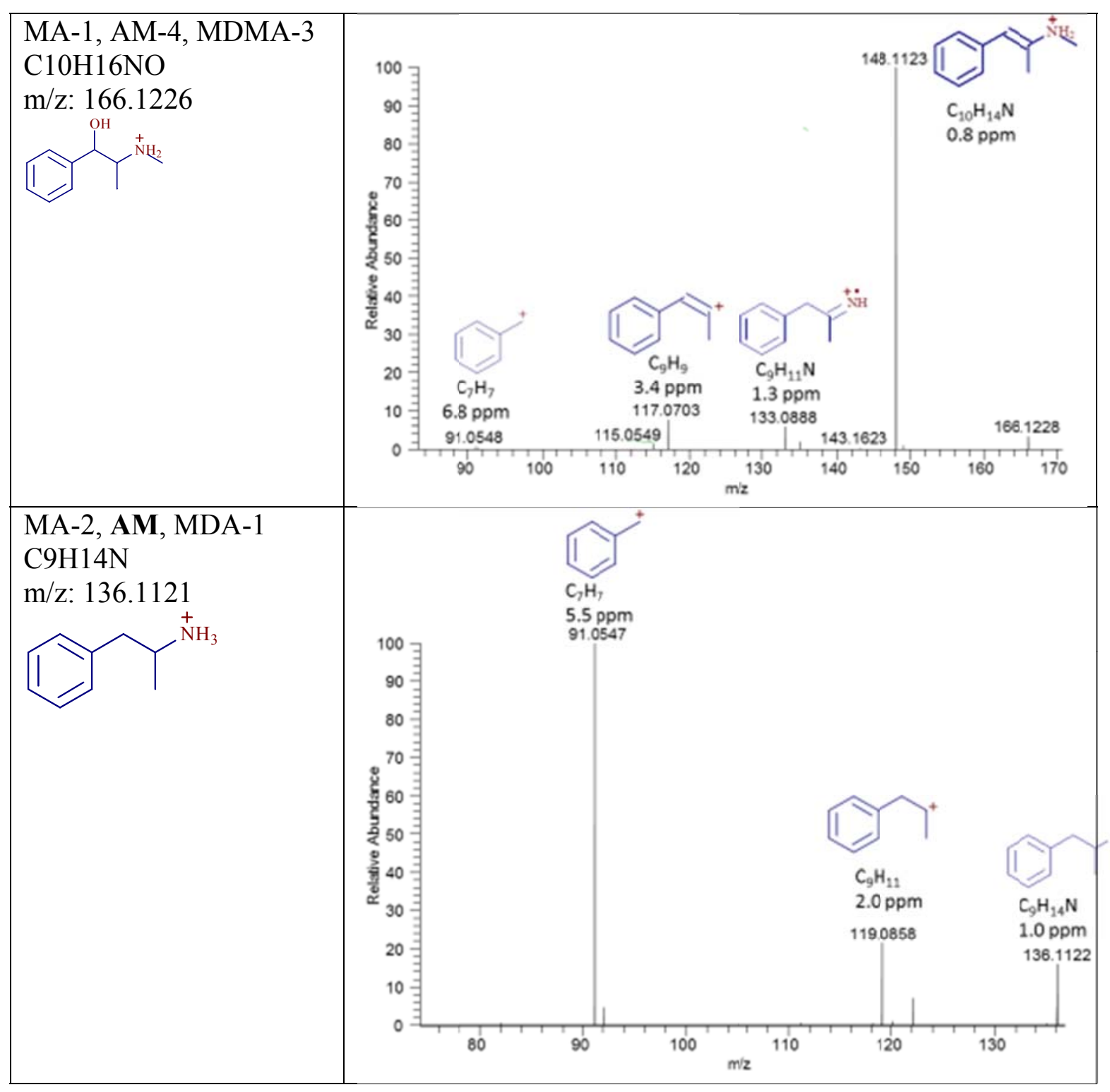




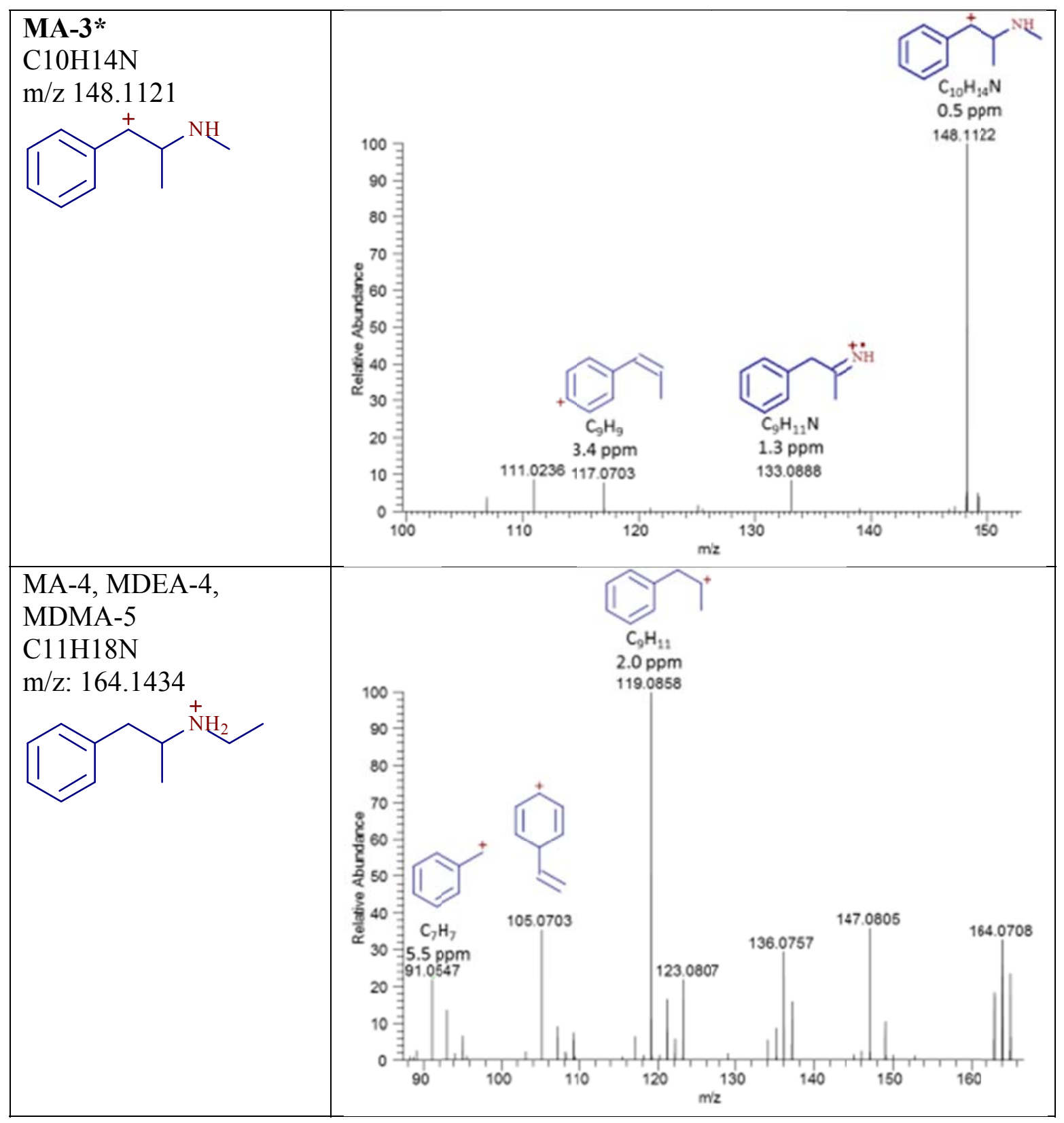




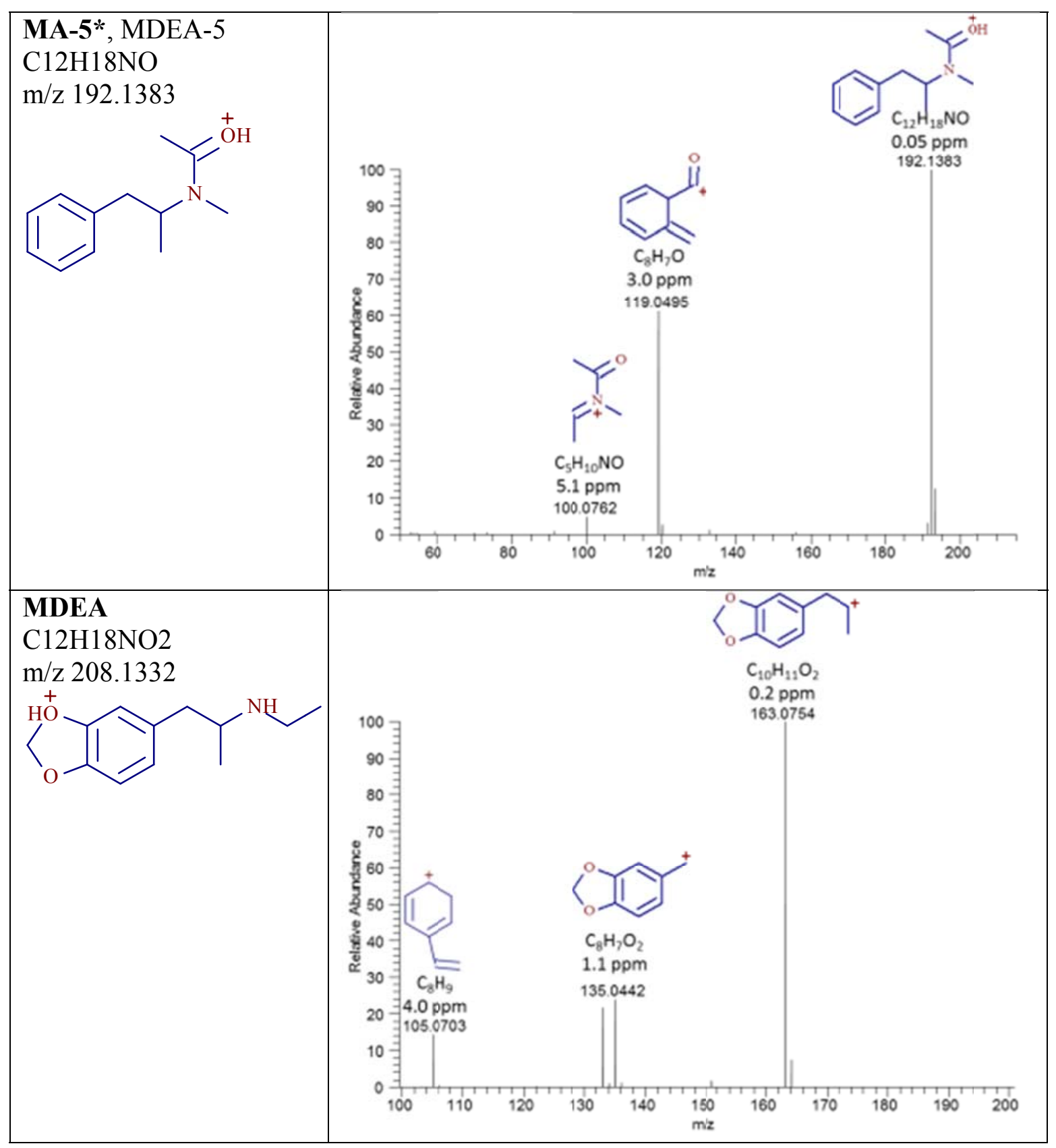




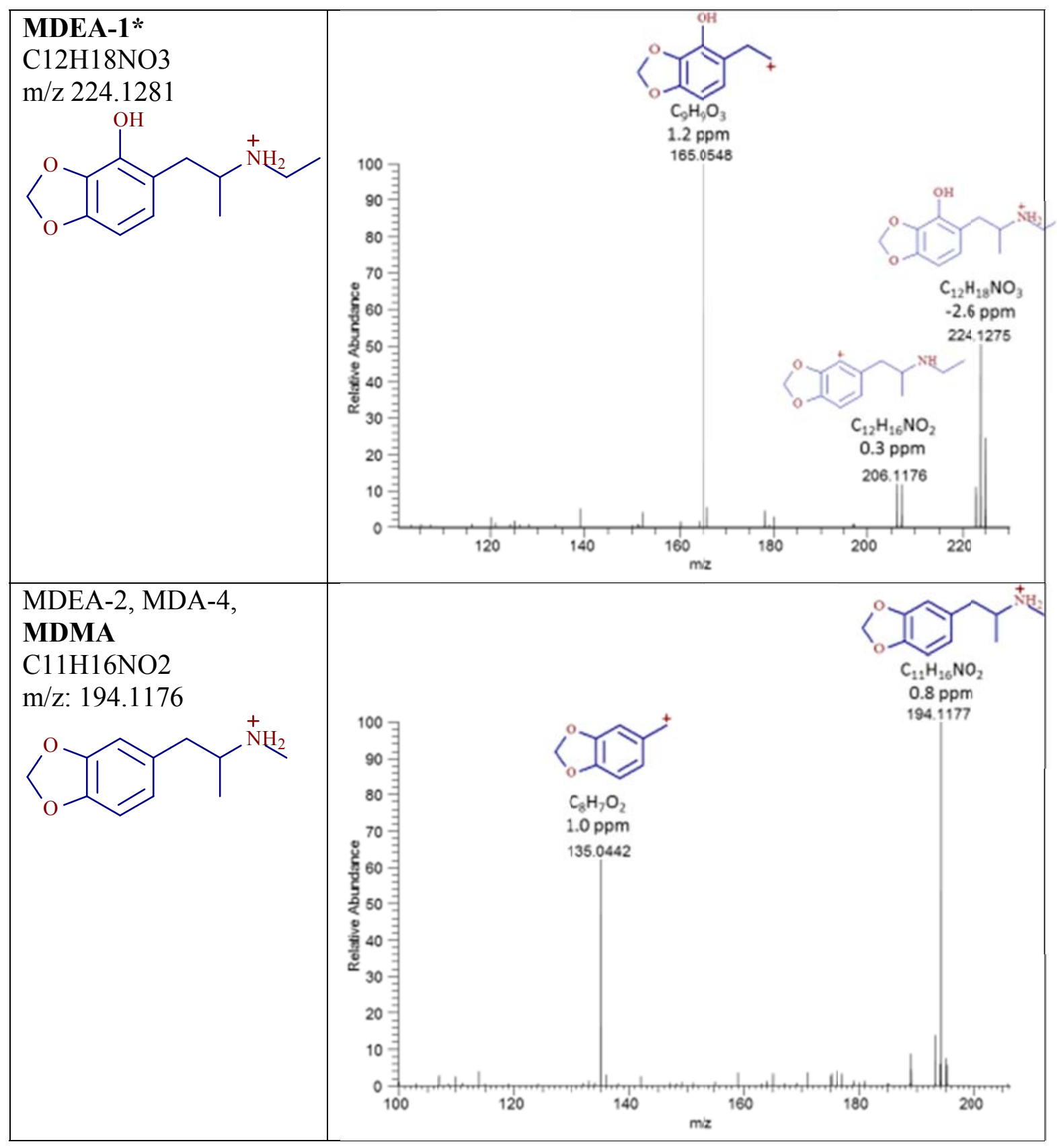




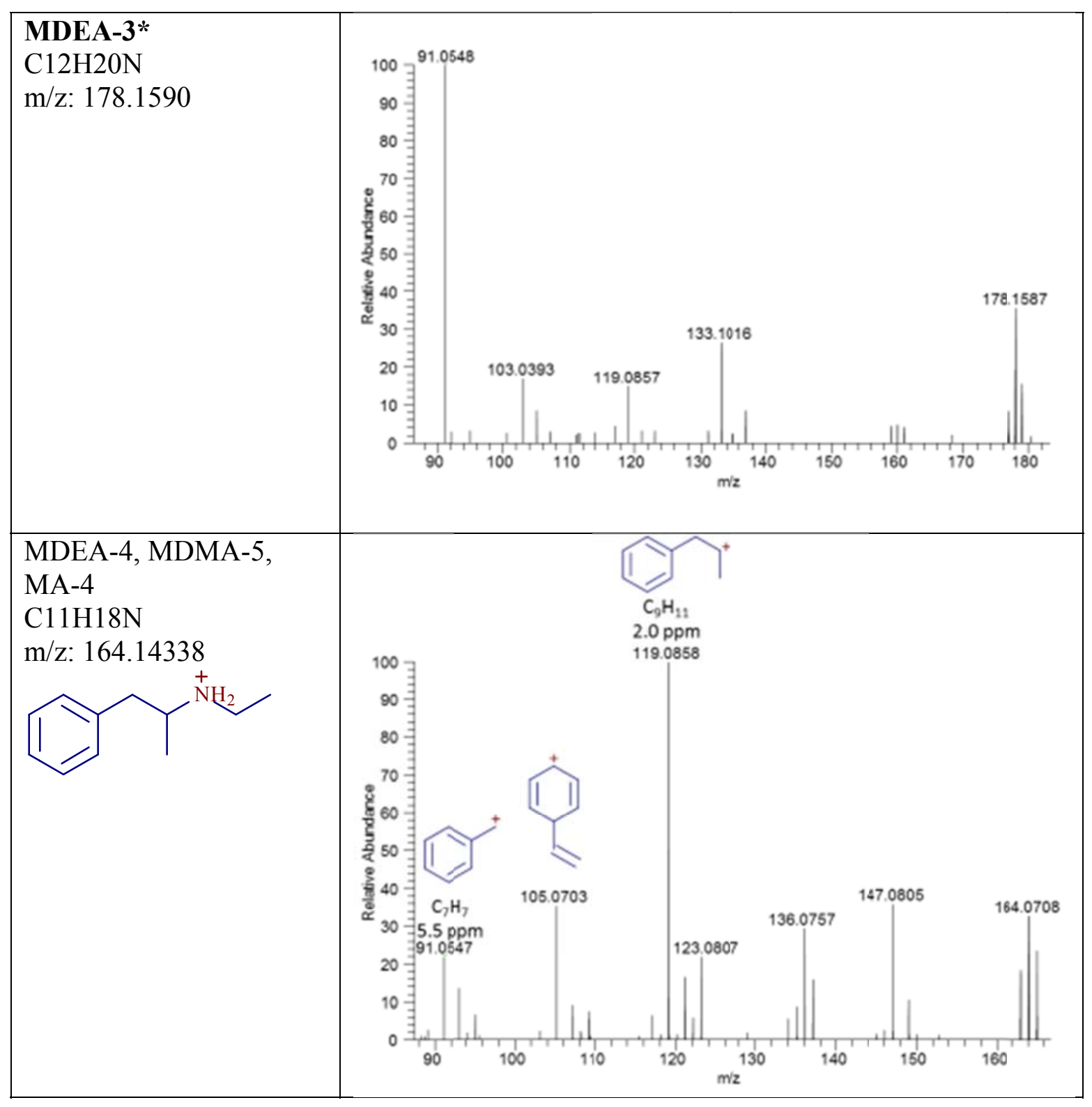




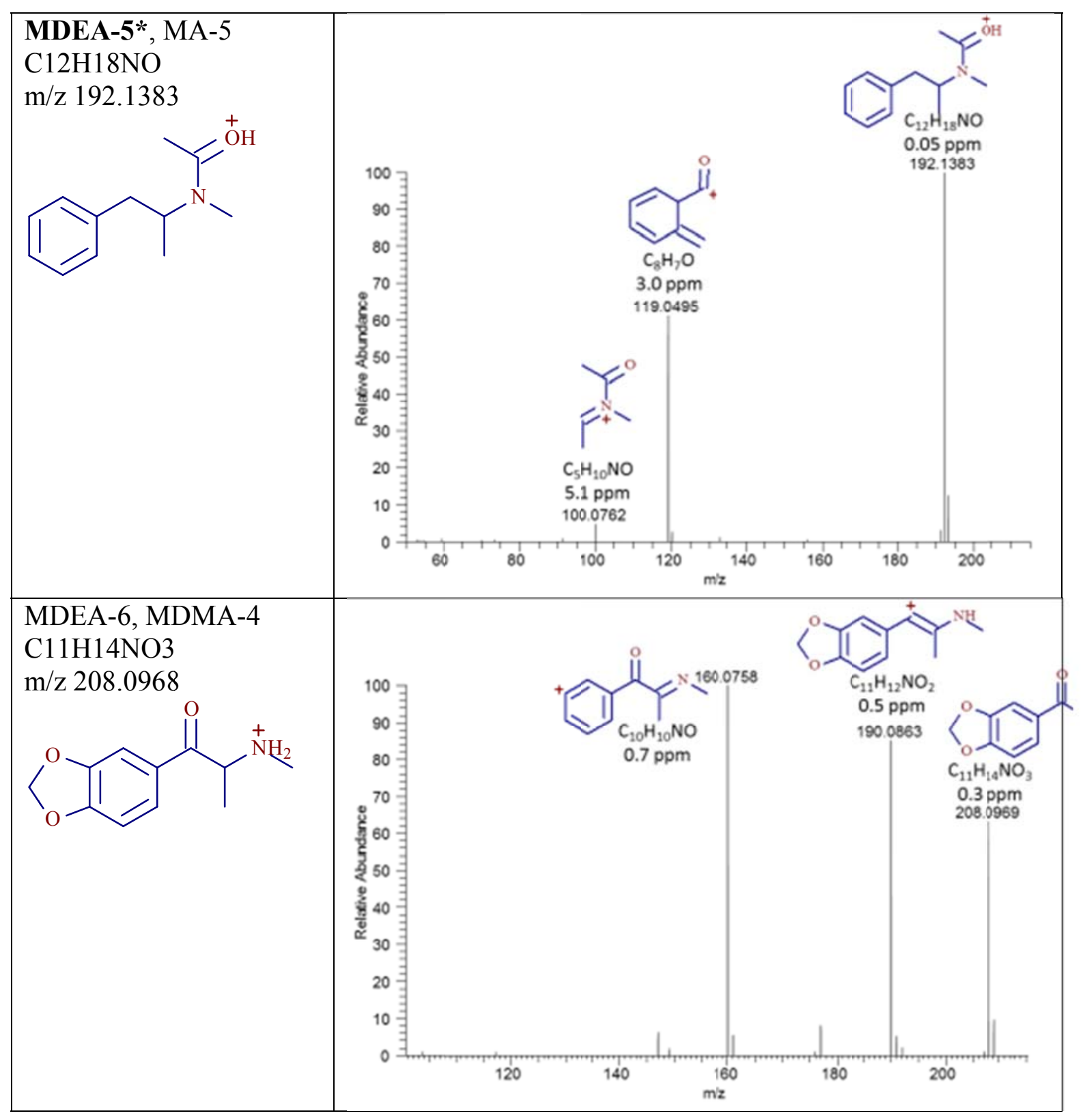




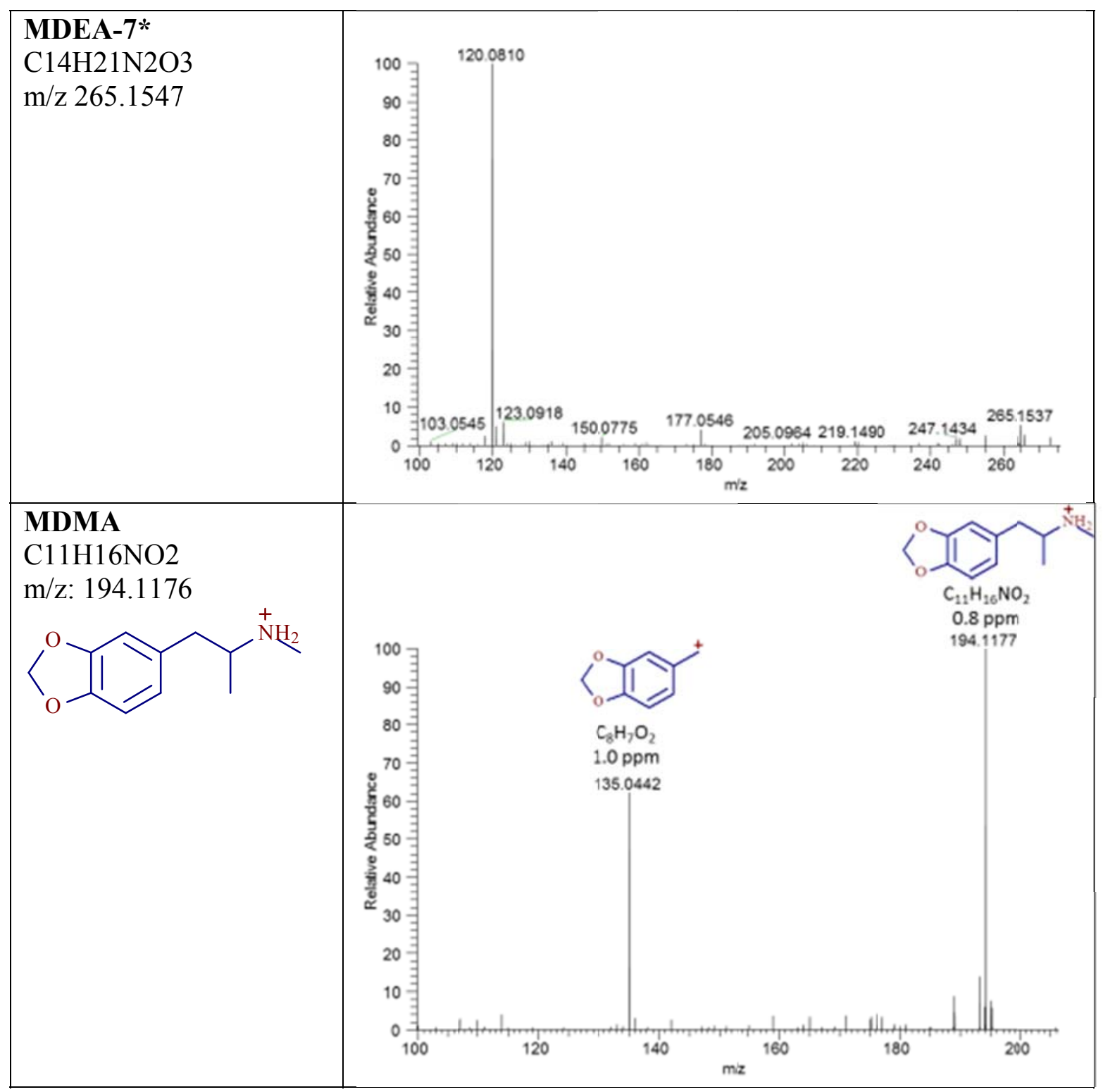




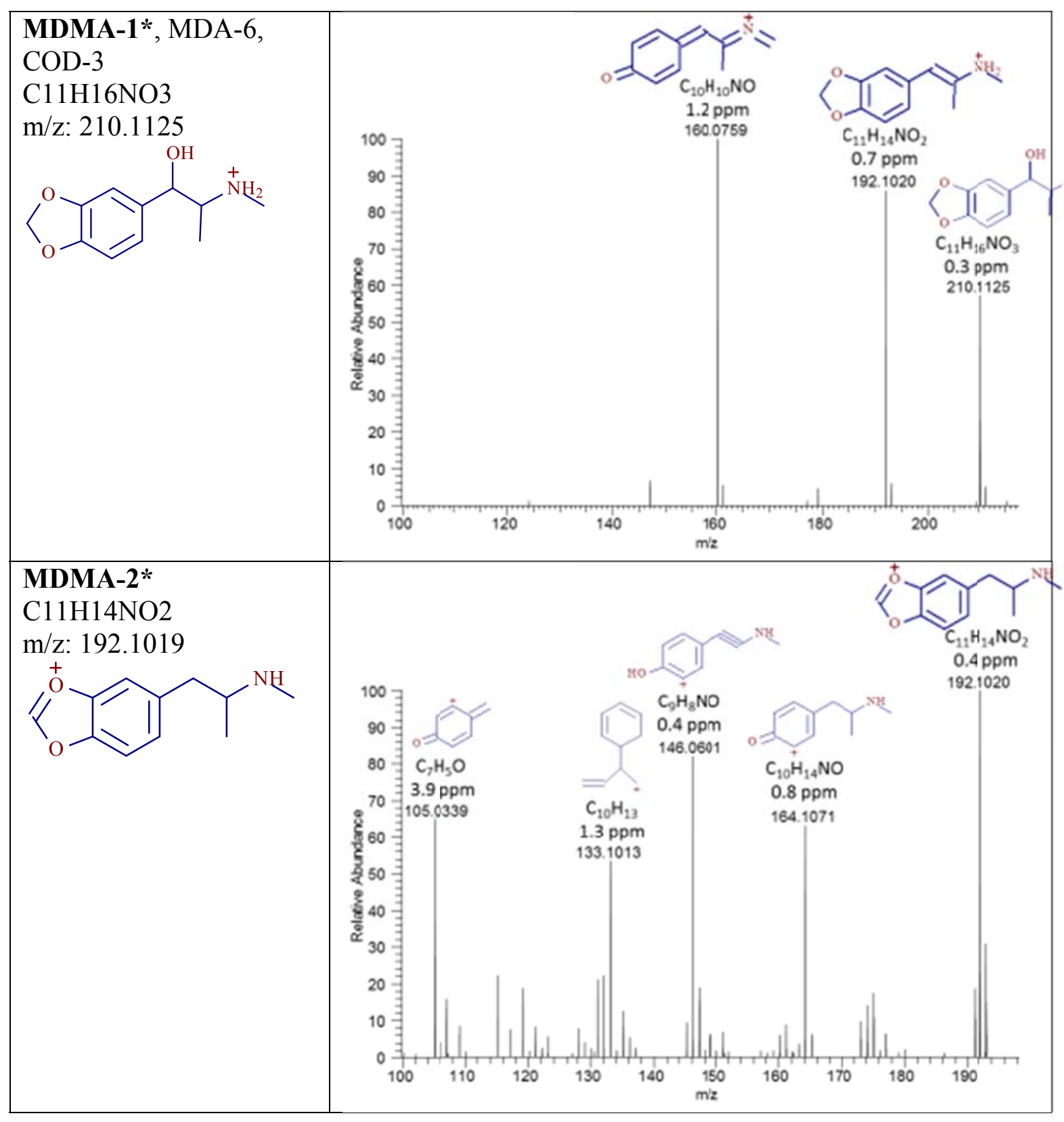




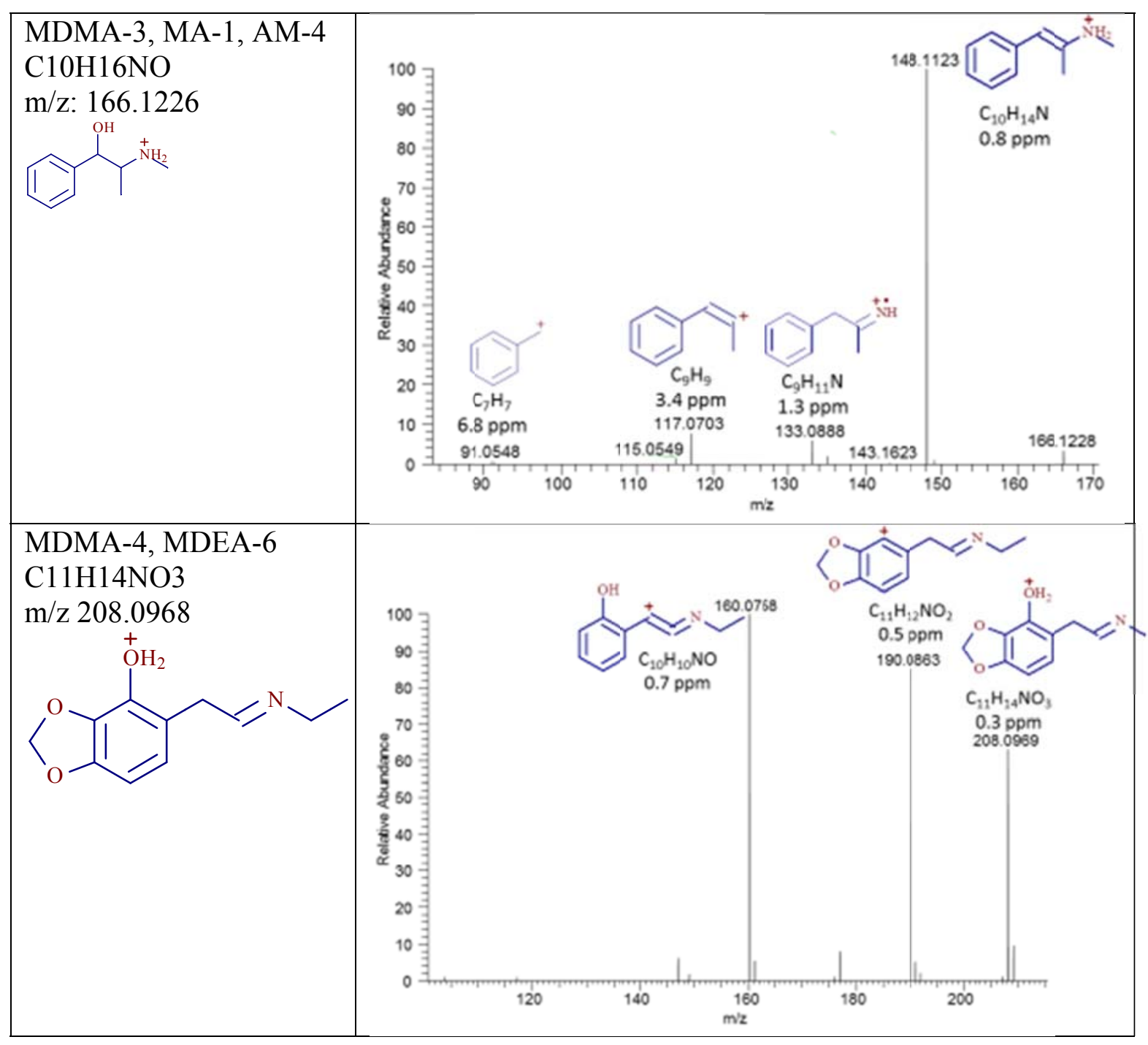




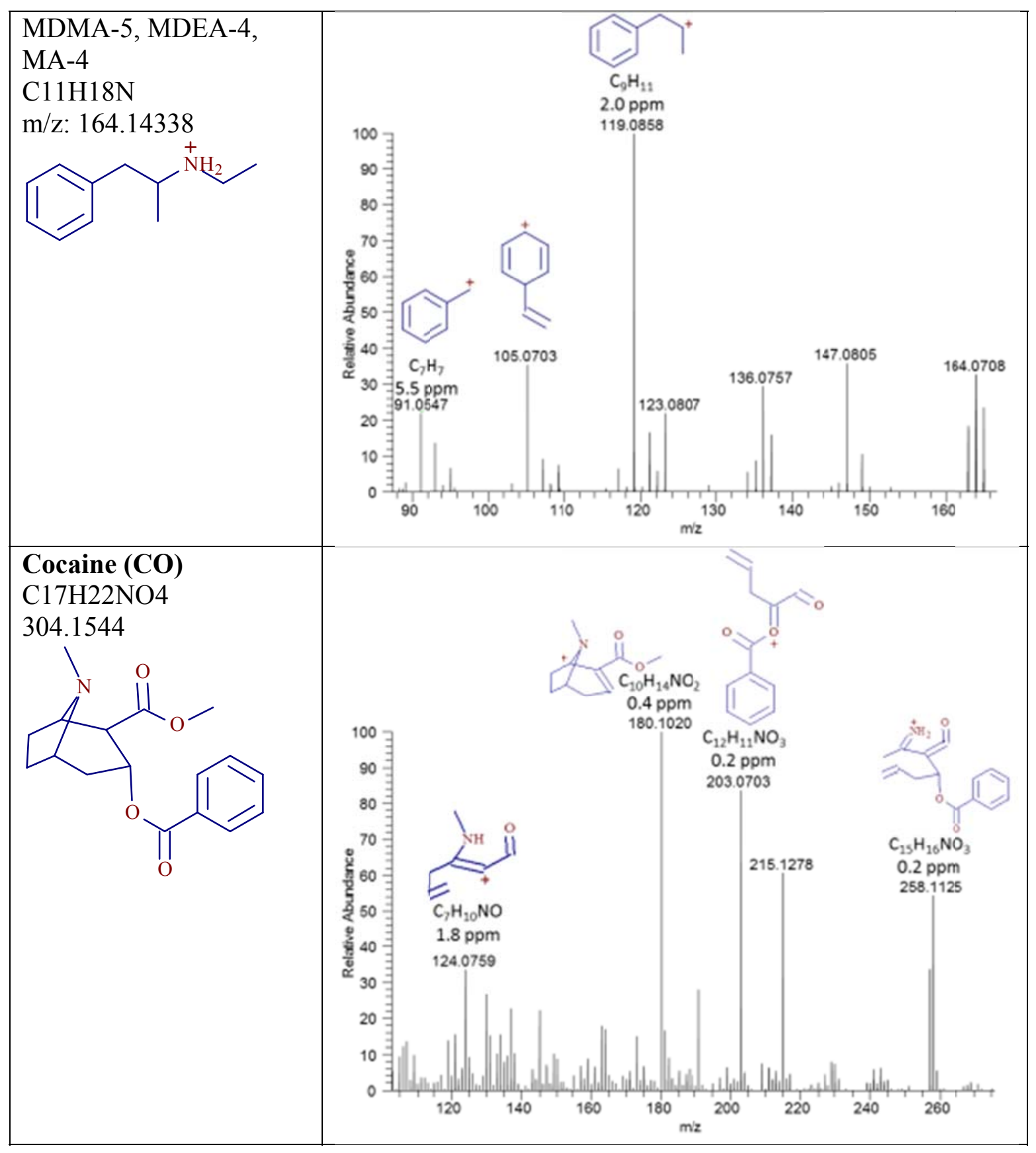




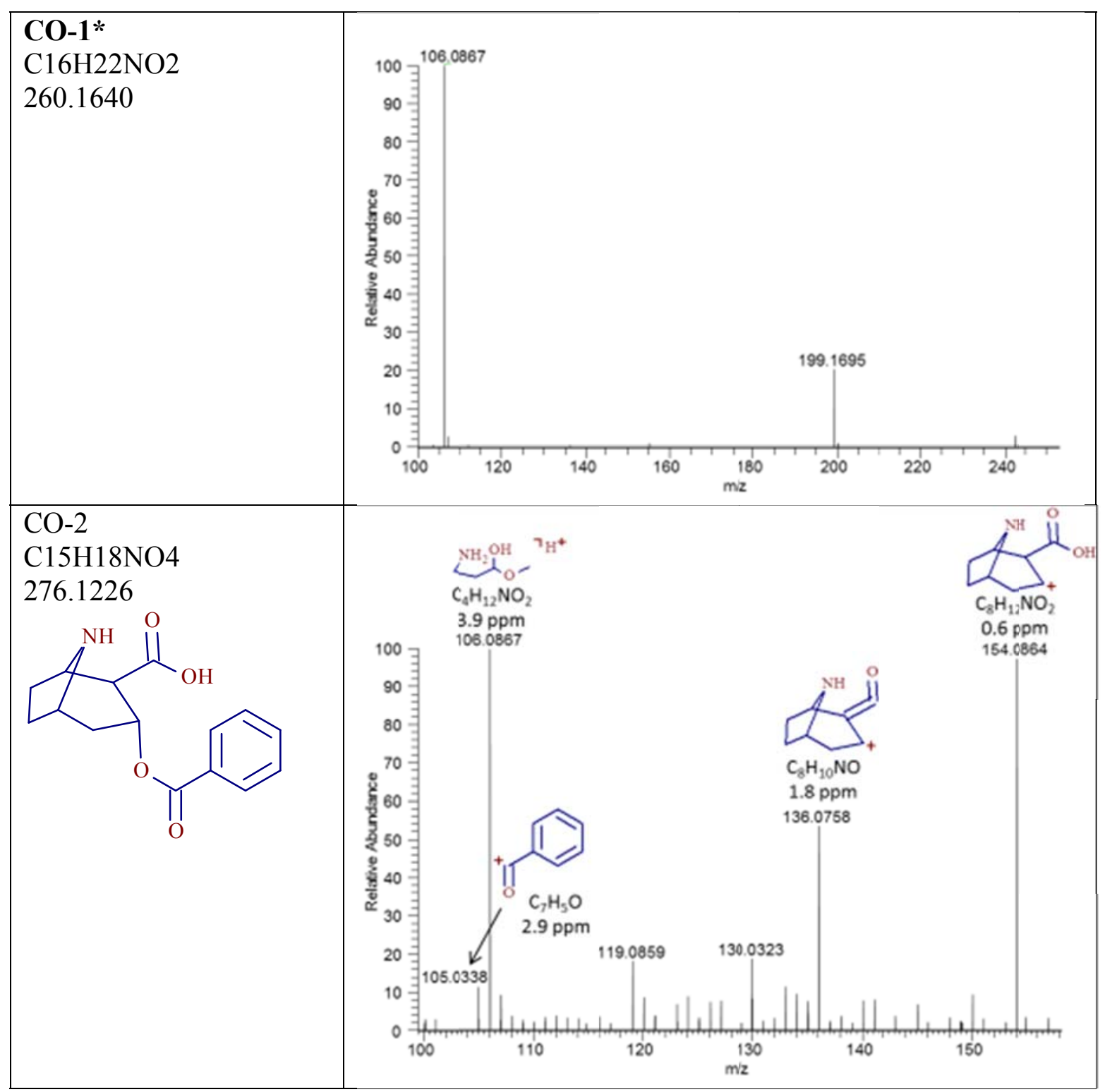




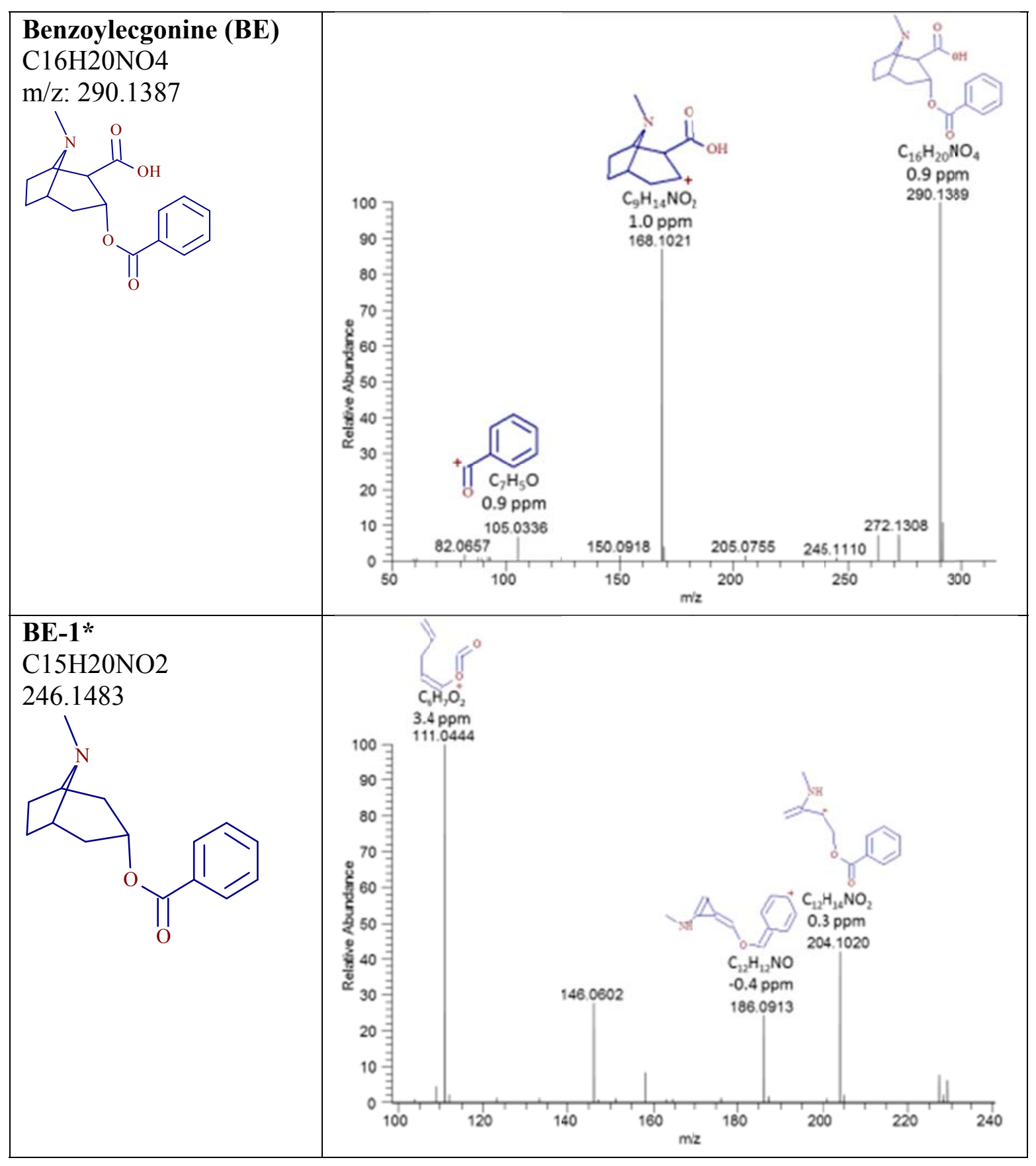




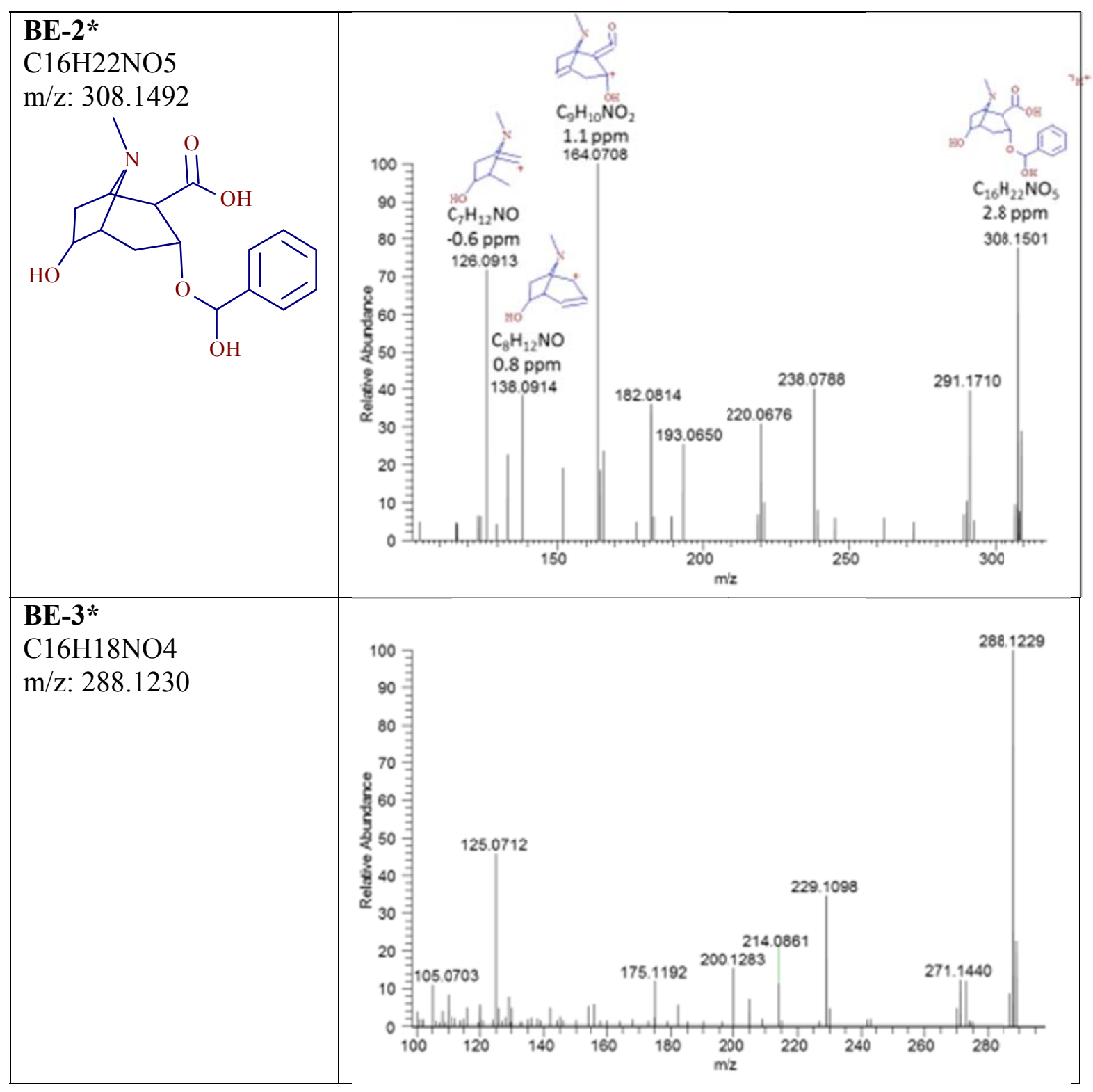




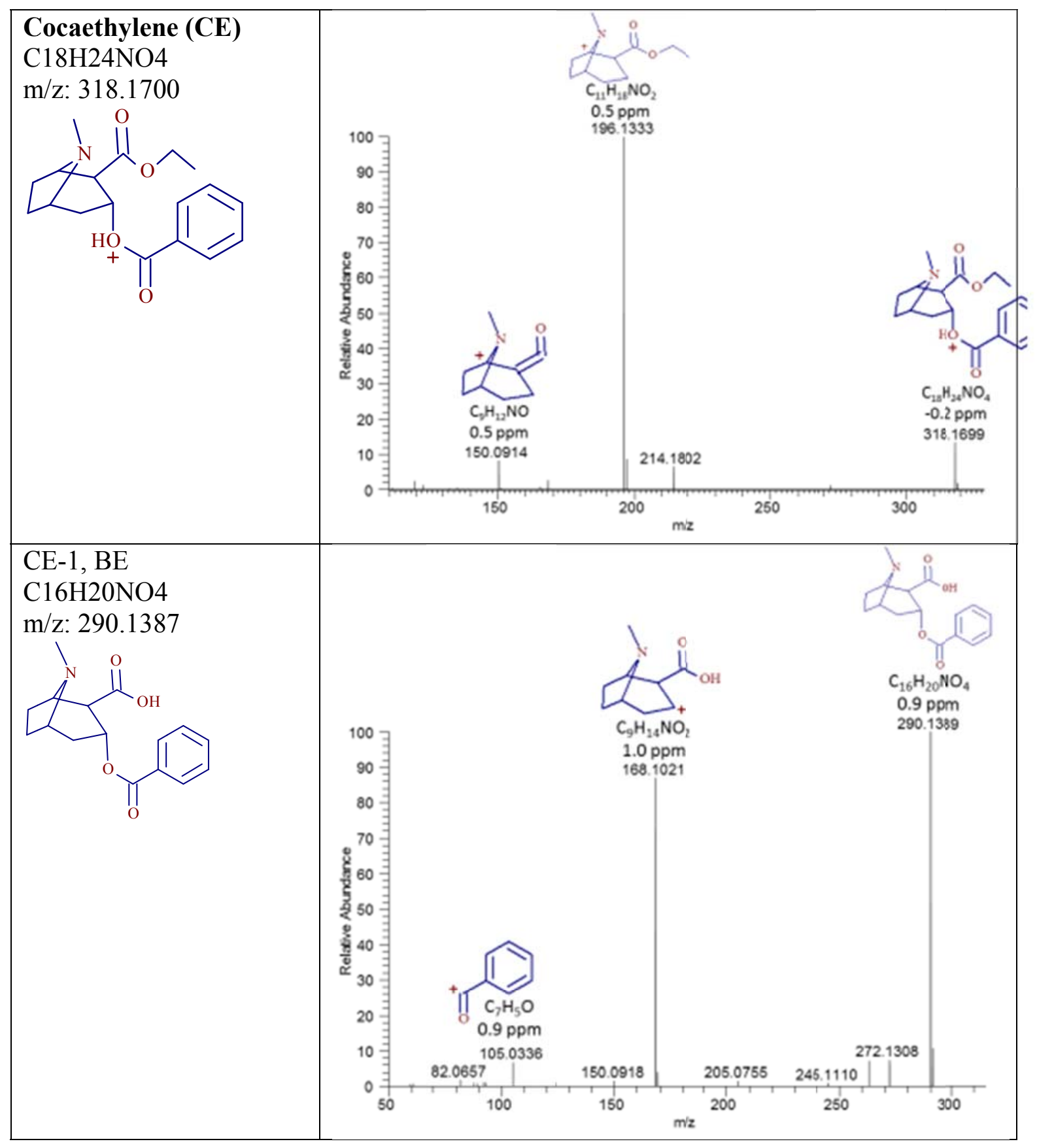




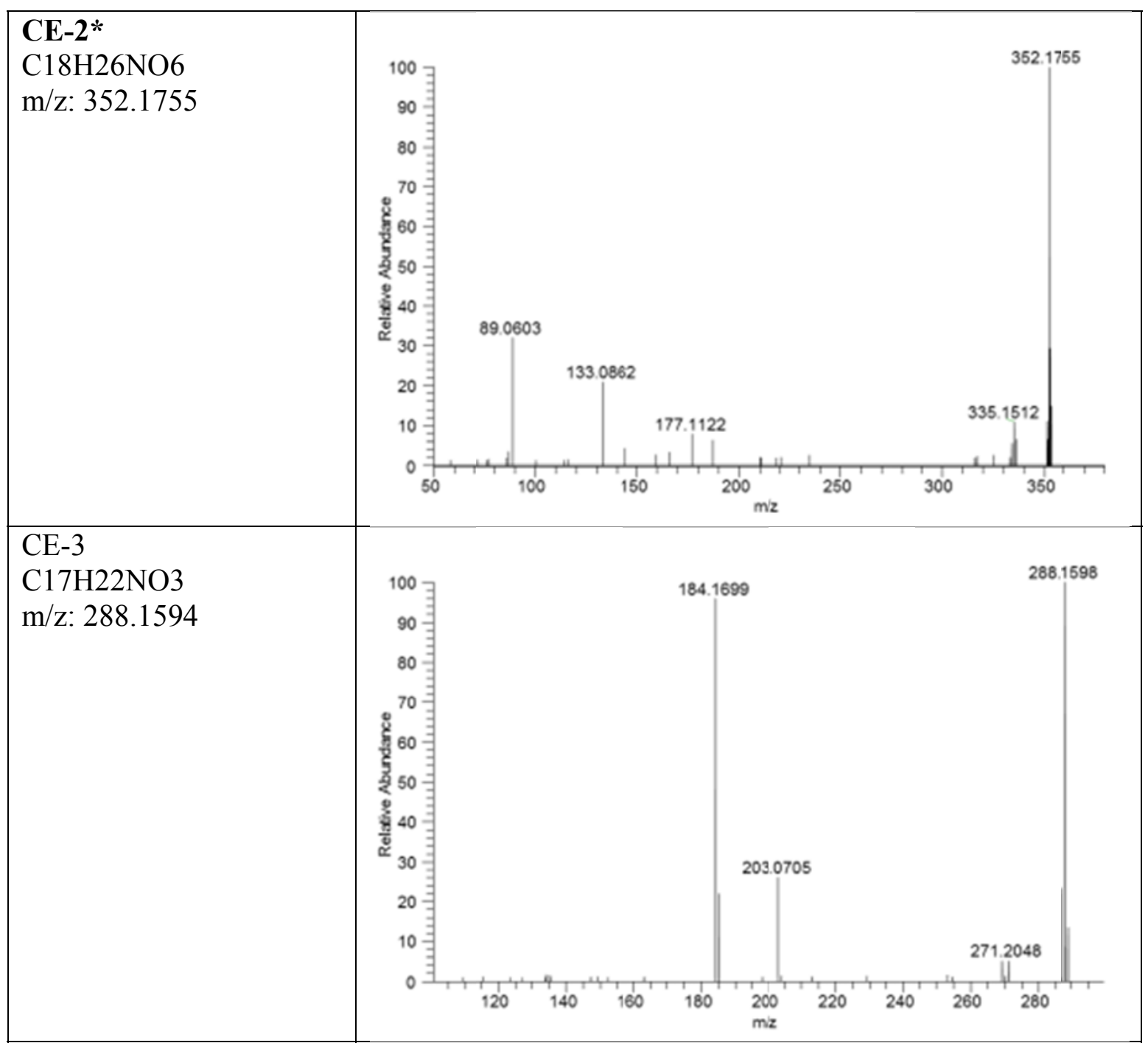




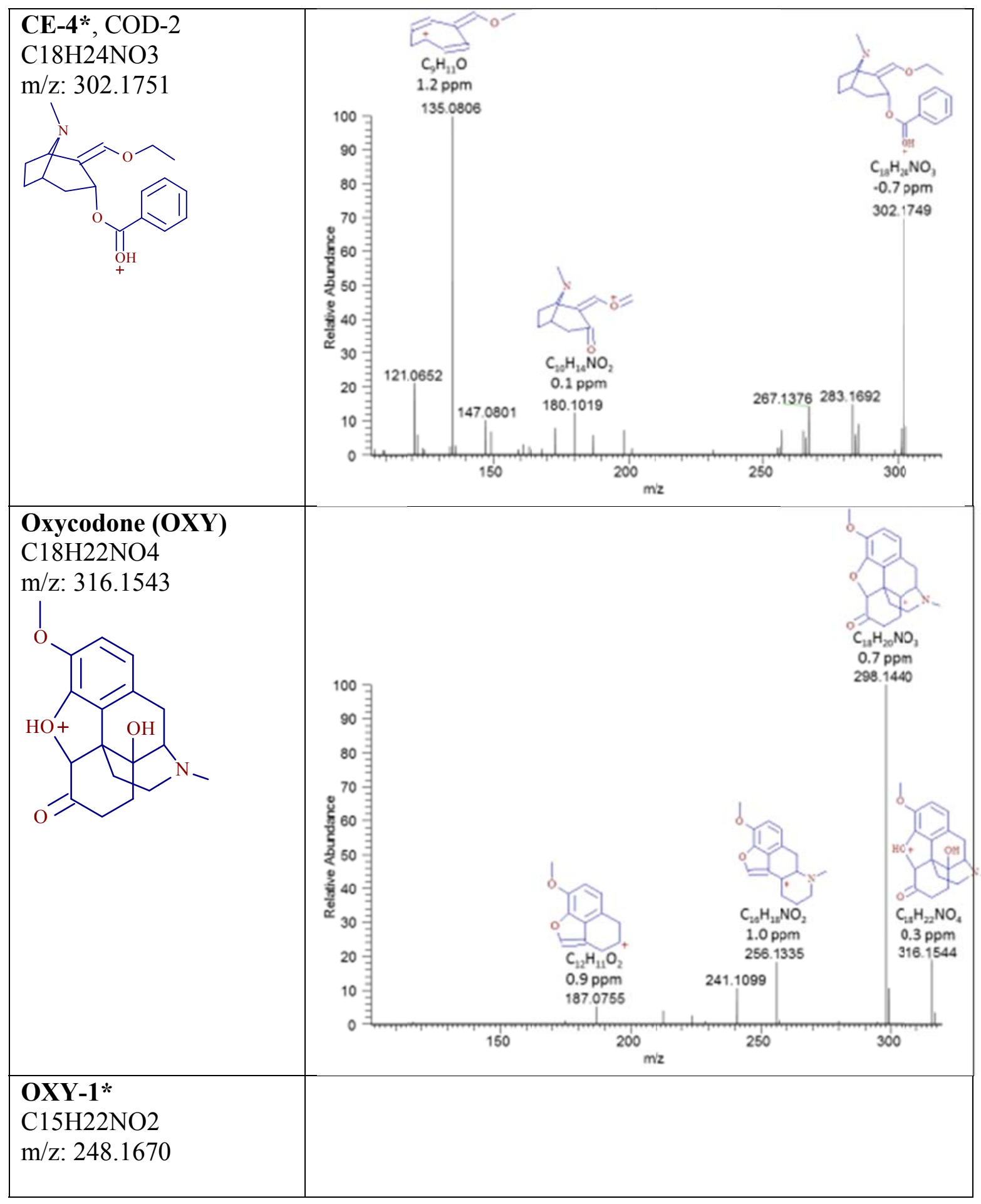




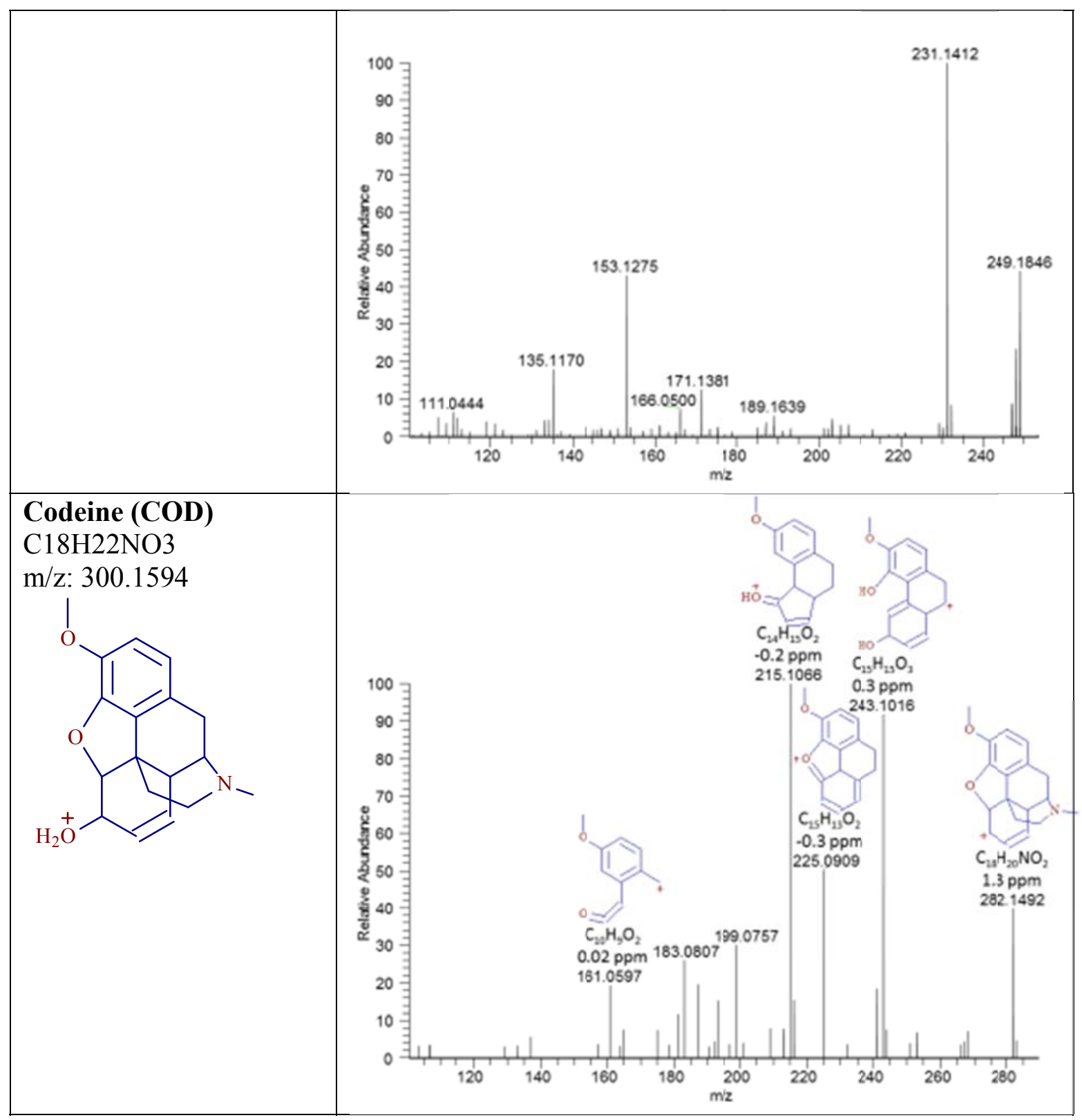




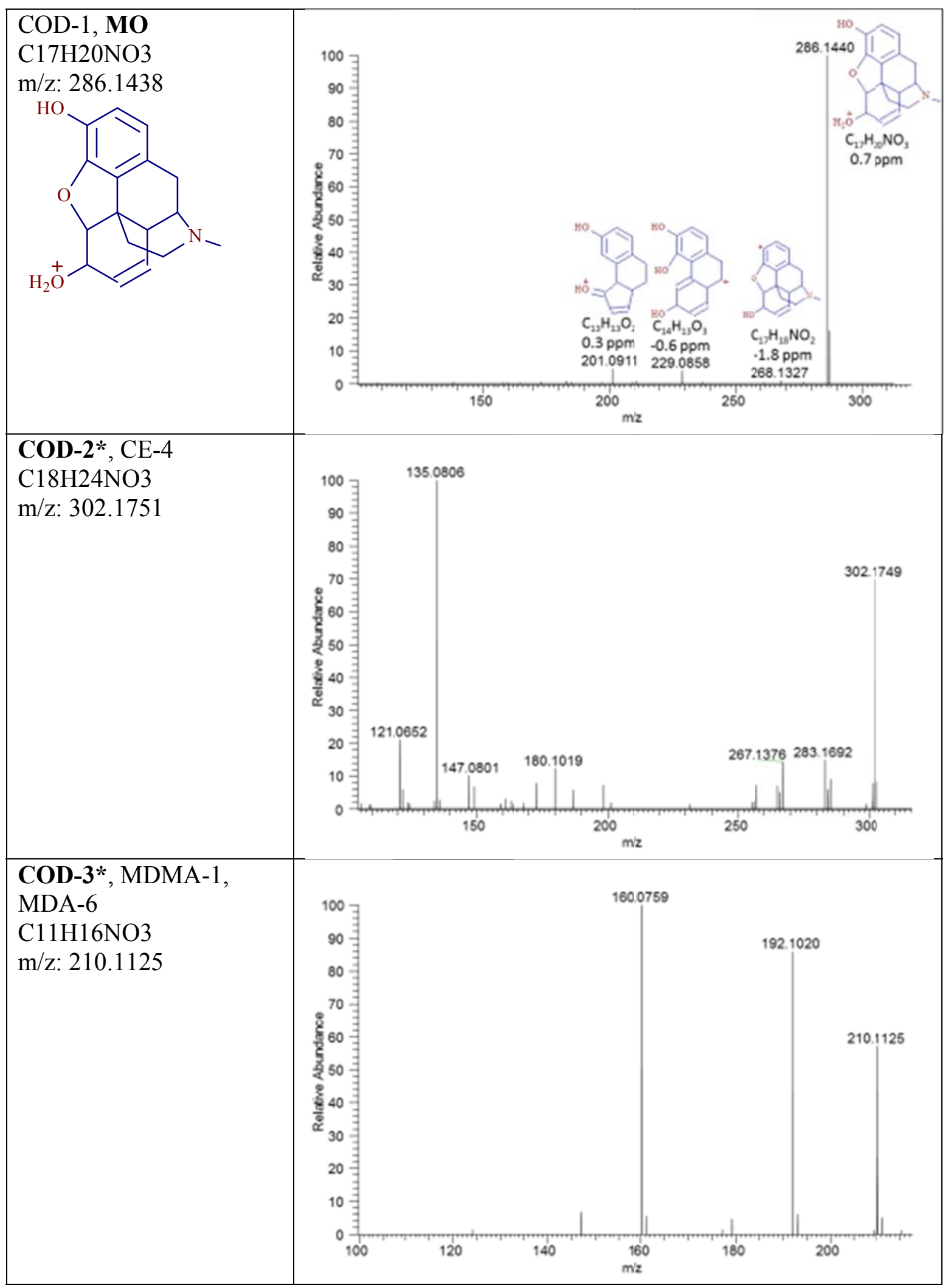




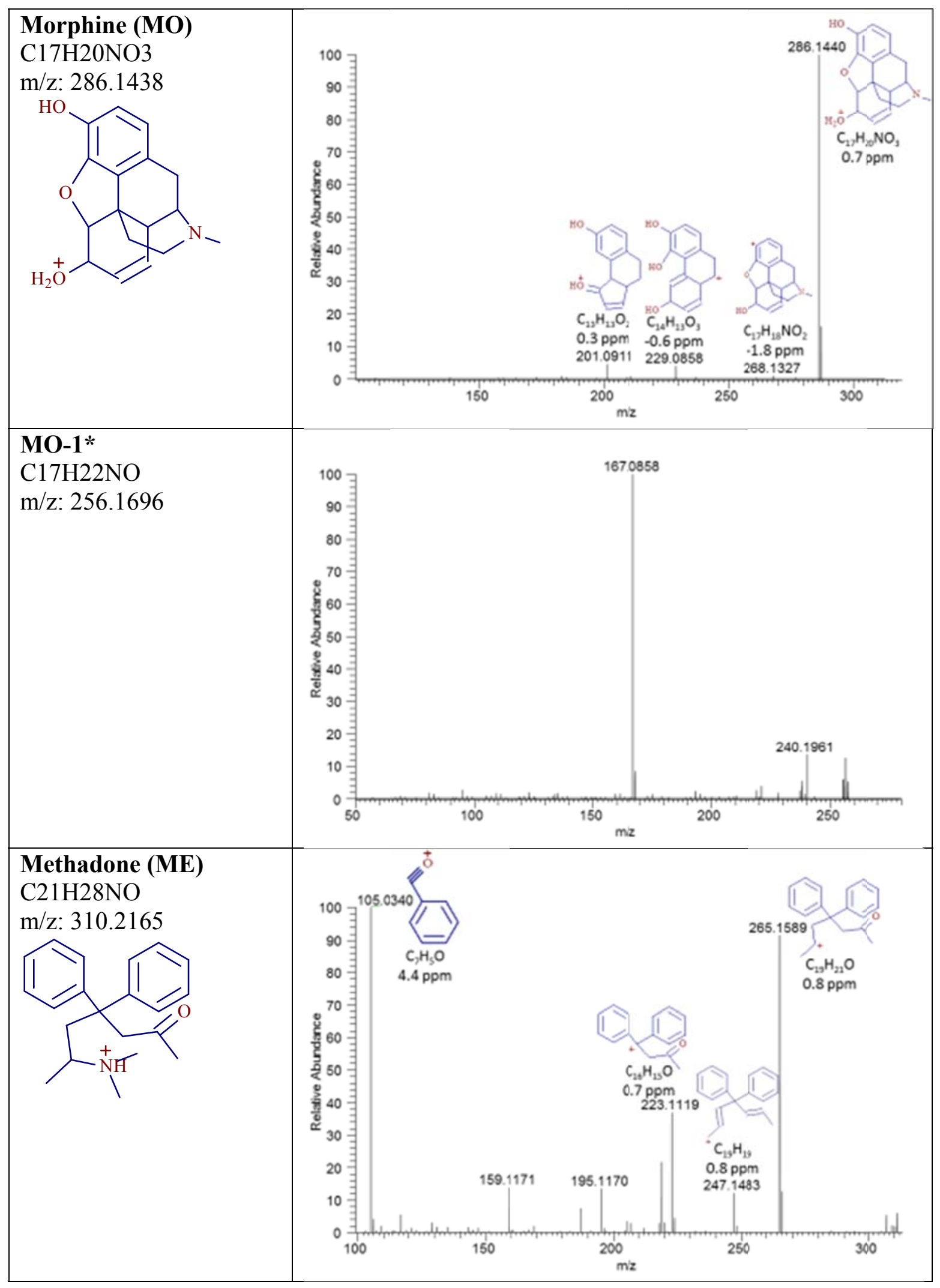




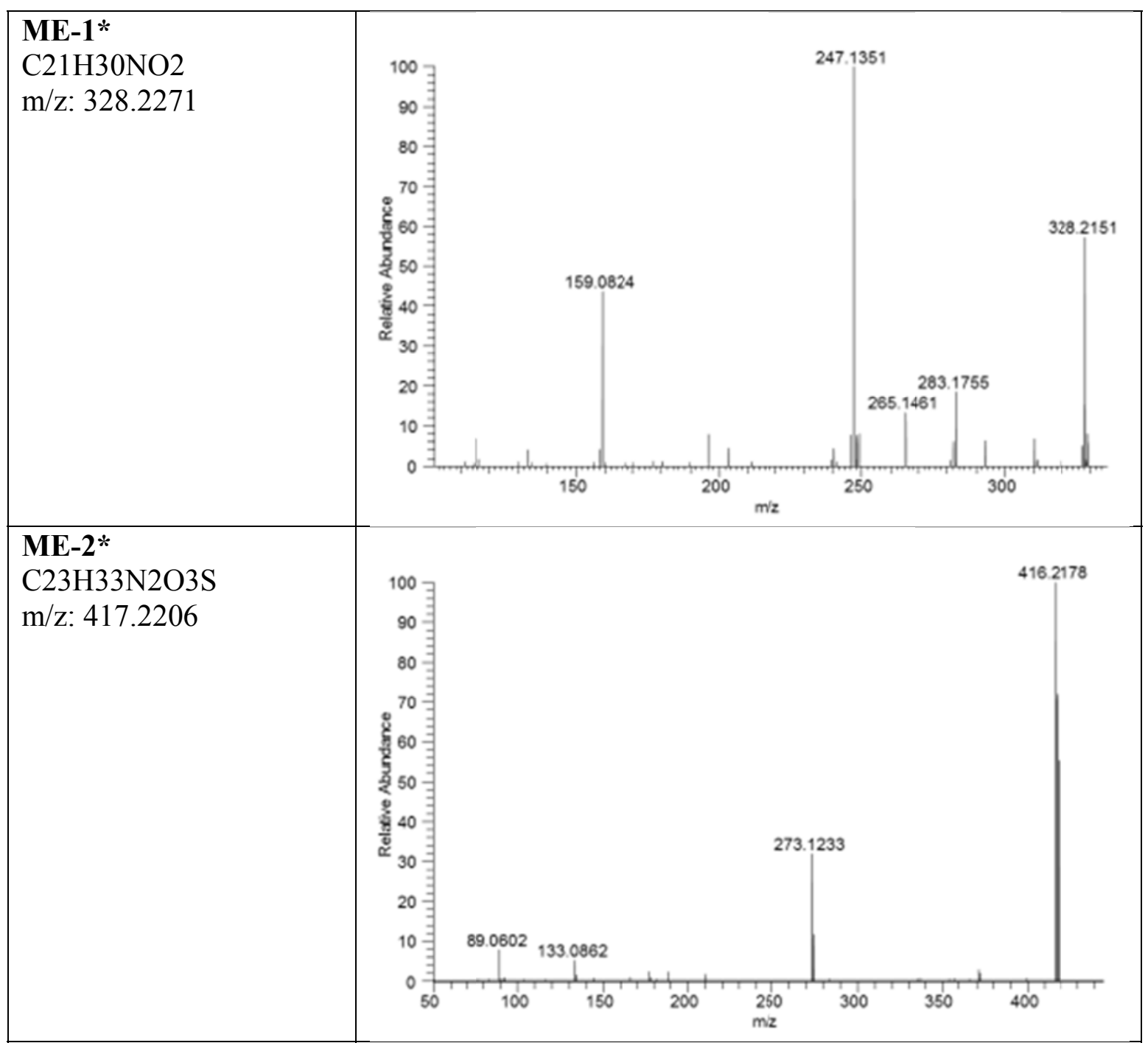




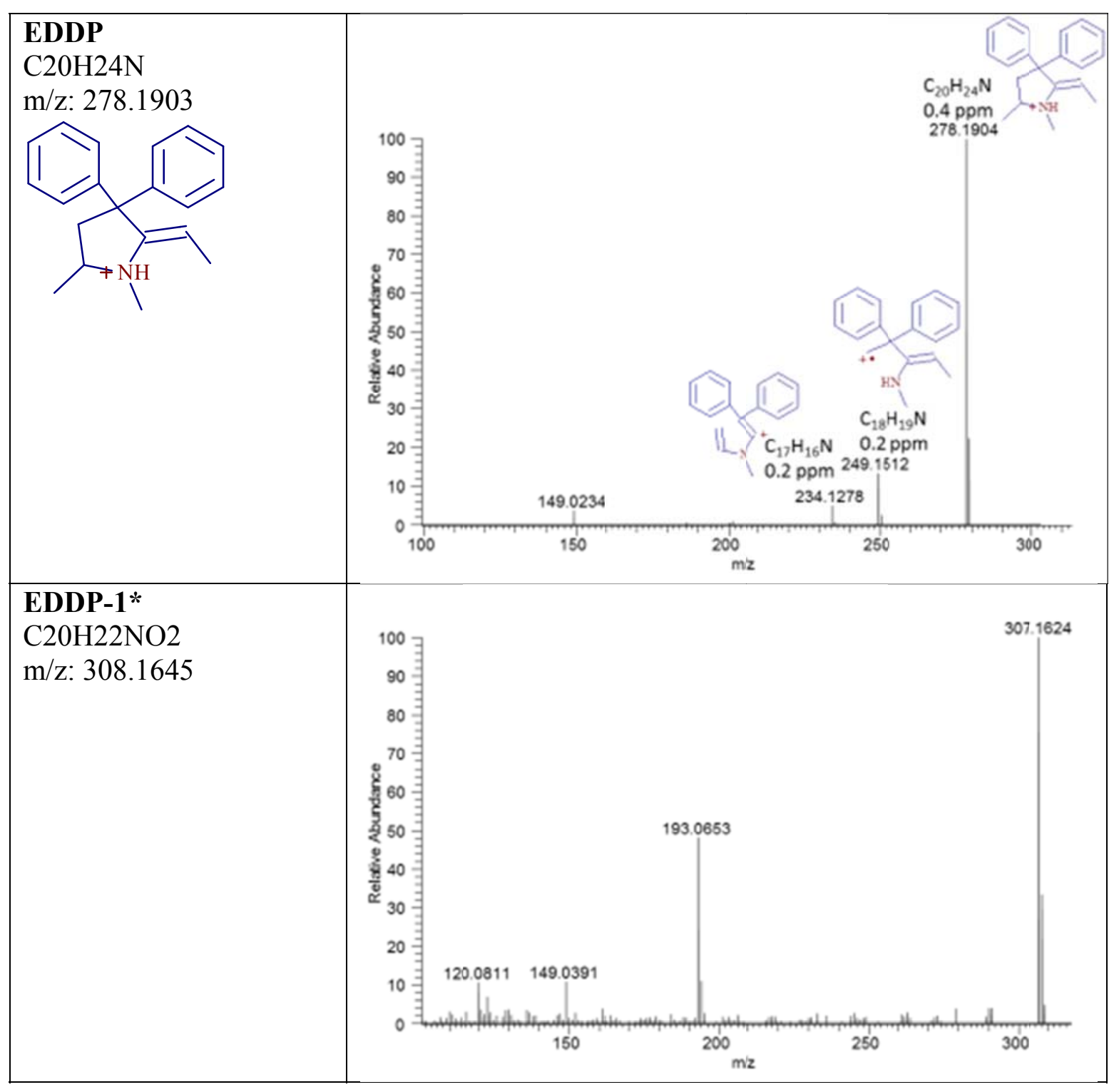




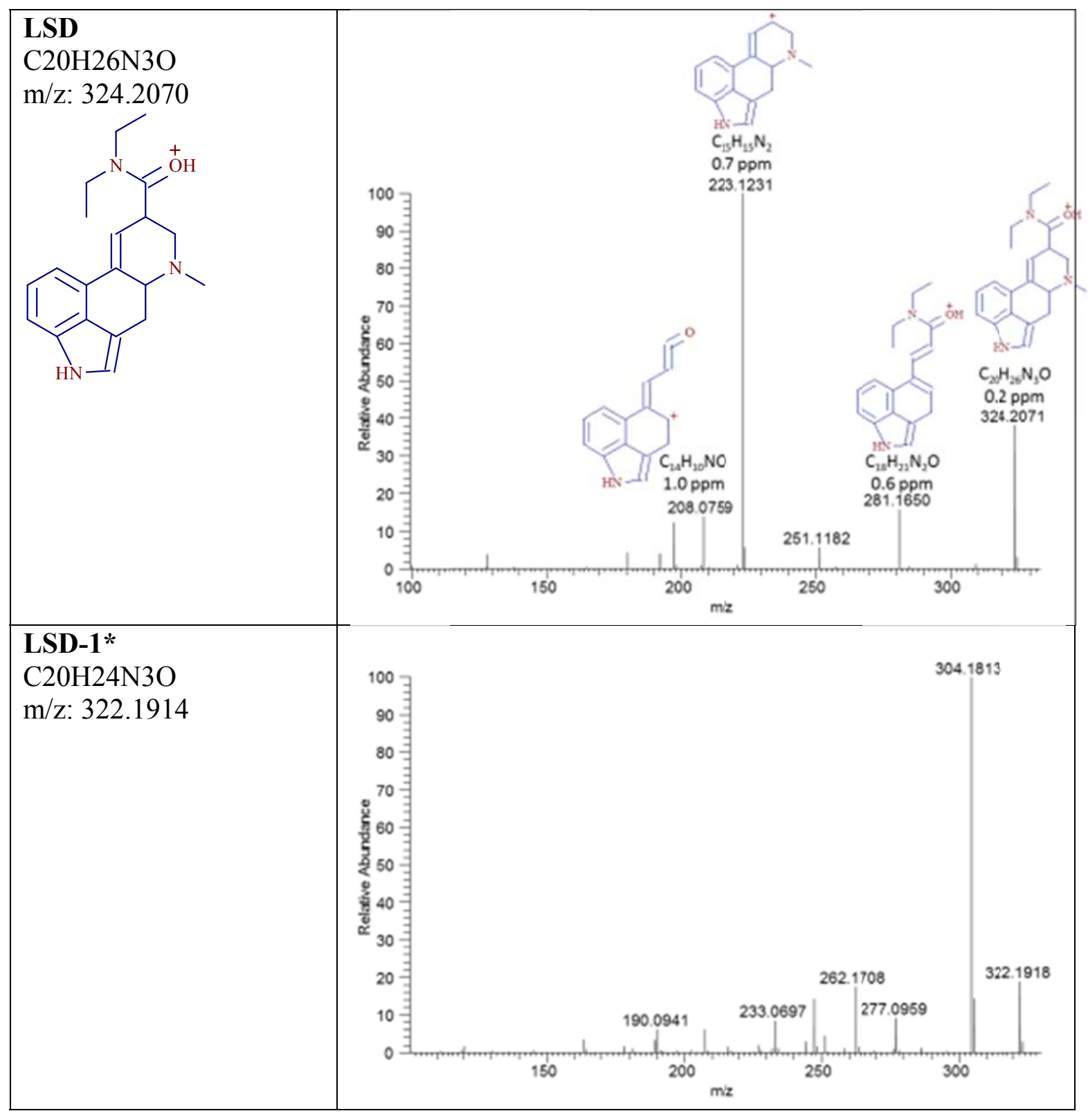




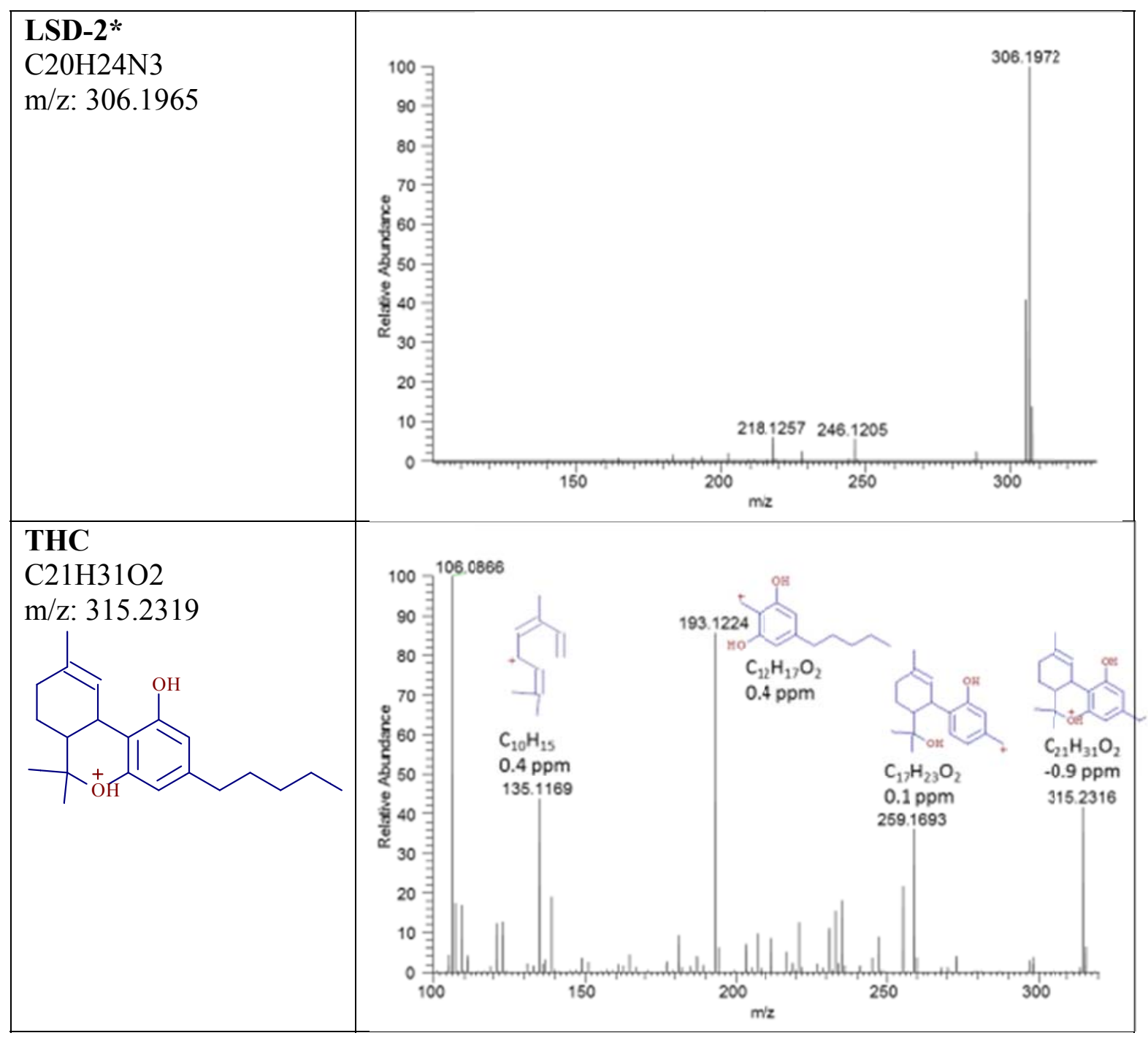




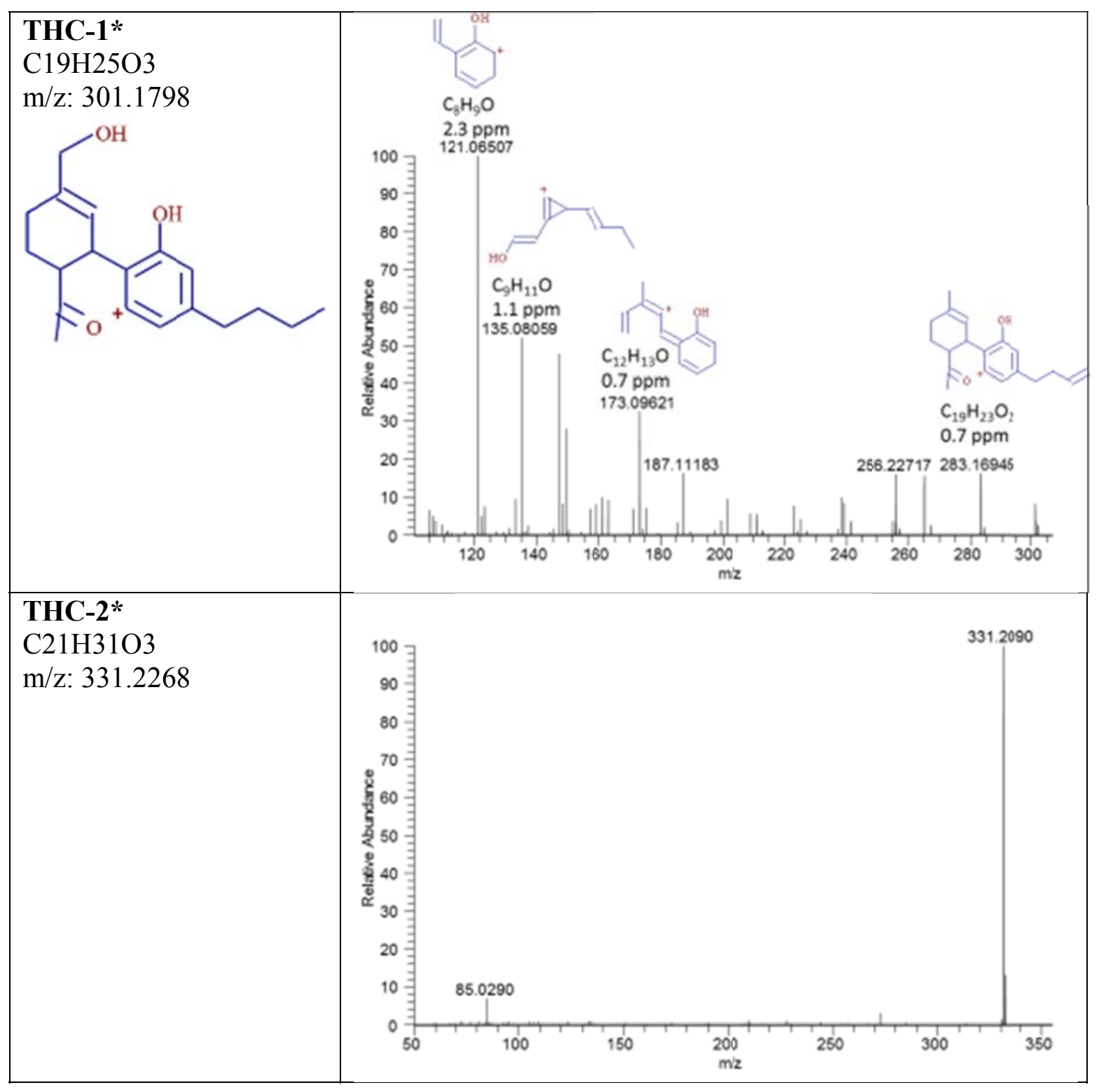




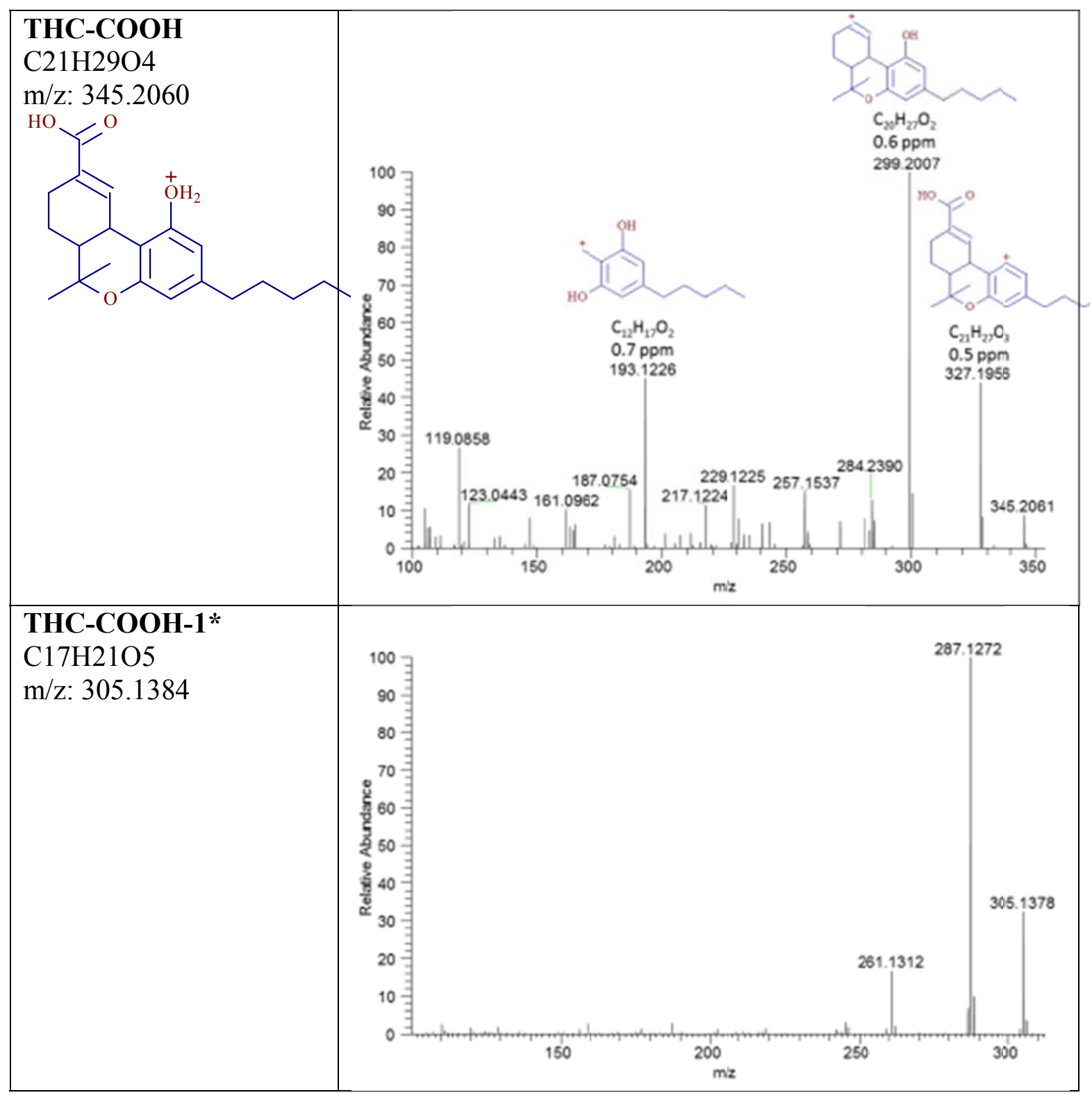

* New tentatively identified TPs in raw influent sewage water. 
VITA

\section{NUBIA VANESA HEUETT}

2015

Dissertation Year Fellowship (DYF)

FIU Graduate School

Miami, Florida

2009

B.S., Chemistry

Florida International University

Miami, Florida

2007
A.A., Chemistry
Broward Community College
Davie, Florida

\section{PUBLICATIONS AND PRESENTATIONS}

Nubia V. Heuett, Cesar E. Ramirez, Adolfo Fernandez, and Piero R. Gardinali. (2015). Analysis of Drugs of Abuse by Online SPE-LC High Resolution Mass Spectrometry: Communal Assessment of Consumption. Science of The Total Environment 511: 319330 .

Nubia V. Heuett, Sudha Rani Batchu, and Piero R. Gardinali. (2015). Understanding the Magnitude of Emergent Contaminant Releases through Target Screening and Metabolite Identification Using High Resolution Mass Spectrometry: Illicit Drugs in Raw Sewage Influents. Journal of Hazardous Materials 282: 41-50.

Jaume Aceña, Sandra Pérez, Piero Gardinali, José Luis Abad, Peter Eichhorn, Nubia Heuett, and Damià Barceló. (2014). Structure Elucidation of Phototransformation Products of Unapproved Analogs of the Erectile Dysfunction Drug Sildenafil in Artificial Freshwater with UPLC-Q Exactive-MS. Journal of Mass Spectrometry 49: 1279-1289.

Nubia V. Heuett, and Piero R. Gardinali. Characterization of influent, surface, and drinking waters by high-resolution mass spectrometry: Understanding the composition of recalcitrant chemicals. Poster Presentation. SETAC Europe $35^{\text {th }}$ Annual Meeting. Vancouver, Canada. May 3-7, 2015.

Nubia V. Heuett, Cesar E. Ramirez, Sudha Rani Batchu and Piero R. Gardinali. Target and non-target analysis of drugs of abuse by high resolution mass spectrometry. Platform Presentation. SETAC North America 35 ${ }^{\text {th }}$ Annual Meeting. Vancouver, Canada. November 9-13, 2014. 
Nubia V. Heuett, Cesar E. Ramirez, Sudha Rani Batchu and Piero R. Gardinali. Communal assessment of drugs of abuse and identification of their transformation products by online SPE-LC-HRMS. Platform Presentation. 248th ACS National Meeting \& Exposition. San Francisco, CA. August 10-14, 2014. (Award for best student platform presentation).

Nubia V. Heuett, Cesar E. Ramirez, Sudha Rani Batchu and Piero R. Gardinali. Communal assessment of drugs of abuse and identification of their transformation products by high-resolution mass spectrometry. Platform Presentation. Third Annual Forensic Science Symposium. Miami, FL. May 1 ${ }^{\text {st }}, 2014$.

Nubia V. Heuett, Cesar E. Ramirez, and Piero R. Gardinali. Analysis of drugs of abuse and their metabolites via online-SPE-HPLC-MS/MS for communal assessment of consumption. SETAC North America 33rd Annual Meeting. Long Beach, CA. November $15,2012$. 